Portland State University

PDXScholar

$6-2-2020$

\title{
Animal Magic, Secret Spells, and Green Power: More-Than-Human Assemblages of Children's Storytelling
}

Angela Molloy Murphy

Portland State University

Follow this and additional works at: https://pdxscholar.library.pdx.edu/open_access_etds

Part of the Curriculum and Instruction Commons, and the Early Childhood Education Commons Let us know how access to this document benefits you.

\section{Recommended Citation}

Molloy Murphy, Angela, "Animal Magic, Secret Spells, and Green Power: More-Than-Human Assemblages of Children's Storytelling" (2020). Dissertations and Theses. Paper 5445.

https://doi.org/10.15760/etd.7318

This Dissertation is brought to you for free and open access. It has been accepted for inclusion in Dissertations and Theses by an authorized administrator of PDXScholar. Please contact us if we can make this document more accessible: pdxscholar@pdx.edu. 
Animal Magic, Secret Spells, and Green Power: More-Than-Human Assemblages of Children's Storytelling

by

Angela Molloy Murphy

A dissertation submitted in partial fulfillment of the requirements for the degree of

Doctor of Education

in

Educational Leadership: Curriculum and Instruction

Dissertation Committee:

William Parnell, Chair

Ingrid Anderson

John Nimmo

Jana Meinhold

Portland State University

2020 
(C) 2020 Angela Molloy Murphy 


\begin{abstract}
Early childhood settings have become contested spaces, or sites of struggle, between economic and sociocultural interests disputing their purpose. Recent years have shown increased pressure on children in early education settings to demonstrate predetermined learning outcomes, which (a) limits the scope of what is possible in the classroom, (b) narrows the range of what learning is considered valid, and (c) privileges the experience and values of the dominant culture, thereby determining who and what matters in early childhood settings. Thus, in the current education climate where conventional knowledges are routinely privileged, unconventional knowledges and small stories from children's lives are frequently disregarded or otherwise pushed to the margins of daily classroom life.
\end{abstract}

The purpose of this post qualitative study was to position children's storytelling as a disruptive force to western, positivist, and humanist knowledges in early childhood education and research. In this study, I am thinking with theory using critical posthumanist/new materialist theories as a research approach to consider children's storytelling in an early childhood setting. Adopting the role of observant participator, I worked alongside ten 2.5-5-year-old (co)-participants using observations, photography, and classroom discussions to investigate the relational and emergent dimensions of children's storytelling. I used pedagogical narration as an approach to data analysis, drawing lines between interconnected episodes and pointing to the more-than-human relational encounters that were present in children's everyday storytelling practices. In 
this study, I found storytelling to be a generative process, produced within a complex assemblage of human and non-human actors. The second finding that emerged is that an expanded concept of narrativity is required to fully attune and attend to the multiplicitous storytelling occurring within early childhood settings. Lastly, in this study, children's stories were shown to have to the potential to act as thought experiments for envisioning possible worlds. This study broke from conventional education research by considering not what worlds are being reflected in children's storytelling, but rather what worlds are being produced. This is an important distinction at this particular moment in history, when we must consider what knowledges are legitimized and what are outcast by our systems of education, and what worlds are produced and reproduced in the process. 


\section{DEDICATION}

I dedicate this dissertation to my brilliant co-researchers in this study; the children of Rowanberry School. This work was only possible because of you. 


\section{ACKNOWLEDGEMENTS}

I have been fortunate to have many helpers along the way in my academic journey. I would like to start by acknowledging my dissertation chair Dr. Will Parnell for offering the perfect balance of support and space I needed to complete this process and really own it. Thanks to you, I was able to find my way and create something I am truly proud of. I am perpetually inspired by you and encouraged by your faith in me. Dr. John Nimmo; since my first class with you, you have asked the questions that need to be asked, and for this I am truly grateful. In your direct way, and always with good humor, you have made my work stronger and made me a better scholar. Dr. Ingrid Andersonyou were the first person I met with in the doctoral program and have been an unwavering source of support and optimism ever since. From Google chats about paper formatting to plotting the next big scholarly adventure; I am so grateful to you. You keep me both grounded and daring. Dr. Jana Meinhold, thank you for your openness and enthusiasm for my work, and for offering me some key considerations. Dr. Anita Bright and Dr. Micki Caskey, the love and encouragement you poured into each of us during our time as a cohort continues to fill me up. I look paying it forward with students of my own. Dr. Rikka Hohti, thank you for inviting me, a fledgling scholar at the time, out to the pub in Jyväskylä for good company and mentorship. It was a pivotal moment for me. Thank you to Catherine Hamm for the gift of the term "thinking wall," which shifted my concept of documentation and was crucial to this work.

Thank you to the families at Rowanberry School for your trust in me and support of this research study, and to the children, who breathed life into this work and made it 
matter. I am eternally grateful to each of you. I hope that I was able to convey the spirit of what we created together during a very special time.

To my dear family_-you are the why and how of this work. I am deeply appreciative of your unwavering support and patience. You knew that this was important to me, and therefore it was important to you. I hope that I have made you proud. 


\section{TABLE OF CONTENTS}

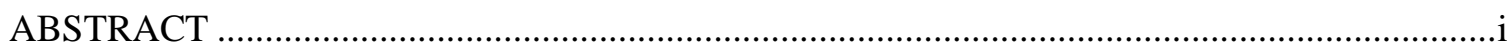

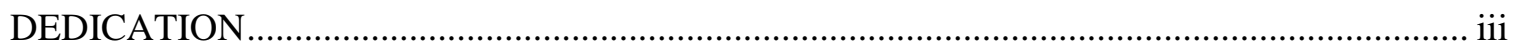

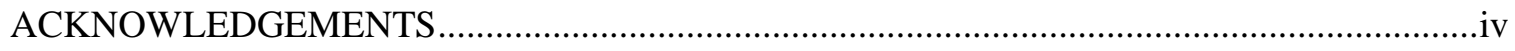

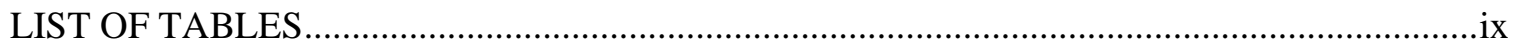

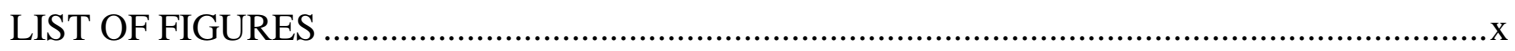

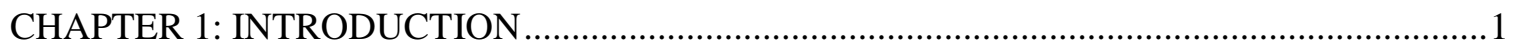

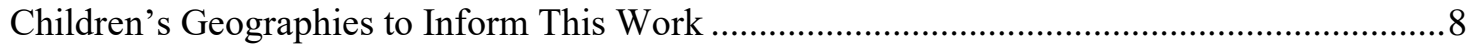

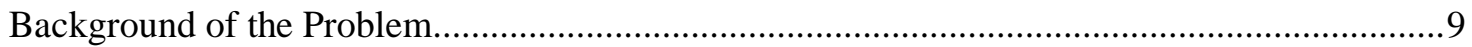

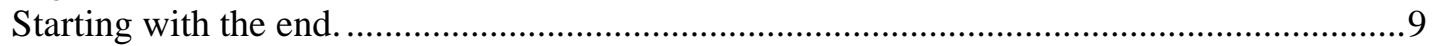

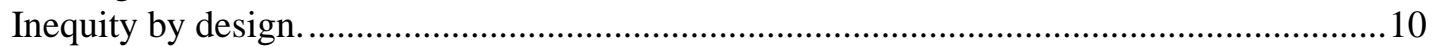

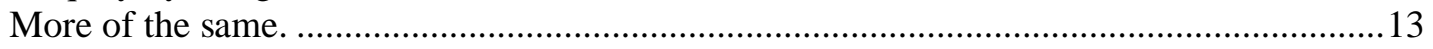

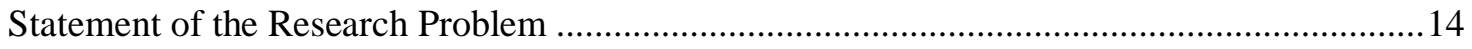

Significance of the Research Problem ............................................................................ 15

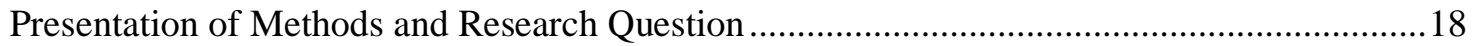

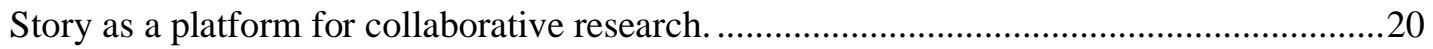

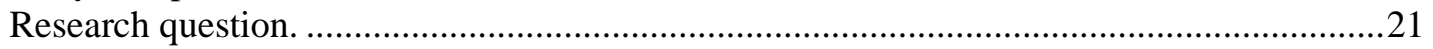

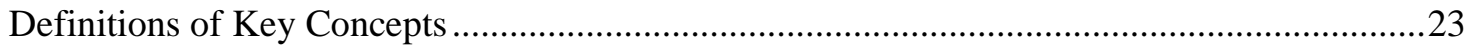

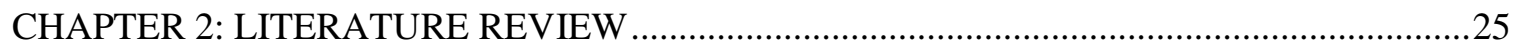

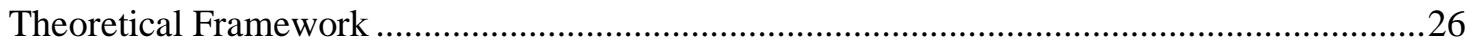

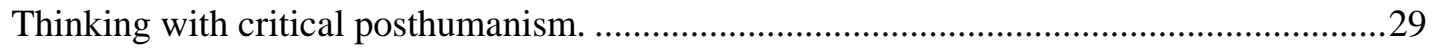

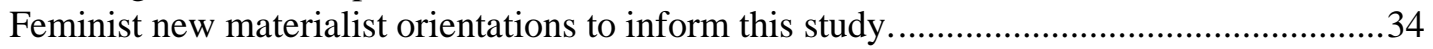

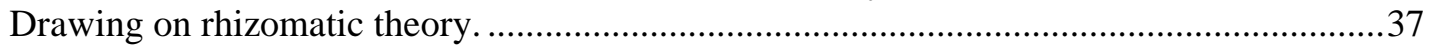

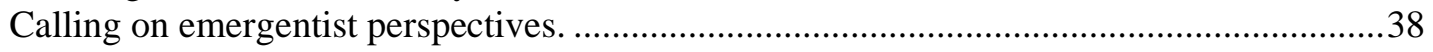

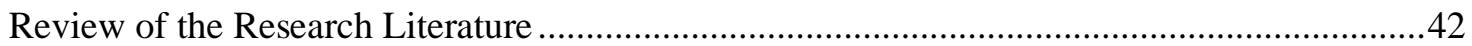

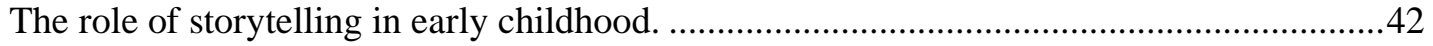

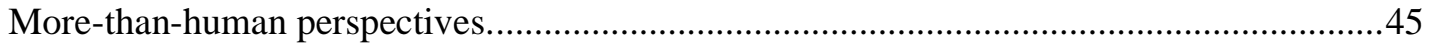

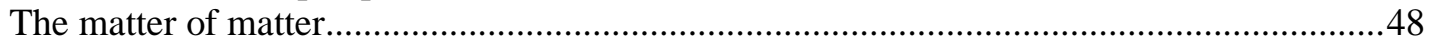

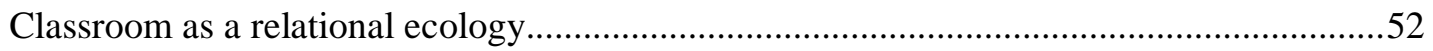

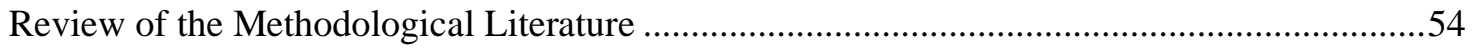

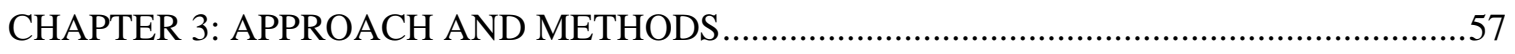

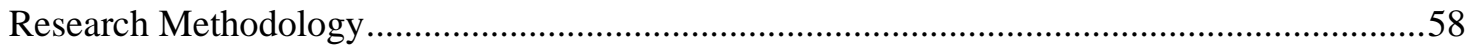

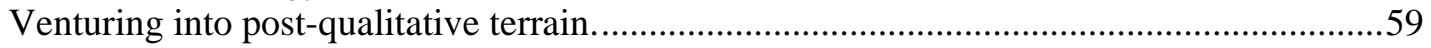


Thinking with theory

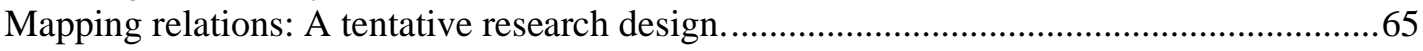

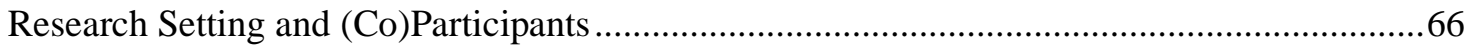

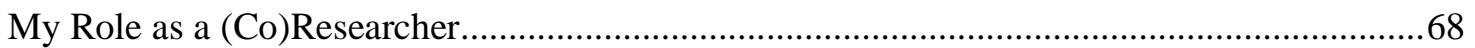

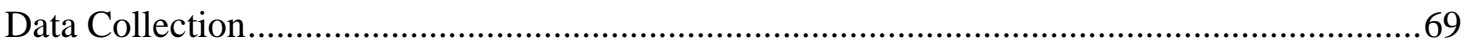

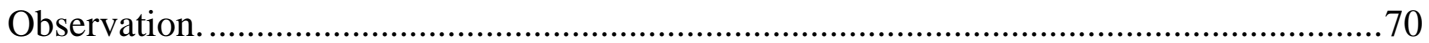

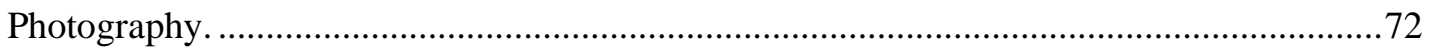

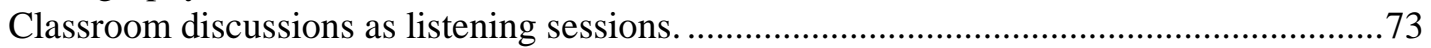

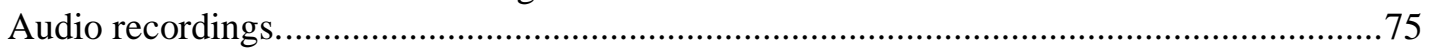

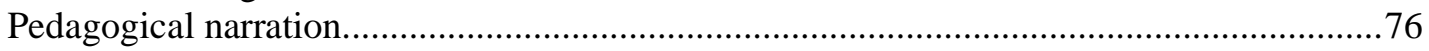

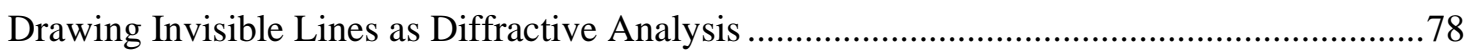

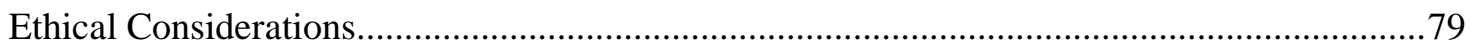

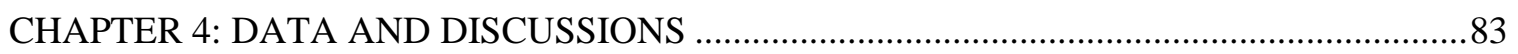

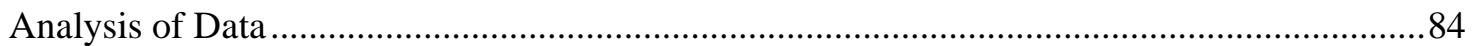

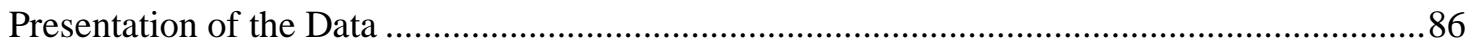

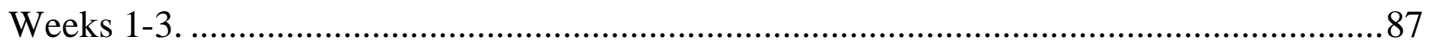

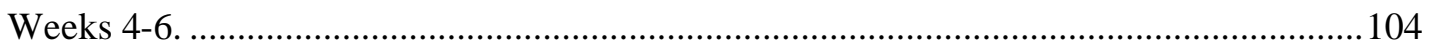

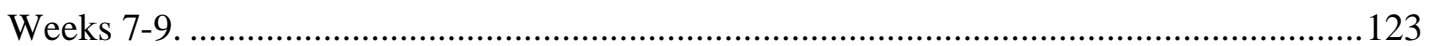

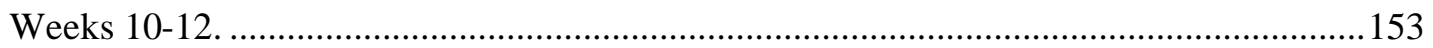

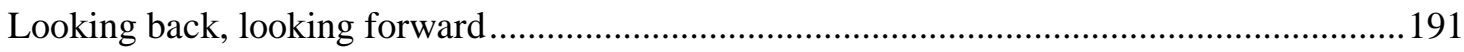

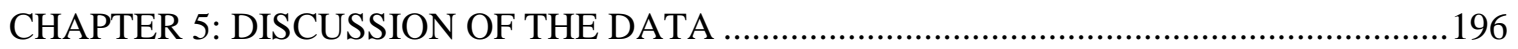

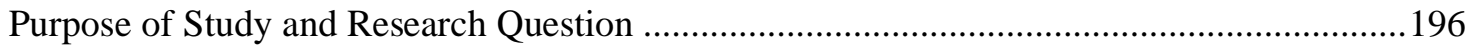

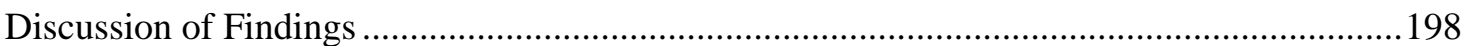

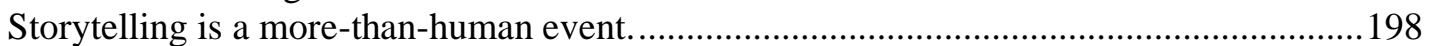

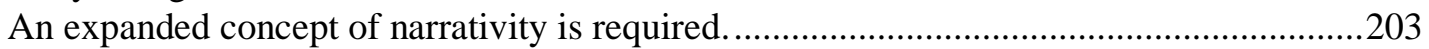

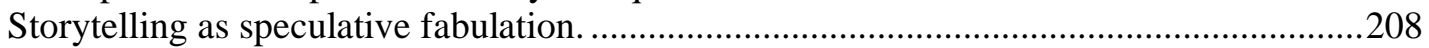

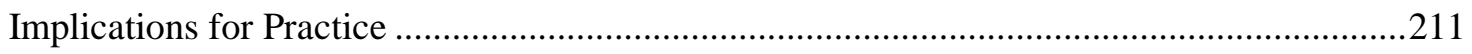

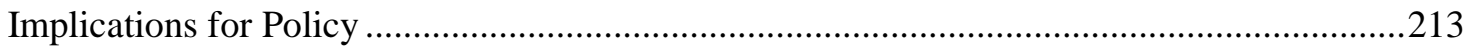

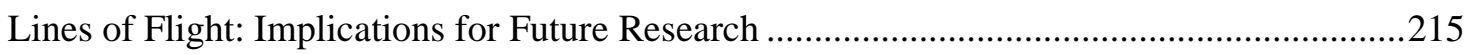

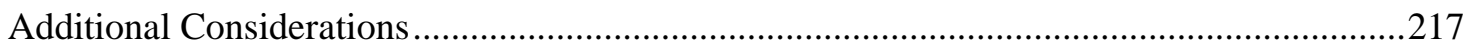

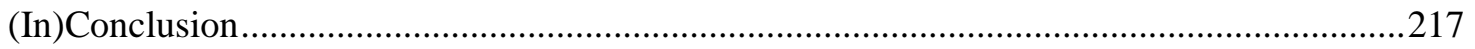

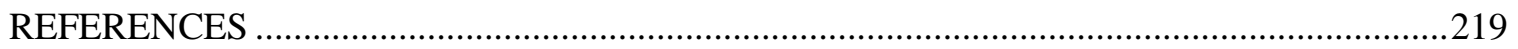

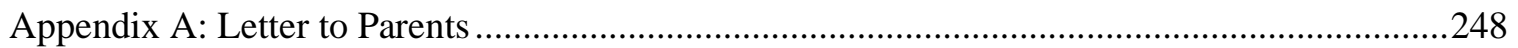

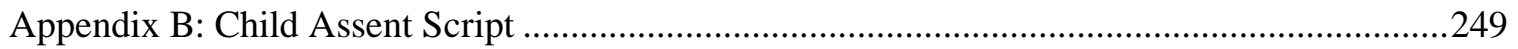

Appendix C: Research Questions, Methods, and Action Required..........................................250 
Appendix D: Research Media Records Release Form ..........................................................251

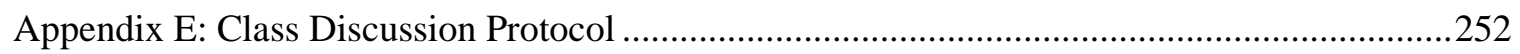

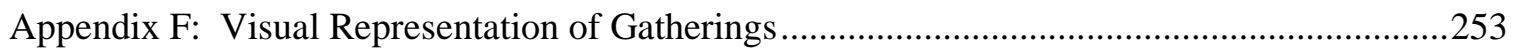

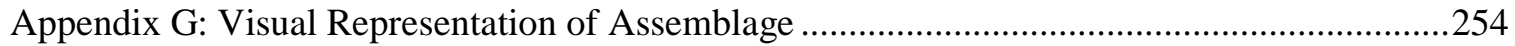




\section{LIST OF TABLES}

Table 1. Common Worlds Theoretical Framework ....................................................2 


\section{LIST OF FIGURES}

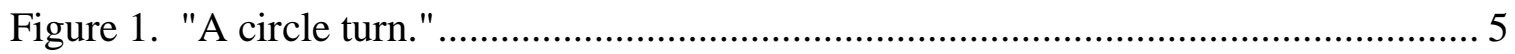

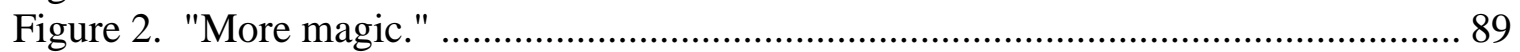

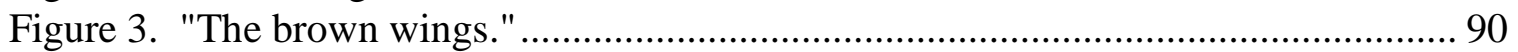

Figure 4. "I'm dead! Get the necklaces!" .................................................................... 91

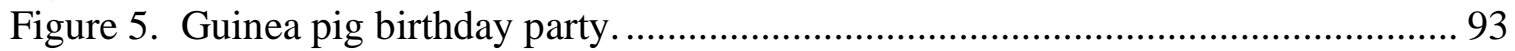

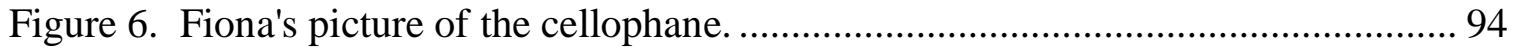

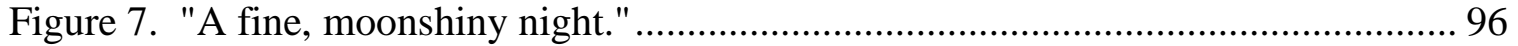

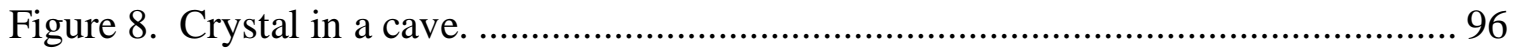

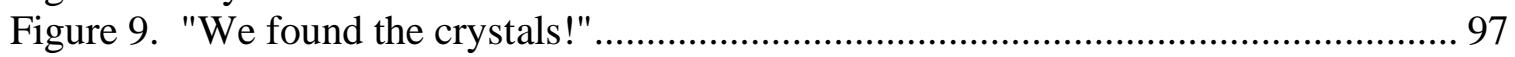

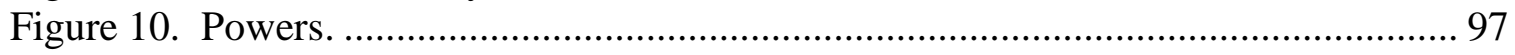

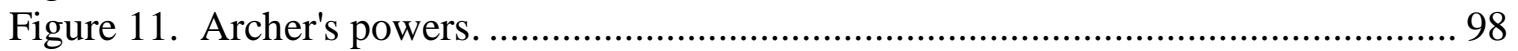

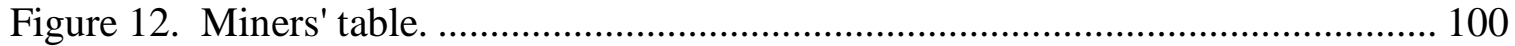

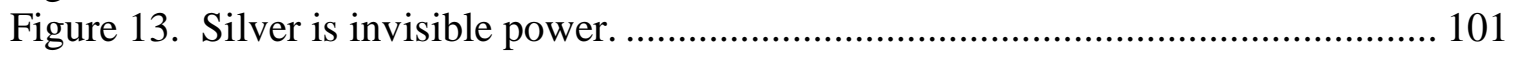

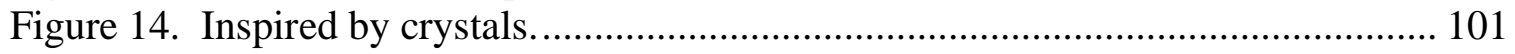

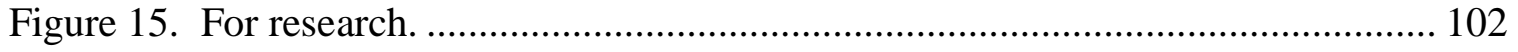

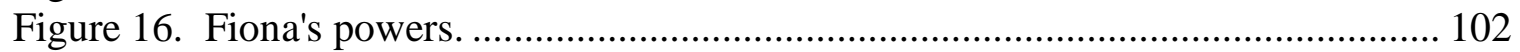

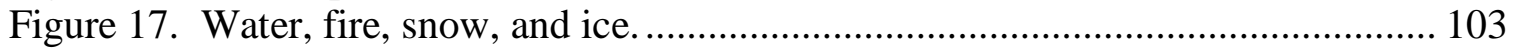

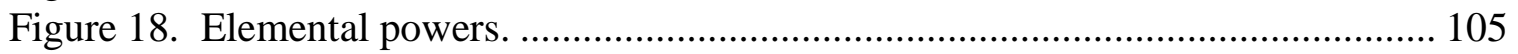

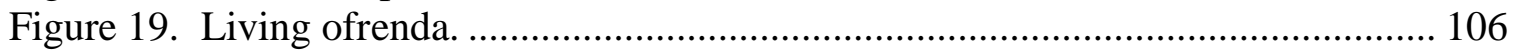

Figure 20. Archer's Maggie story. ……………………........................................ 106

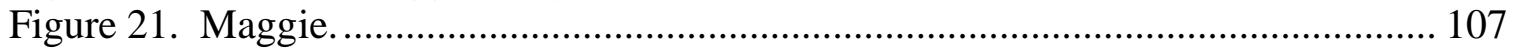

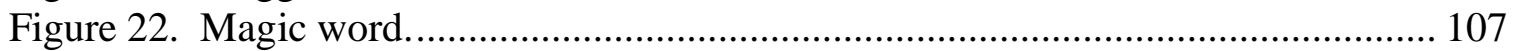

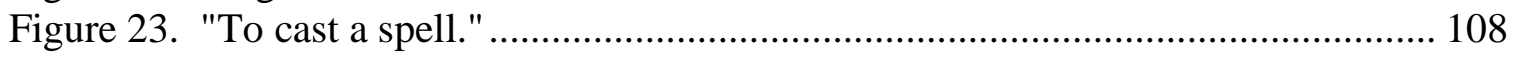

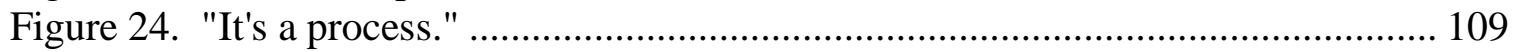

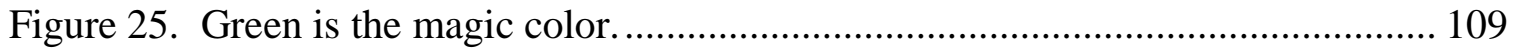

Figure 26. "Magic isn't real!"............................................................................... 110

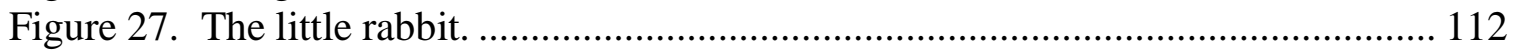

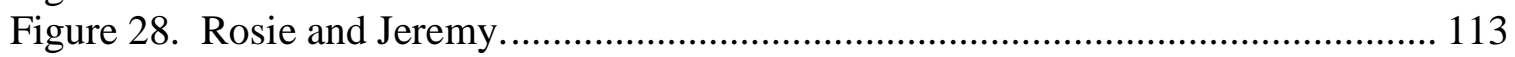

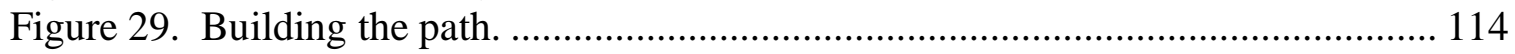

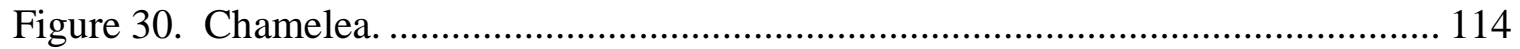

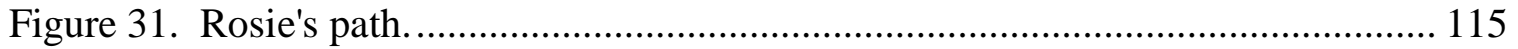

Figure 32. Stopwatch for Rosie. ...................................................................... 115

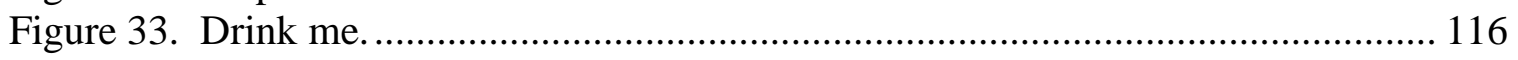

Figure 34. "Now you are the white rabbit." …………….......................................... 116

Figure 35. Jeremy and Rosie get married. …………........................................... 117

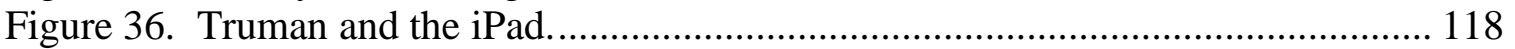

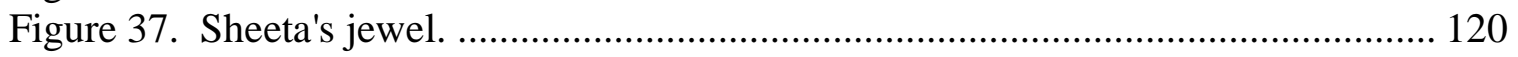

Figure 38. What does it take to see an elf? .............................................................. 124

Figure 39. Fiona's elf story. .............................................................................. 124

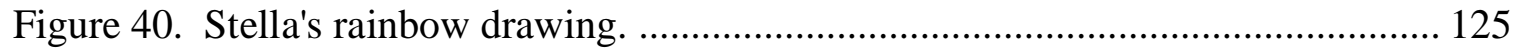

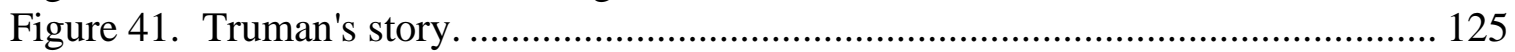

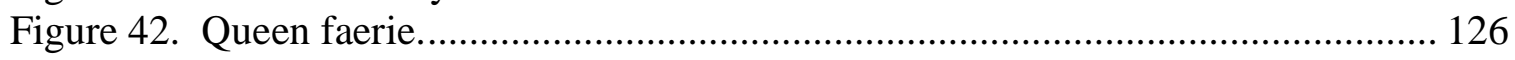




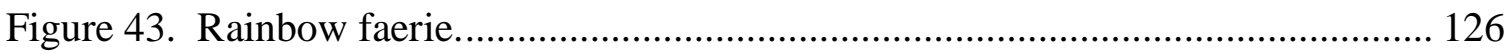

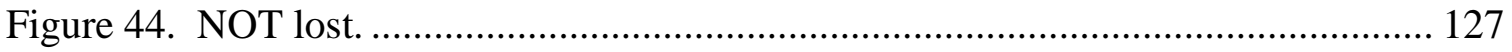

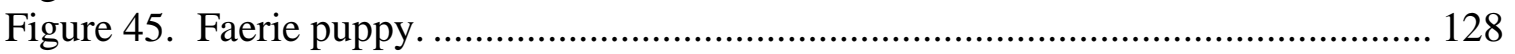

Figure 46. "This egg can make tornadoes." ………….............................................. 128

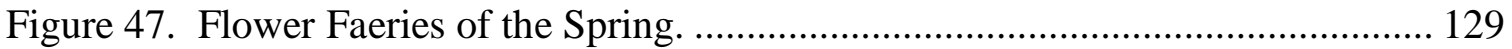

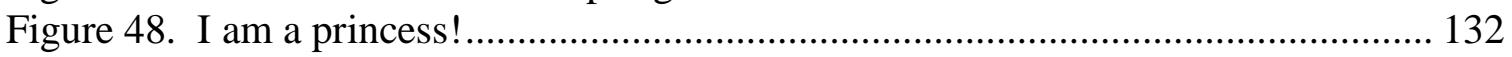

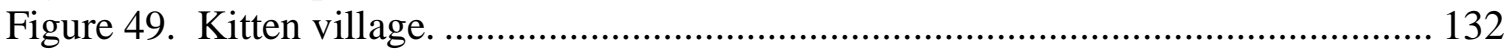

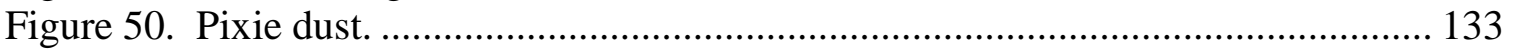

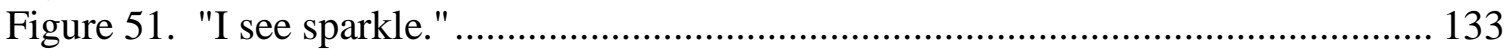

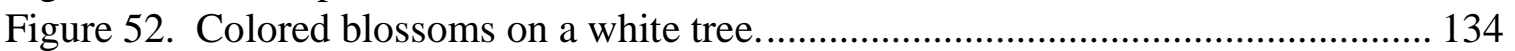

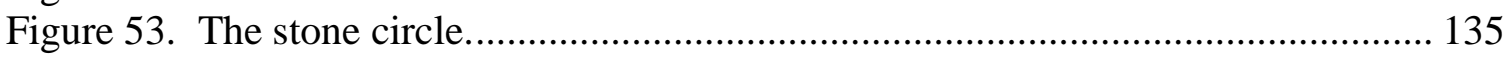

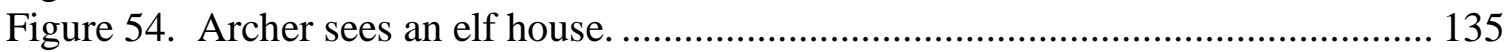

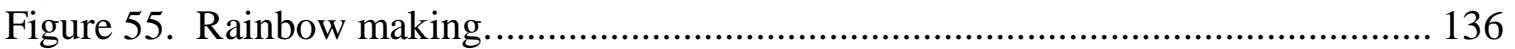

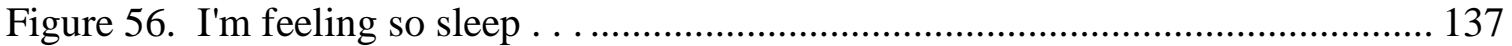

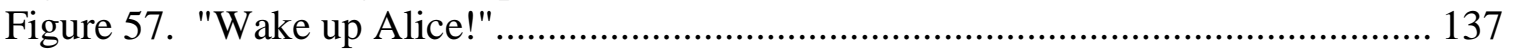

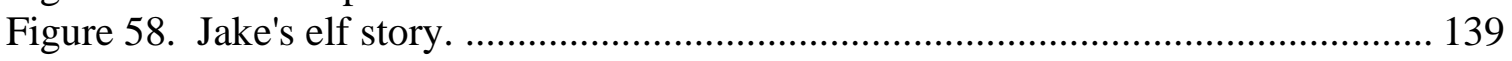

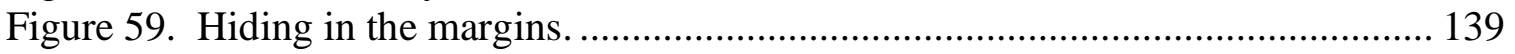

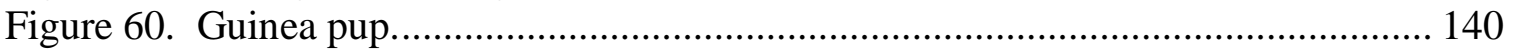

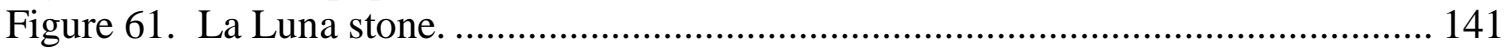

Figure 62. Stories at the Miners' table. .................................................................... 142

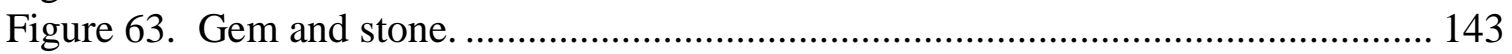

Figure 64. "This is not an ordinary stone." ............................................................. 143

Figure 65. Sleep for one hundred years. ................................................................ 144

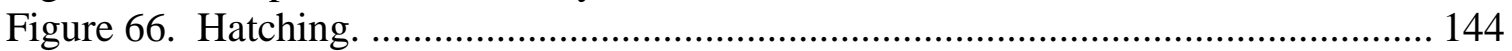

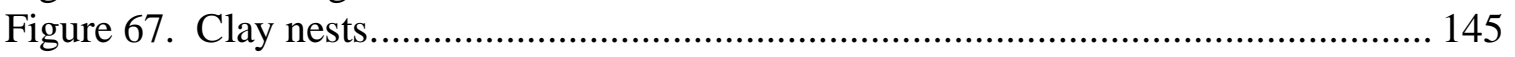

Figure 68. "You're supposed to save me!" ................................................................. 145

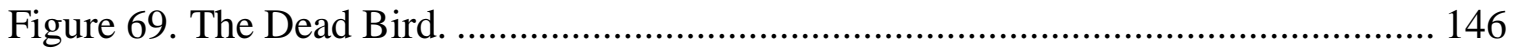

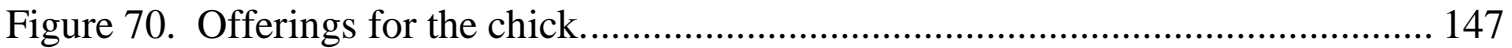

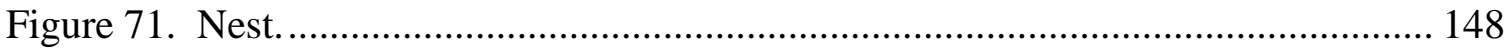

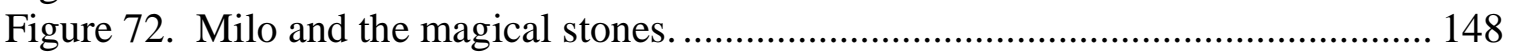

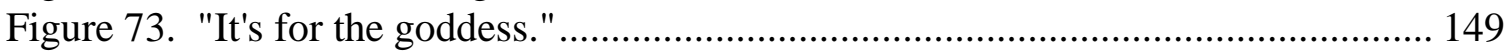

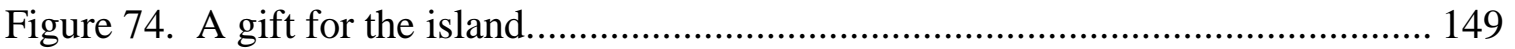

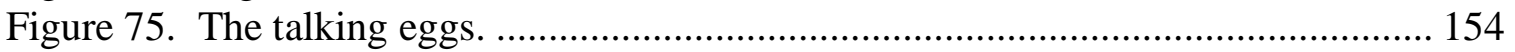

Figure 76. Choosing stones................................................................................... 155

Figure 77. "I guess we choose each other." ………….............................................. 155

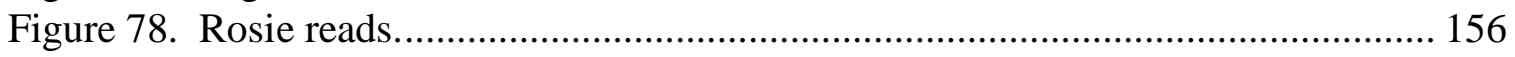

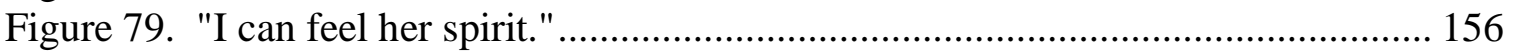

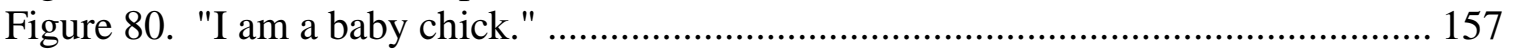

Figure 81. Child of Faerie, Child of Earth............................................................... 157

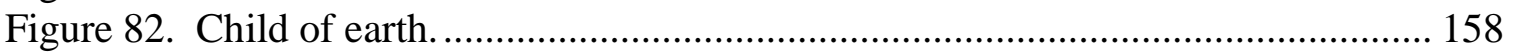

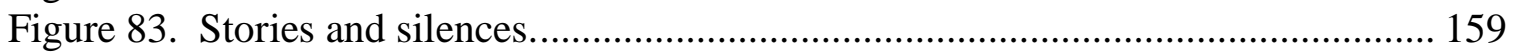

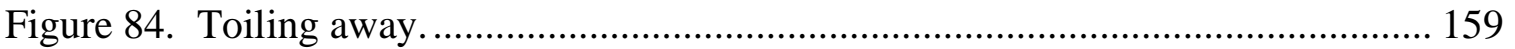

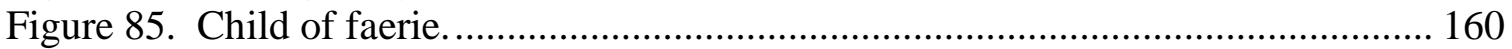

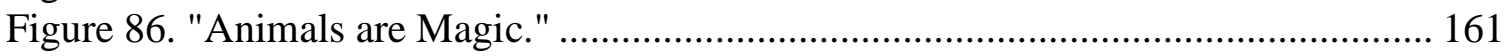




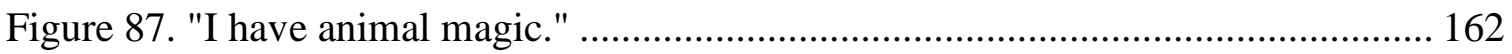

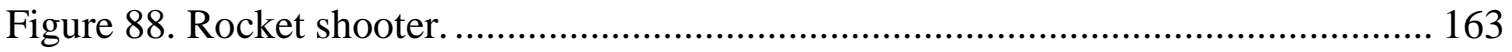

Figure 89. "It starts getting windy." ........................................................................ 163

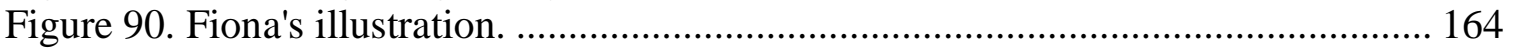

Figure 91. "Once upon a time, there was a big tornado..." .......................................... 165

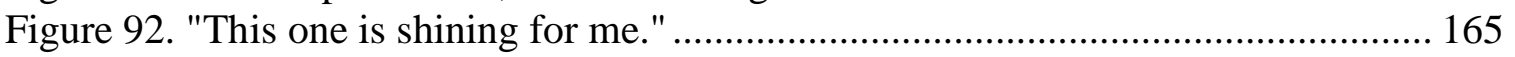

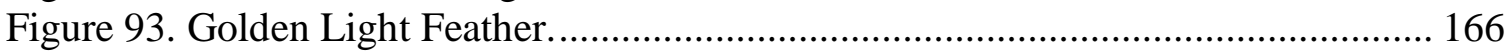

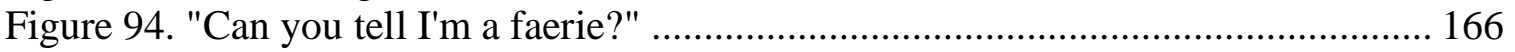

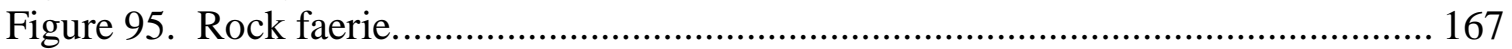

Figure 96. Composing the thinking wall.................................................................. 168

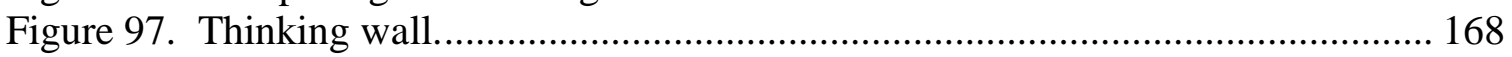

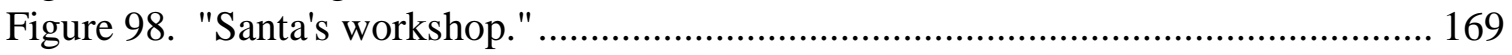

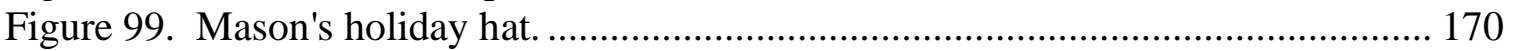

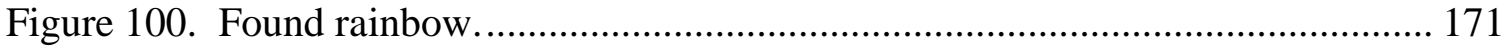

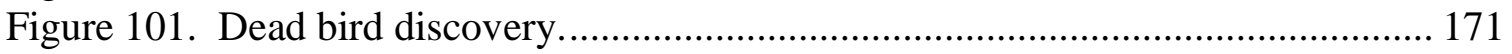

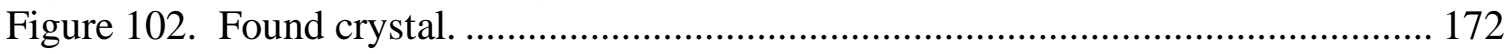

Figure 103. Found crack in the earth. ..................................................................... 173

Figure 104. The grass is moving but there is no wind............................................. 173

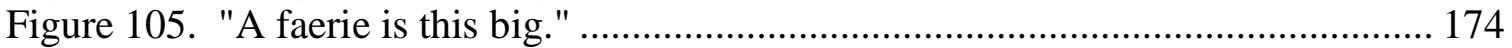

Figure 106. When I Was Small.................................................................................. 177

Figure 107. Re-visiting the tall grass................................................................... 178

Figure 108. Caught in the tall grass. ………………….......................................... 178

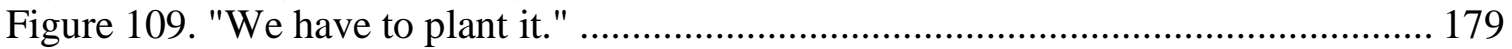

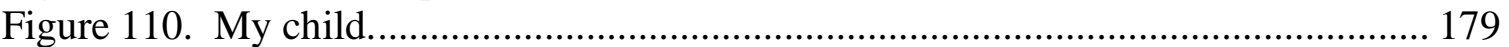

Figure 111. "I'm the elf that took your binoculars." .................................................... 180

Figure 112. Mason and the rainbow. ................................................................... 180

Figure 113. Getting ready for Christmas. ................................................................... 183

Figure 114. The Easter Bunny comes on Halloween.................................................... 184

Figure 115. "It's part of the story, but I don't know how yet."...................................... 184

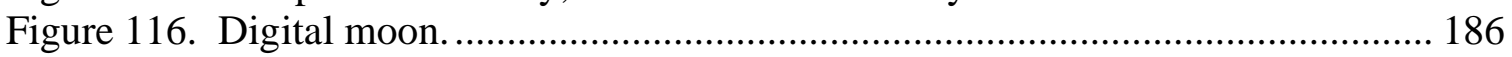

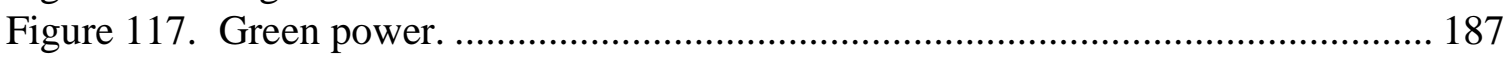

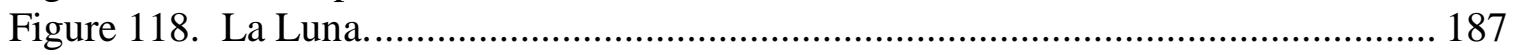

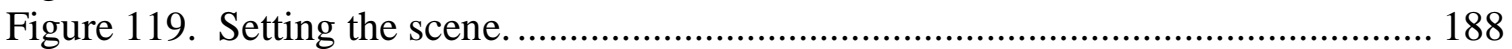

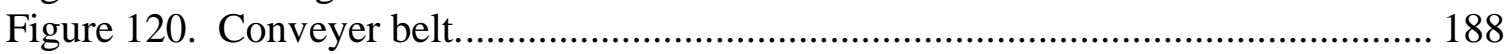

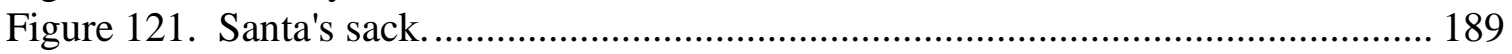

Figure 122. Santa and His Elves Story Assemblage................................................... 193

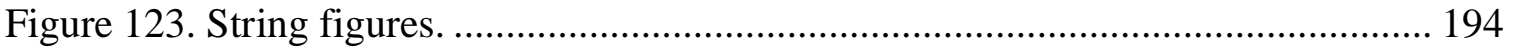




\section{CHAPTER 1: INTRODUCTION}

The stories we need now are not the big heroic ones, but rather smaller stories that help us rethink our big questions in richer veins. (Rose, 2014, para 7).

For as long as there have been organized systems of mass education for young children, (the 17th century) there has been debate about what, why, and how young children should learn (Ariès, 1962; Deacon, 2005; Foucault, 1977). The field of education has long been shaped by a hierarchy of "experts" (Gallacher \& Gallagher, 2008; MacNaughton, 2003; Mozère, 2012) who utilize quantitative data and "scientifically inescapable truths" (Mozère, 2012, p. 60) to manage the education of individuals, groups, and society as a whole (Foucault, 1982).

In recent years, the social function of early childhood education in particular has become a highly contested issue, as economic experts (Heckman, 2006; Organisation for Economic Co-operation and Development [OECD], 2019) drive the discourse regarding the purpose of education for young children and child development experts (Bogard \& Takanishi, 2005; Graves, 2006; Kauerz, 2007; Takanishi, 2016) debate the best practices by which to deliver it. From these expert-driven dominant discourses, rooted in "normal science" (Kuhn, 1962; Lather, 1993; Stengers, 2018; Urban, 2018), or the dominant (western, positivist, and humanist) worldview (Iorio \& Parnell, 2015b; Reconceptualizing Early Childhood Education [RECE], 2014; Soto \& Swadener, 2002), a culture of standardization has emerged, dictating learning outcomes that children should be able to demonstrate according to prescribed timelines (Bloch, Swadener, \& Cannella, 2014, 2018). 
Education is suffering from narration sickness (Freire, 2018). In education climates increasingly focused on learning outcomes, children's irreverent (unconventional and non-standard) narratives are often dismissed, disregarded, and delegitimized by educators who are compelled to locate and quantify the learning that is happening in their classroom (Hursh, 2001; Hursh \& Martina, 2003). Anderson (2014) stated, "Growing demands for accountability through increased public awareness, the view of parents' rights as consumers, and demands of policymakers push conversations about accountability to the forefront of current discourse" (p. 26). Thus, curriculum and classroom interactions are unequivocally shaped by the narrowing of early childhood professional development system requirements and other regulatory factors (Anderson, 2014).

As Foucault (1977) prominently noted, the disciplinary gaze often falls upon those considered exotic and deviant, and by extension, ideas that might be regarded as such. Regardless of teachers' feelings about prescribed learning outcomes, the culture of academic pushdown creates a situation where teachers reinforce conventional ideas that emerge from, or will lead back to, these learning outcomes (Franzén, 2015), disregarding or marginalizing ideas that fall outside of these conventions. The result is that the expertdriven trend of standardized and outcome-based curricula in early childhood education either directly or indirectly determines what is right or wrong (Mozère, 2012) and "whose voices and knowledge count" (Bloch, 2014, p. 24) in early childhood curriculum and pedagogy, and therefore what comes to matter (Barad, 2007; Latour, 2004a), in early childhood education. Mattering is indicative of what we value and legitimize, and 
indeed, what is possible in any given situation. As Barad (2007) stated, "mattering is simultaneously a matter of substance and significance" (p. 3), or, put another way, mattering attends to the production of the material and the meaningful. With the goal of reconceptualizing expert-driven dominant discourses and attending to mattering with children, my research question is, how does the more-than-human matter in children's storytelling?

This research is designed to position children's storytelling as a central force in disrupting the privileging of western, positivist, and ultimately humanist knowledges in early childhood education and research. To this end, I employ an emerging body of anticolonial (Nxumalo, 2015, 2018, 2019; Todd, 2016) and posthumanist and new materialist research to reconsider unexamined educational notions (Barad, 2003; Braidotti, 2013; Lenz Taguchi, 2010b; Myers, 2014, 2015; Pacini-Ketchabaw, 2012; Rautio, 2013). I propose that engaging with children's unconventional storytelling offers a method to center experimentation and surprise in the reconceptualizing of early childhood education, and to encounter knowledges beyond the standard and conventional (Iorio \& Parnell, 2015a).

A seasoned early childhood educator, I have always deeply valued storytelling and story sharing practices in my classroom communities. The following vignette depicts a pivotal moment that shifted my understanding about the potential of story to determine whose voices and knowledge count, or "what stories count and don't count" (Aoki, 1993, p. 262), and what comes to matter in early childhood settings.

Mason is three. He has done several drawings in his journal but has never written a story. Nor has he narrated a story for the class to perform during 
story theater. Instead, he has participated in our storytelling and story sharing practices mainly through acting out the role of characters in the stories of others- playing the part of the rock in Sylvester and the Magic Pebble, or perhaps a bear, a king, or an oak tree in a story written by another child-usually one of the 4 or 5-year-old girls who dominate our storytelling activities. One day he called me over to the writing table and said, "I need you to write my story." I tried to conceal my surprise as I sat beside him to write the words he dictated to me. His journal was open to a page that looked quite like the others, with large, multicolored circular scribbles on it. I offered my customary question: "How does your story start?" He responded with a smile and, tracing his finger on the drawing, said: "A circle turn, a circle turn, a circle turn, a circle turn, a circle turn, a circle turn ..."

Later that morning, as was our usual practice, we held what we call "story theater," where children are invited to share their stories with our classroom community. Sharing at story theater is a way that stories can come to matter. It is a rite of passage; not everyone has been bold enough to take up space in that way. Again, to my surprise, Mason walked proudly to the author's chair and sat down. I was concerned. The children had never performed a story like this - a story that was seemingly not even a story - with no characters, no plot, no beginning, middle or end. What would happen for him in this pivotal moment if this experiment failed? Mason held up his journal to show the class his illustration and began to "read" the story. "A circle turn, a circle turn, a circle turn, a circle turn, a circle turn, a circle turn ..." Before Mason could follow our story sharing conventions of choosing participants or sharing his ideas about how we might act it out, the children stood up and begin to spin around in circles in delight, arms extended, reciting along with him ". . . a circle turn, a circle turn, a circle turn, a circle turn, a circle turn, a circle turn ..." See Figure 1. 


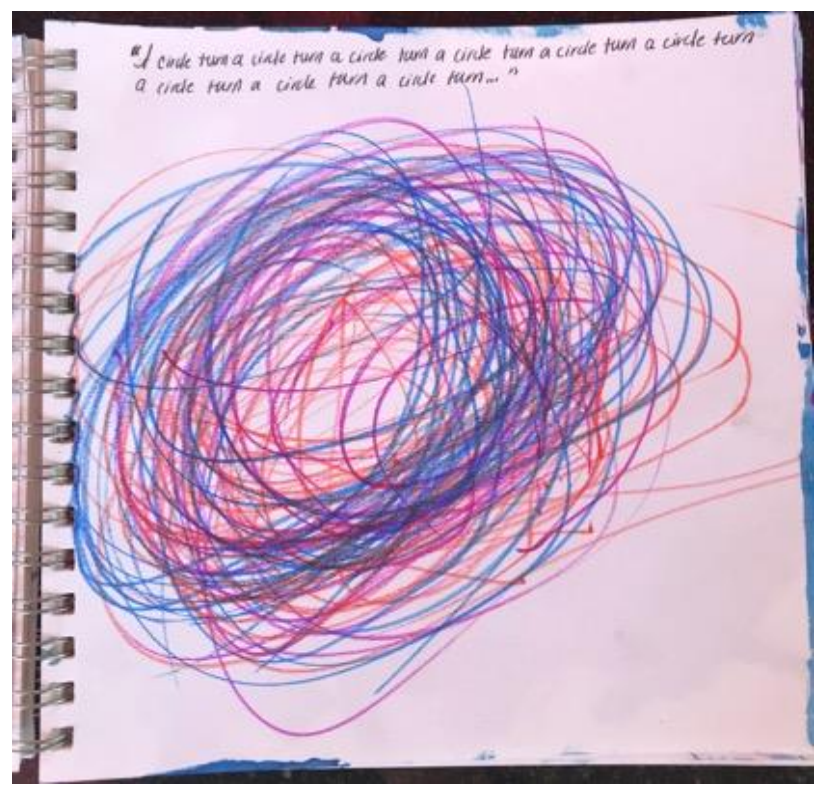

Figure 1. "A circle turn."

As I consider this experience, I find that Mason's story transgressed story sharing conventions that had gone unexamined in my classroom. It came as a surprise, offering a bordercrossing from the margins into our conventional practice, thereby changing what is possible within those conventions (Giroux, 1992b). Several children who had never shared a story before felt emboldened to participate after Mason shared his. Soon our story performances became a mix of silly, nonsensical storytelling told by marks on paper and spontaneous anecdotes from children's lives along with the stories we had become accustomed to as a classroom community; stories which employ the conventions of fairy tales and are illustrated in a familiar representational style (Zipes, 2006). Mason's story performance, with its lack of plot, characters, and linear progression, had made story theater a place where anyone's stories can come to matter.

Witnessing Mason sharing his nonlinear, non-logocentric story with his community was not only transformative for our classroom practices, it also carried 
implications for me as an educator. I had not recognized that unconventional storytelling requires a different sort of attending to, and that because of this, this storytelling had been going unacknowledged in our classroom. These irreverent, or non-standard stories come as they are, and require neither mediation nor interpretation. Stories like Mason's, which are produced the moment the pencil touches the page, or the moment when children's bodies, graphic expressions and other non-human elements bring the story into a particular way of being through a mutual encounter (Bamberg \& Georgakopoulou, 2008; Hohti, 2016b). This experience made me wonder what other surprising stories and embodied understandings lay hidden in the margins of daily classroom life and how I could begin to consciously make space for them in the foreground.

The conscious making of space for unconventional ideas is a pedagogical as well as an ethical consideration. Kessler and Swadener (1992) reminded us that it is critical to problematize the conventions that we have established in our classrooms, in order to make the familiar strange.

The nature of knowledge, as well as the practices that are valued or privileged in the early childhood curriculum, must be examined within a number of larger contexts as well as from multiple perspectives. In order to reconceptualize . . . we will need to become better listeners . . . honor the voices . . . learn how to make the "familiar strange" and many of our prized assumptions problematic. (p. 293) Examining my own storytelling and story sharing practices as an educator forced me to acknowledge that conventional knowledges and normative modes of expression were unintentionally being privileged in my classroom. I had been sidelining that which seemed to be nonsense in our storytelling practices (Olsson, 2009). The pedagogical choice to celebrate tellable (Nicolopoulou, 2004; Ochs \& Capps, 2001) and coherent 
(Gubrium \& Holstein, 1998; Hohti, 2016b) stories that lend themselves to familiar interpretations, while regarding unconventional narratives as a developmental step on the path to real storytelling, carries ethical implications for the classroom community. I consider the ethical implications of this pedagogical choice with Barad's critical posthumanist ethics, in which ethics is a matter of "questioning what is being made to matter and how that mattering affects what is possible to do and think" (Davies, 2016, p. 83). Lenz Taguchi (2005) said that once we revise what we "know" about how children think and learn, we often must change our practice to reflect new understandings. This statement certainly applied to me. Thus, I did not want to continue to enact classroom practices that celebrate only children's conventional ways of knowing and seeing. Rather, I wanted to enlist experimental practices (Davies, 2014a) that would "keep the way open" (Osberg \& Biesta, 2008, p. 325) to unconventional ways of mattering, such as the one produced by Mason and his classmates.

In order to examine and address the question of how the more-than-human matters in children's storytelling, in this chapter, I explore a problem of practice, prophetic pedagogy, or what Lenz Taguchi (2010b) named as starting with the end. To consider prophetic pedagogy, I look in on readiness discourses, preplanned curricula, and look out beyond a reductionist view. To zoom out to the larger context of the problem, I discuss the implications of early childhood spaces as "sites of struggle" (Soler \& Miller, 2003, p. 57). Next, I share thinking with theory (Jackson \& Mazzei, 2012; Lenz Taguchi, \& St. Pierre, 2017) as a methodological choice, and the methods I employed based on my research question. Further, I define key terms before moving to Chapter 2, where I 
outline the theoretical frameworks and the literature informing this study. First, I offer a brief explanation regarding my use of socio-spatial concepts in my discussion of children's storytelling.

\section{Children's Geographies to Inform This Work}

In this research, I use terms such as margins, in-between, mapping, and "making space" to describe children's human and more-than relations in the places and spaces of their lives. I draw upon these concepts, which I derived primarily from the field of children's geographies (Blazek, 2018; Horton, 2018; Kraftl, 2019; Rautio, 2014; Taylor \& Pacini-Ketchabaw, 2017), because they have material and ethico-political implications for children on micro and macro levels - both in their everyday lived experiences and in how they are positioned within a larger social context. Urban (2019) described the ongoing significance of socio-spatial considerations in power relations in saying,

Whether geographically or conceptually, Empire is about the assumed (and enforced) supremacy of the centre over the periphery, the province. This continues to be the case under neo-colonial conditions (Apple, 2003), where physical colonisation has been replaced by political, economic and cultural dominance. (pp. 96-97)

I find these socio-spatial terms useful in considering children's relations in their common worlds, and in educational spaces in particular. The concepts of marginality (Urban, 2014, 2018) and mattering (Barad, 2007; Schlossberg, 1989), and the in-between (Beckett, 2007; Braidotti, 2002; Hohti, 2016a) are especially salient in thinking about the ethico-political nature of children's storytelling in early childhood settings. 


\section{Background of the Problem}

In this section, I describe how readiness discourses seek simplicity and conformity and perpetuate inequity by design (Graue, 1993; Iorio \& Parnell, 2015b). Next, I show how standards of measurement create colonizing frameworks that replicate sameness and repetition in terms of both ideas and practices and shut down possibilities for the extraordinary to emerge in the everyday (Parnell, 2011; Strozzi, 2001).

Starting with the end. In the current education climate, where policy makers, researchers, and funders increasingly expect young children to demonstrate quantifiable, predetermined learning outcomes, there is often little room made for unconventional ways of thinking and knowing in classroom settings (Osberg \& Biesta, 2009). Lenz Taguchi (2010b) reminded us that it has become common practice for educators to start with the end, considering expected learning outcomes and working our way back, preplanning curriculum as a means to deliver content in what can be called "destination learning” (Aoki, 1993; Franzén, 2015; Osberg \& Biesta 2008; Lenz Taguchi, 2010b). Similarly, Malaguzzi (as cited in Cagliari et al., 2016) named pre-planned curriculum as a "prophetic pedagogy" (p. 421) in saying:

[Pre-planned curriculum] contemplates everything and prophesies everything ... sees everything to the point that it is capable of giving you recipes for little bits of actions, minute by minute, hour by hour, objective by objective, five minutes by five minutes. This is something so coarse, so cowardly, so humiliating of teachers' ingenuity; a complete humiliation of children's ingenuity and potential. (pp. 421-422)

As signified by Mason's storytelling experience in my vignette, it is evident that even the most well-conceived classroom practices can unintentionally enact a prophetic pedagogy unless we make room for what Malaguzzi aptly described as the surprise. 
Pre-planned curriculum that looks the same from school to school and year to year, or as E. Jones and Nimmo (1994) referred to it, "embalmed curriculum," in addition to humiliating children's ingenuity, seeks uniformity and linearity rather than viewing complexity as an asset (Franzén, 2015; Osberg \& Biesta, 2009). With uniformity as a guiding star, pre-planned curriculum puts preschools, kindergartens, and nursery schools in danger of becoming nothing more than funnels in the name of kindergarten readiness, enculturating young children into a culture of compliance and narrow-mindedness (Novinger \& O'Brien, 2003). It seems in fact, that this colonizing trend has been increasing in scope and scale despite increasingly complex socio-political landscapes. Lenz Taguchi (2010b) put it this way, "The more complex things become the more we seem to desire processes of reduction and thus increase control, but such reduction strategies simultaneously make us risk shutting out the inclusion and social justice we say we want to achieve" (p. 14). Considering the connection between reductive educational practices and control, I am compelled to wonder whose interests are served by this reductive approach to education, an approach that seeks simplicity and conformity through atomizing children's learning, and what is lost in the process of standardizing (Deleuze, 1992; Lather, 1998).

Inequity by design. Too often, in communities that go underserved, schools have become no more than a "delivery agency model of education" (Young, 2006, p. 28) while functioning as an apparatus to advance capitalist agendas of globalization (Burman, 2008; Paananen, Kumpulainen, \& Lipponen, 2015; Viruru, 2006). “Neoliberal readiness discourses" (Peters, Ortiz, \& Swadener, 2015, p. 33) offer the dangerous story that there 
is one right answer to most problems, and a school-ready child will be capable of discerning it. Though proponents of school readiness might argue that there is a core body of knowledge that is critical to children's future achievement as life-long learners (OECD, 2019; Staggs, 2000), others argue that the push toward kindergarten readiness (Iorio \& Parnell, 2015b) is a dangerous waste of time and energy for all children, and for children in oppressed communities in particular (Freire, 1997). The terrible irony is that the people most in need of emancipation from oppressive social constraints are more likely to be subjected to education mandates in the name of closing the "achievement gap" (Gorski, 2011; Heckman, 2006; Iorio, Parnell, Quintero, \& Hamm, 2018; Lee, 2002) and are therefore denied engagement in participatory, democratic learning opportunities (Algava, 2016; Quintero, 2015). Thus, learning standards have the potential to act as tools for the "maintenance of marginalization" in underserved communities (Gorski, 2008).

Within these frameworks of standardized educational programming, such as the current drive toward preschool-third grade alignment (Early Learning Division, 2017), children are measured in terms of competence or incompetence using normative standards. This fragmented perspective of children from underserved communities often positions them as somehow lacking in comparison with their peers, and perpetually in need of catching up (Gorski, 2011; Lee, 2002; Swadener \& Lubeck, 1995). Though couched in equity, the deficit minded paradigm of educating young children outside of communities of privilege perpetuates the very cycle of oppression that it claims to 
interrupt, and reproduces inequity by design (Algava, 2016; Bloch et al., 2014, 2018;

Giroux, 1983; Gorski, 2011; Kessler \& Swadener, 1992; Kumashiro, 2000).

Additionally, the learning outcomes that are deemed necessary for kindergarten readiness are decontextualized to the student and their experience and privilege the dominant paradigm; typically, white, Eurocentric/Euro-Western, and anthropocentric, or human centered perspectives of teaching and learning (Grosfóguel, 2009; Parnell \& Iorio, 2015; Quintero, 2015; van Dooren \& Rose, 2016). The compulsory assimilation of children into a universal, one-size fits all standard (Osberg \& Biesta, 2009) marginalizes or outcasts ways of thinking, knowing, and being that cannot assimilate into the dominant culture and acts as a technology for reproducing whiteness and racism as a norm (M. Miller, 2016). This forced assimilation is delivered by what some critical theorists refer to as the hidden curriculum (Jay, 2003; Leonardo, 2004; Rahman, 2013); the ideology of whiteness as the implicit normative standard in school curriculum.

Macedo (1999) aptly referred to standards of measurement that are unattainable by marginalized populations as the colonized condition in education. Further, oppressive learning standards have been wielded as technologies of power (Petitfils, 2015; Viruru, 2006) to protect and perpetuate dominant power structures (Giroux, 1992b) and have “colonized the intellectual development of an entire generation" (Petitfils, 2015, p. 40) through legislative mandates such as No Child Left Behind and Race to the Top. These programs, and countless others like them, exemplify ever narrowing standards of normativity encroaching on the lives of young children (RECE, 2014). 
More of the same. Learning standards also promote what Deleuze (1994) and Giroux (1992a) referred to as circular or orthodox thinking. In orthodox thinking, the possibilities for a creative thought are blocked by recognizing and reproducing representations of that which is already known, thereby suppressing unconventional ideas. Orthodox thinking both relies on and produces "stability, linearity, predictability and closure" (Moss, 2018, p. 118). Adherence to learning standards reinforces orthodox thinking and ensures the repetition of the same harmful histories, lesson plans and practices that are already in place (Kumashiro, 2000). However, as we are becoming increasingly aware, "more of the same" in education is no longer an option (Moss \& Urban, 2010). In Disrupting Early Childhood Education Research, Moss (2015a) posed the question, "Is it the job of researchers to offer further tools to aid the exercise of such elite power, or help disrupt it?" (p. xv). In a response to this query, child and education researchers ought to consider resisting normalizing practices in education research to make space for a multiplicity of perspectives (Lenz Taguchi, 2016; Lenz Taguchi \& Palmer, 2014; Martin \& Kamberelis, 2013).

The problem of orthodox thinking in education propelled me as a researcher into seeking experimental practices that offer alternatives to repetition and sameness and make way for surprise (Lenz Taguchi \& St. Pierre, 2017). Moss (2008) contended that "without experimentation, we are locked into an endless round of reproducing, in which the same prescribed means pursue the same known ends, in a repetitive and sterile process that gradually decays from the tedium of repetition" (pp. 30-31). Following Moss, I argued that children's unconventional storytelling offers an experimental 
construct that educators and pedagogists can use to reconceptualize early childhood practices and pedagogies and can serve as a guiding force in moving away from more of the same standards, practices, and oppressive pedagogies in education.

\section{Statement of the Research Problem}

Critical scholars argue that the trend toward standardized curricula generates a colonizing framework that reinforces dominant (western, positivist, and humanist) worldviews and positions the adults who design, teach, and administer these technologies as the experts and gatekeepers of knowledge (Cannella \& Viruru, 2003; Iorio \& Parnell, 2015b, 2018). This legacy reinforces dominant power structures (Ogbu, 1988; Petitfils, 2015; Viruru, 2005, 2006) and fosters a culture of sameness and repetition in educational practices (Kumashiro, 2000; Moss, 2018). Due to the growing emphasis on predetermined learning outcomes - in the field of early childhood education at large, from regulatory agencies and funders, and within individual school systems and classrooms - there often is little room made for children's storytelling in children's busy, content-filled school days. Even circle times and morning meetings, where children have traditionally shared small stories from their lives, are often used by teachers to deliver information (Bamberg \& Georgakopoulou, 2008; Hohti, 2016a). Because of this focus on delivering content, children's unconventional and personal stories (Gubrium \& Holstein, 1998) have been marginalized (Freire, 2018; Giroux, 1992b) or hidden in the between-zones (Braidotti, 2002; Hohti, 2016a, 2018) of the school day where there seemed to be "nothing to see" (Braidotti, 2002, p. 173). 
In Gilles Deleuze: An Introduction, May (2005) argued that children ought to consider for themselves that which is "interesting, remarkable or important" (p. 81) within experiences. Narration is one powerful way children sift through their experiences and show what they find significant in the world around them (Engel, 2006). In the readiness culture, however, children's own production of meaning is sidelined by necessity as educators redirect children's attention back to discrete learning points. In these instances, we "fail to offer children the opportunity to engage with encounters in an unpredictable way, and we curtail opportunity to allow for the different, the interesting or the remarkable" (Cliffe \& Solvason, 2016, p. 3). Simply put, by attending solely to conventional knowledges in our classrooms, we shut down possibilities for wonder and surprise (Moss, 2015a), and for the extraordinary to emerge in the everyday (Parnell, 2011; Strozzi, 2001). Consequently, the trend of standardized, outcome-based curricula in early childhood education marginalizes children's irreverent ways of knowing, being, and doing, determining what matters in early childhood settings.

In the current education climate where conventional knowledges are routinely privileged, I wonder what different, interesting, and remarkable stories might lie hidden in the margins of early childhood classrooms, and how we can begin to attend to these small stories in a way that opens us up to wonder and surprise.

\section{Significance of the Research Problem}

Early childhood settings have become contested spaces, or "sites of struggle" (Soler \& Miller, 2003, p. 57) between economic and sociocultural interests disputing the purpose of early childhood education. Recent years have shown increased pressure on 
children in early education settings to demonstrate predetermined learning outcomes, which (a) limits the scope of what is possible in the classroom, (b) narrows the range of what learning is considered valid, and (c) privileges the experience and values of the dominant culture, thereby determining what matters in early childhood settings. (Cannella, \& Viruru, 2003; Moss et al., 2016; Moss \& Urban, 2017). On the international level, the OECD has developed a cross-national set of early learning outcomes through the International Early Learning and Child Well-Being Study (OECD, 2019). Cross-national learning standards have been problematized by reconceptualist scholars who challenge the pretense of universality that underpins these initiatives (Moss et al., 2016; Moss \& Urban, 2017; Urban 2019). Their contention, as is mine, is that universal standards are a neo-colonialist project for uniformity that intentionally overlooks the diversity of context, culture and purpose found in early childhood (Moss \& Urban, 2017), and that global testing schemes seek to "reduce the rich diversity and complexity of Early Childhood Education and Care to a common standard, measure and outcome" (Moss \& Urban, 2017, p. 253). These presumed universal standards are decontextualized from children's culture and daily experiences, not to mention individual and cultural ways of experiencing the world (Quintero, 2015) such as sensing and attuning. Further, designs for universality in early childhood curriculum are implicated in the ongoing project of colonization of Indigenous people and the systemic erasure of Indigenous ways of knowing (Rahman, 2013). In the context of the U.S. Pacific Northwest, westernized education has been used to abrogate the knowledge and culture 
of Indigenous groups since the 19th century (Fee, 2019). Presumed "universal” learning standards are an extension of these colonizing efforts.

The prescription for universality in learning outcomes fosters a culture in early childhood settings where irreverent ways of knowing and being are ignored and delegitimized, and the "tiny things" and "small stories" (Hohti, 2016b) that matter to children are lost (Cannella, Swadener, \& Che, 2007; Kozol, 2000). As Rinaldi (1998) stated, ". . . the potential of children is stunted when the endpoint of their learning is formulated in advance" (p. 118). This endpoint learning belittles the child and diminishes the potential for early learning communities to create and innovate, and in the words of Loris Malaguzzi (as cited in Cagliari et al., 2016), is "a ridiculous simplification of knowledge, and a robbing of meaning from individual histories" (p. 378). Additionally, the learning standards that necessitate endpoint learning privilege the experience and values of the dominant culture, perpetuating inequity by reinforcing existing power structures and a culture of sameness, repetition, and orthodox thinking in education (Deleuze, 1994; Kumashiro, 2000).

In the face of immense academic pressure on young children in early childhood education settings, many early childhood educators are working to generate new possibilities both in the classroom and on a systemic level, or what has been referred to as the micro and macro levels of early childhood (Moss, 2018; Olsson, 2009; Urban 2018). Moss (2015b) assured us that

despite the best efforts of the "dictatorship of no alternative," early childhood education is, in fact, alive with a multitude of narratives, perspectives and debates [and] discourses of control can be disrupted, childhoods can be less regulated, and there are alternatives and resistances. (p. 236) 
What, then, are the alternatives, and how can we resist the 'danger of the single story' (Adichie, 2009) that dictates there is no alternative to things as they are?

Reconceptualist scholars have worked over the last two decades to disrupt homogenizing and oppressive trends in early childhood education, and a Critical Perspectives on early childhood education special interest group was founded in 1999 within the American Educational Research Association to bring this critical research to an international audience (Bloch et al., 2014, 2018; Kessler \& Swadener, 1992). The Common Worlds Research Collective (2020) has used feminist common worlds methods and inquiries into children's relations with place, with the material world, and with other species to challenge the monolithic narratives that underpin early childhood education and propose a radical reimaging of what is possible for early childhood. Inspired and informed by the work of these scholars (Bloch et al., 2014, 2018; Parnell \& Iorio, 2015; Taylor \& Giugni, 2012), I suggest that only by attending to children's emergent and relational meaning making processes and thereby engaging with "a multitude of narratives," (Moss, 2015b, p. 236) can educators begin to reconceptualize the goals of early childhood education alongside children; its content, and methods.

\section{Presentation of Methods and Research Question}

When considering the role of learning in early childhood education, the focus should not be about how educators can reduce children's thinking into terms that we can understand and measure, but rather, how educators might begin to understand and respond to children's emergent and relational ways of thinking (Iorio \& Parnell, 2015b; 
Rotas, 2015). But how can we approach this monumental shift in focus in the midst of such deeply entrenched education conventions?

The call for democratic experimentalism (Moss, 2017; Unger, 2005), or the "organisation of a collective experimental practice from below" (Unger, 2005, p. 179) is a compelling one, as we have evidence of the effectiveness of this practice, from the municipal schools of Reggio Emilia, Italy (Moss, 2018, p. 68), and Te Whāriki curriculum of the Early Childhood Education and Care schools of Aotearoa/New Zealand (Carr et al., 2016; L. Mitchell, 2019). If we respond to this call, pushing out into continually expansive experimental practices that refuse reduction and containment, perhaps we can be guided by the question of what matters to children and how that mattering is produced.

It has been well documented that children's learning unfolds in emergent, contextual, and most significantly for the purposes of this research, relational ways (Murris, 2016; Olsson, 2009; Rotas, 2015; Taylor, Blaise, \& Giugni, 2013; Urban, 2018). This learning is often invisible using conventional scientific methods of observation and cannot easily be reduced to identifiable standards of measurement. In response to this phenomenon, Kumashiro (2000), and Urban (2014, 2018), informed by critical pedagogy, (Freire, 2018), have suggested that educators ought to look to the margins of our classrooms to notice what we have been missing, thereby attending to ideas that have been sidelined in the name of simplicity, sameness, and control. This brings me to wondering what experimental methods educators can employ to attend to the small stories (Bamberg \& Georgakopoulou, 2008; Hohti, 2016a) hidden in the margins of daily 
classroom life. Quintero (2015) reminded us that "children are the consummate communicators about the personal, and communal experiences they bring to early education must be communicated and built upon" (p. 30). Children's storytelling offers a collaborative platform for inquiry. It is not only linguistic storytelling, however, but nontextual narration we must attend to when looking to the margins. By doing so, we can "eschew the heroic tales of major individuals on the big stage and seek out alternative, minor, but powerful polyphonic stories of multiple small players, quietly changing worlds together on the margins" (Taylor \& Pacini-Ketchabaw, 2018, p. 7).

Story as a platform for collaborative research. Stories are a defining quality of existence - if a thing exists, it has a story. Heidegger (1962) argued that stories are a means of examining one's "being-in-the-world." The importance of story in young children's lives, and correspondingly in early childhood education has been thoroughly documented (Bruner, 1986, 1991; Cremin et al., 2016; Engel, 2003; Floyd \& Cooper, 2008; Karlsson, 2013; Paley, 1986, 1988, 1990, 1998, 2000, 2009; Puroila, Estola, \& Syrjälä, 2012; Quintero, 2015; Riessman, 1993). Cooper (2009) applied Heidegger’s (1962) proposal to the lives of children in saying, "Young children use stories to interrogate what they know about the world-and what they might know" (p. 66). Through traditions of story-making and story-sharing in early childhood education settings, storytelling has emerged as a platform for children and researchers to collaborate on learning and meaning-making (Binder, 2013; Cooper, 2005, 2009; Iorio \& Parnell, 2017; Iorio et al., 2017; Paley, 2000, 2009; Puroila et al., 2012; Quintero, 2015, 2017). Quintero (2017) spoke to the potential of stories as a meeting place for research in saying, 
The day-to-day stories of children and their [teachers] show that a framework of story - personal stories, imaginary stories, historical stories, and other types of story - has promise as a way for adults and children to collaborate on teaching, learning, and on research. (p. 183)

Children's narrations have also been understood as dynamic meeting places in which children's inner lives and their external worlds meet each other (Ahn \& Filipenko, 2007; Puroila et al., 2012). It is in this sense that children's stories act as generative spaces for becoming-with the world (Haraway, 2008b). Hohti (2016b) argued that these "narrative meeting spaces" carry the potential to expand our thinking about children and childhoods. By researching children's narrative processes and attending to the small stories they share, we can come to know what children value, what they find remarkable and important in their daily lives, and what big ideas (Chaillé, 2008) they are grappling with in the margins of their school experience (Paley, 1990, 1998, 2000). Simply put, we can begin to learn what matters to children outside the boundaries of sanctioned school curriculum and activities.

Research question. My initial attempts to establish a research question led me to: How do humans, non-humans, and materials matter in children's storytelling? However, due to the fact that nearly all of the previous research regarding children's storytelling has focused exclusively on the human realm, I wanted my research to attend to that which is other than human in children's storytelling, or what I refer to as the morethan-human. Therefore, I reframed my inquiry and corresponding study to address the question, How does the more-than-human matter in children's storytelling? In this investigation, I use the definition of "more-than-human" suggested by Puig de la Bellacasa (2017) who used the phrase to indicate non-humans and other than humans 
such as things, objects, other animals, living beings, organisms, physical forces, and spiritual entities.

In this research, I am "thinking with theory" (Jackson \& Mazzei, 2012; Lenz Taguchi \& St. Pierre, 2017) to use critical posthumanist/new materialist and poststructuralist theories as a post-qualitative research methodology (Lather, 2013; Lather \& St. Pierre, 2013; St. Pierre, 2011, 2013). My research is premised on the understanding that as researchers, we are already always entangled with the world, and therefore research is an entangled practice (Barad, 2007; Hohti, 2016b; Kind, 2013; Meyers, 2014). Kind (2013) referred to the nature of research with children as "a lively entanglement" (p. 434). As Barad (2007) noted: "Knowing does not come from standing at a distance and representing something, but rather from a direct material engagement with the world" (p. 49). With Barad's assertion at the heart of this study, my research was enacted through direct material engagement with children and their stories.

The multimodal approach to data collection was essential for this research because I attended to stories in multiple forms. Among other things, this included stories that did not employ traditional conventions, such as being told chronologically, with a clear beginning, middle and an end (Hyvärinen, Hydén, Saarenheimo, \& Tamboukou, 2010; Puroila et al., 2012). Also included were "nonsensical" stories, stories co-narrated with non-humans and materials, and stories generated outside of the logocentric narrative tradition, which privileges children's oral or written storytelling (Franzén, 2015; Puroila et al., 2012) due to the presumption that language is the epitome of meaning (St. Pierre, 2011). Even in my classroom, where storytelling practices are a regular part of the 
curriculum, unconventional stories such as these need attending too to avoid becoming lost in-between sanctioned activities or pushed to the margins of the school day.

This chapter discussed the problem of universalized learning standards in the field of early childhood education and described why it is an issue of critical concern. Next, I proposed storytelling as a platform for collaborative research to address the problem of decontextualized and reductionist curriculum. In the following chapter, we examine literature relevant to this key issue. Before doing so, however, it is necessary to define key concepts that I use in this research study.

\section{Definitions of Key Concepts}

- Assemblage: A web of diverse human and nonhuman elements in intra-action with each other, producing generative affects beyond the vital force of each materiality considered alone (Bennett, 2010).

- Entanglement: A term from quantum physics referring to the relational nature of things, the complexity of which renders it impossible to consider the implications of any element in isolation. (Barad, 2007).

- Ethico-onto-epistemology: Ethics (as well as politics) and practices of knowing and being cannot be isolated from one another but rather are mutually implicated and constitutive (Barad, 2007).

- Diffraction: Unlike methods of reading one text or set of ideas against another where one set serves as a fixed frame of reference, diffraction involves reading insights through one another in ways that help illuminate differences as they emerge (Barad, 2007).

- In-between: A pedagogical space that is "under the radar" of teachers' attention, yet vital to the daily life of the child.

- Materiality: Landscape, objects, weathering, air, and atmosphere (Ingold, 2011).

- Matter: The term "matter" refers to phenomena of substance and significance in their ongoing materialization. 
- Mattering: The material world and its meaning are co-constituted through the process of mattering. Mattering also indicates having value in a particular context (Jones, 2018).

- Narrative: Can refer to a story, but also includes the context and the materialdiscursive process of producing the story (Puroila et al., 2012).

- Pedagogical narration: A term commonly used in British Columbia, pedagogical narration is selective, partial, contextual, and situated documentation that produces a material-discursive expression of learning and their intra-action with more-than human things, thought, affect, concepts, and environment, bringing energies and forces to the project work that open up new possibilities (Olsson, 2009).

- (Feminist) poststructuralism: The theory that thinking is non-linear and transgressive; resisting normalizing and oppressive binary classifications.

- Rhizomatic theory: The theory that thought has no beginning, no end, just a "middle of things, with unlimited possible pathways (tubers) that open up an ever-expanding multiplicity of connections/directions" (Deleuze, Guattari, \& Massumi, 1987, p. 23).

- Small stories: Stories that might seem insignificant to adults and are often hidden in the "in-between" moments of the day (Beckett, 2007; Braidotti, 2002; Hohti, 2016a). 


\section{CHAPTER 2: LITERATURE REVIEW}

Since the birth of formal education, there has been debate among scholars, philosophers, educators, psychologists, and even economists about what, why, and how young children should learn. Despite these well-worn debates that position child as innocent, child as protagonist, the rights-bearing child (Greene \& Hill, 2006); innocent child in need of protection, child as a "return on investment" (Heckman, 2006) to bolster national capital, there has been little research on children's emergent and relational production of knowledge. These significantly under researched knowledges cause me to consider what children care about; what they want to learn more about; how they grapple with making meaning of their world; and how these factors impact their educationearly childhood content, methods, and experiences.

Children's storytelling, and in particular storytelling deemed as unconventional, offers a framework for addressing these questions. An overview of early education reveals, with a few notable exceptions, a global movement that aims to dictate what knowledges are deemed as legitimate, and consequently, what knowledges are not. However, actual children in real classrooms continue to resist this reductionist trend with transgressive thinking, bold experimentation, and storytelling from the margins. By attending to these stories from the margins, (Freire, 2018; Giroux, 1992b), educators can, alongside children, keep the way open to unconventional knowledges and reconceptualize what matters in early education settings. The purpose of this study is to 
position children's storytelling as a central force in the disruption of the privileging of western, positivist, and humanist knowledges in early childhood education and research. This review of literature will orient readers to the theoretical frameworks I enlist to address the issue of mattering with children: critical posthumanism and feminist new materialism(s). Additionally, I employ emergentist theories (Davies, 2014a; Osberg, 2008; Osberg \& Biesta, 2008), which hold powerful implications for the nature of research — both the children's research and my own. I call on these frameworks as they are premised on the upending of dominant (western, positivist, and humanist) worldviews (Iorio \& Parnell, 2015b; RECE, 2014; Soto \& Swadener, 2002) and thus necessitate a launch into new ontological and pedagogical terrain. Next, I present a review of the literature addressing the role of storytelling in early childhood. Then I discuss literature that addresses the research question of how the more-than-human matters in children's storytelling. After exploring the research literature that pertains to the question, I look to literature that challenges the exclusively human views of classroom communities, reconceptualizing them as a relational ecology. Finally, I offer a brief review of the methodological literature that is relevant to this research.

\section{Theoretical Framework}

My theoretical framework draws heavily upon reconceptualist scholarship; a postfoundational, feminist, poststructuralist, and postcolonialist reconceptualizing of early childhood education (Bloch et al., 2014, 2018), and common worlds research, which focuses upon the ways in which our past, present and future lives are entangled with those of other beings, non-living entities, technologies, elements, discourses, forces, 
and landforms (Common Worlds Research Collective, 2020). Latour (2004a) offered the concept of common worlds, (from Plato's term "the commons”), which has become a powerful pedagogical tool for educators and childhood scholars to reconsider the significance of children's relations with physical and pedagogical places, with the material world, and with other beings (both human and non-human. Latour reminded us that common worlds are not fixed geographies, but rather, worlds in the process of progressive composition. Common worlds frameworks "challenge the mistaken assumption that we are exceptional and therefore separate from the rest of the world" (Taylor \& Pacini-Ketchabaw, 2015, p. 511), and are important to this research in that they encourage us to consider the more-than-human worlds in which we live (Haraway, 2008a, 2008b; Malone, 2016a). Additionally, common worlds research encourages educators to resist the urge to "look away" (Haraway, 2016b) from our global predicament and instead "stay with the trouble" (Haraway, 2008b, 2016b) by acting on possibilities for engagement with the messy, difficult, and ethically complicated matters that emerge in daily classroom life. The pedagogical potential of critical encounters, as Nxumalo, Vintimilla, and Nelson (2018) pointed out, often "remains hidden as an absent presence in most early childhood spaces" (p. 443); meaning that opportunities to engage with challenging issues are often ignored. In considering our common worlds, where past, present, and future lives are entangled (Blaise, Hamm, \& Iorio, 2016), the intentional centering of curriculum which is "otherwise" (Nxumalo et al., 2018, p.444) than dominant discourses, comfortable inquiries and conventional practices becomes a critical aspect in the work of mattering with children (see Table 1). 
Table 1

Common Worlds Theoretical Frameworks

\begin{tabular}{|c|c|c|}
\hline \multicolumn{3}{|c|}{ Common Worlds Theoretical Frameworks } \\
\hline Common worlds & \multicolumn{2}{|l|}{ Two strands of inquiry } \\
\hline \multirow{4}{*}{$\begin{array}{l}\text { An inclusive, more than } \\
\text { human notion that focuses } \\
\text { upon the ways in which } \\
\text { our past, present, and future } \\
\text { lives are entangled with } \\
\text { those of other beings, non- } \\
\text { living entities, technologies, } \\
\text { elements, discourses, forces, } \\
\text { landforms. }\end{array}$} & $\begin{array}{l}\text { Inquiries into children's relations with the } \\
\text { more-than-human }\end{array}$ & $\begin{array}{l}\text { Feminist Common } \\
\text { Worlding Methods }\end{array}$ \\
\hline & Inquiries into children's relations with place & \multirow{3}{*}{$\begin{array}{l}\text { Hopeful, generative, } \\
\text { relational, situated, } \\
\text { and experimental } \\
\text { methods to extend the } \\
\text { contributions that } \\
\text { feminists have made } \\
\text { to social justice to } \\
\text { include a vision of } \\
\text { ecojustice }\end{array}$} \\
\hline & $\begin{array}{l}\text { Inquiries into children's relations with } \\
\text { materials }\end{array}$ & \\
\hline & $\begin{array}{l}\text { Inquiries into children's relations with other } \\
\text { beings }\end{array}$ & \\
\hline $\mathrm{Ada}$ & esearch Collect & \\
\hline
\end{tabular}

Common worlds work disrupts binaries such as nature/culture and human/ nonhuman material/immaterial to make way for new possibilities in education that acknowledge the entangled and relational nature of our world. I draw from reconceptualist scholarship and common worlds frameworks to both zoom out to the larger (macro) pedagogical and societal, and even planetary factors at play, to zoom in on the (micro) practices (Deleuze et al., 1987), or minor politics - the politics of the everyday playing out in the classroom (Dahlberg \& Moss, 2005), and to consider how these elements impact each other (Moss, 2018; Olsson, 2009; Urban 2018). Within these lines of research, critical posthumanism and feminist new materialism(s) are the theories most central to the work of mattering with children. These theoretical frameworks provide a challenge for humancentric early childhood research by asking us to consider 
"what might happen if we give up exhausted structures and [instead] attend to what is happening?" (St. Pierre, 2011, p. 623). Propelled by a desire to "give up exhausted structures," in early education and research, St. Pierre's question helped me to consider how I might attend to what is already happening with children's narratives outside of the exclusively human realm and attend to children's storied relations with place, materials, and other beings.

Thinking with critical posthumanism. It has been argued that it is "timely for early childhood scholars to make a greater contribution to broader 'more than-human' or post-humanist conversations that have been gathering momentum in the social sciences over the last couple of decades" (Taylor, Pacini-Ketchabaw, \& Blaise, 2012, p. 81). This research is aligned with the (feminist) critical posthumanism developed by Donna Haraway, Karen Barad, and Rosi Braidotti, among others, which is strongly informed by the work of Gilles Deleuze and Felix Guattari. Critical posthumanism advances a framework of relational learning with material, place, human, and nonhuman actors as opposed to a child centered and exclusively human social framework (Barad, 2007; Braidotti, 2013; Coole \& Frost, 2010b; Murris, Reynolds, \& Peers, 2018; Nxumalo \& Pacini-Ketchabaw, 2017; Pederson, 2010, 2015; Rice, 2016; Rotas, 2015; Snaza, 2015). Common worlds researchers Taylor and Giugni (2012) poignantly reminded us, "we (humans) are not alone in our common worlds; and secondly, these worlds are not only about us" (p. 112). Thus, in the quest for social and planetary justice, "we" are not who we thought "we" were (Wolfe, 2010). 
Critical posthumanism "moves away from perhaps the most basic premise within social sciences research" (Ulmer, 2017, p. 834) by reconceptualizing who and what is social, thereby rejecting the presumption that "humans are the only species capable of producing knowledge" (Ulmer, 2017, p. 834). This recognition is significant for education research, because when humans are decentered as the only possible knowers (Lupinacci \& Happel-Parkins, 2016; Murris et al., 2018; Ulmer, 2017), it challenges the notion that education is a social phenomenon taking place solely between human beings (Lenz Taguchi, 2011). It is also significant in that it problematizes the anthropocentrism that is woven into education practices to the point of being invisible. For example, as part of problematizing the "anthropocentric gaze" (Hultman \& Lenz Taguchi, 2010, p. 526) posthumanist scholarship aims to decenter anthropocentric (human centered) and logocentric (language centered) ways of knowing and being (Barad, 2003; Kuby, 2017a, 2017b; Lenz Taguchi, 2011). This endeavor is not intended to dismiss the indisputably critical role of language in education, but simply to make way for knowledges outside of the humanist logocentric tradition.

Digging deeper into critical posthumanist literature regarding education, Murris (2016) offered a reconceptualization of education practices where "all earth dwellers are mutually entangled and always becoming, always intra-acting with everything else ... Individuals materialize and come into being through relationships; and so does meaning" (p. xi). Braidotti (2002) argued that, given this loss of the single ontological subject, learning how to think about the dynamics in-between relations, or in the "between zones" (p. 174), is crucial. Hohti (2016a) applied this concept to education, referring to the 
between zones in her mapping of the relational dynamics of her third/fourth grade classroom, noting that the emerging connections and between spaces of entanglement are, after all "where everything happens" (Koro-Ljungberg et al., 2015). The findings of these posthumanist researchers are significant to the present study, because if knowledge is indeed produced in-between relations, these between zones could also be where everything happens in terms of children's storytelling.

While those working with posthumanist concepts work to draw connections between humans and nonhumans to reconfigure our notion of the social, critics of posthumanism caution that we must be careful not to turn our backs on the indispensable lessons on power and oppression that have derived from critical theory. To address this concern, Petitfils (2015) argued for the "decentering" of the human (as he has been depicted) in light of posthumanism, but also for "recentering" the human "so that we might not forget the work of our humanist histories" (p. 31). Thus, the critical nature of critical posthumanism, which is primarily concerned with "realizing the democratic possibilities and limits of humanism in a new globalized age, in relation to global interactions between former colonial masters and subjects, and between gendered subjects (no longer reducible to two neat types)" (Snaza et al., 2014, p. 48). Snaza et al. (2014) pointed out that critical posthumanism aligns with efforts for social justice in its recognition that "a wide variety of seemingly disparate critical approaches (feminism, anticolonial and antiracist thought, technology studies, ecology, etc.) have a common ground in directly challenging the ways humanism has restricted politics and education" (p. 41). Considering the substantial history of marginalization and oppression 
engendered by humanism, Snaza et al. argued that "curriculum studies could benefit from always engaging with the 'human' as problematic" (p. 41). This problematic vision of the human, of course, is the idealized Vitruvian, or Universal man. This particular, White, cis-heteronormative masculine version of the human invoked by humanism is "upheld and enforced through White supremacy, colonialism, racism, slavery, neoliberalism and patriarchy" (Truman, 2019, p. 1), and is therefore necessary to challenge.

It is also important to note that in the term posthuman, the "post" is not antihumanistic. As Edwards (2010) reported of the word posthuman, 'It is not 'after' in terms of going beyond, but in terms of offering a constant experimentation with, or questioning of the human" (p. 6). For example, while critical theory inquiries work against the marginalization and oppression of humans, critical posthuman research “expands these same objectives on a planetary scale" (Ulmer, 2017, p. 1), and offers a "new form of political enquiry which attends to the interconnectedness of the human and more-than-human world" (Taylor, 2011, p. 432). Ulmer (2017) aligned with critical posthumanist scholars Braidotti, Haraway, Colebrook, and Alaimo in pointing out that "justice involves more than what can be found solely within the realm of human relations. Rather, justice is also material, ecological, geographical, geological, geopolitical, and geophilosophical" (p. 833). Simply put, "Justice is a more-than-human endeavor" (Ulmer, 2017, p. 833).

It must be pointed out that the vitality and interconnectedness of matter is central to many Indigenous knowledges and it has been for centuries (Fee, 2019; Gathering the 
Stories of Place, 2015; Malone, 2016a; Smith, Tuck, \& Yang, 2019; Truman et al., 2019; Tuck \& McKenzie, 2015; Wall Kimmerer, 2013a, 2013b). Nxumalo (2014) reminded us, for example, that Indigenous ways of knowing have consistently taught that "human subjectivities are inseparable from their more-than-human relations and responsibilities" (p. 54). Thus, this idea is neither new, nor unique to posthumanism. It is rather, one of the many conceptual overlaps between Indigenous knowledges and posthumanist orientations. Therefore, critical posthumanism is both allied with, and dependent on Indigenous knowledges for its understandings of a more-than-human, relational ontology. To act as a true ally, however, it is crucial for non-Indigenous posthumanist scholars to engage with Indigenous scholars and their knowledges with respect, humility, and an acknowledgement of the ongoing project of colonialism and erasure in the academy (Todd, 2016). Sundberg (2014) spoke to a need for decolonizing practices in saying, "geographical engagements with posthumanism tend to reproduce colonial ways of knowing and being by enacting universalizing claims and, consequently, further subordinating other ontologies" (p. 2). Sundberg (2014) proposed that posthumanist scholars take up practices of walking with or walking alongside Indigenous scholars and ontologies to cultivate an ethos mutual care, learning, engagement, and solidarity.

Further, the movement toward posthumanist thinking has also criticized as an attempt by humans to "argue themselves out of the picture" (Braidotti \& HlAnajova, 2018, p. 95) at a time when climate change caused by the impact of human civilization requires urgent human action. Theorists working with critical posthuman perspectives contend that it is precisely because our human-centric ways of operating in the world 
have significantly contributed to environmental degradation that a fundamental shift in perspective is required (Bennett, 2010; Lloro-Bidart, 2018; Murris et al., 2018; PaciniKetchabaw, Taylor, \& Blaise, 2016; Parnell, Downs, \& Cullen, 2017; Rotas, 2015; Steffen, Broadgate, Deutsch, Gaffney, \& Ludwig, 2015; Taylor, 2017). Embracing a critical posthumanist stance, this research responds to the charge for humans to consider how we might live well with human and non-human others (Taylor \& Giugni, 2012) in times of extreme precarity. I approached this task by reconsidering what matters and what could matter (Barad, 2003; Latour, 2004b) in early childhood education, and how children might produce those ways of mattering with the more-than-human.

Feminist new materialist orientations to inform this study. The ontological or material turn in philosophy (Lather, 2016; McNeil, 2010) has made way for new materialist research or "renewed materialisms" (Coole \& Frost, 2010a, p. 5) to emerge as a force within early childhood studies internationally (Barad, 2007; Bennett, 2010; Hultman \& Lenz Taguchi, 2010; Myers, 2015). This investigation offers new perspectives in education by considering the "much-neglected subject of material for educational research and practice” (Franzén, 2015, p. 1937). New materialist orientations reconceptualize matter, not as a passive thing merely constructed or represented by social processes, but as a vibrant, agential, mutually generative force (Alaimo, Hekman, \& Hekman, 2008; Barad, 2007; Bennett, 2004, 2010; Braidotti, 2002; Coole \& Frost, 2010b). Bennett (2010) referred to matter as vibrant, with a vital materiality that runs through and across bodies, both human and nonhuman. 
It is easy to mistake new materialist theoretical orientations either as a denigration of humans or an elevation of things. However, this would be a misinterpretation. "The point is not to reify or bring into focus 'things.' The point is in fact to contest the notion that things (including objects, texts, human bodies, intentions, concepts etc.) exist separately and prior to the lines of relations that must be constructed among them" (Fenwick, 2010, p. 108). This inquiry examined the storied "lines of relations" of children's storytelling, thus illustrating how "matter matters" in processes of becoming and knowing in this early childhood setting (Fenwick, 2010).

As with critical posthumanism (Barad, 2003; Braidotti, 2013; Coole \& Frost, 2010b; Pederson, 2010, 2015; Rotas, 2015; Snaza, 2015), which is entwined with new materialism in a tangle that is difficult to unravel, new materialist research in education disputes the existence of the ontologized human and solitary knower acting upon inert objects in a linear exchange (Barad, 2007; Lather \& St. Pierre, 2013; Mazzei \& Jackson, 2016). New materialist orientations propose a relational ontology where human, nonhuman, and material actors (Latour, 2004a) come together uniquely in each moment in a complex web of relations. This web has been described by Latour (2004a) as a gathering or network, by relational materialists (Hultman \& Lenz Taguchi, 2010) as an assemblage, a concept of distributive agency (Deleuze \& Guattari, 1983), and by Haraway (2016b) as a sympoietic system. Critical Posthumanists (Barad, 2007; Braidotti, 2013; Ingold, 2011; Pink, 2008) and others conceptualize this web of relations as an entanglement; a pedagogical place of multiplicity. The term "entanglement" comes from quantum physics and refers to the complex relational nature of things, which renders it 
impossible to consider the implications of any element in isolation (see Barad, 2007). In this research I employ all these terms.

Although vital materialism, relational materialism, and sociomaterialism each have their own conceptual nuances, each of these new materialist orientations are grounded in the notion that matter and meaning are inseparable and mutually produced (Barad, 2007; Bennett, 2010; Lenz Taguchi 2010b). Rather than the simple linear exchange implied by interactions, intra-actions (Barad, 2007) are complex and shifting encounters between interdependent entities that produce new modes of being and knowing, in which each — in this case, children and materials — constitutes the other (Rautio, 2014). Thus, working with new materialism(s) in education means attending to mattering with children; the understanding being that materials matter to children, and this mattering is central to their production of knowledge. In this research, I drew inspiration from many new materialist frameworks such as agential realism (Barad, 2007), vital materialism (Bennett, 2010), and relational materialism (Lenz Taguchi, 2010b) in a framework I call the feminist new materialisms.

To practice thinking with new materialist concepts, we might return to Mason's unconventional story to consider how the unique entanglement of classroom storytelling practices, child author, teacher, journal, colored pencils, and spinning classmates encountered to "produce newness" (Kuby, 2017b, p. 883), in this case, new understandings regarding storytelling within our classroom community. Through the intra-action of these elements, stories that emerge in scribbles and stories that can be "acted out" with moving bodies were legitimized, and therefore came to matter. 
The feminist new materialist concepts of vital materiality, entanglement, intraaction, and mattering offer an approach to reconsidering children's narrative practices such as Mason's with an ever-widening eye (Rinaldi, 2006) to the complexity that they entail, and not be limited by taken-for-granted-assumptions (Franzén, 2015) or established conventions in regard to education, children, or the nature of children's storytelling.

Drawing on rhizomatic theory. Additionally, I draw from the work of poststructuralist theorists Deleuze et al. (1987), who introduced rhizomatic learning theory, which uses the rhizome, a continuously growing horizontal underground stem, as a metaphor for the construction of knowledge. Rhizomatic theory suggests that, like rhizomes, thought has no beginning, no end, just a "middle of things, with unlimited possible pathways (tubers) that open-up an ever-expanding multiplicity of connections/ directions" (Deleuze et al., 1987, p. 23). Malaguzzi used the Deleuzian concept of the rhizome as a metaphor for complexity; a guiding principle in the municipal schools of Reggio Emilia, Italy, once describing knowledge as a "tangle of spaghetti" (Moss, 2006). Childhood and education scholars employ this powerful construct to show the way actors and events produce connections in early childhood settings, and also as a post-qualitative methodology in education research (Davies, 2014a; Honan, 2004, 2007; Kuby, 2017a; Olsson, 2009; Sellers, 2013, 2015).

Rhizomatic theory is important for my theoretical framework in illustrating both the non-linear way that children produce knowledge, often starting in the middle, and the chaotic, emergent nature of research. Like rhizomes, thinking resists structure and grows 
in a nomadic fashion, always fragmentary, inherently transgressive in nature. Thus, rhizomes provide a rich construct for the fragmentary and emergent nature of storytelling. As Lather (1993) suggested, "Rhizomes work against the constraints of authority, regularity, and commonsense, and open thought up to creative constructions" (p. 680). Further, rhizomatic theory brings a focus to what is being produced in any given situation rather than an interpretivist paradigm that focuses on what an interaction means (Kuby, 2017b). I used rhizomatic theory in this research to allow new possibilities and questions to emerge and to acknowledge that my research began in the middle of happenings that are already always unfolding (Cliffe \& Solvason, 2016). Additionally, conceptualizing children's storytelling as rhizomatic allowed me to resist the desire to show the trajectory of their stories in a linear way, from start to finish. Though ideas with implicated relations did occasionally burst into view in the form of stories or discussions about stories, the relational connections were often nomadic, meaning they were characterized by constant movement, and thus could not be empirically linked to particular points of origin.

Calling on emergentist perspectives. Like most research that enacts poststructuralist theory, I also worked with emergentist orientations in early childhood practice and pedagogy. Using an emergentist perspective, classrooms are considered public or "worldly spaces" (Biesta, 2006, p. 11) of relationships. As a researcher thinking with emergentist orientations, my goal was "not to ensure a desired end is reached with a minimum of fuss, but rather always to complicate the scene, to unsettle the doings and understandings of those being educated, in order to keep the way open" 
(Osberg \& Biesta, 2008, p. 325). Keeping the way open often meant attending what emerged in the moment; to curriculum-as-lived rather than curriculum-as-planned (Aoki, 1993; Olson, 2012). Attending to emergence is about thinking and working in a rhizomatic way.

E. Jones (1970) introduced the term emergent curriculum (Bredekamp \& Rosegrant, 1995; Helm \& Katz, 2016; E. Jones \& Nimmo, 1994; Wien, 2012) to refer to the instinctive approach many educators use for developing curriculum based on children's interests and activities. Emergence illustrates the importance of remaining open to the not-yet-known (Davies, 2014a; Parnell, 2012) in work with young children. Two well-known strands of emergent curriculum are the project approach (Katz \& Chard, 1994), and the emergent curriculum used in the city preschools of Reggio Emilia, Italy (Edwards, Gandini, \& Forman, 1993; Rinaldi, 1995). Though each of these articulations of emergent curriculum have distinct features, they are similar in that they call for children and teachers to negotiate their choices, planning, and learning through sustaining in-depth project work. As Jones and Nimmo (1994) explained, emergent curriculum is often misunderstood to indicate a child-led curriculum without structure, goals, or teacher planning. When I say I worked with emergentist ideas, I am not referring to the common misconception of emergence as merely "following the child," but rather to emergence as a vibrant, lived curriculum.

Emergent curriculum, when enacted with critical perspectives, offers a powerful form of resistance against "embalmed curriculum" and theme-based, standardized, or 
otherwise prescribed curricula that increasingly govern life and learning in the early childhood classroom (Jones \& Nimmo, 1994). As Nxumalo et al. (2018) wrote,

Through its invitation to educators to enact transformational and collaborative pedagogical practices that take seriously children's theories and curiosities, emergent curriculum has potential to create important cracks in the increasingly normalized techniques of framing early childhood education as a preparatory site for already predetermined desired subjects of neoliberal economies. (p. 434)

It is with this desire to "take seriously children's theories and curiosities" and "create important cracks" in unquestioned classroom practices that I enlist a space of emergence (Osberg \& Biesta, 2008) for this research—a conceptual/pedagogical space that allows opportunities to encounter that which is “different, strange, and other" (Biesta, 2006, p. 69), and therefore offers a resistance to homogenizing practices.

The first thing to notice about the curriculum as a "space of emergence" is that it is not a space of common ground. This means education only takes place where "other-ness" - being with others who are different from us - creates such a space. In this sense, it is the plurality of the "space of emergence" that educates. (Osberg \& Biesta, 2008, p. 324)

The intentional inclusion of ideas which might be regarded as "other" (Bhabha, 1996) than conventional is a decolonizing approach, reclaiming heterogeneity and offering “potential orientations for bringing needed complexity" (Nxumalo et al., 2018, p. 437) in contested early childhood spaces. In this vein, Nxumalo et al. (2018) called for educators to stay with the trouble that emergent curriculum offers by making visible and attending to marginalized ideas that come up in practice with children. Working with emergence in this way enables me to position this work as a resistance to assimilationist pedagogies and practices, keeping the way open for that which might be considered "different, strange, and other" (Biesta, 2006, p. 69). 
Emergentist epistemologies challenge the idea that meaning is acquired, and suggest that instead, meaning is continuously made and remade through engagement with our world (Common Worlds Research Collective, 2020; Davies, 2014a). According to van Dooren (2014), stories participate in this emergence of matter/meaning. "Stories are a part of the world, and so they participate in its becoming [and] storying the world [is] utterly inseparable from lived experience and a vital contributor to the emergence of 'what is"' (p. 10). In the spirit of van Dooren, I suggest that children's narratives are generative figurations that both emerge from the world and generate its ongoing production.

How does the more-than-human matter in children's storytelling? There is very little, if any, research on children's storytelling that attempts to address this question, which is born from a combination of powerful research on the importance of children's storytelling from a sociocultural perspective, and emerging research the significance of more-than-human actors in children's everyday lives. In the following review of the literature, I outline a brief history of research on children's storytelling and its monumental contributions to the field of early childhood education. I go on to indicate a gap in the literature and exemplify ways in which researchers are responding to it. Finally, in the review of the methodological literature, I create a picture of how critical posthumanist/feminist new materialist approaches can offer a theoretical framework and approach to address the research question of how the more-than-human matters in children storytelling. 


\section{Review of the Research Literature}

In the literature review, I present research literature that addresses, either directly or indirectly, the question about how the more-than human might matter in children's storytelling. But first, a brief history of research on children's storytelling is required to locate intersections and points of departure in regard to the present study.

The role of storytelling in early childhood. Young children often combine, fantasy, reality, people, materials, and nonhumans in their narrative productions, creating relational entanglements (Hohti, 2016a) in what Bruner (1986) referred to as "narrative spaces of knowing.” Bruner (1991) argued that children create and maintain these narrative spaces to construct "narrative truths" (p. 13) which, he noted, may constitute reality rather than simply referring to it. Of narratives, Spaggiari (1997) said that "The traces that children leave us of their lives and thoughts cannot be enclosed in words alone, but need something more: images, drawings, writings, and above all narratives (p. 10). Vivian Gussin Paley's (1986, 1988, 1990, 2000, 2009) work with children and their stories over more than two decades has been seminal to our understanding of the importance of story in the lives of young children. Paley illustrated how children use storytelling to navigate their world and construct their identity, and how a practice of writing and sharing of stories holds particular potency in the social life of a classroom community to transform and to heal. Jones and Nimmo (1994) pointed out that in childcare settings, where children often come together as strangers, stories can be used to create the authentic community educators desire by "build(ing) a shared culture" (p. 71) of meaning among children and families. 
Quintero and Rummel (2014) offered storying and the construction of collective narratives as a way of reconceptualizing education from a place of context and meaning. Building upon the foundational work of Bhabha (1996), Quintero (2017) pointed to storytelling and story creation as the framework for a generative space she refers to as the "third space." Quintero described the third space as a space of meaning between the colonizing force of the global north, which dictates developmental norms, learning standards, and pedagogical practices that are grounded in Eurocentric modernity and underrepresented perspectives from the global south, which place alternative narratives and marginalized populations at the center. Quintero (2017) contended that children are a marginalized population whose stories need telling. Her work is relevant to my research in that it shows how children's storytelling, inherently and necessarily contextual, can be used as a form of resistance and generate alternatives to the colonizing force of standards of learning and development.

Hohti's (2016a) narrative ethnographic (Gubrium \& Holstein, 2008; Tedlock, 1991) research addressed the small stories and tiny things within her classroom that reveal hidden or ignored aspects of children's lives. Hohti found that these stories are hidden in the in-between moments of children's school day and have typically been overlooked by teachers and researchers alike (Beckett, 2007; Braidotti, 2002). She noted that these stories are often personal stories (P. J. Miller, Potts, Fung, Hoogstra, \& Mintz, 1990), or the relaying of events from one child to another and are indicative of what the child finds to be significant. Hohti's research is critical to my work in that she explores classrooms as spaces of entanglement, and children's stories as dynamic meeting spaces 
(Ahn \& Filipenko, 2007; Puroila et al., 2012) of encounter that "enlarge the space for thinking about children and childhoods" (Hohti, 2016b, p. 1).

Paley’s $(1986,1988,1990)$ seminal work with young children shows the importance of children's stories from an unequivocally humanist perspective. In her ethnographic and autoethnographic accounts of classroom life, she depicts children's use of fantasy play and storytelling to grapple with the complex issues of their everyday lives: violence, gender stereotypes, fear, poverty, consumerism, belonging, and more. Paley (1990) held a vision of connecting everything that happened in her classroom by “drawing invisible lines” (p. xi) between children's stories, generating connections between the stories and thus between the children. For Paley, the essential value in children's storytelling both emerges from and returns to social constructivist theory (Vygotsky, 1978). Puroila et al.’s (2012) work reinforces Paley’s central sociocultural theme, showing that when children have the opportunity to narrate together, it strengthens the classroom community; "they [children] co-construct their friendships, peer cultures and identities" (Cremin \& Flewitt, 2017, p. 18). Paley’s demonstration of the powerful potential of story for children's identity development and socially constructed meaning making has figured prominently in the respect that storytelling is regarded with in early childhood education.

Paley's (1990) original story play curriculum, a combination of storytelling and play, called for children to dictate stories to a teacher who writes them down verbatim and later read aloud to the class, who act the story out as directed by the child author. By offering two modes of expression, storytelling and story acting, children have the 
opportunity to share their stories in multiple ways, thereby increasing the potential for narrative control (Binder, 2014; Cooper, 2005). Countless storytelling and story sharing practices have emerged from this form, which has since been expanded to include additional modalities such as drawing, and nontextual modalities such as visual arts, music, and gesture (Binder, 2014). Though the storytelling and story sharing practices that are derived from Paley's work have pushed out into multiple modalities (Binder, 2014) and experimental methods (Soto, 2005; Waters, 2014); some even working in direct confrontation to the culture of accountability in Early Childhood Education (Cremin, Flewitt, Swann, Faulkner, \& Kucirkova, 2018; Mardell \& Swann, 2017); to date, these practices have all retained Paley's original focus on an exclusively human sociocultural experience.

Recent views on narrative research have highlighted the need to expand analyses beyond the contents of stories to the dynamic, social, and relational dimensions of the narrating processes (Gubrium \& Holstein, 2008; Hyvärinen, 2008; Puroila et al., 2012). This expansion of narrative research allows for a shift to other-than-human factors that play a role in the matterings of daily classroom life. Using a lens of relationality, this study considers both narrative processes as they relate to humans, other-than-humans, and the stories themselves. With this research, I aim to expand childhood narrative studies to consider the wider human, nonhuman, and material-discursive (Barad, 2007) relational dimensions of the narrative process.

More-than-human perspectives. Though early childhood education is firmly rooted in exclusively human sociocultural views of childhood (Vygotsky, 1978), there are 
multiple more-than-human (Haraway, 2008a) perspectives that are influencing the field from the margins. The phrase more-than-human implies that, although early education in particular is entrenched in exclusively human social realm, there is more going on in the classroom than merely human actions and inert things/beings. Simply put, "humans aren't the center of things, and, so, the human/non-human binary and the implicated hierarchy doesn't hold” (Myers, 2015,p. 4). Childhood researchers working with posthumanist and new materialist orientations are finding this reflected in early childhood education contexts in particular (Blaise et al., 2016; Hohti, 2016a; Kuby \& Crawford, 2018; Nxumalo \& Pacini-Ketchabaw, 2017; Pedersen, 2010; Puroila et al., 2012; Rautio, 2013; Taylor et al., 2013).

The ideas put forth by Deleuze and Guattari (1983, 1987, 1988, 1994), for example, inspire childhood and education scholars to rethink childhood(s) as a product of assemblages of both human and non-human entities (James \& Prout, 2015; Prout, 2005, 2011). Haraway's (2003, 2008b, 2016b) feminist posthumanism captures the intellect and imagination of multiple childhood and education scholars (Blaise et al., 2016; Iorio, Hamm, Parnell, \& Quintero, 2017; Molloy Murphy, 2018; Nxumalo \& PaciniKetchabaw, 2017; Pacini-Ketchabaw \& Nxumalo, 2015; Taylor, 2017; Taylor et al., 2013; Ulmer, 2017) who are actively thinking with her ideas in education research and practice.

For example, Taylor et al. (2013) and Hohti (2018) engaged with Haraway’s (2008b) feminist narrative strategy of "bag lady story-telling" to explore the ethics and politics of child/nonhuman, and child/material encounters. These whimsical and 
sometimes troubling stories of unexpected partners or "queer kin" (Haraway, 2004) offer a different kind of story in which there are surprises and beauty but no easy answers. Though bag lady stories are pedagogical narratives/images/anecdotes dreamed up by adults, they carry profound implications for the role of narrative in not only grappling with our common worlds (Haraway, 2008b), but in (re)configuring new ones. Haraway has referred to this practice of using storytelling to make oddkin as "storytelling for earthly survival" (Haraway, 2017).

In a similar manner, van Dooren's (2014) "lively stories” use narration as a pedagogical tool to consider more-than-human socialities (Tsing, 2013) and to document the multiple entanglements of the common world of creature communities (Blaise et al. 2016). Van Dooren and Rose (2016) pointed out that "the intention here is not to slip into the hubris of claiming to tell another's stories but, rather, to develop and tell our own stories in ways that are open to other ways of constituting, of responding to and in a living world" (p. 85). In this vein, multispecies ethnographies are being used as a way to attend to research with the more-than-human (Haraway, 2008b; Lloro-Bidart, 2018; Pacini-Ketchabaw et al., 2016; Taylor \& Pacini-Ketchabaw, 2015). For instance, Nxumalo and Pacini-Ketchabaw (2017) used multispecies ethnography in considering the implications of classroom pet pedagogies, and to challenge the "humancentric lens of children's development, which is insufficient at this time of anthropogenic change that calls for radically different ways of viewing our relationships with more-than-human others" (p. 1423). These experimental narrative practices work to shift our perspective 
away from a solely human one and make way for more-than-human ways of understanding, both in classrooms and in the larger world (Bell \& Russell, 2000).

Hamm and Boucher (2017) foreground Aboriginal perspectives (in the Australian context, the term Aboriginal is claimed and preferred over the government's term Indigenous) in their work with early childhood educators and children on practices of teaching and learning with/from place and more-than-human others. They engaged with Latour's (2004a) concept of "learning to be affected" and Watts's (2013) "PlaceThought" as a conceptual frame in their work with educators and children. Place Thought is the Anishinaabe (First Nations people from southern Canada) worldview, consistent with Aboriginal epistemologies, that "land is alive and thinking" (Watts, 2013, p. 21). Their work has profound implications for those teaching and learning in engagement with the land and Indigenous ways of knowing.

The matter of matter. The material turn has given child studies and education scholars a new/old way of conceptualizing classroom life and learning that upends conventional anthropocentric perspectives and practices. To this end, Barad (2003) contended that "language has been granted too much power" (p. 801) and it is time to turn to the matter of matter. In referring to the matter of matter, Grosz (2002) spoke of a "submerged tradition" of things which "conceives of the thing, not as other, but as provocation or incitement for the subject: the thing is that which prompts us to act, to invent, to practice, to extend ourselves beyond ourselves" (p. 78).

Drawing upon this submerged tradition, Rautio's (2013) Children who Carry Stones in Their Pockets: On Autotelic Material Practices in Everyday Life shows how 
materials matter to children in their daily classroom life, and how humans both shape and are shaped by our material surroundings. Pointing out the relational exchange between humans and the things in their environment, she invites us to imagine walking along a riverbank, and states that the seemingly natural activity of throwing stones in the river depends greatly upon the existence of stones. She stated, "We would not think of throwing stones if there were no stones to throw" (Rautio, 2013, p. 404). Rautio's (2013, 2014, 2017) work illustrates the social/discursive construction of knowledge, and how things come into being through mutual encounter or intra-action.

Latour (2004a) portrayed mutual encounters between humans and materials with the statement, "They [objects] too act, they too do things, they too make you do things (pp. 242-243). Lenz Taguchi (2010a) described how mutual encounters shape our thinking: "Our meaning-making and the learning we do is dependent on the material world around us. The material world acts upon our thinking just as much as our thinking acts upon it'' (p. 49). Kuby (2017b) applied this concept to children and materials by saying, "Our experiences with children indicate that often it is in the moment of playingwith, becoming-with that something appears. The speaking back-and-forth-betweenchild-and-the-materials produce newness" (p. 883). I draw from this literature because the concept of a mutual encounter between humans and materials, shaping human thinking and producing "newness" provides interesting implications for the production of stories in early childhood settings.

The concept of storied matter (Iovino \& Oppermann, 2012, 2014; Oppermann, 2018) has significant implications for the study at hand. The term storied matter comes 
from the field of ecomaterialism and refers to the idea that "matter is not only lively, agentic, and generative, but also densely storied" (Oppermann, 2018, p. 1) with narrative agencies acting as "active co-authors that shape the world and co-determine our existence" (Oppermann, 2018, p. 3). Although ecomaterialism is not concerned with education or child studies, the theory that matter is an active co-author in shaping the world directly pertains to my research question about how the more-than-human matters in children's storytelling.

Exploring children's narrative processes in the context of a day care center, Puroila et al. (2012) established that children's spontaneous "everyday narratives" (Ahn \& Filipenko, 2007; Ochs \& Capps, 2001), though rarely the topic of research, illuminate fleeting moments and experiences that children find significant and contribute their shifting identities. They found that children's everyday narratives are characterized by "fragmentariness, multimodality, collaboration and a complex relationship between narratives and their contexts" (Puroila et al., 2012, p. 192). Furthermore, they discovered that children's narrative rights (see Gubrium \& Holstein, 1998); the ethical and moral right for children to express themselves and to be understood by others, are somewhat dependent on the institutional and cultural conventions of their school setting. They state, "Children cannot always freely narrate, express and communicate themselvesthere are limitations regarding what children can tell, when they can tell it and how children's narratives are valued in the everyday life of day care centres" (Puroila et al., 2012, p. 201). For example, these researchers observed that children's spontaneous everyday narratives flourished during open-ended times such as during free-play, 
drawing situations, and outdoor time, whereas they were less present during times when adults had more control over children's talk and action such as circle times and meal times. The findings of Puroila et al.'s study is significant to the study at hand in that it demonstrates that children's everyday narratives, like unconventional knowledges and transgressive thinking, have the tendency to hide in-between the visible, highly valued conventions of children's school day.

Myers's (2015) post-qualitative research on more-than-human relationships in a kindergarten class shows how children's relations with things are conceptualized within early childhood education. Myers employed Barad's (2007) notion of entanglement in data production, using photos and narration to "think with the data." Although she did not specifically study children's storytelling practices, her use of posthumanist and poststructuralist theories, as well as her use of post-qualitative methodology is relevant to my research because I am "thinking with" feminist materialisms and critical posthumanism as a post-qualitative methodology.

Like Myers (2015), Hohti (2016c) engaged with the concept of entanglement in her research study Now-and Now-and Now: Time, Space and the Material Entanglements of the Classroom. In this work, she revealed that, "Attending to entanglements can help unsettle simplified ideas about material beings as dead, numb and only a means for human agents to achieve 'higher' goals, thereby inviting us to a more refined inspection of relations between children and things" (p. 20). Examining the work of these scholars, we see the notion of entanglement consistently emerge as a conceptual strategy for attending to relational lines between humans, nonhumans, and materials. 
Drawing from her theory of "vital materiality" Bennett (2010) posed the question: "What might be possible if we give the force of things more due?" (p. 118). Reconceptualist scholars Tesar and Arndt (2016) took up Bennett's vital materialist challenge to make a shift from thinking solely about "think-power" to also consider “thing-power" and "thing-hood" in children's lives, a proposal that seems fitting for young children and their apparently "irrational love of matter" (Bennett, 2010, p. 61). Bennett (2010), who spoke of the agential qualities of matter as "creative materiality" (p. 56), defined thing-power as "the curious ability of inanimate things to animate, to act, to produce effects dramatic and subtle" (p. 6). Bennett's question leads me to wonder what the implications are for "the force of things" (Bennett, 2004) in the world of children's storytelling beyond being simply "screens upon which humans project their intentions, meanings, signs, and discourses" (Bryant, 2011, p. 247).

Classroom as a relational ecology. All too often we defer to conventional wisdom that dictates that young children learn best in a predetermined hierarchy of knowledge, from experts who are the gatekeepers of that knowledge, and within an (exclusively human) sociocultural context. One way to account for post-humanist and feminist new materialist challenges to education is to disrupt the framework of human exclusivity, radically expanding the conventional socio-constructivist framing of classroom communities. There is a small but growing group of child and education scholars taking up this work of reconceptualizing classroom communities as more-thanhuman (Arndt \& Tesar, 2016; Davies, 2014a; Fenwick \& Landri, 2012; Hohti, 2016a, 
2018; Kuby \& Crawford, 2018). For example, Davies's (2014a) work depicts classroom communities as relational, plural, and emergent. She wrote:

Being open, and being vulnerable to being affected by the other, is how we accomplish our humanity; it is how the communities, of which we are part, create and re-create themselves. We are not separate from the encounters that make up the community but, rather, emergent with them. (Davies, 2014a, p. 10)

Davies's concept of vulnerable, relational, and emergent communities comprised of both humans and nonhumans has profound implications for the social world of classroom communities, and thus for the storytelling practices that emerge from them.

Lather (1998) and Rotas (2015) proposed the concept of classroom as a relational ecology in which the in-between spaces are unknowable. This focus on the inbetweenness of relational encounters can be traced back to Deleuze (1987) who stated: "In a multiplicity what counts are not the elements, but what there is between, the between, a site of relations which are not separable from each other" (p. viii). Kuby and Crawford (2018) furthered the work of reconceptualizing classroom communities by contesting the habitual focus on the human in classrooms, saying, "Our focus is not on what the human does to materials and with others, but on the togetherness or inbetweenness of humans, materials, time, space, and so forth" (p. 22). This view offers a radical departure from conventional understandings of classroom communities, and presents an interesting dilemma for established theories about the social element of children's storytelling practices. Additionally, it echoes the idea that in a relational ecology, the in-between is "where everything happens" (Koro-Ljungberg et al., 2015).

Studies drawing from sociomaterial orientations also interrogate assumptions about who and what counts as social in social constructivism. (Fenwick \& Landri, 2012). 
Sociomaterial studies problematize "visions of education that emphasise output driven learning, accountability, standardisation, performativity, representationalist forms of knowledge, and so forth. Sociomaterial approaches analyse and interrupt such enactments by making visible the everyday, particular micro-dynamics of education and learning" (Fenwick \& Landri, 2012, pp. 3-4). Similarly, my research study used critical posthumanist/feminist new materialist frameworks to make visible the micro-dynamics of classroom practices in regard to narrative practices. Specifically, I explored the relational ecology, or the "more-than-human socialities" (Tsing, 2013) of an early childhood classroom and examined how this relational ecology mattered for children's storytelling and narrative productions.

\section{Review of the Methodological Literature}

Because this research works in opposition to overly simplistic and reductionist approaches that "narrow the bandwidth of our thinking, living and producing" (Parnell \& Iorio, 2017, p. 1), it follows by necessity that the methodology I employed echoes this stance. In this research study, I am thinking with theory (Jackson \& Mazzei, 2012; Lenz Taguchi \& St. Pierre, 2017) to activate critical posthumanist/feminist new materialist theories as a post-qualitative approach to research (St. Pierre, 2011, 2013; Lather \& St. Pierre, 2013; MacLure, 2015). My intention behind this approach is to highlight the complexity and multiplicity of perspectives present within early childhood contexts.

My research is premised on critical posthumanism/feminist new materialisms, which recognize that the production of meaning/matter in classroom life happens in the relational, or in-between places that are often overlooked; where there is seemingly 
"almost nothing to see" (Braidotti, 2002, p. 173). Therefore, research that attends to a relationality framework (Barad, 2007; Haraway, 2008b) is of particular interest to me. One notable instance of thinking with relationality comes from the work of Blaise et al. (2016), who enacted a relationality framework using feminist modest witnessing, Deborah Bird Rose's $(2014,2015)$ feminist and ecological witnessing, and van Dooren's (2014) lively stories. These approaches have been engaged to attend to complex relations while "out and about" with young children in Victoria, Australia. Blaise et al. (2016) used pedagogical narration as a tool to shift the focus to more-than-human relations, and from "matters of fact" to "matters of concern" (Latour 2004a); which encourages us to consider "what teachers are paying attention to and how they are paying attention in their everyday work with children" (Blaise et al., 2016, p. 33). Researchers attending to relational frameworks can make a conscious move from traditional methods of observation toward "shifting, engaging, and noticing" (Iorio et al., 2017, p. 126) what occurs between humans and nonhumans in early childhood contexts.

Hohti’s (2016a) research addressed the between zones (Braidotti, 2002) in her mapping of the relational dynamics of her third/fourth grade classroom, noting that the emerging connections and between spaces of entanglement are, after all "where everything happens" (Koro-Ljungberg et al., 2015). Hohti employed the use of a classroom diary to create a format where children felt free to say, write, and express their thoughts about school in any way they wanted. Rautio (2013) used participatory research and thinking with theory to attend to the in-betweens, or "assemblages" in her study of children's autotelic practices with materiality in daily classroom life. Assemblages are 
useful in this work, for as Anna Tsing (2015) said, “Assemblages are open-ended gatherings. They allow us to ask about communal effects without assuming them" (p. 22-23).

Puroila et al.'s (2012) research, although employing narrative ethnography, is useful for this study in that they engage with posthumanist and poststructural theories in their study of children's narrative practices. Both Kuby (2017a) and Kuby and Crawford's (2018) research hold implications for my work because they employ thinking with theory (Jackson \& Mazzei, 2012) as a methodological approach in their studies of children's narrative practices in writers' studio. Additionally, they enlist posthumanist and poststructuralist theories in their work, which directly pertains to the present study.

Having reviewed the literature that is relevant to the study, let us now turn to Chapter 3 for a discussion of the research approach and methods. In Chapter 3, I represent the problem of universalized learning outcomes in early childhood education and remind readers of the purpose of this investigation into children's storytelling. Next, I explain why I turned to post-qualitative research approaches for this study. Lastly, I outline the specific research approach and methods I used to address how the more-thanhuman matters in children's storytelling. 


\section{CHAPTER 3: APPROACH AND METHODS}

Early childhood settings have become contested spaces, or "sites of struggle" (Soler \& Miller, 2003, p. 57) between economic and sociocultural interests disputing the purpose of early childhood education. Recent years have shown increased pressure on children in early education settings to demonstrate predetermined learning outcomes, which (a) limits the scope of what is possible in the classroom, (b) narrows the range of what learning is considered valid, and (c) privileges the experience and values of the dominant culture, thereby determining what matters in early childhood settings (Cannella, \& Viruru, 2003; Moss et al., 2016; Moss \& Urban, 2017). This phenomenon creates a culture of repetition and sameness in education that marginalizes ways of knowing, being, and expressing that live outside of the established conventions in education. By attending to children's emergent and relational meaning making processes and thereby engaging with "a multitude of narratives," (Moss, 2015b, p. 236), educators can begin to attend to marginalized knowledges, and reconceptualize early childhood education alongside children; its content, and methods. Moving from a focus on understanding or interpreting the world "as it is" to acknowledging our participation in a relational figuration of the world is a massive turn, requiring unconventional methodologies. As Ulmer (2017) powerfully stated, "more-than-critical methodologies are needed for a more-than-human world" (p. 834).

The purpose of this study was to position children's storytelling as a central force in the disruption of the privileging of western, positivist, and ultimately, humanist 
knowledges in early childhood education and research. Children's storytelling holds rich potential to illuminate what matters to children, what they value and think about, and how this mattering is produced. My intention for this research is to make space for ideas, and consequently children, who might otherwise be pushed into the margins of daily classroom life (Pérez \& Saavedra, 2017; Schlossberg, 1989). With the aim of reconceptualizing conventions that dictate who and what is valuable in early childhood spaces and attending to mattering/meaning making with children, my research question is: How does the more-than-human matter in children's storytelling?

A note about terminology: There is great disparity in how the concepts of story and narrative are employed in research. Some researchers use the terms interchangeably, while others view narration as a broader concept, such as a tendency marking the trajectory of a person's life or the conditions under which storytelling occur. For the purposes of this research study, I use the term story to refer to anecdotes and narrative expressions, whereas the term narrative also covers the material-discursive context and the entangled process from which the story was produced.

\section{Research Methodology}

In much the same way that educators might look to the margins of their classrooms to challenge homogenizing curriculum and classroom practices, critical early education scholars are urging researchers to look to the margins of "normal research" (Urban, 2018) to reconsider what ways of thinking otherwise might be possible for early childhood research (Parnell \& Iorio, 2015, 2017). Urban (2018) critiqued dominant education research paradigms in saying, "the dominant research paradigm carries the risk 
of perpetuating rather than countering exclusion and marginalization" (p. 285). As Kuby (2017a) pointed out, "These limiting ways of researching restrict methodological imagination; privilege particular ways of knowing, being, doing, teaching, learning, and assessing; and perpetuate the inequitable status quo in our schools and communities" (p. 150). For these reasons, new methodological approaches are called for to "produce different knowledge and produce knowledge differently" (St. Pierre, 1997, p. 175), to "tell different stories" (Moss, 2015a, p. xv) and to "live differently" (Hultman \& Lenz Taguchi, 2010, p. 540); interrupting the cycle of repetition and sameness that has locked our systems of education into circular, or orthodox thinking (Deleuze, 1994; Giroux, 1992a). This study — a study that looks to the margins of classroom life to explore how early childhood pedagogy and practice could be otherwise than it is—-by necessity calls for ways of researching that do the same.

Venturing into post-qualitative terrain. An avid believer in the transformative power of stories, I began my doctoral journey with the assumption that I would likely use a qualitative methodology for my research study and dissertation. However, during the 2-year period of intensive reading and writing preceding the dissertation, I encountered people, ideas, and writings that "contaminated" (Tsing, 2015, p. 27), or fundamentally altered, my way of thinking. This path began when I discovered Malone's (2016b) research on child-dog encounters in the slums of La Paz. One day, electrified, I was discussing the implications of this work with my advisor in his office. As I turned to leave and he swiveled back around to his desk he said over his shoulder, "You might want to look into the work of the common worlds research collective." This simple 
statement began a trajectory that is still unfolding, which has included among other things, a return to my academic roots in philosophy, an upending of my ontological and epistemic grounding, and a radical departure from my previous understandings about the foundations of classroom pedagogy and practice.

Though this trajectory shaped the nature of my research interest in children's storytelling, I clung to the hope that I would find a well-known, highly legitimized methodology that could provide structure for my tangential, rhizomatic thinking so I could "focus on the research." I imagined that finding and applying the right methodology would lend much needed validity to the unconventional posthumanist research I was undertaking. It took time for me to realize that it would be problematic to attempt to apply a methodology to my research that was inconsistent with the theoretical framework for my study (critical posthumanism and feminist new materialisms). As Lather and St. Pierre (2013) indicated, "Entanglement makes all the categories of humanist qualitative research problematic" (p. 630). It took even longer to recognize that there simply is not a conventional methodology that is compatible with a theoretical framework premised on the notion that knowing and being are inseparable (Barad, 2007). St. Pierre (2018) noted, "It never occurred to me that particular onto-epistemological arrangements enable particular methodologies or no methodology at all' (p. 603). As I discovered this for myself, I began to truly feel lost as a researcher.

It was in this state of mind that I attended the VIII Conference on Childhood Studies in Jyväskylä, Finland in hopes of resolving my methodological dilemma. While at the conference, I had the opportunity to see several examples of education research 
framed by posthumanist and new materialist orientations. I approached a researcher whose work greatly inspires me and ended up at a corner pub with her and several other researchers discussing post-qualitative methodology. This conversation was critical for my understanding of the paradox of working in a posthumanist way, freely and joyfully, but with little roadmapping to show the way. After discussing my research interests at length, the researcher suggested I explore thinking with theory (Jackson \& Mazzei, 2012; Lenz Taguchi \& St. Pierre, 2017). Though not a methodology in the traditional sense, it does offer an approach to research whereby one can use "concept as method" to approach research in full acknowledgment of its entangled nature (Lenz Taguchi, 2016; Lenz Taguchi \& St. Pierre, 2017). St. Pierre (2018) stated that a post-qualitative researcher must "live the theories (will not be able not to live them)" (p. 604). It eventually became clear that thinking with theory was just the methodology without methodology (KoroLjungberg, 2015) I needed to proceed, as the only strong footing I had was critical posthumanism and feminist new materialisms; the theories with which I was now living and breathing.

With further research, I discovered that the call for the reconceptualization of qualitative methodologies is not new (Davies, 2010; Koro-Ljungberg, 2012, 2015; KoroLjungberg et al., 2015; Lather, 2013; MacLure, 2013; Myers, 2014; Parnell, \& Iorio, 2015). There are others, who in an epistemic crisis, have felt the need to seek out ways of thinking, doing, and researching otherwise than humanist traditions allow. Seeking out what might come after conventional humanist qualitative research methodologies (St. Pierre, 2018), I ventured somewhat tentatively into post-qualitative (Lather \& St. Pierre, 
2013; MacLure, 2015; St. Pierre, 2011, 2013, 2018, 2019) terrain. I found that this is not an uncommon path for researchers engaging in posthumanist/new materialist inquiries, who often find qualitative research incommensurable with these theoretical orientations. Though I was "bursting forth toward" something new, there was a way in which embracing post-qualitative research also felt like coming home (Vagle, 2009).

Post-qualitative inquiries were born from necessity; when, for some researchers, humanist qualitative ways of doing research no longer fit (St. Pierre, 2018). The work of post-qualitative inquiry is not to discover, interpret, and represent what is, but rather "to bring into being that which does not yet exist" (Deleuze, 1994, p. 147) through experimentation with material worlds. For, as St. Pierre (2019) noted, "it is the not yet, the yet to come - the immanent - that marks post qualitative inquiry" (p. 4). Postqualitative inquiry is unique in that it must be "invented anew each time" (St. Pierre, 2019, p. 9), and thus, there can be no prescribed methodology or fixed research design. One of the challenges inherent in working in this way is the question of where to begin ... if not with a research question, a design, or a methodology, then where?

Following Deleuze's (1988) observation that post-qualitative inquirers seem to begin already "in the middle" of an inquiry (p. 123), Derrida (1974) advised that we begin research "wherever we are; in a text where we already believe ourselves to be" (p. 162). I find great encouragement in this idea, as I am "beginning" this research in the middle of my teaching career, and after more than a decade of thinking about and experimenting with storytelling in the classroom. Working in a post-qualitative way, I do not need to pretend that I am at the beginning of an inquiry, or that this research has 
unfolded in a linear way, with a firm starting point and definitive plan. Rather, I can be authentic in starting wherever I am, "in the text where I already believe myself to be."

I worry, of course, that this way of researching that deconstructs seemingly “settled places" (Lather, 2013, p. 642) within established research practices will be considered too strange for the academy, and that if I follow a post-qualitative trajectory it will be difficult to find academic validation. However, I take comfort in the words of St. Pierre (2018), who argued:

The too strange is, however, the provocation, the knot, the world kicking back, the too much that demands experimentation. Inquiry should begin with the too strange and the too much. The rest is what everyone knows, what everyone does, the ordinary, repetition. Post qualitative inquiry asks that we push toward the intensive, barely intelligible variation in living that shocks us and asks us to be worthy of it. (p. 607)

It is with these words that I step forward as a post-qualitative researcher and "begin" this research journey.

Thinking with theory. The purpose of this study was to position children's storytelling as a central force in the disruption of the privileging of western, positivist, and humanist knowledges in early childhood education and research. The recognition that that "non-human elements are always already present" (Ulmer, 2017, p. 833) in early childhood environments called me to engage with theories that will support an inquiry into children's storytelling with this recognition at the center. Therefore, in this research, I am thinking with theory (Jackson \& Mazzei, 2012; Kuby, 2017a; Lenz Taguchi \& St. Pierre, 2017) to use critical posthumanist/feminist new materialist theories as a postqualitative approach to research (Lather \& St. Pierre, 2013; St. Pierre, 2011, 2013, 2018, 2019). Thinking with theory is premised on ethico-onto-epistemology (Barad, 2007; 
Lenz Taguchi, 2010a; Pérez, \& Saavedra, 2017), or the understanding that learning is relational and practices of knowing and being cannot be separated, but rather "are mutually implicated" (Jackson \& Mazzei, 2012, p. 116). From this ethico-ontoepistemological stance, it follows that theory and practice are inexorably entangled, and that research and analysis is itself an entangled process, comprised of meaning-making and production simultaneously (Davies, 2014a). Thinking with theory relies on the Deleuzian concept of thinking with rather than thinking about theories and "emphasizes the not-yet known over the known and predetermined" (Rautio, 2014, p. 464). Thus, a "thinking with" approach served as an excellent companion to my research goal of contesting endpoint learning, and the culture of sameness and repetition that is so pervasive in education and dominant forms of education research.

Thinking with theory has also been referred to as concept as method, (Lenz Taguchi, 2016; Lenz Taguchi \& St. Pierre, 2017) which Deleuze et al. (1987) defined as "experimentation in contact with the real" (p. 12). Rather than categorizing data, thinking with theory invites researchers to seek out "hot spots," where the data is said to spark or glow, "resonating in the body as well as the brain" (MacLure, 2013, p. 661) and creating a sense of wonder (MacLure, 2013). This approach holds the primary intention of resisting normalizing practices (Lenz Taguchi, 2016; Lenz Taguchi \& Palmer, 2014; Martin \& Kamberelis, 2013) in pedagogy and research. This approach not only invited me, but required me, to remain open to wonder and surprise (Moss, 2015a).

Though thinking with theory is newly emerging as a research approach, there is a rich history of scholarship behind its premise that theories are already enacted in research 
rather than a "lens" through which we can view a separate and unchanging world (Deleuze, 1994; Deleuze \& Guattari, 1994; Parr, 2010; St. Pierre, 2019). Illustrating this idea, Kuby (2017b) suggested, following Olsson (2009), that what is needed is an encounter in between theory and practice. Taking this idea further, Lenz Taguchi (2010b) contended that "Practice is in fact continuously and already doing and practicing educational theories, whether we are aware of it or not” (p. 21). Deleuze and Guattari (1994), whose ideas inspired this approach, explained their philosophy of the relationship between concepts and practices in saying that they "link up with each other, support one another, coordinate their contours, articulate their respective problems" (p. 18). Applying this thinking to the present study, it could be said that critical posthumanism and feminist new materialisms are already doing children's storytelling, and I am thinking with these theories as a way of mapping the relations that constitute children's narrative processes.

Mapping relations: A tentative research design. I began my research design with Haraway's (2003) question about design, "How does one map relationships between significant others?" (p. 6-7). This question captures the dynamic potential and the amorphous nature of my investigation. I enacted this inquiry on how the more-thanhuman matters in children's storytelling by mapping the relations between children and more-than-human actors; drawing invisible lines between interconnected episodes and participants (Martin \& Kamberelis, 2013).

This relational between zone I studied has been alternately referred to by researchers as overlooked, hidden, and even unknowable; a place "where there is almost nothing to see" (Braidotti, 2002, p. 173). It was a daunting task to map the territory of 
this shifting and hidden between zone that is neither strictly social (discourse, culture) or material (e.g., matter, nature, the non-human), but rather a mutually constitutive entanglement of the two. Nxumalo (2016a) suggested that researchers exploring relationality might take up creative methodological approaches to attend to the "implicated relationalities in a world where humans are not the only actors" (p. 50). For me, this approach involved moving from traditional methods of observation, toward "shifting, engaging, and noticing" (Iorio et al., 2017, p. 126) what is happening in the classroom; engaging multiple perspectives and attending to complexity.

\section{Research Setting and (Co)Participants}

I completed this research in a home-based Portland area preschool which I founded as director and where I acted as the primary classroom teacher. This 15-year-old school is inspired by the educational project of the early childhood programs in Reggio Emilia, Italy, with a curriculum that reflects a strong image of the child and the values of inquiry, experimentation, and creativity. Consequently, the children were familiar with some of the language, tools, and strategies of inquiry and (re)presentation. Grounded in anti-bias education, inclusion and equity are the foundation of our daily classroom practices. Above all else, we cultivate relationships with an ethic of care and concern, which extends beyond the human members of our classroom community to include our school animals, plants, and the things in our environment.

The child (co)-participants of this study were ten 2.5-5.5-year-old children who attended school together four days a week. Four of these children identified as female, and six as male. The children were from middle class families with varying backgrounds, 
belief systems, and family compositions (single parent, same-sex parents, etc.), and all lived in the urban neighborhoods surrounding the school. Five of these children have had siblings who previously attended the school, so the well-established school culture and traditions were particularly strong during the year that the study took place.

It was important to me to do this research in a setting where there were strong relational connections present in the classroom community and thus a lively and dynamic narrative culture. Though each school year the storytelling culture has its own unique flavor and recurring concepts, this was a particularly vibrant year for storytelling. I was surprised at the vigor with which narrative concepts took root; shooting off into multiple directions and emerging as changed, yet recognizable.

During the study, I was able to immerse myself in the daily life of the school in a natural and comfortable way. There were additional adults present in the classroom in a teaching role during the course of the study. Though they had ideas to contribute as participants of the classroom community and part of the assemblage, they were ultimately not the focus of this investigation.

Because my (co)-participants were young children, transparency was crucial from an ethical perspective. I started by obtaining a written document of informed consent from the parents in regard to their child's participation (see Appendix A). Next, I described the study to the children; requesting and recording their verbal consent for participation (see Appendix B). As stated in my protocol, I used pseudonyms throughout the study to protect the children's identity. 
Though I refer to the children in my study as "(co)-participants," it is important to acknowledge that participation in terms of knowledge production or research, is not something granted to someone but essentially takes place simply through being (Fenwick \& Edwards, 2011, Gallacher \& Gallagher, 2008, Rautio, 2013). As Rautio (2013) observed, "Children might not need adults to provide them with equipment and allocate special spaces and time for participation. They might need an adult to take seriously the things and actions with which they encounter their worlds anyway" (p. 396). In other words, children are always already participating in knowledge production and research. The challenge comes in taking their daily material encounters seriously.

Further, since "non-human elements are always already present" (Ulmer, 2017, p. 833) in early childhood environments, human beings are not the only participants in a research study (Rotas, 2015). In view of this, I set aside my formerly held notions about participation in order to "keep the way open" (Osberg \& Biesta, 2008, p. 325) to participation beyond the exclusively human realm. Conceptualizing research as a "lively entanglement" (Kind, 2013) with children and more-than-human participants offered me a framework to (re)consider who and what participated in this research.

\section{My Role as a (Co)Researcher}

As Barad (2007) noted, "Knowing does not come from standing at a distance and representing something, but rather from a direct material engagement with the world" (p. 49). The relational and entangled nature of researcher, research subjects, and that which is being researched was intrinsic to both the theoretical framework and the 
methodology for this study (critical posthumanism/feminist new materialisms) and is part of the argument in favor of the reconceptualization of early childhood research.

Attending to the concept of direct material engagement, I adopted an active membership role (Henward, 2015) as a teacher, co-researcher, and observant participator (Mein, 2011; Rautio, 2014; Tedlock, 1991) alongside children. Observant participation focuses on "the relations and interactions of all of the people involved, researcher included and with his/her everyday social skills as an inseparable part of the research" (Rautio, 2014, p. 464). The observant participator role allowed me a way to be explicit about my position as both a teacher and co-participant-researcher (Parnell, 2011) who is already entangled in this work. I will address the issue of researcher subjectivity later in the chapter under the heading "Ethical Considerations."

\section{Data Collection}

In this research, a multimodal approach to data collection (written/graphic, visual, auditory) was essential because I gave consideration to stories in many different forms; stories that do not employ traditional conventions, such as having a beginning, middle and an end, nonsensical stories, and stories that were produced in intra-action with nonhumans and materials. I also attended to stories that were generated outside of the anthropocentric and logocentric storytelling tradition which focuses on children's oral or written narratives (Franzén, 2015; Puroila et al., 2012). As noted in the first two chapters of this proposal, these are the types of stories that might hide in the margins, even in classrooms where a regular storytelling practice is part of the curriculum. 
I gathered data produced over a 12-week period with 10 children aged 2.5-5.5. The data in this study consists of observations, photographs of children in the classroom and outdoor spaces, photographs of the material artifacts of children's narrative processes (e.g., loose parts arrangements, clay work, graphic productions), children's own photographs, and audio recordings of narrations and discussions about narrations. Additionally, the anecdotal notes and freewriting gatherings I produced were churned into critical pedagogical narrative segments, entitled drawing lines, which are used as both a data source and an approach to data analysis. My strategy for each of the data collection and analysis methods is outlined in detail below (see Appendix C).

Observation. In this critical posthumanist/feminist new materialist research that draws upon relationality frameworks rather than human-centric ones, using observation as a method is a complicated matter. Traditional methods of child observation are premised on separability of the knower (the subject) and the known (the object), and "the assumption that an objective, external truth can be recorded and represented accurately" (Pacini-Ketchabaw, Nxumalo, Kocher, Elliot, \& Sanchez, 2015, p. 123). Additionally, observation has a history of being used as a colonizing force, both extracting from, and simultaneously consuming its subject. The ethico-onto-epistemological stance associated with critical posthumanism; that ethics, politics, and practices of knowing and being cannot be isolated from one another, makes research an entangled process, and conventional observation methods ethically, politically, and ontologically problematic (Barad, 2007; Lenz Taguchi, 2010a). 
Therefore, my process of observation involved moving from traditional methods of observation toward a holistic witnessing (Rose, 2015) approach grounded in curiosity and care (Puig de la Bellacasa, 2017; Rose, \& van Dooren, 2017). In my observations, I practiced "shifting, engaging, and noticing" (Iorio et al., 2017, p. 126) classroom happenings beyond the human context. This means that during my observations, I shifted my attention from the children, engaged with material practices, and noticed the ways in which the children were called into connection with nonhumans and materials. Because of this intentional shift in perspective from the exclusively human realm, my anecdotal notes occasionally moved from describing the actions of children to describing the movements of materials and other classroom actors.

During the 12-week data collection period, I completed daily observations. The formal observations occurred during a 90-minute period between 9:30-11:00 a.m. during the children's choice time. I chose this period because children were typically engaged in open-ended play and are free to choose multiple activities, such as dramatic play, painting, drawing, and working with clay. By observing during an open-ended choice time, I had the opportunity to observe a wide variety of narrative scenarios and practices. Typically, my observations extended beyond the 90-minute timeframe and continued throughout the day. During my observations, I took anecdotal notes (Chaillé \& Britain, 1991) about classroom happenings, while "shifting, engaging, and noticing" (Iorio et al., 2017, p. 126) between classroom happenings involving the children and more-thanhuman presences. In the role of observant participator (Mein, 2011; Rautio, 2014; Tedlock, 1991), I was involved in typical classroom activities such as everyday 
photography practices and conversations with children while simultaneously engaging in observation.

Following each of the formal observation periods and the consequent class discussions, I engaged in roughly 15 minutes of free-writing, as a pedagogical space for gathering my thoughts. I wrote these anecdotal notes (Chaillé \& Britain, 1991) and freewriting "gatherings" from my time as an observant participator (Mein, 2011; Rautio, 2014; Tedlock, 1991), on an iPad and later churned them into pedagogical documentation as a form of data analysis (see upcoming section).

Photography. This study employed the use of photography as an "entangled" method of data collection (Hohti, 2016a; Kind, 2013; Myers, 2015). While the language of photography implies that the camera, a tool of science, can be used to "capture" and objectively reflect an "unmediated copy of the real world" (Sturken \& Cartwright, 2009, p. 17), I engaged the use of photography as an approach to worldmaking rather than world mirroring (Goodman, 1976). Following the work of Kind (2013), I explored the ways in which photography can help me attend to the in-between spaces and consider how things, in this case, humans and nonhumans, are "spun together in a dense web" (Bennett, 2004, p. 354) of relational entanglement in children's narrative spaces.

There is a growing body of research literature pertaining to children's use of photography to produce their own record of their everyday experiences (Kind, 2013; Kinnunen, \& Puroila, 2016; Malone, 2016b; C. Mitchell, 2011; Myers, 2015; Nimmo, Marcilio, Fowler, \& Goyal, 2018). Providing children with cameras offered them the opportunity to move away from their customary role of the researched into the role of 
researcher (Nimmo et al., 2018). Additionally, it gave children a method of multimodally narrating (Kinnunen \& Puroila, 2016) what they found to be "interesting, remarkable, or important” (May, 2005, p. 81) in their everyday lives.

Photography was be used in three ways for this study. Photographic data consists

of:

1. Photographs taken by me of the children both inside and outside the classroom.

2. Photographs taken by me or the children of material artifacts of children's narrative processes, such as loose parts arrangements, clay work, graphic productions, and so on.

3. Photographs taken by the children of people/things/places that they find to be important for their narrative processes.

Children had access to iPads throughout the day and used them freely with the understanding that we are taking photographs to investigate the storytelling they do while at school with the provocation, Who/What at school is important for your storytelling? Photos taken on the iPads automatically loaded to the school laptop's photo stream for viewing at our class discussion later in the day (see following section). At the class discussions, I invited the children to relay what is important to them about the photograph. The photographs and corresponding conversations were catalogued and recorded as data. I obtained parental consent to use photos of the children as part of the data (see Appendix D).

Classroom discussions as listening sessions. Immediately following the daily observation periods, we had class discussions where we gathered for a conversation about the happenings of the morning. The design for these class discussions was inspired by 
the "Listening Sessions" created by Nimmo et al. (2018) for the project, Voices of Children: Intercultural Collaborations in Understanding and Documenting the Meaning of Children's Rights through Dialogue and Video. The intention of listening sessions is to (re)position children as active rather than passive contributors in research regarding them. For this study, we utilized class discussions to invite children's active contribution by engaging in dialogue with them about their stories and their narrative processes.

During the class discussions, stories told that morning were shared with the storyteller/(s)' permission. Children were invited to share these stories any way they wish; such as telling the story themselves, having an adult read the story aloud, inviting friends to perform the story, sharing a journal illustration or photograph of material work that was part of their storytelling process, or any combination of these sharing methods. I did not limit story sharing to the given examples, however ... I wanted to make room for surprises in storytelling and story sharing, as in the case with Mason's circle turn story sharing, where something important spontaneously emerged. I kept written documentation of the dialogue that occurred following the story sharing (or non-sharing). These discussions were audio recorded digitally on an iPad and transcribed as data (see Appendix E).

These class discussions were a diffractive process rather than a reflective one (Barad, 2007, 2014; Davies, 2014b; Lenz Taguchi, 2012). This distinction is important because reflection implies that in our discussions, we (as subjects) would be standing outside the narrations and narrative experiences and looking in or looking back on them (as objects). Rather, our gatherings and discussions diffractively changed the data and 
effectively generated new data. For example, when describing the conditions of storytelling, the stories often changed to account for conditions at the moment of recounting. I would casually note the change, giving the child/children the chance to revert to their original telling, which they rarely did. Sometimes the stories shared at the class discussions had little in common with the original telling, having been diffracted with an hour of classroom experiences, ideas, and discussions.

The term diffraction, a concept central to new materialisms (Barad, 2007), is borrowed from physics and refers to the way in which water, sound, and light waves bend and move (Højgaard \& Søndergaard, 2011). The movements that occur in these mediums suggest that the differences we perceive in them are generated from within, or in a mutual encounter between the subject and the object. As Pacini-Ketchabaw et al. (2015) explained, "diffraction moves us away from representational reflection and helps us visualize assemblages of different matter such as people, early childhood spaces, materials, and discursive meaning in an encounter" (p. 42). Calling out the diffractive nature of our classroom discussions acknowledges the material-discursive entanglements that emerged between children, their stories, and other actors in the assemblage of class discussions, shifting the data and producing new meanings.

Audio recordings. With both children's consent and parental consent, I audio recorded narrations and discussions about narrations that occurred throughout the school day. In a commitment to the hundred languages of children and a diversity of expression through multimodal data collection, it was important for this study to have the ability to capture storytelling that uses singing, humming and other vocalizations that elude textual 
description. The primary objective of audio recording, however, was to ensure the accuracy of transcribed dialogue. Audio recordings were transcribed verbatim and time and date stamped.

Pedagogical narration. The anecdotal notes (Chaillé \& Britain, 1991) and freewriting gatherings that I produced were churned into pedagogical narrations (Berger, 2010; Kuby \& Crawford, 2018; Lenz Taguchi, 2010b; Olsson, 2009; Pacini-Ketchabaw, 2010; Pacini-Ketchabaw et al., 2015), which I used as both a form of data and a method of diffractive data analysis. The gatherings were the 'and, and, and...' of the stories and their relations; a pulling in of connected threads (see Appendix F).

In the pedagogical narrative segments, however, I draw invisible lines (Paley, 1990) across time and space in order to consider the more-than-human relational material/discursive encounters that are present in children's stories and narrative processes. This approach served as a way of both expanding my appreciation of "the practice and conditions of storytelling" (Gubrium \& Holstein, 1998, p. 165) and restorying the research, much like the autoethnographic components in Paley's (1986, 1988, 1990) work. However, following post-qualitative thinking, my emphasis was on a diffractive analysis of, rather than a definitive interpretation of events. These writings attend to the complexity present in children's everyday narrative practices (Nxumalo, 2014; Tsing, 2011) by engaging "multiple perspectives and subjectivities" (PaciniKetchabaw et al., 2015, p. 266).

As Bentley and Pinedo-Burns (2017) pointed out, "Pedagogical narration, like the life of the classroom, is often messy" (p. 60). With this in mind, I used pedagogical 
narration not with the intention of creating a tidy narrative, but rather to "complicate the scene, unsettling the doings and understandings of others" (Osberg, 2008, p. 158), including my own, and to help "keep the way open" (Osberg \& Biesta, 2008, p. 325) for unexpected ideas to emerge.

Pedagogical narration has been referred to as a lively knowing-doing (Hodgins, Thompson, \& Kummen, 2017, p. 195) practice in line with the new materialist concept of thinking and doing simultaneously. This practice provided a way for me to diffractively consider what questions were being produced and what problems were under construction in children's narrative practices without "looking away" from controversial topics or complicated matters that arise (Kuby, Rucker, \& Kirchhofer, 2015; Olsson, 2009). This move has been referred to as making a shift from matters of fact to matters of concern, a way of expanding work with children to consider the complex entanglements in our common worlds (Blaise et al., 2016; Iorio et al., 2017; Latour 2004a).

I engaged with pedagogical narration as a method to push beyond the boundaries of that which is typically "granted a hearing" (Mazzei, 2007, p. 632) in documentary processes, and to address what emerged in this study of children's storytelling. To accomplish this, I narratively zoomed in (Hohti, 2018) on moments where I encountered pedagogical knots (Nxumalo et al., 2018, p. 438), meaning moments of pedagogical complexity that I found "interesting, remarkable, or important" (May, 2005, p. 81), or to draw attention to "small stories" and encounters that might have otherwise gone 
unnoticed. As with other written data pertaining to this study, these pedagogical narrations contain pseudonyms for children's names.

\section{Drawing Invisible Lines as Diffractive Analysis}

I organized the empirical data in this study - observations, photographs, audio recordings of children's narrations, and discussions about narrations by the date on which they were expressed. I then began, as Paley (1990) described, drawing invisible lines between interconnected episodes to look at their relational aspects. This entailed describing narrative linkages, which are stories told in accountably linked ways, such as stories that follow the same plot, stories that contain the same concepts such as witches or lost children, or stories that end in the same manner (Gubrium \& Holstein, 1998, 2008). Drawing invisible lines between interconnected episodes also meant diffractively exploring more subtle, implicated relationalities (Nxumalo, 2016a) between stories and between narrative scenarios. These implicated relationalities were, for instance, stories that emerge under similar narrative circumstances (such as personal anecdotes told during outside play). There is also an implicated relationality that exists between stories that intentionally upend storytelling conventions. One example of this is a perennial favorite among the preschool children I work with that is typically told during mealtimes: "Once upon a time, THE END!" In this example, implicated relationalities worth exploring might consist of (a) who tells these story fragments, (b) when they tend to emerge, and (c) why they are reliably considered funny, interesting, and memorable to those who hear them. 
As expected, I encountered stories that were off the map of interconnected episodes; stories that held no relational connection that I am able to detect. Stories that seemingly come from nowhere cannot be dismissed, however, particularly in a study attending to marginality. Otherwise stories such as Mason's that come as a surprise and confound all expectations can keep the way open for ways of mattering that perhaps have not yet been imagined. In the spirit of attending to off the map data, I also addressed narrative silences where children refused to share their story or discuss their thinking, or to tell any story at all (Gubrium \& Holstein, 1998).

Acknowledging the entangled nature of research, it is important to note that my data analysis was also an entangled process. This means that rather than standing outside the data and looking in, I actively engaged with the data by "mapping routes of 'reading' through space and time” (Bozalek \& Zembylas, 2017, p. 120) to consider the relational dimensions of the data. Thus, my process of "drawing lines" was a mapping of rhizomatic relationalities between bodies, events, materials, and categories in order to "make connections between entities that do not appear to be proximate in space and time" (Barad, 2007, p. 74). This process of analysis, which allowed for diffractively "reading insights through one another" (Barad, 2007, p.30), occurred throughout the study.

\section{Ethical Considerations}

I come to this research from an ethico-onto-epistemological perspective, holding the position that ethics, politics, and practices of knowing and being cannot be isolated from one another but rather are mutually implicated and constitutive (Barad, 2007). So rather than being an afterthought, ethical concerns were implicit in every aspect of this 
research (Maxwell, 2013). My research approach thinking with theory is premised on ethico-onto-epistemology (Barad, 2007; Lenz Taguchi, 2010b), the idea that because theory and practice are inexorably entangled, research and analysis itself is an entangled process (Davies, 2014a). In this way of thinking, research is comprised of meaningmaking and production simultaneously and is unescapably laden with ethical and political implications. For example, my choice to give special attention to stories from the margins is an ethical and political one, informed by Barad's (2003) critical posthumanist ethics, in which ethics is a matter of questioning what is being made to matter and how that mattering affects what is possible to do and think.

I acknowledge myself as an entangled and subjective researcher who carries world views, beliefs, and values that are inevitably entangled with this research. For example, I come to this work from the perspective of a White settler woman raised on the west coast of the United States. I hold a strongly anti-assimilationist position regarding education, which means that I have a particular affinity for children's thinking and doings which might be considered transgressive to established classroom/school norms. Also, I have a fervent belief in the power of stories and am committed to preserving the integrity of the stories I relay as a part of this research. Though posthumanist subjectivity is a complex and contested concept (see Davies, 2010; Højgaard \& Søndergaard, 2011; Snaza, \& Weaver, 2015), I view myself as a "bold and not anonymous" (Parnell, 2011, p. 4) participant in this work; regarding my subjectivities as part of the data.

While my familiarity with the children gave me privileged access to the nuances of the classroom culture, it also presented the challenge of possible closures in my 
thinking. By closures, I am referring to hardened ideas that would prevent me from being open to surprise. With the goal of questioning any taken-for-granted assumptions (Franzén, 2015) that I might hold, I accepted the challenge that Henward (2015), following Thorne (1993), posed for adults learning from children — to take the closely familiar and render it strange. Given this charge, I employed the use of critical pedagogical narrations (MacNaughton, 2003; Pacini-Ketchabaw et al., 2015) as a data collection/analysis tool and a strategy to actively disrupt closures in my thinking. I position myself in an active membership role (Henward, 2015) as a teacher, co-researcher, and observant participator (Mein, 2011; Rautio, 2014; Tedlock, 1991) alongside the children. The consideration of power relations in the study was crucial, as power dynamics are already present in and entangled with the daily life of a classroom. Thus, addressed the uneven power dynamics that result from my privileged position as a teacher and adult researcher while in the midst of the study itself (Koro-Ljungberg, 2012).

I addressed the uneven power dynamics by enlisting children as active participants and co-researchers. Additionally, I actively worked to insure children's narrative rights; the ethical and moral right for children to express themselves and to be understood by others (Puroila et al., 2012). To hold this intention, I not only followed member checking protocol by inviting children to correct misunderstandings about their work, their words, and their ideas, but also pushed out beyond this convention by giving children the opportunity to add to or amend their work. I also insured children's right to refuse participation in any part of the study. 
My research strategy of working with a small group of children limited the stories I was able to address, simply by virtue of the number of children I encountered during the course of this study. I am confident, however, that I attended to enough stories to adequately address my research question regarding how the more-than-human matters in children's storytelling. Despite the intentional design of research with a small group, I was not able to bring every story into the frame of this study; a testament to the incredibly rich and complex world of children's narrativity.

Having described the research approach and methods used in this investigation, we now turn to Chapter 4 regarding data and discussions. The following chapter presents the data that I gathered during the research study and outlines the primary findings that emerged from this data. 


\section{CHAPTER 4: DATA AND DISCUSSIONS}

This study addresses the issue of predetermined learning outcomes in early childhood settings, which (a) limit the scope of what is possible in the classroom, (b) narrow the range of what learning is considered valid, and (c) privilege the experience and values of the dominant culture, thereby determining what comes to matter in early childhood settings (Cannella \& Viruru, 2003; Moss et al., 2016; Moss \& Urban, 2017). This phenomenon creates a culture of sameness, repetition, and orthodox thinking (Deleuze, 1994; Kumashiro, 2000), in which the possibilities for a creative thought are blocked by recognizing and reproducing representations of the already known.

The purpose of this post-qualitative study is to position children's storytelling as a disruptive force to the privileging of western, positivist, and ultimately, humanist knowledges in early childhood education and research, making space for ideas and knowledges that might otherwise be pushed to the margins. Acknowledging a need to resist "more of the same" in early childhood research and practice, in this study I am thinking with theory to enact critical posthumanist/new materialist theories as a postqualitative approach to research children's narrative practices in an early childhood setting (Jackson \& Mazzei, 2012; Kuby, 2017a; Lenz Taguchi \& St. Pierre, 2017). Thinking with theory, a post-qualitative "methodology without methodology" (KoroLjungberg, 2015), relies on the Deleuzian concept of thinking with rather than thinking about theories; acknowledging research and analysis as an inexorably entangled 
processes (Davies, 2014a). My research question is, How does the more-than-human matter in children's storytelling?

\section{Analysis of Data}

The data in this study consists of observations, photographs of children in the classroom and outdoor spaces, photographs of the material artifacts of children's narrative processes (e.g., loose parts arrangements, clay work, graphic productions), children's photographs, and audio recordings of narrations and discussions about narrations. Though my intention was to limit my formal observation periods to two 90minute sessions a week, I found myself immersed in my role as participant-observer at all times in the classroom. While I did complete my 90-minute observation periods followed by free-writing gathering sessions as planned, I also came to acknowledge that we were living the data in this study, and that significant findings would spill over into every aspect of our day. This means that whenever I noticed an event that I perceived to be connected to the storytelling study, I shifted into observation mode, asking provocative questions and/or documenting the occurrence. Thus, my iPad and camera were my constant companions during the 12-week study for notetaking and photographs.

Similarly, I found relegating children's use of the iPads to particular times in the day to be limiting to their narrative processes. Because of this, children had access to iPads throughout the day for ongoing re-production of that which they found to be “interesting, remarkable, or important” (May, 2005, p. 81) in their school day. The provocation for taking photographs was: Who/What at school is important for your storytelling? The use of photography as an "entangled" method of data collection (Hohti, 
2016a; Kind, 2013; Myers, 2015) revealed the more-than-human nature of children's daily experiences at school. Unlike my photos, the children's photographs only occasionally had human subjects; instead featuring assemblages, movements and flows, and visual impressions of their experiences.

I enacted daily class discussions as 'listening sessions' (Nimmo et al., 2018) as designed in the Methods section of Chapter 3. In these discussions, children shared narrations, photos, stories, and drawings from the morning; a diffractive process of attending to storytelling that produced new stories, new understandings and new ways of mattering for our classroom community. These extraordinarily creative and unpredictable sessions provided a platform for rich, multimodal dialogue and exchange. The class discussions were recorded, transcribed, and catalogued as a data source.

In addition to the data collection methods outlined above, I crafted pedagogical narrations as a diffractive approach to data analysis (Parnell, Anderson, \& Molloy Murphy, 2019) to map connections between narrative episodes and other significant relational factors in the narrative assemblages. This was often enacted by diffractively reading one text or set of ideas through another, such as reading one story through a previously told story or event, or through a book we had been engaging with as a classroom community (Barad, 2007). This process allowed me to draw lines of relation "between entities that do not appear to be proximate in space and time" (Barad, 2007, p. 74).

It is important to note that there are multiple threads I did not follow during the 12-week study. I recognize that the lines that I drew were unique not only to me, but to 
research spacetimematterings, or phenomena as material entanglements threaded through the universe - in this instance, the spacetimematterings were the productions of my research practices threaded through space and time (Barad, 2007). Thus, I acknowledge the research process as partial and uneven by necessity. Rather than viewing this as a shortcoming of the study, however, I regard it as a testimony to the multiplicitous nature of daily life in an early childhood classroom and a recognition of the entangled nature of research.

\section{Presentation of the Data}

In this section, I present select data from our 12-week immersive study, which provides a glimpse into the rich narrative life of one early childhood classroom community. During this relatively short time, an astounding number of narrations were produced. The "beginnings" and "endings" of these narrative threads were sometimes discernable, and other times so far reaching as to be virtually undiscoverable. As noted in Chapter 3, Deleuze (1988) noted that (post-qualitative) inquirers seem to begin already "in the middle" of an inquiry (p. 123), and similarly, Derrida (1974) advised that we begin research "wherever we are; in a text where we already believe ourselves to be" (p. 162). These words were particularly salient as I embarked upon a study with children who were thriving in the midst of a vibrant narrative culture created together over the course of one to three school years together. The presented data from this research study is a zooming in on 12 weeks of their dynamic narrative culture, intended to highlight its complexity rather than dissect or essentialize it. 
The data consists of vignettes of narrative events that address the question of how the more-than-human matters in children's storytelling. I share events in chronological order to best show the emergent and rhizomatic nature of this study. For example, rather than following the thread of the concept of ghosts directly through the study by collapsing the timeline, a chronological reading of the data shows that ghosts came up in week one and went underground, re-emerging in week 12. I have broken down the 12weeks of data into four 3-week sections for organizational purposes.

My anecdotal notes (Chaillé \& Britain, 1991), or free writing gatherings from my time as an observant participator (Mein, 2011; Rautio, 2014; Tedlock, 1991) are embedded as data following the corresponding narrative events. Next, I use pedagogical narration (Berger, 2010; Lenz Taguchi, 2010b; Olsson, 2009; Pacini-Ketchabaw, 2010; Pacini-Ketchabaw et al., 2015; Kuby \& Crawford, 2018) for data analysis; drawing invisible lines (Paley, 1990) between narrative events and elements in a world where "humans are not the only actors" (Nxumalo, 2016a, p. 50). These pedagogical narrations, entitled drawing lines, are included at the end of each 3-week section.

I have written children's quotes verbatim, as I found the emphasized words, sounds, and utterances children made to have material significance. Additionally, I italicized children's words for prominence as explained below. Photographs taken by the children and/or myself are included as figures following relevant text to offer a presentation of data that reflects the multimodal nature of the study.

Weeks 1-3. In the first three weeks of the study, I introduced formalized processes to the research that was already well underway in this classroom community. 
It was March, the flowering of the school year. The children were several weeks into a rainbow study we had launched in order to complete their vision of painting a rainbow from observation, as one would do a life drawing. Since we could not depend on having an actual rainbow to look at as they painted, we had been capturing images of rainbows as we encountered them and bringing them into the classroom. Our lively documentation space in the classroom, which we refer to as "the thinking wall," was plastered with photos the children had taken of skies and rainbows, along with the provocation, What is research? This inquiry was commonly referred to as our "rainbow research." At school, children used iPads, and occasionally my phone to take pictures for rainbow research. Other images on the thinking wall were sent from school families who spotted rainbows while out in the world. Aside from a few conversations describing the formal research processes that were being implemented for the 12-week doctoral research study, it was business as usual for this dynamic group of children who were already "in the middle" of the text of their own inquiry.

\section{March 18th}

On March 18th, we begin our first data recorded through direct observations and field notes. I present the data as narrative vignettes, which consist of my field notes embedded with quotes and photographs offered as part of the context for each episode. Following Hohti (2018), I italicized the vignettes to indicate a "zooming in" on a moment, while I reverted to normal font to show "how the inquiry moves outwards, adding layers and connections to other studies and ideas" (p. 7). Additionally, I offered the vignettes with a time signature to give the reader a sense of the day's unfolding. 


\section{0:00 a.m.}

Ana, Stella, and Fiona are painting the rainbow on the mural we are collectively referring to as "Flower Garden World." They are working from a photograph of a rainbow taken by a child on an iPad during our "rainbow research." Ana accidentally bumps Fiona's paintbrush. The liquid watercolor paint is as thin as water, and before long, dark blue watercolor has dripped on the rainbow, blooming in tiny spiderlike explosions. Fiona frowns and drops her head. After a brief pause Ana says, "It looks beautiful, like a starry sky." Stella responds, "It's magic in the rainbow. Let's make more." The girls abandon the rainbow replication they have been planning for weeks and begin splatter painting the rainbow with dark blue watercolor. A group of children gather to watch. The children sing, and hum as they splatter paint. They begin chanting, "More Magic! More Magic! More Magic!" over and over as they create blue splashes across their painting (see Figure 2). Ana notices me taking notes and relays what is happening.

Ana: "I accidentally bumped Fiona's brush. But it looked like, kind of like there was stars on there. So, then we kind of kept doing it, and it now it really looks like it looks kind of pretty, see!"

Me: "I see it!"

Fiona: "And it also looks kind of like magic, Stella said, and, and then we did more of it so it would make MORE magic."

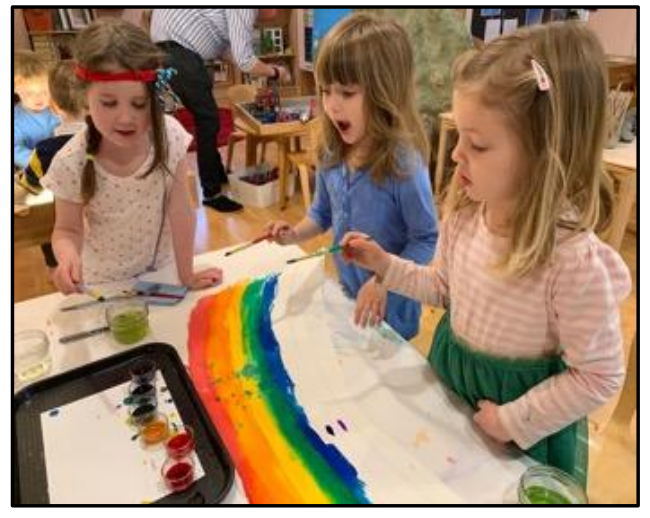

Figure 2. "More magic."

\section{0:25 a.m.}

Ana is wearing a blue silk around her neck like a cape. She announces, "My name is Twinkle Snow." Fiona is wearing a rose-colored silk cape; a favorite among our classroom things. She says, "I am 'Rose Snow Queen,' a queen because my wings are the biggest."

Stella says, "I am the oldest daughter because my wings are the mediumist. So, you (Ana) are the little sister. My name is snowflake." 
Ana: "Jake is the dad. He has the brown wings."

Fiona: "The brown wings" (see Figure 3).

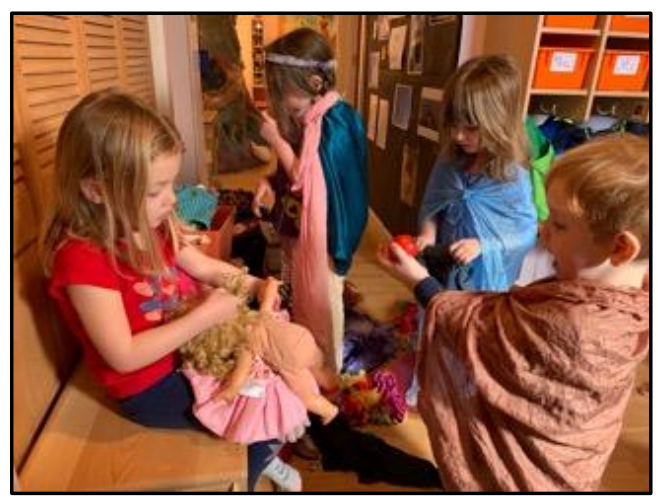

Figure 3. "The brown wings."

\section{0:50 a.m.}

Ana: "Here's our dinner. We are very poor Faeries, so this is all we have. The baby gets to eat all the food because she was just born.

A few minutes later:

Ana has dumped wooden fruits and vegetables from the play kitchen into a cob tree in the center of the classroom, declaring, "We found the never-ending food tree! We have all the food we need for the rest of time and we're not poor anymore. Gather it up, quickly!" The children gather up the play food into aprons and baskets with delight. Stella pulls a wooden egg from deep within the tree, saying, "This egg is a magic egg. We can eat it for breakfast every day."

\section{1:15 a.m.}

Truman, "I'm dead! Get the necklaces!" Children chant "Magic, Magic, Magic” or "More magic! More magic!" while covering him in necklaces (see Figure 4).

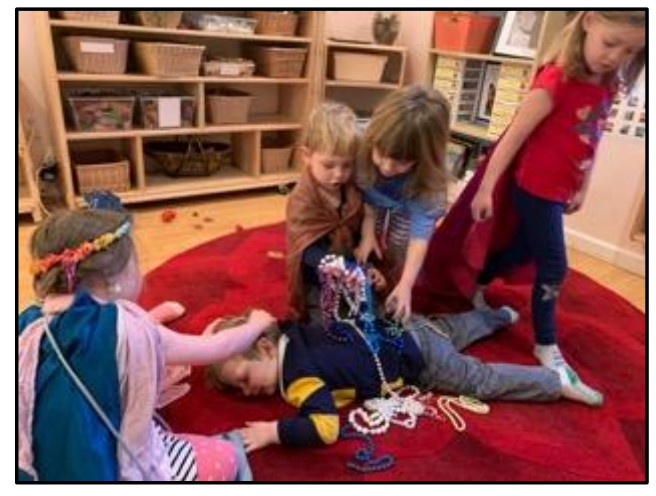


Figure 4. "I'm dead! Get the necklaces!"

The following segment consists of my first free-writing gathering, written immediately following the preceding narrative events. I have borrowed the term gathering from Latour (2004a) to situate these writings in the flow of moving experiences. Gathering is an action, an active assembling of things that matter. Of gatherings, Latour wrote, “A thing is, in one sense, an object out there and, in another sense, an issue very much in there, at any rate, a gathering ... the same word thing designates matters of fact and matters of concern" (p. 233). These free-written gatherings are offered throughout the data presentation section alongside corresponding narrative events.

\section{Gatherings}

Thinking with critical posthumanism/feminist new materialisms, I am interested in the ways in which materials influence children's narrative play. The necklaces; the ceramic egg; the rose silk cape. Like Rauito's (2013) observation that the seemingly natural activity of throwing stones in the river can only be produced by the presence of both human and stones, I wonder to what extent our classroom "things" provoke a

particular type of storyline in the children. Better put, how do our classroom things invite children into narrative play?

I noticed some gendered play today (for example, the girls assigning Jake the brown silk wings to indicate he is the dad) and wondered, are the materials themselves gendered in some way or are children simply using them in a gendered way based on their experiences and ideas? I suspect the gendered play is a product of both, and more. 
For example, children often represent who they are in a story by associating themselves with items of a particular color according to social constructs pertaining to color. Today this tendency was illustrated by Fiona depicting her queendom with the largest (rose colored) wings and Stella claiming the role of the eldest daughter because her wings are the "mediumist." Ana is relegated to the role of the little sister with the smallest wings, and Jake is assigned the role of the dad because he has the brown wings. However, this choice was likely also made because he is male. Did Jake choose the brown wings because they felt appropriate for him to wear as a boy? What would have happened if he had instead worn the rose silk cape? Having been keenly attuned to issues of gender in the early childhood classroom for quite some time, I carry questions such as these around in my daily life with children (see Blaise, 2012).

I also noticed that the concept of magic was threaded throughout the children's stories and play as it has been all year - the magic never-ending food tree, a magic egg that can be eaten for breakfast every day, magic splatters in the rainbow, and magical, life-restoring necklaces and jewels. The phrase "More magic" was said on more than one occasion today. What exactly does magic mean to these children? I carry this question forward with me into the next day of our study and beyond.

\section{March 19th}

This morning I receive a text from the former preschool parent who gifted us our guinea pigs; she tells me that today is the brothers' first birthday. I make an announcement to the children, who immediately begin to adorn the studio for a birthday party (see Figure 5). 


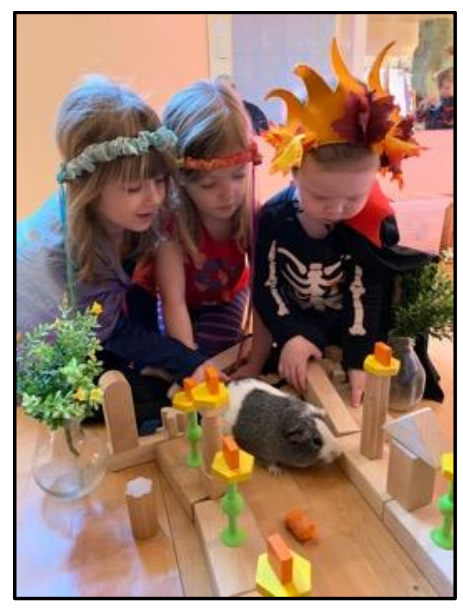

Figure 5. Guinea pig birthday party.

\section{0:40 a.m.}

A few children are concerned that the party will over-excite the guinea pigs. To address this, Ana tells Jeremy (one of the guinea pigs) the following story:

Once upon a time there were two guinea pigs and they were best friends and they loved each other. They decided one day to have a slumber party. But, little did they know, the slumber party was in a haunted house and there was a ghost. There's an old, old ghost. And since anybody ever came there, nobody ever came back. So, the guinea pigs had to be aware of the ghost. So, then the guinea pigs had to find a place to live. 'Cause where they live is where the slumber party is. They are going to invite all their friends. But it turns out to be a big no no, because the party was in a haunted house and the ghost ended up ruining the party. One ghost smashes the bed and the other ruins the game. The guinea pigs tried to say "no, don't!" but they couldn't talk, couldn't stop them, so they tried a different way to stop them. They tried to stop them by grabbing them, but their hands just went right through them. So, they had to run home. The End.

Ana finishes the story and says: "We can write happy birthday Leroy and Jeremy and put it on their cage because it's their birthday and the story is for them. I think he (Jeremy) enjoyed the story because he was very calm!" Me: "Do you know what inspired the haunted house part?"

Ana: Long pause. "A dream I had a long time ago. I got the slumber party because I saw a Berenstain Bears where they were having a slumber party. That's where I got the slumber party." 


\section{March 20th}

The study continues. On this day, as on many days, journals are offered on a classroom table along with various tools for writing and drawing. I inform the children that I will be available throughout the morning to hear about their work and write down words for them to share with the class later if they choose.

\section{9:50 a.m.}

Fiona has been drawing in her journal and calls me over to tell the following story: "Once upon a time there was a king and queen that decided to have a ball one night. And they choosed a ball place that had a bunch of porches so the people could go on them. And then all of the guests came, and all of the people came inside the ballroom and had the ball. And then in the middle of the ball it came dark. And the ghost came. And then the ghost showed out fire from its mouth and scared all the people away Then the people had to go home because the ghost was too scary. The End." Me: "Wow. Do you know how you came up with this story?"

Fiona: "At first I looked at those things (colored cellophane) that made different colors and that reminded me of a haunted house and then I thought about a ball and then I made this picture" (indicates journal). I need a picture of that ..." Fiona runs off to take a photo of the colored cellophane arrangement that reminded her of a haunted house (see Figure 6).

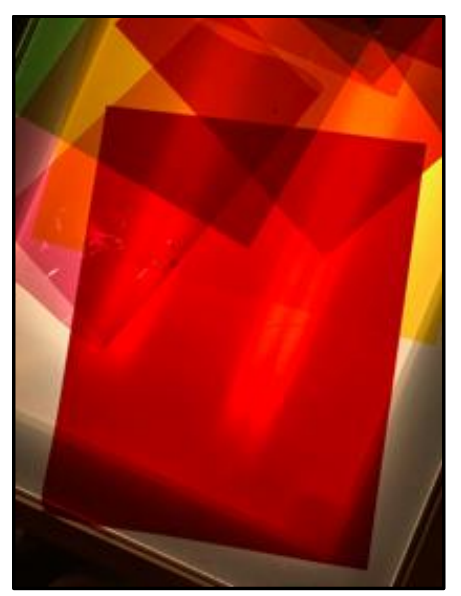

Figure 6. Fiona's picture of the cellophane. 


\section{Gatherings}

Thinking back to Fiona's description of the "ball place that had a bunch of porches so people could go on them," I realize that her story not only connects to Ana's haunted house story, but also to a favorite book of ours during this time, The Talking Eggs (San Souci, 1989). In the book, the child protagonist Rose visits the home of an "old granny" whose farm is alive with magic. In one scene, Rose and the granny sit on the porch together, laughing and clapping for the dancing farm animals who are holding a fancy ball in the yard. They are dressed in finery and dance late into the night (see Figure 7).

Using diffraction to "read" Fiona's story, through another, The Talking Eggs (San Souci, 1989); significant aspects emerge. Although Fiona's story features a ball with porches, it is centered on human activity, with the only significant nonhuman presence being a ghost. The "ball place that had a bunch of porches" could also connect with our book The Nutcracker (Jeffers, 2007) where the ballroom is depicted as a grand space bordered by balconies on many levels.

Ana's guinea pig birthday party story from the day before featured animals and ghosts as protagonists rather than humans. My announcement about the guinea pigs' birthday was clearly an element in the story assemblage, as well as events from Ana's home life such as the Berenstain Bears show she saw about a slumber party. Although I am intrigued by her mention of her "dream from a long time ago," in the moment I felt that she was reaching for an answer that would sound better than "I don't know." Ana 
has a sophisticated understanding about the nature of ideas and creativity; perhaps her response was a way of saying to me, "It came from somewhere, but I don't know where."

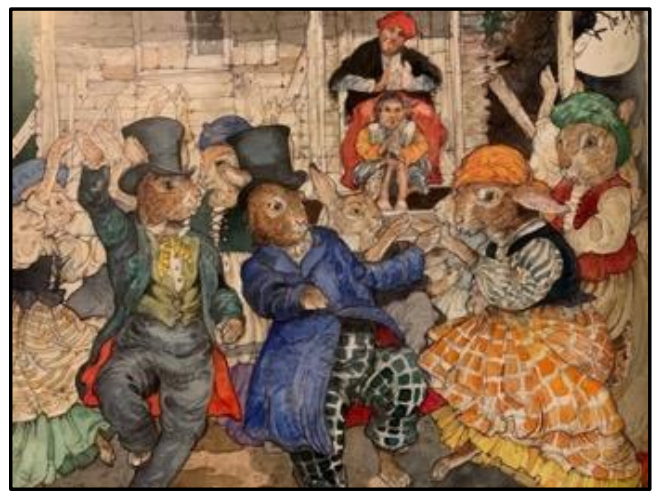

Figure 7. "A fine, moonshiny night."

\section{April 1st}

\section{9:50 a.m.}

Ana takes a photo of clear quartz crystals and plastic prism pieces, saying, "I got inspired of this about a crystal in a cave" (see Figure 8).

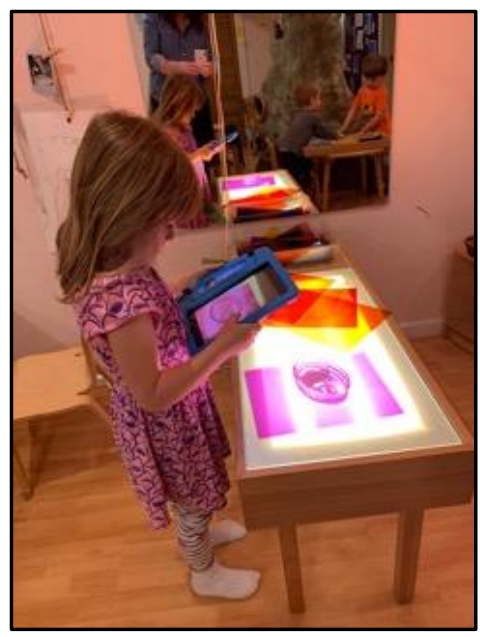

Figure 8. Crystal in a cave. 
She proceeds to the dress up corner, recruiting several children to play by saying, "Take all the crystals and run!" She races to the box of crystals and says "We found the crystals in a cave! Now we are not poor faeries anymore!" They join her, stuffing crystals in pockets and sacks (see Figure 9).

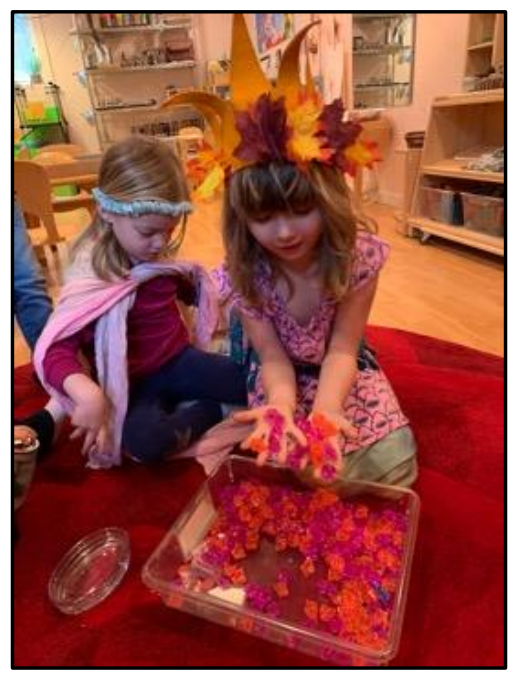

Figure 9. "We found the crystals!"

\section{0:10 a.m.}

The children are pulling on a lei in the dress up corner; it breaks. The silk flower petals scatter across the floor. The children begin grabbing handfuls of them (see Figure 10).

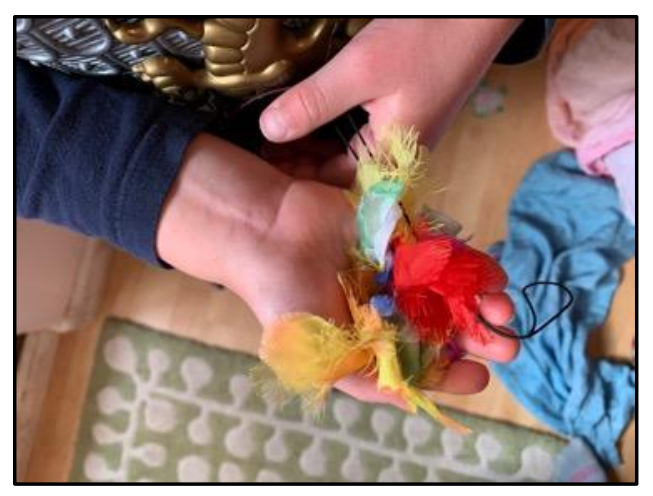

Figure 10. Powers.

Jake: "I got fire power. And lightening."

Fiona picks up a big handful, saying, "I have every power there is." 
By the time Archer makes it to where the pile was, there are no powers left. The children spread them out on a tray and create an elaborate process to divvy them up.

Archer quietly walks over to the writing table and begins drawing and cutting (see Figure 11).

A few minutes later Jake approaches Archer, asking, "What are you making?" Archer: "Nothing."

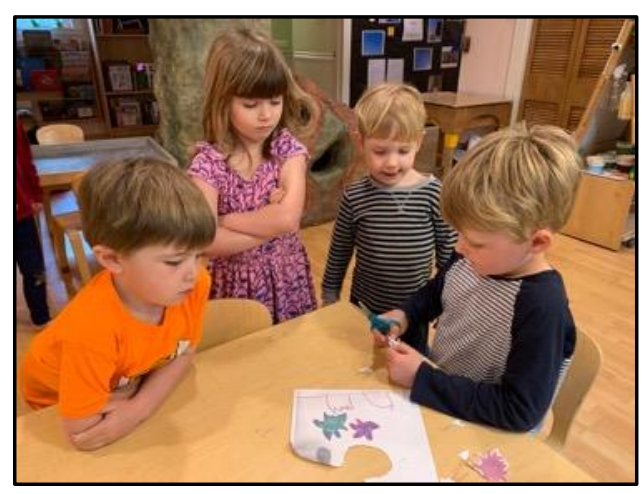

Figure 11. Archer's powers.

Fiona watches him for a moment, then sits down to join him at the table, drawing small symbols on watercolor paper and cutting them out. Within a few minutes Ana has joined them as well. Archer looks at me, smiling, and says quietly, "These are my powers."

\section{0:40 a.m.}

I ask Fiona about the powers she made.

Fiona: "Swirl power makes a tornado. This one, (purple) is to make everything dark but the houses. The other purple one makes the house is dark but nothing else. This one (green) is the only power that makes a cage out of leaves. This one (yellow flower) is sun power and water power and this one (red flame) is fire power."

Me: Do you have all these powers now that you drew them? She nods her head. Others join them, but it is almost snack time and they do not get very far.

\section{1:00 a.m.}

At class meeting we look at photos and discuss the morning. The children make a list of the powers that were made or could be made. Ana makes the argument that love is the strongest power.

Ana: "Love comes from your heart, like you love friends and stuff. That's why I said the most power comes from your heart, 'cause you can love things . . it comes from your heart, like, if you love your mom so much."

Me: "When you say that the most power comes from your heart, are you talking about the actual organ that is in our chest, beating and pumping blood? Or... 
Ana: (pointing to her chest) "Yes."

The following free-writing segment was written late in the morning on April 1 st in the midst of the school day and edited later for clarity. As with all of the written gatherings, I may reach outside of the day's events to make meaning of them. For example, in the gatherings that follow, I call in Bennett's (2010) concept of "thing power" to consider the vitality of inanimate things in the children's narrative play.

\section{Gatherings}

The concept of Thing-Power, which Bennett (2010) defined as "the curious ability of inanimate things to animate, to act, to produce effects dramatic and subtle" (p. 6), wove its way through the morning. In fact, Thing-Power seems to be one of the "radical relationalities" (Nxumalo et al., 2018, p.446) that the children are researching at the moment through their narrative play. They are exploring questions such as, What things have power, and why? Is thing power, and power in general, limited; or is there an endless supply? This last question is a critical one, for the answer to it has far reaching implications regarding if power ought to be hoarded or shared.

I noticed that the stones from the "miners' table" are now regularly used in children's storylines. The stones start off each morning on the tray, then migrate around the classroom in pouches, hands, pockets, baskets, and boxes, collaborating in stories and play. The stones call to children with a particular sparkle, unique texture, size, or shape. They are alternately referred to as gems, jewels, stones, and crystals. The children have also added their "name stones" to the miners' table, which have words written on them as 
a wish for the child. These stones were made by the parents at the beginning of the school year (see Figure 12).

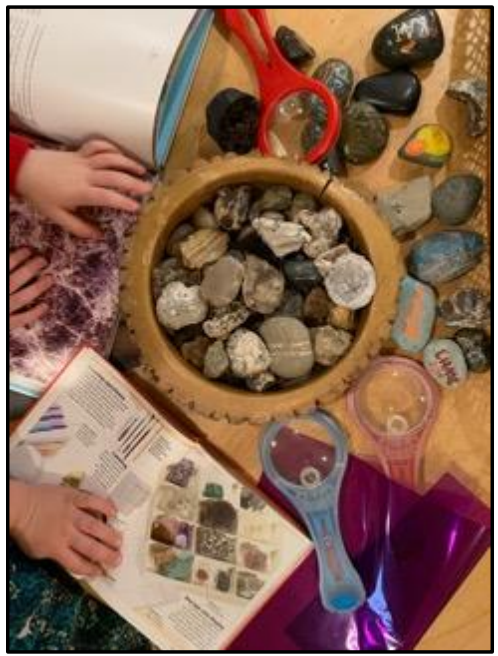

Figure 12. Miners' table.

\section{April 2nd, 2019}

The children start off their morning by continuing the activities from the day before. I have offered watercolor paper, shiny markers, and scissors at the table where Archer made his powers yesterday, along with the written provocation, "What does your power look like?" Archer visibly takes pride in the fact that his classmates and I were inspired by his idea. He is, however, maintaining silence about what his particular powers are.

\section{9:40 a.m.}

Ana is at the writing table working with watercolor paper, markers, and scissors. She says, "I'm making my power. Silver is invisible power" (see Figure 13). 


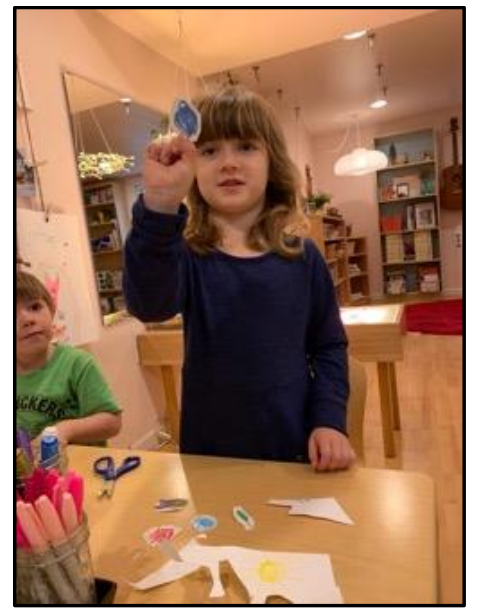

Figure 13. Silver is invisible power.

Me: "Why silver?"

Ana: "Because it's the closest I can get to invisible. I'm inspired by crystals, which are actually invisible. See..." She shows me a photo she had taken that morning on the iPad (see Figure 14). It is very similar to the photo she took that inspired her crystal narrative yesterday.

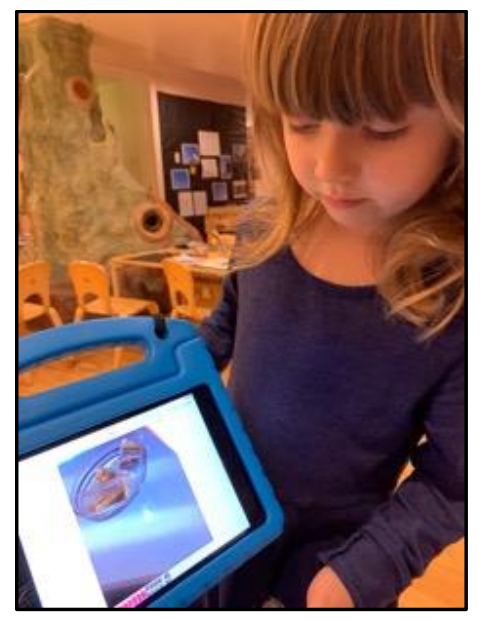

Figure 14. Inspired by crystals.

Me: What is your power for?

Ana: "If you want a crystal and you can't find one, you can just turn something into a crystal and there you go. That's how you use that. And this (small leaf cut out) is the leaf power. When they are leaf skeletons you can make cages out of it."

Truman: "I'm making Elsa's power."

Me (to Truman): "I keep hearing you mention Elsa's power. What is it?" 
Truman: "To create ice and snow." Truman shows me something he drew on a piece of watercolor paper. He has made marks with an ice blue sparkly marker. Then he runs to the bookshelf to get a book. He shows me a page in the book, saying, "It's the witch in 'Room on a Broom.", Ana takes a photo of him holding the book. "For research," she says (see Figure 15).

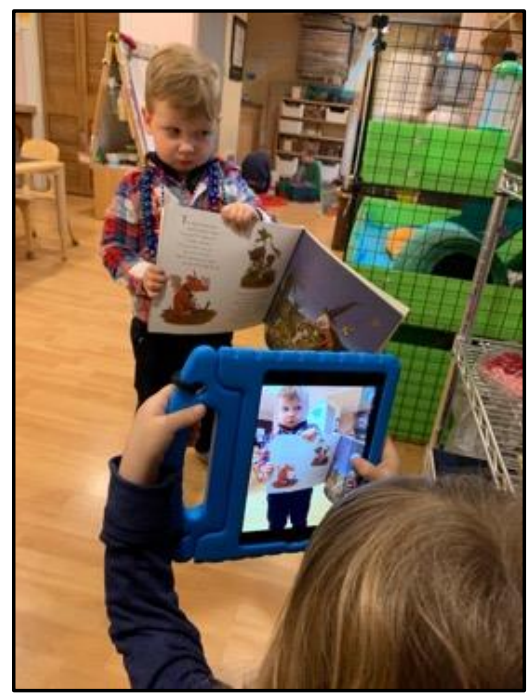

Figure 15. For research.

Fiona has made more powers and wants to tell me about them, "This is my chicken power. It can turn someone into a chicken or a duck. This is a rainbow power that makes a rainbow. This is a darkness power and a moon power. I can make it dark and it can make a moon if you want. This power can make a cage and it can make grass in a cage" (see Figure 16).

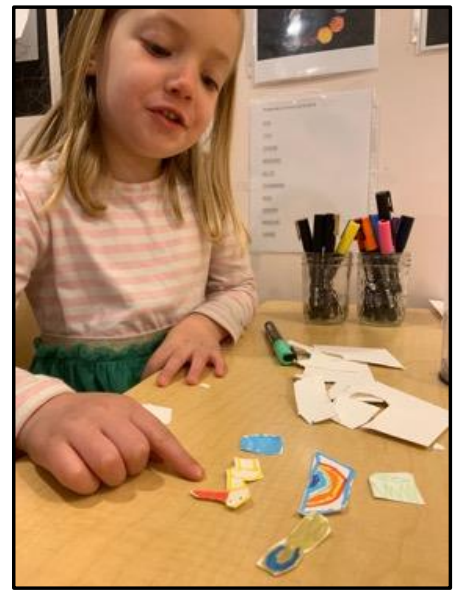

Figure 16. Fiona's powers. 
Mason joins the others in making powers. He makes water, fire, snow, and ice power, asking Fiona what color she thinks each should be (see Figure 17). He asks me to label each power on the back with its corresponding name.

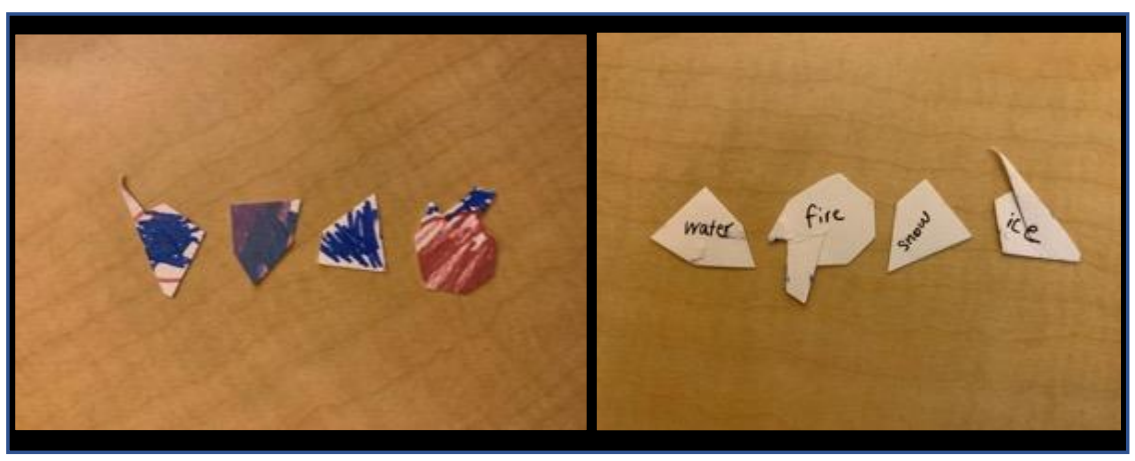

Figure 17. Water, fire, snow, and ice.

In the following section I share my first pedagogical narrative writing, which "draws lines," or shows connections between narrative episodes and concepts from weeks 1-3. Rather than a comprehensive or definitive account of significant findings from the first few weeks, these pedagogical narrations are intended to complexify the events; to raise questions and pedagogical possibilities.

\section{Weeks 1-3-Drawing Lines}

There are several concepts, such as the power of magic stones, other-than-human beings (ghosts) who ruin a party, and the association between colors and seasons, elements, and powers that emerged repeatedly in the children's narrations during the first 3 weeks. However, there are only few clearly interconnected narrative elements at this point in the study.

During the narrative play on April 1st (week 3) Ana said, "We found the crystals in a cave! Now we are not poor faeries anymore!" This brought the "never-ending food 
tree" from March 18th (week 1) to mind, where the problems of poor and hungry faeries are resolved by magic. Also, there is a clear line that can be drawn between the story that Fiona told about ghosts who scare everyone away from a ball and the story that Ana told the day before at the guinea pig birthday about ghosts who ruin a sleepover. Ana cited a Bernstein Bears film as inspiration for the slumber party in her story, and Fiona pointed to a stack of cellophane on the classroom light table as the impetus for the haunted house in her story.

In weeks 1-3, the children's awareness of the deeply storied nature of the morethan-human world has become evident. Stones are powerful, with varied abilities; watercolor drops spread magic as they bleed across paper; colors carry significant associations. Next, we will delve into weeks 4-6 of the study, where some narrative threads disappear beneath the surface in the fabric of our daily school lives, while others re-emerge in unexpected places.

Weeks 4-6. Weeks 4-6 are a dynamic period for preschool happenings. During this time, I began fostering a rabbit at the preschool and placed fertile eggs under our broody hen for her to hatch. Easter also fell during this three-week period. This assemblage of thematically connected events from children's home and school lives (bunny, eggs, Easter) contributed to the production of narrations shared during this time.

April 10th, 2019

\section{9:20 a.m.}

We are gathered at morning meeting in conversation about school happenings. I say, "I have been listening to your stories and discussions, and it seems that many of you are thinking about magic. What can you tell me about magic?" 
Ana: "I started doing magic because of the Faeries. I met the Faeries and they gave me pixie dust, so that's how I started on it."

Me: "What is magic for?"

Ana: "You can use magic to make things, like snowflake and ice power can be used to make a castle ..."

Stella: "You could make an actual ice castle that you could go into."

Fiona: "Elsa actually did make her house with her powers."

Me: "Are magic and power the same thing?"

Fiona: "Yes."

Archer: "Magic gives you power."

Stella: "No..."

Truman (interrupting): "Elsa Power! I have Elsa power."

Jake: "Lightning Power and fire power!"

Stella: "I have 2 Elsa dresses that fit me and 3 that fit Eliot"(her brother, also a student). Me: "Do the dresses give you power?"

Stella: "Kind of."

Throughout the morning, the children continue the activity of using paper and markers to create elemental "powers" that they use throughout the day (see Figure 18).

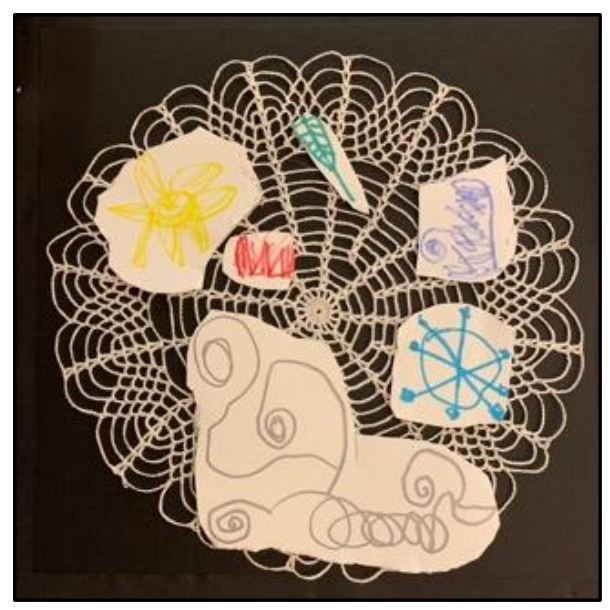

Figure 18. Elemental powers.

April 11th, 2019

One of our cherished school friends moved to Seattle after winter break. The children discuss daily how much they miss her. Ana suggests making an ofrenda for her (which means offering in Spanish) like they do in the film Coco (2017). "Even though she's not dead, we can still make one for her to remember her with." We discuss the kind of things that might be on an ofrenda, and the children immediately begin gathering Maggie's favorite things from around the classroom. The sparkly horses. The pink silk. The blue 
jewel. I print the photo that Maggie's mom texted me of Maggie fishing in a tiny pond at their new house and place it among the other things on the ofrenda. I invite the children to draw pictures, tell stories, and write letters for Maggie and place them on the ofrenda. Eliot has also seen Coco (2017) and is disturbed by the idea of making an ofrenda for Maggie. "Maggie is not dead, she's in Seattle." We agree to call it a "Living ofrenda" to distinguish it from the ofrendas used in Día de los Muertos (see Figure 19).

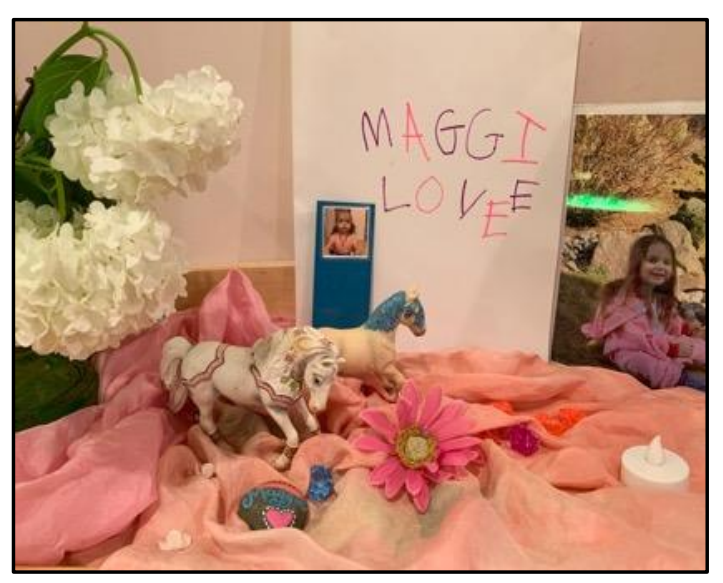

Figure 19. Living ofrenda.

\section{0:00 a.m.}

Archer draws a picture and tells a story about Maggie catching a fish in the pond and cooking it for her family for dinner. He said he got the idea from the photo of Maggie (see Figures 20 and 21). I ask him if he would like me to send his story to Maggie, and he responds, "Just put it on the ofrenda."

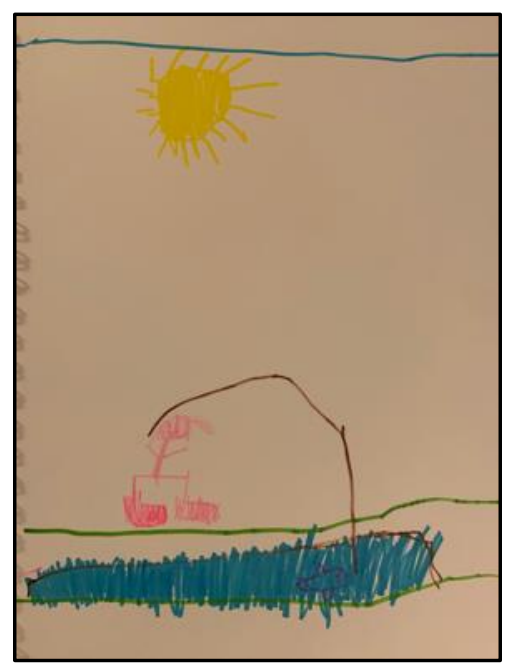

Figure 20. Archer's Maggie story. 


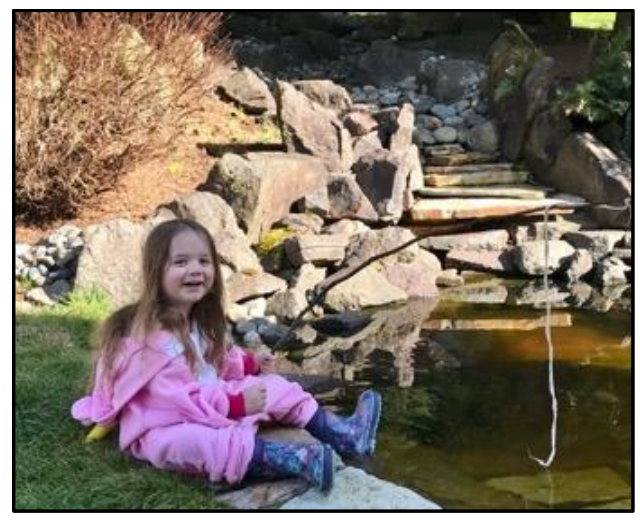

Figure 21. Maggie.

\section{0:40 a.m.}

One of the most treasured items in our classroom is a talisman I brought back from Peru in September. It contains tiny colored stones, oils, herbs, and seeds and alabaster Figures, and was made by a folk doctor from an area of the Amazon rainforest known as Ayacucho. The children refer to it, notably, as "Magic Word" (see Figure 22). Ana and Archer are using Magic Word in a storyline about finding homes for people who do not have homes; a matter of direct material concern for those of us living in Portland.

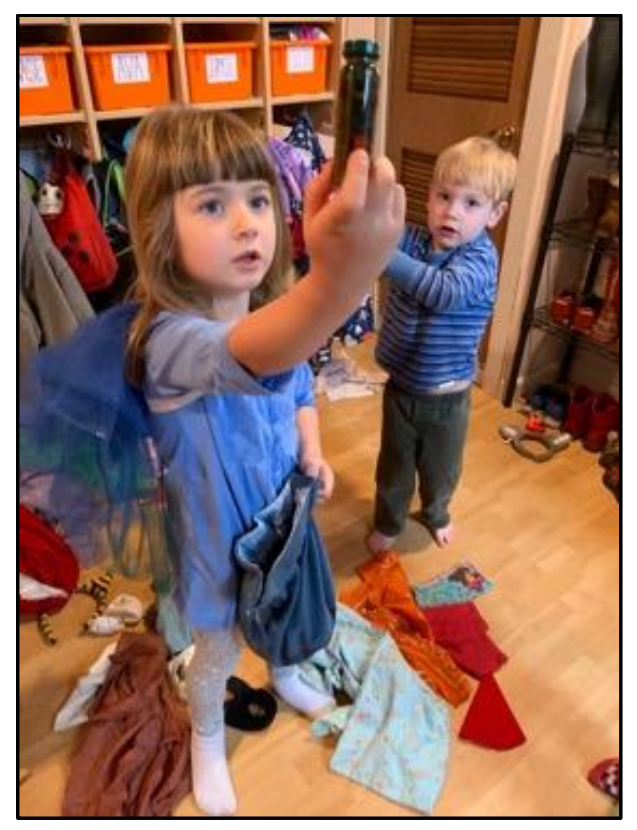

Figure 22. Magic word. 
I enter the room, and Ana explains to me the drama that is currently unfolding. With a sense of urgency she says, "A magician gave this to me to help people that were nice people that were trying to find homes. And he gave it to me so I can help them. And if Archer gets it, he could use it in a way that doesn't help them, that, that could take AWAY the homes that I gave them. So that's why I don't want him to have it." (Walking away) "So I'm going to go collect the magic."

Archer: (Makes exploding/laser sound and points at Jake) "POW! Get him!"

He pretends to attack Jake, who is the magician in this storyline. Ana puts three marble eggs inside a larger plastic egg, then puts the plastic egg inside a blue velvet sack. This is the magic that will stop Archer from stealing Magic Word. She uses it to "cast a spell" on Archer and retrieve Magic Word (see Figure 23). This narrative play eventually draws in several other children and carries over to their outside play.

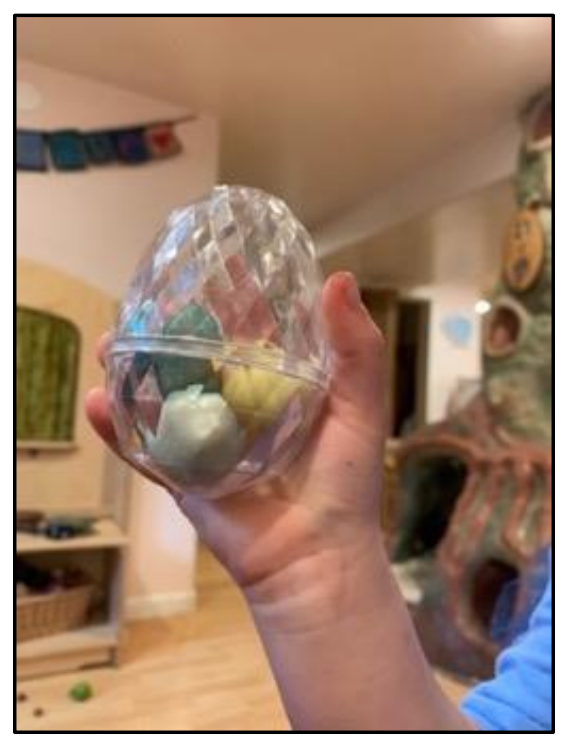

Figure 23. "To cast a spell."

April 15th, 2019

\section{9:30 a.m.}

Stella looks around the classroom, gathering eggs, jewels, a sparkly stone, and plastic leaves into her basket, saying to herself, "I'm trying to make a real spell. I am a real faerie you know. I need some other magic bits."

Jake: "I am an elf and I am your friend."

Ana: "You can live in my farmhouse."

Archer (to Ana): "Are you a witch?"

Ana: "Witches can make a good or bad magic, we don't care." 


\section{9:30 a.m.}

The children are color mixing on the light table. They refer to the mixtures as "potions" or "spells." Jake announces, "I made dark goldish."

Ana: "It worked! I made green. I had to take time to put blue in and put it in there. It took time, it's a process, you know, green is the magic color. I used my magic. I had to say the magic words, mix some of this with a little of that, and then it will go poof" (see Figures 24 and 25).

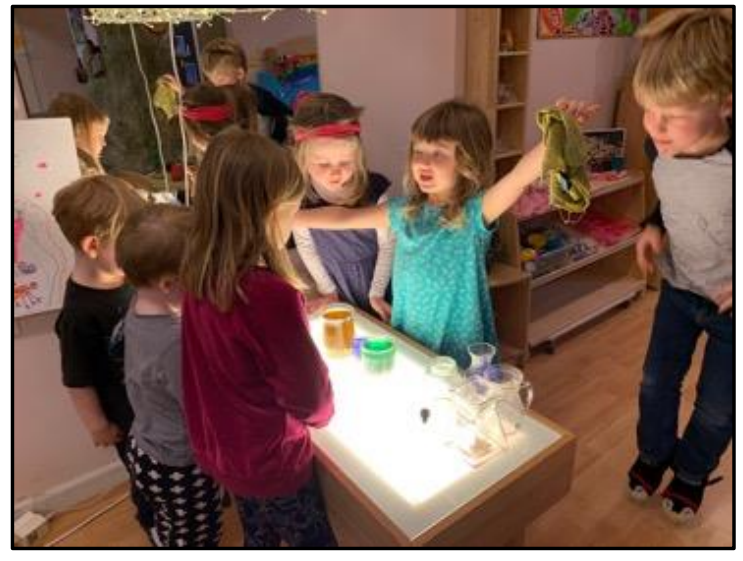

Figure 24. "It's a process."

Ana: "I just really need to make this one spell . . but the magic is not very strong. I'm going to take some very dark green and mix it in."

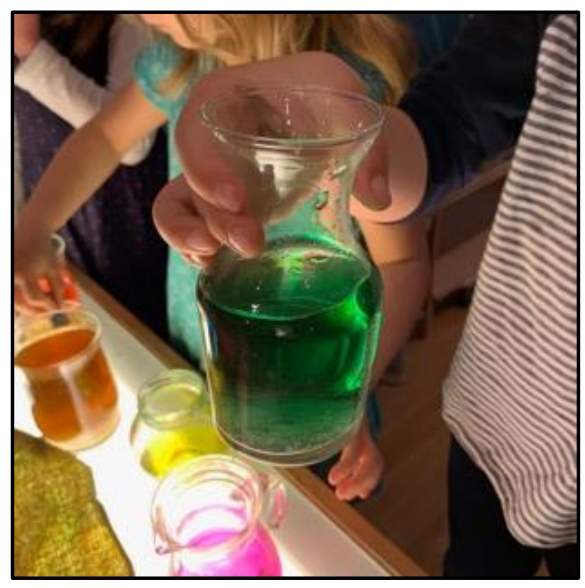

Figure 25. Green is the magic color.

Ana: "I learned this from my uncle. He was a musician. A magic person. A magician." Me: "What does a magician do?" 
Ana: "They make magic potions like us."

\section{0:40 a.m.}

Talk of "magicians" has continued throughout the morning, and Fiona and Ana decide to perform a magic show. During the performance, Ana asks the audience to close their eyes so she can make Jake disappear. When their eyes are closed Jake runs out of the room.

Archer (peeking): "They are tricking us! Magic isn't real" (see Figure 26).

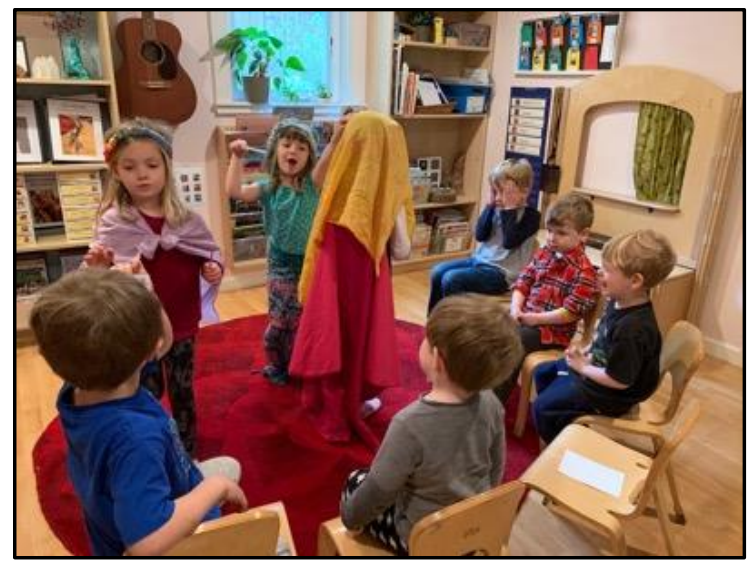

Figure 26. "Magic isn't real!"

The following free-writing gatherings segment was written on April 15th but does not pertain exclusively to the events of that particular day. In it, I consider the pedagogical significance of Christmas in my classroom community.

\section{Gatherings}

The compelling concept of elves emerged in the children's narratives in December when Christmas was a big topic of discussion. Following the school's anti-bias policy, I do not include holidays in the curriculum. At some point this year, however, I came to the realization that Christmas was a part of the home culture of every child in my class, and that the children were taking a special interest in this point of connection. So, while we did not celebrate Christmas at school, I stopped shutting down children's 
Christmas related small stories and anecdotes, much of which pertains to elves and magic.

The books at school have also contributed to the children's interest in elves. We have a book called Child of Faerie, Child of Earth (Yolen, 1997), where a child and an elf become friends and visit one another in their respective worlds. We also regularly read The Tomten (Lindgren, 1960), a book about an elflike creature who cares for farm animals. Then there is our current favorite: The Talking Eggs (San Souci, 1989). While not specifically depicting elves, features a host of other-than-human beings who live at the farmhouse with the old granny, whom the children have identified as a witch.

Reading Archer's text through The Talking Eggs (San Souci, 1989), I wonder if Archer was making a conscious connection when he asked Ana if she was a witch. The character old granny, a crone figure, does invite people to her farmhouse as Ana did, and the "good" or "bad" magic that happens for them in the story is directly related to the characters' own disposition and behavior. For example, a kindhearted child receives magic eggs that bestow her with riches, and her mean-spirited sister receives magic eggs filled with snakes, spiders, and wasps who Mason her all the way home. Ana's casual comment seems to also speak to this notion, "Witches can make a good or bad magic, we don't care."

We return to the study in the middle of week five, where a rabbit who arrives unexpectedly becomes the focus of storytelling and play.

\section{April 17th, 2019}

I read a posting on my online neighborhood forum in which a woman needed a home for a very sweet rabbit she could not care for herself; she had inherited it from her adult son. 
I went over to meet the rabbit and learn the details of the situation. As I was talking to the woman on the porch of her house, a young man emerged from the front door and handed me a cat carrier. He was fighting back tears. The rabbit was his therapy animal, and he was unable to continue care for her as he had recently lost his housing. I offered to care for her until he could secure housing. He called her "Rosie," and I agreed to do the same. Today I gave the children Rosie's history as I understand it and brought her into the classroom to get familiar with the children and the space.

\section{2:00 p.m.}

Ana wants to tell a story to Rosie to welcome her to Rowanberry. She has drawn a picture for her on a piece of paper and asks me to write the following words. "I love you Rosie. Please don't nibble on the paper this story is on. You could nibble on your food and toys. We like petting you Rosie. And by the way Rosie, those carrots we gave you-I noticed you weren't really eating them. You can eat them. They're really good, they're yummy. I have some in my lunch today."

Ana saw me writing on my iPad and asked me to write the last part with blue letters because it refers to her and the rest of the quote is about Rosie. Ana and Fiona are sitting together with Rosie. Ana says, "She nipped me. I think I saw a bit of blood on her lip." Fiona gives Rosie a carrot, and Ana tells her, "Maybe she'll drain all the juice from it. Like Bunnicula."

\section{April 18th, 2019}

Easter is in 3 days, and there has been a great deal of anecdotal stories shared among the children about the Easter Bunny and finding eggs. One of the children brought in a book called The Little Rabbit (Dunn, 1980) and we read it during class meeting (see Figure 27). Rosie, the foster rabbit, is now comfortable with us, so she is able to roam freely around the classroom during the school morning. After class meeting, the activities of the morning revolve around Rosie.

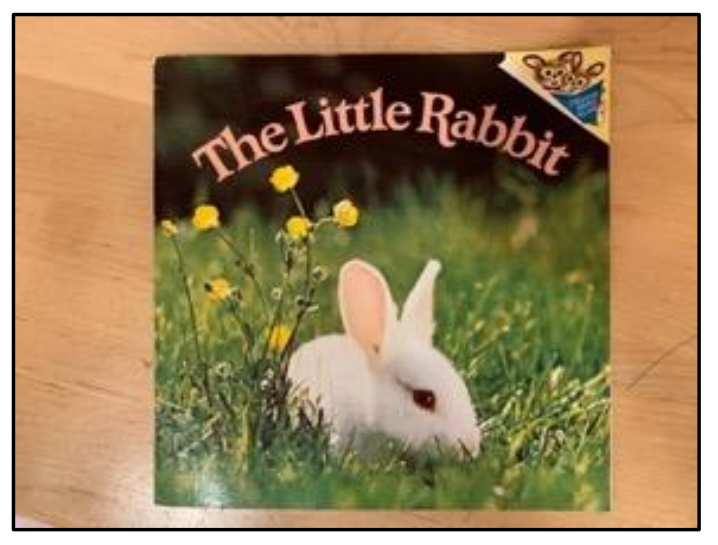

Figure 27. The little rabbit. 


\section{9:50 a.m.}

Fiona indicates that she would like to write a story for Rosie. She and Stella sit down to draw in their journals. They draw side-by-side in silence. Then Fiona narrates her story to me.

Fiona: "Once upon a time there was a bunny named Rosie. And Rosie was hopping along, and she found a guinea pig. And the guinea pig was named Jeremy. And the bunny loved the guinea pig, so they decided to marry. And two unicorns were the bride. (That's the heart for them loving each other.) The end" (see Figure 28).

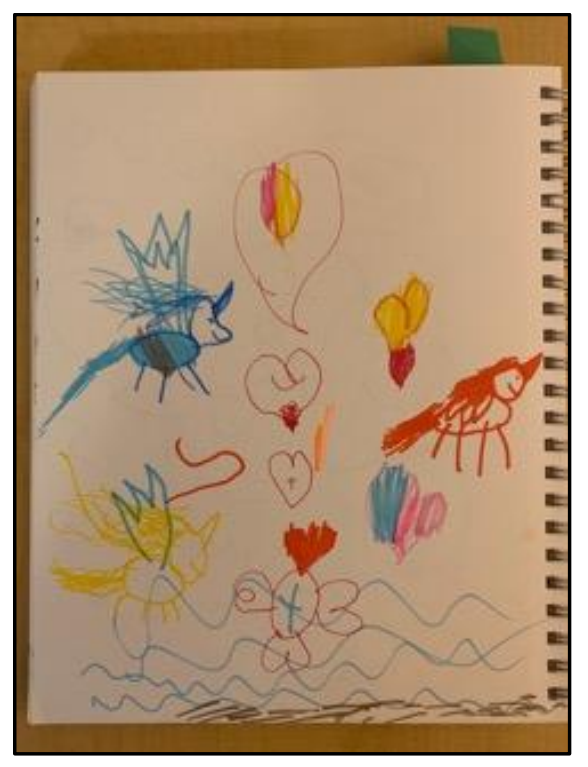

Figure 28. Rosie and Jeremy.

\section{9:55 a.m.}

Mason and Kyle are setting up a track for Rosie to follow (see Figure 29). Several other children are drawn to this activity. After a struggle for creative control, Ana and Archer decide to build another one across the room.

Kyle drapes blue fabric across the track, saying, "She has to jump over the ocean." Mason (removing the blue fabric): "No she doesn't. She can swim." He puts down a section of astroturf saying, "Here's grass, because she will like that." Kyle: "There is a carrot at the end waiting to be eaten."

Mason: "She has the climb up that, jump over that, because rabbits can jump, swim through this, then go around these. Then go up with us to get her carrot. This is the jeweled road that she goes down, then she finds her friend, and her friend points this way ...”

Kyle: "Yeah that way, to the carrot." 
Jake: "What's the friend's name?"

Mason: "Chamelea."

I do not notice it at first, but Mason has placed a tiny green lizard near the carrot on Rosie's path. The lizard is "Chamelea" (see Figure 29).

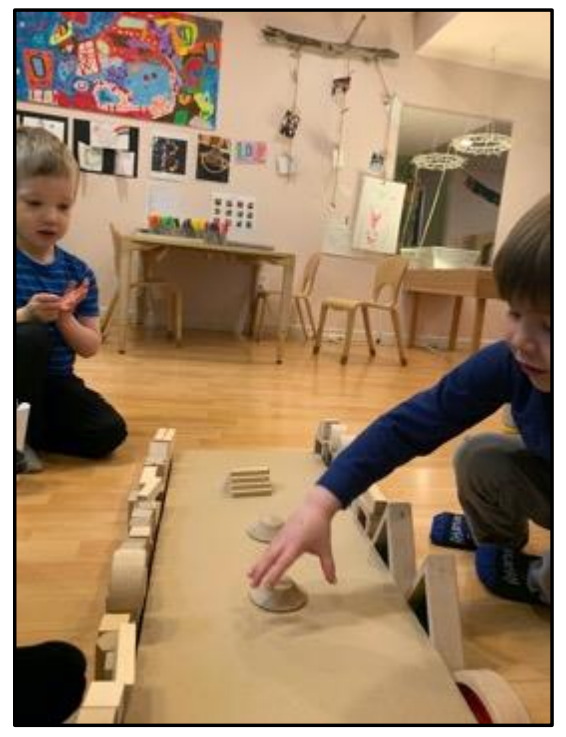

Figure 29. Building the path.

Rosie follows the path to the carrot. Halfway down the path she stops; Ana encourages everyone to sing to coax her along to the end (see Figures 30 and 31). It seems that the song and her friend Chamelea helped Rosie find her way.

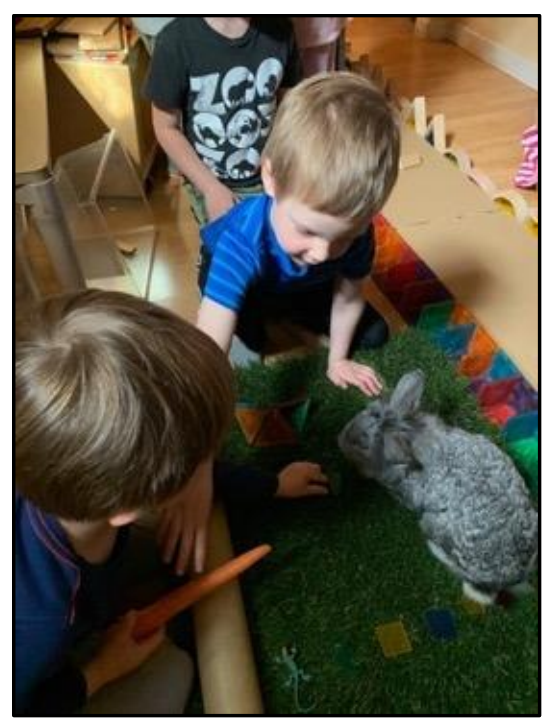

Figure 30. Chamelea. 


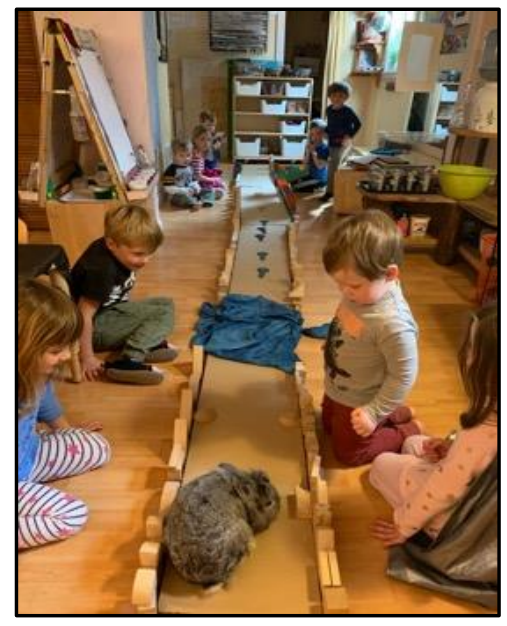

Figure 31. Rosie's path.

April 22nd, 2019

\section{9:10 a.m.}

It is the day before Easter. Ana has come to school dressed like Alice from Alice in Wonderland. She walks in late to class meeting and sits down on the rose rug to join us. "I am Alice," she says in a British accent. Jake leans over to me and whispers, "Is that really Alice?"

After class meeting, I bring Rosie into the classroom from her outdoor hutch. Ana sees the rabbit as I bring her in. "Oh! There's the white rabbit." (To Rosie) "Where's your stopwatch? Oh, you lost it. I'll make you one." She makes a stopwatch out of watercolor paper and tapes it to Rosie's "cozy spot" on the shelf, saying, (in a British accent), "There. Now you can tell the time" (see Figure 32).

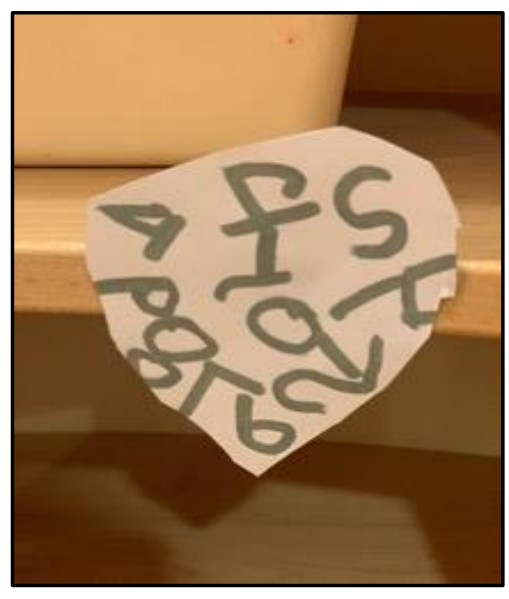

Figure 32. Stopwatch for Rosie. 
Truman drops to the ground and hops up to Ana. "I'm a bunny rabbit." She walks over to Fiona, saying, "Is this the Drink Me bottle? The lid doesn't come off, so, no" (see Figure 33).

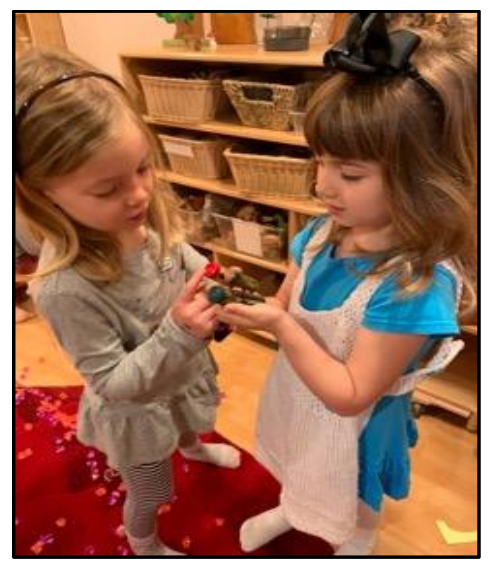

Figure 33. Drink me.

She examines several bottles with Fiona. "Not this one. The Drink Me bottle is skinnier than that." I offer her a small amber colored spray bottle that we use to mist plants. She examines it, then sprays herself with water and suddenly drops to the floor, saying, "I shrank!" Stella approaches Ana and Fiona.

Stella: "Do you guys want Rosie's magic egg? It's what Rosie used when she wanted do magic stuff without anyone seeing."

Fiona: "Yes, I was actually looking for that."

Truman: "I'm a bunny rabbit."

Ana puts a silk on Truman saying, "Now you are the white rabbit." She places rabbit ears on his head (see Figure 34).

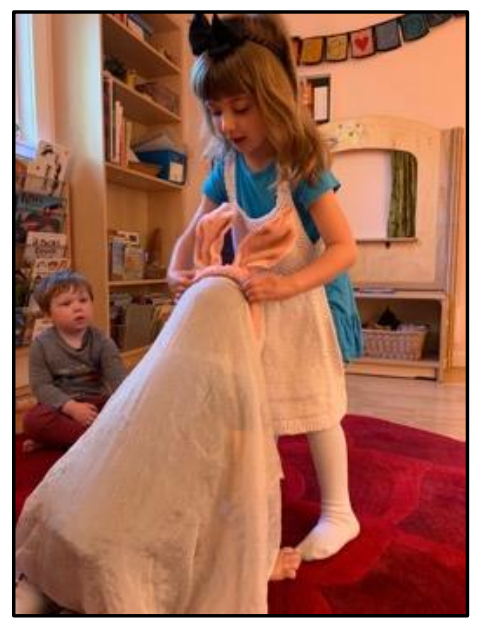

Figure 34. "Now you are the white rabbit." 
"You're late!" she exclaims, pushing him into the hollow of the cob tree. "This is the rabbit hole." Archer runs up to Ana, "shrinking" her with the spray bottle.

Ana (to Jake): "Get cookies! They make me big again."

Jake gives her pretend cookies and she pops back up, full-sized. Archer sprays her

again. She jumps up on a table and batts him away, shouting, "You're nothing but a deck of cards!"

\section{0:15 a.m.}

I am sitting on a chair in the studio observing and taking notes on the iPad. Archer walks across the room to me and declares, "Magic is not real." Mason overhears him and chimes in, "It's just a distraction." Archer adds, "It's just a distraction so people don't see the one doing the magic."

This is clearly something they have talked about before. I attempt to draw a distinction between the everyday magic that some of the children have been referring to and magic shows that are performed as entertainment for an audience. Archer seems skeptical that there is a difference between the two.

\section{1:05 a.m.}

Today we have story theater, a convention where children are invited to act out stories they have written or stories they spontaneously create. Fiona wants to act out her story about Jeremy and Rosie's wedding.

Fiona: "Ana should be Rosie, and I'll be Jeremy."

Me: "Why Ana?"

Fiona (pointing at her): "Because . . because she's Alice so . . ."

Ana: ". . . so I know about rabbits."

Fiona (smiling): "Yeah."

They giggle. I feel, as I often do, that I have asked children to put something into words that is understood between them and is somehow diminished when verbalized. Fiona asks me to read the story while they act it out (see Figure 35).

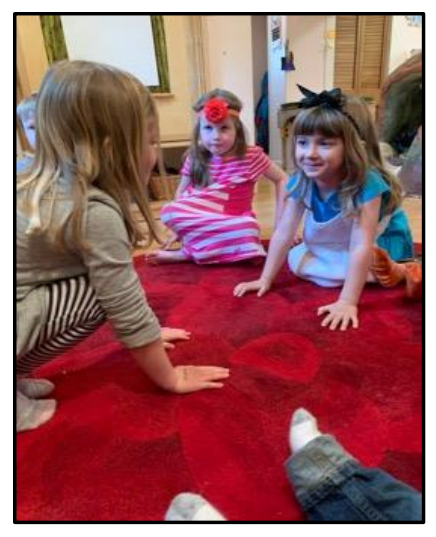

Figure 35. Jeremy and Rosie get married. 
Fiona and Ana proceed to share their nonsense stories (as inspired by The Book With No Pictures). These stories had been previously "written" by them in their journals. Ana wants me to read hers aloud, which I do, much to the amusement of the children. Fiona reads her own. The children laugh in response, because the "stories" are a series of letters, sounds, and silly words (see Figure 36).

\section{2:55 p.m.}

When it is time to put shoes on to go home, Truman rattles off a familiar phrase "I am inspired by ..." and runs across the room to take the blue iPad off its home on a hook in the studio. He is 2 and $1 / 2$, and often enjoys running through the classroom one last time just before being picked up. Truman mutters something about a video and his cousins, opening up the photo app and swiping through the camera roll. Mason gruffly informs him that his family is not on the iPad, saying "It's not for videos of your family. It's for taking pictures of things at school. It's for research" (see Figure 36). Truman grabs the iPad back from him and begins taking photos of seemingly random things in the classroom, such as the schedule of the day, while repeating "I am inspired by ..."

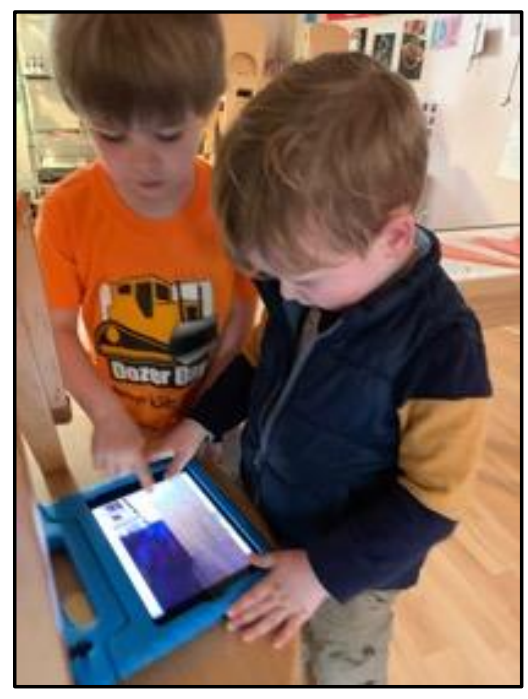

Figure 36. Truman and the iPad.

I wrote the following free-writing gatherings segment specifically in response to the events of April 22nd regarding Fiona and Ana's nonsense stories, and the encounter with Truman, Mason, and the iPad. 


\section{Gatherings}

Fiona and Ana's nonsense storytelling reminded me of an interesting trend today. The Book With No Pictures, a wildly popular book at preschool, is premised on the idea that adults MUST "read" all the words on a page if asked to. The words themselves are a series of letters and sounds and silly words strung together, and when read aloud, it sends the children into rollicking laughter. Fiona and Ana's story from today had the same basic idea...the disruption of sense. Why is this concept so interesting, remarkable, and important to children? After today's story event, I believe it has something to do with the material power of letters and words, in this case, to disrupt commonsense and provoke laughter.

The encounter between Truman, Mason, and the iPad brought me back to a moment in Kinnunen and Puroila's (2016) article, where a child participant in a Finnish photography study lamented not being able to take a picture of her sister. Her sister was very important to her but was not present at the day care center where the study was situated. This child's remark made the researchers realize that although the day care center was the intended subject of the study, the children's stories extended to include their relations beyond the school walls. Thus, the provocation to take photos of things that they found important or interesting at school was limited by the scope of the study.

I wonder what Truman is inspired by. Was he thinking about the video of his cousins before he picked up the iPad, or did the iPad remind him of the video of his cousins? Further, is this sequence of events discernable, and significant? It is also possible that Truman was simply using a phrase he has heard others say in order to gain 
access to the iPad. However, I feel that Truman was relaying something of importance to him, though it was missed by both Mason and me.

This event reminded me that this was not the first time that Truman walked around the classroom taking seemingly random photos while saying the word "inspired." Because I could not see the connections, and/or because he was not articulating them, I had taken little notice. I suspect that I missed out on dozens of narrative connections and small stories (Hohti, 2016) from Truman in the in-between places (Beckett, 2007;

Braidotti, 2002); the times and spaces that are often overlooked; where there is seemingly "almost nothing to see" (Braidotti, 2002, p. 173). I spoke with his mother after school, who told me that his cousins recently sent him a funny video that he loves to watch. She also mentioned he has often used the word "inspired" at home, and seemingly in context.

\section{April 23rd, 2019}

Ana walks into school this morning introducing herself as Sheeta from Castle in the Sky (2012). She repeats the name of the character and the film a few times because we are not familiar with it. She explains that the jewel she is wearing is magical, and that she and her mom made it at home (see Figure 37). Later in the morning the jewel emerges as a significant actor in Ana's story.

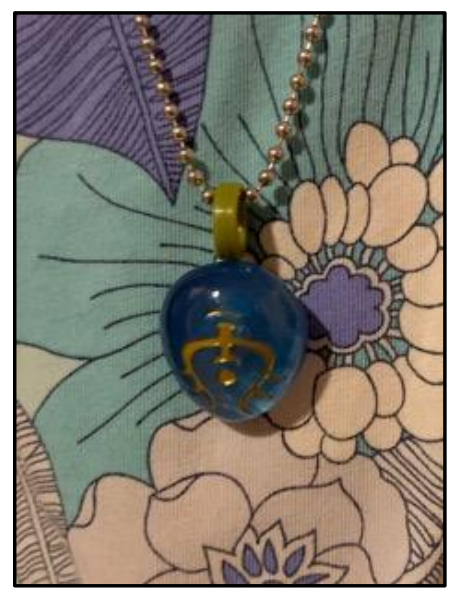

Figure 37. Sheeta's jewel. 


\section{9:05 a.m.}

I have an exciting announcement for the children this morning. I have given Louise, our broody hen, fertile eggs to sit on. She has been broody for several weeks and attempts to cure her of it have failed. If all goes well we will have baby chicks hatching in 20 days and Louise will begin caring for the chicks. The children are very excited and enlist the help of a visiting kindergartner to make a chicken chart to count down the days until hatching.

\section{0:30 a.m.}

Today is Mason's 5th birthday. As Ana painted his birthday crown he commented, "You picked the colors that were my favorite colors from when I was born...from age zero to two." Ana has used the same watercolor technique from the rainbow painting, splattering dark watercolor spots onto a lighter colored painting. The dark spots spread like stars on the paper. She responds, "Yep. I just knew it. The stars are 'KPOW!' your sparkle power." Mason smiles.

\section{0:50 a.m.}

We are eating snack and Ana begins telling a story.

Ana: "You know it starts out scary, but then it ends that everyone is A-Okay. Alright Archer? So. We're in the basement... We heard a noise. There's nothing down there. The lights were on; there was a bed. The light turned on, and then it was gone. And then we went down, we went down . . . Suddenly Archer appeared! He went, 'Hi guys!' And then . . . and it was Archer that was making the sounds! So . . but there's actually a monster in there. BUT! We defeat him, in the end. And everything is A-Okay. So. We go in the basement. At THE BOTTOM LAYER of the basement. It's really dark, but my necklace starts glowing RED. Normally it glows light blue but this time it's glowing RED. And I Figure it out . . after I Figured it out, um . . . when it's glowing red that

means something's coming TOWARD us. And it was glowing bright red, and that means something is big and coming toward us. It's true. So. I got out my necklace. I, I had to think of a power. I got a spell in my mind. Then I had to use it . . I forgot the words. So. We jumped a big jump, way up onto the ceiling of the chandelier. In the basement. And we stay there and we're very quiet. But ... the monster was coming really close. My necklace stopped glowing, because the monster turned right, and we were forward. And it started glowing blue again, just like right now . . ." Truman interjects, “. . . and the monster's like, 'Hi guys!',

Mason: "Did it actually glow red?"

Ana: "Yeah. And then we're like, 'whew.' And then ..."

Truman: ". . . and then like, "HI! HI GUYS!"

Ana: "And then we jumped down from the chandelier. But it made noise! (She gasps.) So, we ran, and we turned left. And my necklace started glowing red again. And then it 
started glowing blue, thankfully. Because the monster was going . . . (in a silly voice) BACKWARDS!" (Truman laughs loudly.)

In the following section, I use pedagogical narration as a way to draw lines between narrative events and elements occurring in weeks 4-6 and discuss some of the ways in which the more than human mattered in children's storytelling during this time.

\section{Weeks 4-6-Drawing Lines}

In weeks 4-6, children extended their narrations regarding stones, gems, and jewels. During this three-week period, the children spent many hours examining, walking with, and playing with stones from the miners' table, which came to be vibrant participants in the narrative life of the classroom community. Stella used a variety of stones to make a "real spell" in week 5, gathering eggs, jewels, a sparkly stone, plastic leaves, and other "magic bits" into a basket. Jewels also showed up in stories as allies, such in the story Ana told in week 6 where Sheeta's blue jewel glows red to warn of approaching danger.

Nonhuman animals, our rabbit Rosie in particular, had a significant role in the stories told in weeks 4-6. Children communicated directly with Rosie by talking to her, telling her stories, and singing to her. In turn, Rosie was a participant in the children's storylines. For example, she was a protagonist in Fiona's story Rosie and Jeremy from week 5 and was cast in the part of the white rabbit in Ana's Alice in Wonderland storyline in week 6. On that same day, Stella talked about a magic egg that Rosie used "when she wanted do magic stuff without anyone seeing." This story fragment, barely noticeable in-between the other, more visible storylines playing out that day, brought rabbits and eggs together for the first time. 
Weeks 7-9 bring us to the second half of this research study, which has begun to gain momentum and take on a life of its own. During this period, I begin to get a sense of the magnitude of data that is being produced and the impossibility of capturing it all. At the same time, a surprise package arrives in the mail and sets off a narrative trajectory that will play out for the remainder of the school year. We will see our first glimpses of this narrative trajectory in weeks 7-9.

Weeks 7-9. Following the same research methods in weeks 1-3 and 4-6, the data from weeks 7-9 shows the re-emergence of some narrative concepts that had temporarily slipped beneath the surface (such as elves and rainbows) and the emergence of "new" narrative threads of which the origin is uncertain. During this three-week period, nonhumans begin to take a more significant role in the narrative life of the classroom community. This is evidenced both in the children's relations with other species, and their small stories about living and dead presences in the children's arboretum. On the morning of April 29th, a package delivery presents a significant new element for the children's relations with the more-than-human.

\section{April 29th, 2019}

This morning I greet the children with a package from my friend Ragnhildur Jónsdóttir in Hafnarfjörður, Iceland. Hearing that the children had been talking about elves, she mailed us a book, a letter, and drawings and postcards from her elf garden. The book, What Does It Take To See an Elf? (Fróði, 2018), was dictated to her by an elf named Fróði (see Figure 38). The book gives hints about seeing elves and shows an illustration of an elf wrapped in a rainbow. Since both elves and rainbows have been a topic of research this year, the children are immediately enthralled. 


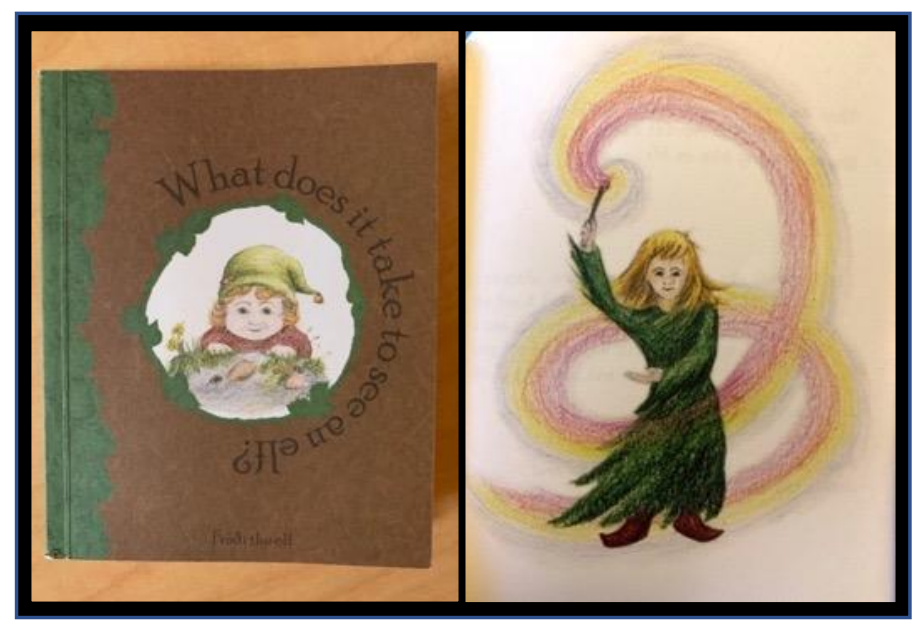

Figure 38. What does it take to see an elf?

\section{9:40 a.m.}

Stella and Fiona are drawing rainbows in their journals, chatting as they work. Fiona asks me to write down words for her story.

"Once upon a time there was an elf. And the elf was walking. And the elf saw a rainbow. And the rainbow was magic. And the gnome climbed up on top of the rainbow and the elffollowed. And the elf was on top of the rainbow, and the elf grabbed the diamond and the star at the top. The diamond and the star were magic. And the elf used them to make his dinner when he didn't have any groceries. The End" (see Figure 39).

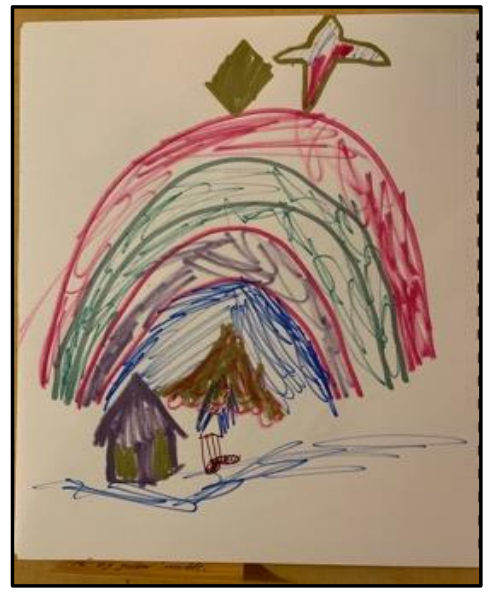

Figure 39. Fiona's elf story.

Stella: I'm drawing a rainbow because rainbows are always magic. The purple and the pink are also magic (see Figure 40). Mine is going to be just a picture not a story. She runs over to the dress up baskets to find wings. 


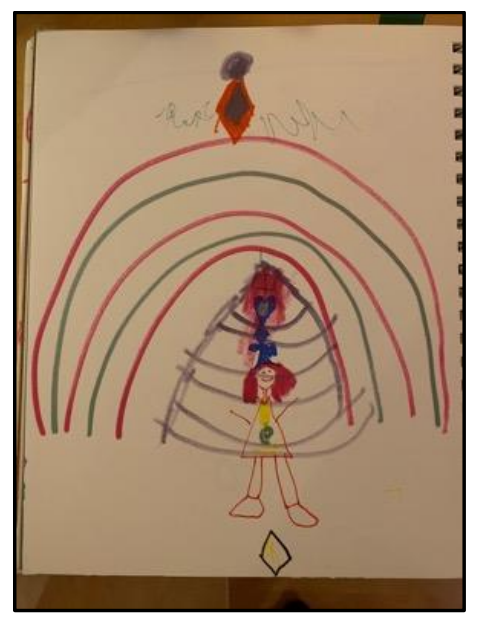

Figure 40. Stella's rainbow drawing.

Truman joins them at the table and draws a picture of his own. He says to me, "Write this. It's a lightning that dies the faerie into an egg" (see Figure 41).

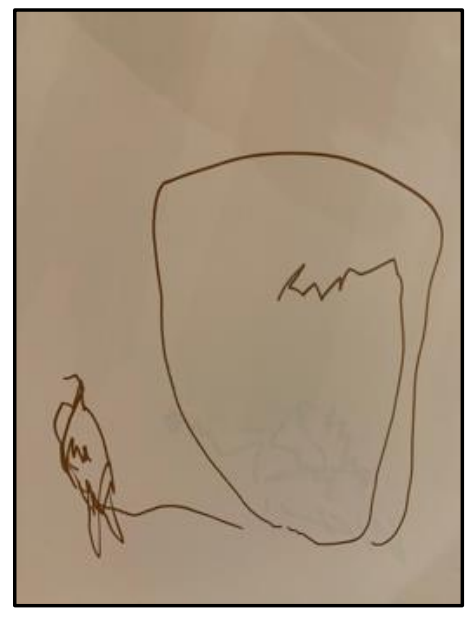

Figure 41. Truman's story.

He leaves the writing table and approaches Jake. "Do you want to build a magic faerie house with me?" Jake shakes his head no and runs to the dress up area to join Stella and Fiona. Truman builds a house with magnetiles, and says, "I need something to crack it. The lightning cracks the house and then dies the faerie. I need string to lock it tight." I find a string for him and move on to observe children in dramatic play. Stella acknowledges my presence, and gesturing to Jake, says, "I found a dragonfly faerie." She turns to Fiona, saying, "Where are your wings? I am the queen faerie 
because I have the biggest wings." Touching her braided hair, she adds, "And the queen has a braid" (see Figure 42).

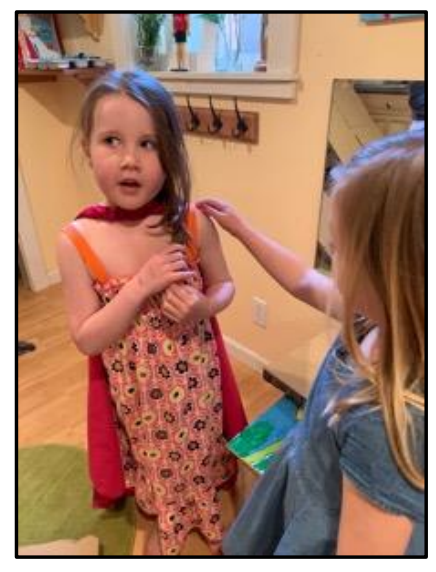

Figure 42. Queen faerie.

Fiona: "I'm the cold winter faerie. I come out and fall and winter and you come out in summer and spring."

Stella: "How about I can come out a little bit and fall and winter so we can play?"

Fiona: "And I can come out a little bit in spring and summer."

Truman has come in to join them. He puts on a rainbow vest saying, "I'm a rainbow faerie. I got this (referring to the rainbow vest) from the magic store" (see Figure 43).

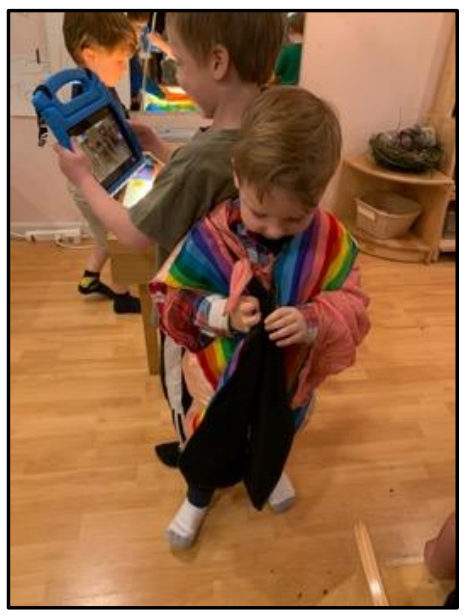

Figure 43. Rainbow faerie.

Stella (about Fiona): "Her wings remind me of fall leaves that change color, so she kind of looks like fall."

Fiona: "Yeah! And they feel ... crunchy, like leaves." 


\section{0:05 a.m.}

Mason and Kyle are playing Lost and Lonely Kittens. This game has re-emerged multiple times throughout the school year. Today, they have worked hard to make a sign that says, "Lost, Lonely Kitties." Mason solicits Fiona and Stella to take care of them. Kyle: "Faeries care for animals that are hurt..."

Mason: "Or lost."

Kyle: ". . animals that are hurt or lost or something."

After playing this for a few minutes, Stella says, "I guess we need to make a new sign, because they aren't very lost and lonely anymore." Fiona carefully adds the word "not" to the sign and reads it to Mason, Kyle, and Archer. Kyle tapes it back onto the kitten house, reading it aloud (see Figure 44). This small change to the sign seems to legitimize a new chapter in their narrative play.

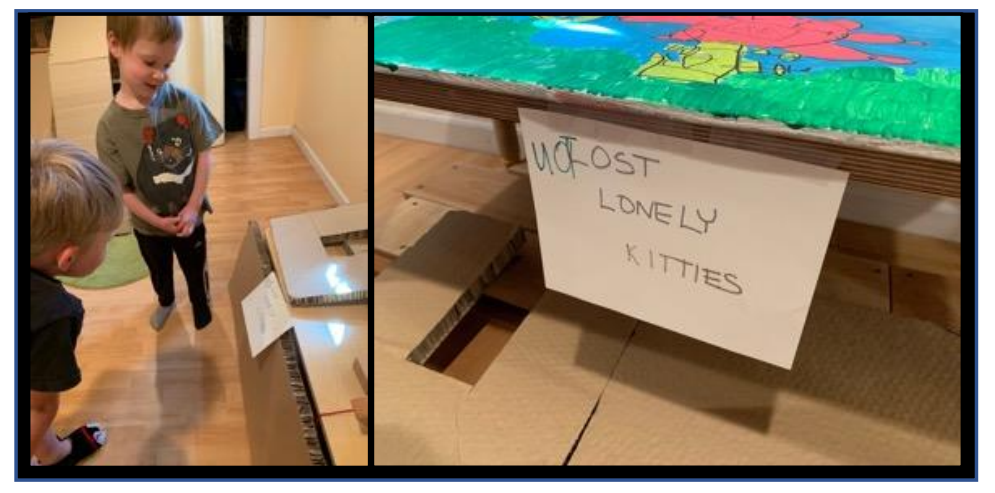

Figure 44. NOT lost.

\section{0:20 a.m.}

Stella (about Jake): "This is our puppy. He doesn't really like it when you don't listen to him, so listen to him when he talks."

Me: "Are you saying that because Jake doesn't like it when we don't listen to him? I know we have talked about that..."

Jake nods while Stella and Fiona pet his head (see Figure 45). 


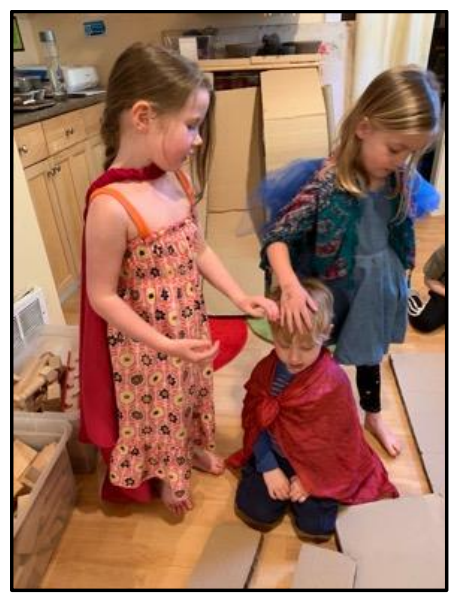

Figure 45. Faerie puppy.

Stella: "Yes. And also, because he's a puppy. When we first got him from the store he was very shy of us then he realized we were friendly. Yesterday he met our bunny and now he loves her."

Fiona: "He's not shy of us because we are faeries."

Jake whispers something in Stella's ear, and Stella says, "How Jake is talking is how you speak Spanish like a kitten.”

\section{0:40 a.m.}

Fiona pulls glass and ceramic eggs out of the velvet sack one by one. She holds up a clear glass egg and says, "This one makes things clear when you need them to be." She holds up a white ceramic egg, "This one can make snow and ice," and a marbled clear egg, "This egg can make tornadoes" (see Figure 46).

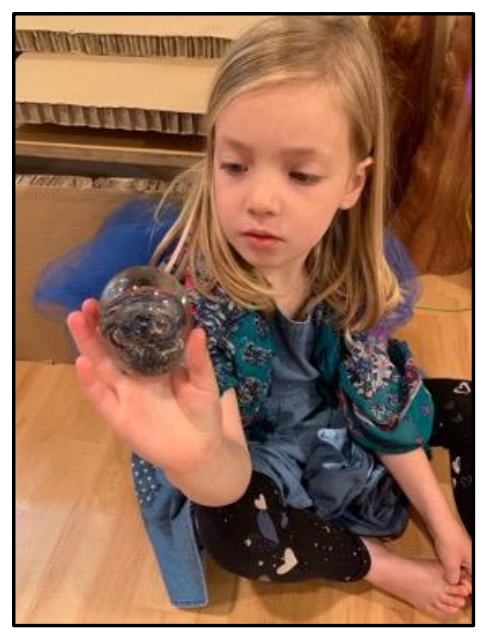

Figure 46. "This egg can make tornadoes." 


\section{0:45 a.m.}

I am with a small group of children in the studio when I overhear an emotional debate from the other room about whether or not people can see faeries. I sit on the carpet near the arguing children to observe.

Stella says to Fiona, "Real faeries live in my garden and I'm the only one in her family who can see them." Fiona begins crying and responds, "People can't really see faeries." Mason agrees with her. "They can't."

I quietly ask Fiona, "Are you feeling upset that Stella said she saw a faerie?"

Fiona: (Still crying) "YES. Because she didn't. People can't see faeries."

Stella: "Yes they can, and I really can. I went to a special place that no one else can go to and I saw faeries there. I'll tell you this ... when you see grass and flowers blow and wobble but there's no wind then you know there are faeries near." The two walk away together. It seems they walked away to continue their discussion alone.

It is no accident that this discussion is happening the same day we read the elf book about huldufólk (hidden people) from Ragnhildur and Fróði. There are many similarities between Stella's small stories and the book, What Does It Take to See an Elf? (Fróði, 2018).

\section{1:05 a.m.}

Fiona and Stella have set aside their dispute and are sitting on the rose rug looking at Flower Faeries of the Spring (see Figure 47). Fiona says, "I can't be a winter faerie because it's sunny and warm outside. If I go out there I would melt and not get my powers back till fall when I turn into a faerie again. When it's spring I am this faerie and when it's summer I'm this faerie" (pointing to pages in the book).

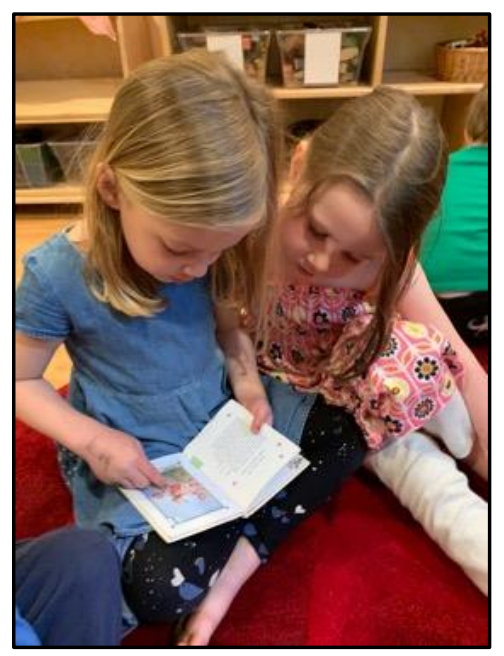

Figure 47. Flower Faeries of the Spring. 
Archer says something inaudible to Fiona. She responds, "A spring faerie would just freeze in the winter. Her powers wouldn't come back until the spring."

This idea is connected to several favorite books at school, such as The Story of Jack Frost and The Snow Child where a magical winter being melts or disappears when the weather begins to warm and returns the following winter.

\section{1:40 a.m.}

We are outside in the play yard. Stella's small story from this morning has found its way to the children's outdoor play.

Fiona: "I can feel the wind even though there's really no wind."

Archer: "We know what that means ..."

Stella (pointing to the bushes): "Fiona, I saw a faerie! Because the trees are blowing but I can't feel the wind." She runs away.

Fiona: (Chasing after her, angrily) "No!"

Mason and Kyle have brought all the classroom eggs into the treehouse to continue narrative play that they started inside this morning. While they seem very invested in this storyline, they are not willing to discuss it with me.

The following pedagogical narrative segment was written on April 29 th and consists of free-writing gatherings regarding a particular child in the study and her narrative approach.

\section{Gatherings}

I have noticed that Stella often says "real" when she talks about faeries. ("I'm making a real spell. I'm a real faerie you know.') It seems important to her to be clear that she is not referring to faeries one might see in a cartoon or toy store. She may also be asserting her belief in faeries, with the knowledge that some adults and children consider them to be pretend. She also describes magic as something one could use to "make an actual ice castle that you could go into." Further, she tends to narrate her small stories anecdotally and without any sense of pretense, as if they actually happened to her. This includes stories with faeries, elves, and talking animals. I was reminded about this 
tendency in her narrations by the small story she shared with Fiona today: "Real fairies live in my garden and I'm the only one in her family who can see them." Nonhumans and materials are key to Stella's speculative fabulations because she is suggesting that the world is alive with animals that can talk, faeries that are real, and magic eggs that help Rosie to "do magic stuff without anyone seeing."

Following established conventions in literacy curriculum, stories are categorized as either "fiction" or "nonfiction." Stella's tales resist these categories, falling somewhere in-between and yet altogether outside of them. Her approach to storytelling brings to mind what Haraway (2016a, 2016b) and Stengers (2011) referred to as speculative thinking. Her stories are a proposal of sorts; a way of portraying what might be; of offering a big "what if?” by way of her fabulations. Whitehead (1978) argued for the value of "untrue" propositions by saying that propositions are "lures for feeling" (p. 25), and thus, it is more important for a proposition to be interesting than true. Perhaps the truth or untruth of Stella's stories is a false distinction, and rather, her stories propose a vision of the world in which such things are possible.

Next, we return to the classroom, where children continue to illustrate the various ways that matter matters to them in terms of their narrative world.

\section{April 30th, 2019}

\section{9:55 a.m.}

Truman has asked me to help him tie a silk scarf around his neck. The fabric hangs down in front of him and he slowly dances around, watching it move (see Figure 48) saying: "I'm a princess! See!" 


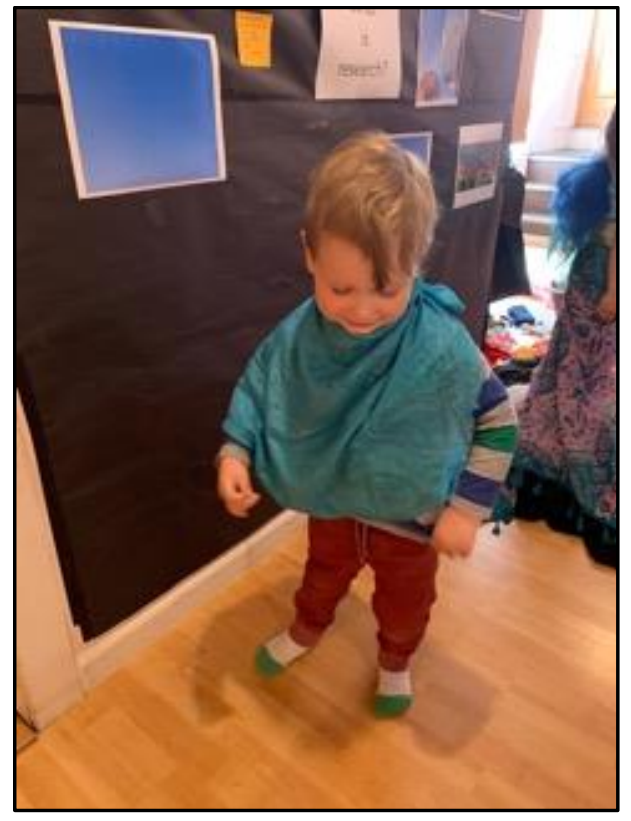

Figure 48. I am a princess!

\section{0:00 a.m.}

Today the "lost and lonely kitten" play continues. The kittens live together in a village made of cardboard. Monsters come and scare them, and they fight back (see Figure 49).

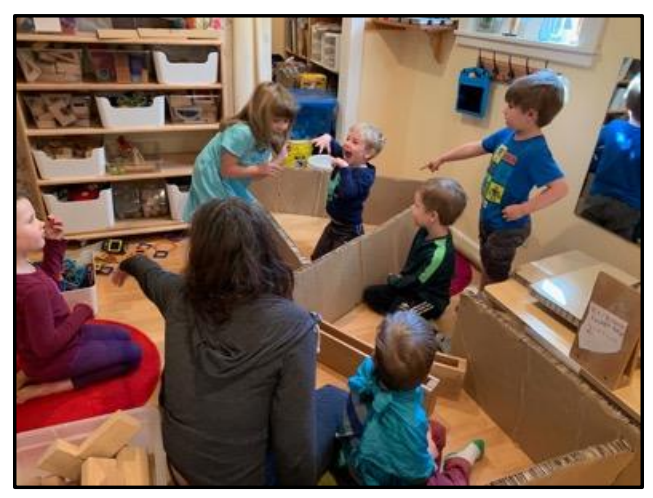

Figure 49. Kitten village.

The idea of faerie dust/pixie dust emerges in their play, and the kitten storyline stops while several children leave to make faerie/pixie dust (see Figure 50). It will protect them from monsters. They combine ground amethyst, glitter, tumbled glass, and clay dust while discussing their process with one another. The pixie dust migrates immediately back to the kitten village and is used to ward off monsters. 


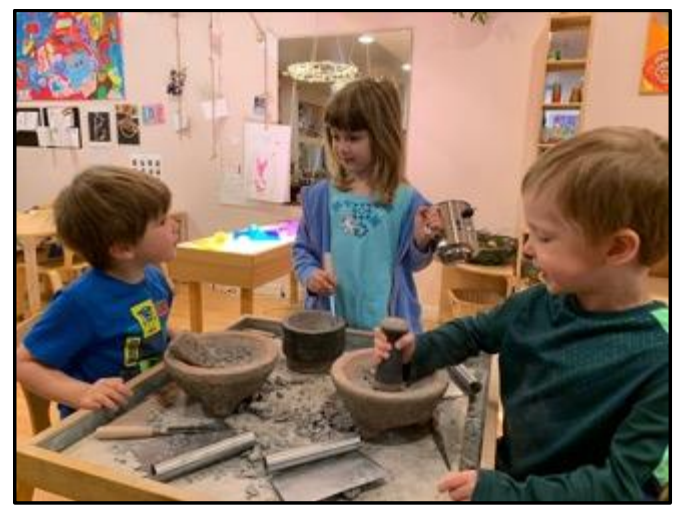

Figure 50. Pixie dust.

\section{May 2nd, 2019}

Today we are returning to the Children's Arboretum. Archer is referring to this outing as an "Elf Watch," and he has requested that we bring the book What Does it Take to See an Elf? (Fróði, 2018). He carries it with him as if it will act as a charm to bring success in his endeavor. We also have our iPads, binoculars, and sketch pads, which frequently accompany us to the arboretum, though these tools are not required or even recommended to see an elf.

\section{9:40 a.m.}

On the way to the bus stop we came to the shiny stone garden at the end of our street (see Figure 51). Taking a photo, Ana says, "I see sparkle. I think elves live here!"

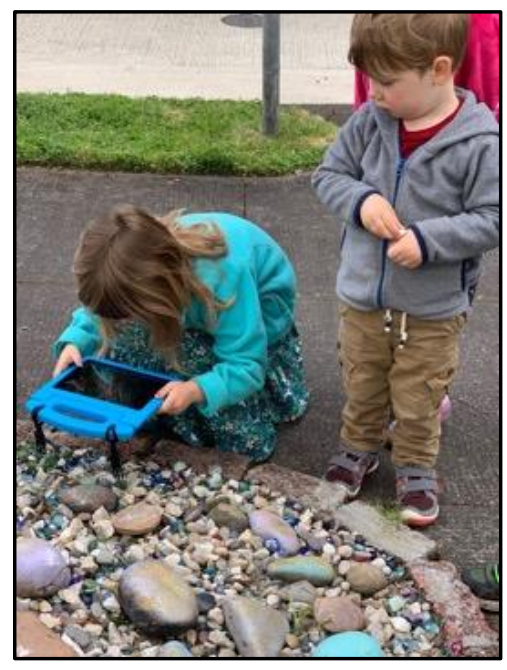

Figure 51. "I see sparkle." 


\section{0:05 a.m.}

We came upon a dead bird while walking to the arboretum and I draw the children's attention to it. We gather around the bird for a few moments.

Archer: "I think it got ran over by a car. It's flat."

Me: "There ARE lots of cars around here."

Ana: "That's really sad."

Archer: "I think it was a baby. I saw an egg."

\section{0:25 a.m.}

We have arrived at the arboretum. The tree near our gathering place is covered in white blossoms. As we draw closer, we notice colored blossoms in one spot (see Figure 52). Stella: "They are magical, they're actually growing there!"

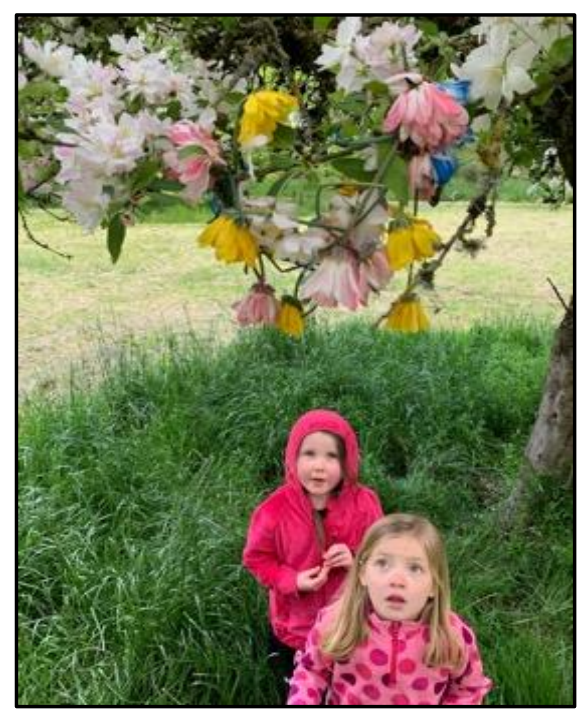

Figure 52. Colored blossoms on a white tree.

She picks a yellow flower from beneath the tree. "I am a faerie and my name is buttercup."

Fiona is holding a rose, and says, "My name is Rose." She hands Ana a white flower, saying, "You can be Lily"

\section{0:45 a.m.}

We are gathered for snack at our usual place, which we refer to as "the stone circle" (see Figure 53).

Mason: "People are buried here. It's a graveyard!"

Archer: "A graveyard." 
Mason: "It really is! Look." (Points to spray paint on the stone foundation.)

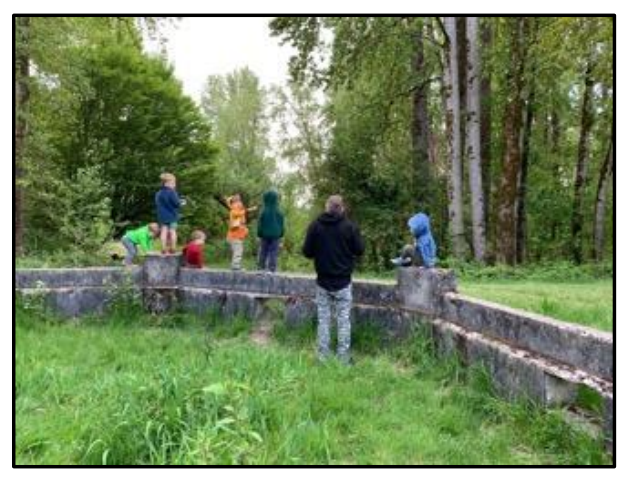

Figure 53. The stone circle.

\section{0:55 a.m.}

Kyle has called a small group over to a grove for an Elf watch.

Archer: "We have to be quiet and not move. (Hushing the others) Shhh! Listen."

There is a long moment of silence.

Ana: "I see an elf!"

Kyle: (Looking through binoculars) "I need to look closer."

Truman: "I am an elf!"

Ana: "I feel the wind."

Fiona: "I see flowers."

Archer: "I see a dead elf!"

A few minutes later he asks me to follow him to an area of stumps and vines, saying,

"There's an elf house. Right there" (see Figure 54).

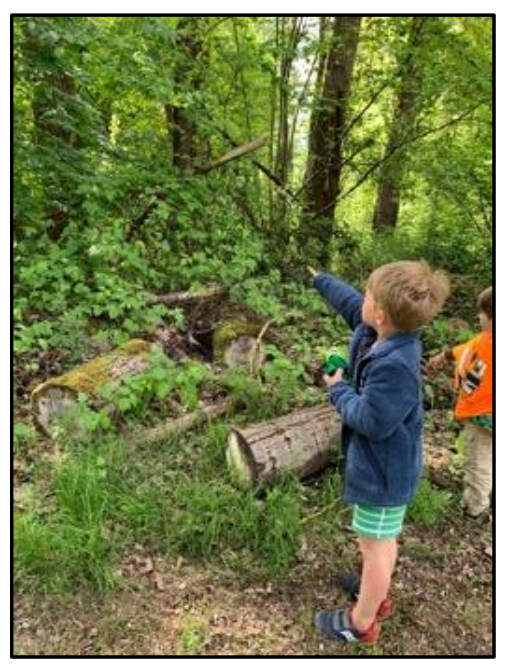

Figure 54. Archer sees an elf house. 
Mason, Jake, and Ana take photos of elf homes with the iPad. Mason goes on to experiment with the binoculars and the iPad to create a rainbow (see Figure 55). He declares, "When you see a rainbow, there's probably an elf." This idea is taken from the discussion we had after reading What Does it Take to See an Elf? (Fróði, 2018). Mason and I take a few experimental pictures using my phone and the iPad and manage to create an image of a prism (rainbow) he is pleased with. Once back at school, we print the photo and talk about it during our class discussion. Jake proposes that perhaps we did not actually see elves because the rainbow was not big enough. Mason argues that it does not matter because elves are small. Ana reminds everyone that she actually did see an elf, so it worked.

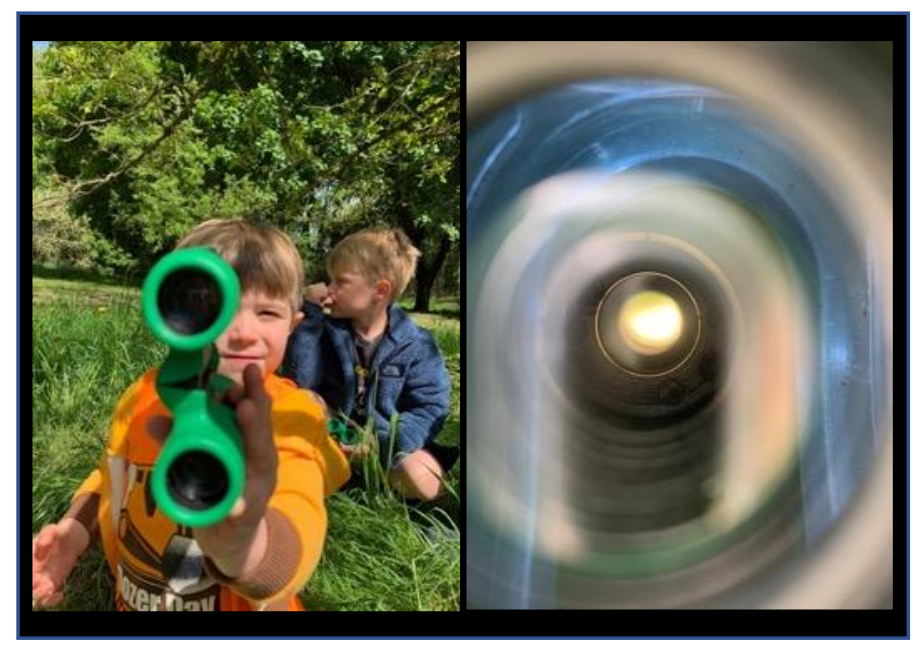

Figure 55. Rainbow making.

\section{2:05 p.m.}

We have to cross a big meadow of grass on the way back to the bus. Ana says, "I'm feeling so sleepy... I just need to rest," before collapsing on the ground (see Figure 56). 


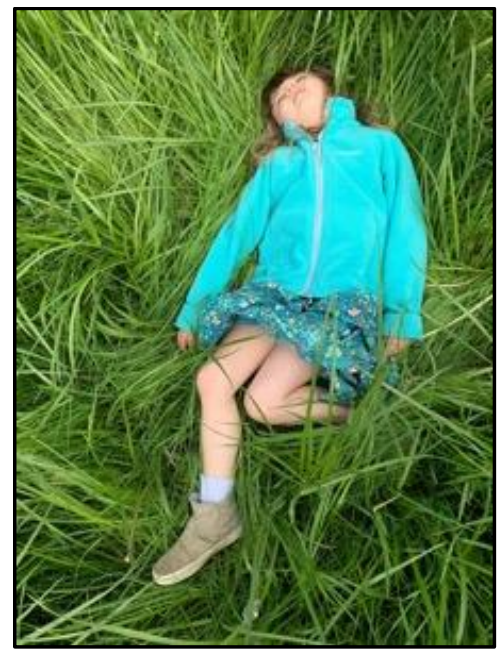

Figure 56. I'm feeling so sleep ...

Archer, Jake, and Fiona recognize this as a line from Alice in Wonderland, which we read repeatedly in the fall. They call "Wake up Alice!" and "We have to see the wizard!" while showering her with grass. She is revived (see Figure 57).

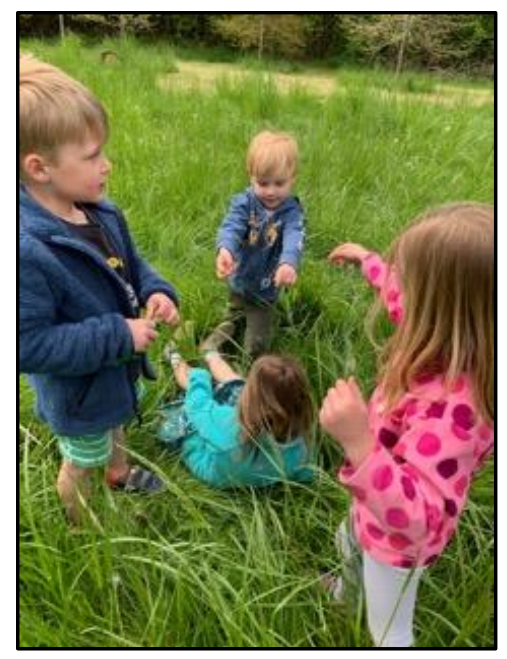

Figure 57. "Wake up Alice!"

The following free-writing gatherings consider death as a more-than-human actor who walked alongside us in the arboretum on this day; participating in the narrative culture and small stories that emerged in this context. 


\section{Gatherings}

Death was our more-than-human companion at the arboretum today. Our dead bird encounter, though brief, was a participating factor in the children's narrations and

play. For example, Archer said he saw a dead elf while we were on our elf watch. Mason suggested that people are buried at the stone circle, proclaiming, "It's a graveyard!" I thought about the ways in which this was true. There must be countless bodies, human and otherwise, that have died on this land and whose presences are part of the more-thanhuman socialities we encounter here (Tsing, 2013). I also considered how stories, whether it be stories of the dead or stories of the land itself, do not require human witnesses in order to matter. There are undoubtably stories that hang in the air before we appeared on the scene and linger behind long after we have disappeared (Harris, 2018).

Today the children's stories, proposals, and fabulations are an acknowledgement of the "absent presences" (Nxumalo, 2016b, p. 641) of the arboretum. Thinking with critical posthumanism/feminist new materialisms, I have come to regard both absences and stories as lively presences in their own right. I aim to honor the life of these presences, while also attending to commitments and connections and "irreducible relations of responsibility" (Barad, 2010, p. 265) to this land and its original stewards. Nxumalo's $(2015,2016 \mathrm{~b}, 2018)$ refiguring presences has provided a fitting methodology for continued work in this area.

May 6th carries us into the next week of the 12-week study. Throughout this section that includes weeks 7-9, death continues to walk alongside us as a vibrant 
presence in the more-than-human socialities (Tsing, 2013) of our classroom culture, and thus, of our narrative productions.

\section{May 6, 2019}

Today I offered printed photos taken by the children of elf homes on our trip to the arboretum and natural materials for construction. Jake told a story about an elf who lives at the arboretum and hides from humans when grown-ups are around (see Figure 58).

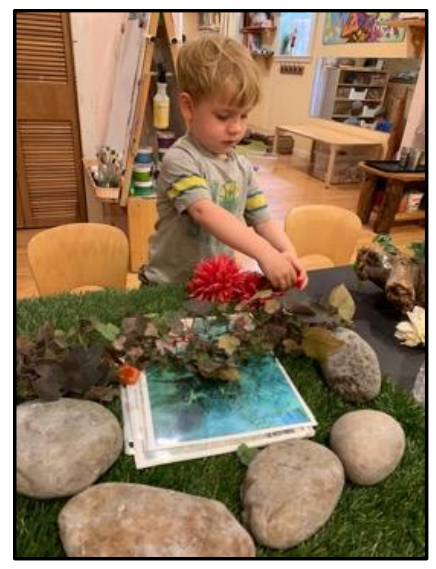

Figure 58. Jake's elf story.

\section{1:40 a.m.}

During outside time, Archer, Fiona, Stella, and Jake sit together at the very edge of the play yard, partially obscured by trees and shrubs, and discuss encounters with elves and faeries at the arboretum. Jake says something about elves hiding from adults. When I come closer to better hear their conversation it comes to a halt, so I move away (see Figure 59).

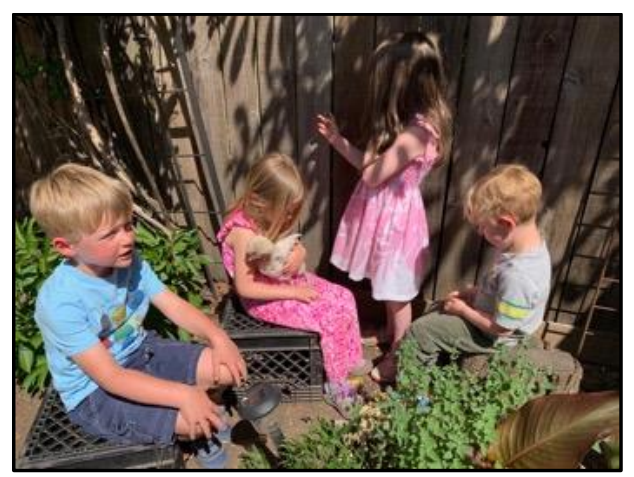

Figure 59. Hiding in the margins. 
May 7 th, 2019

\section{9:40 a.m.}

Stella announces that she is a superhero who cares for animals, such as baby lions. Jake drops on all fours and comes over to her with his head bowed playfully, showing her that he is a baby lion. She pets him. I take out the guinea pigs to hold by request from another child. Stella states that she cares for small animals like guinea pigs. She feeds Jeremy a carrot, repeating that this is what she does, this is how she cares for little animals. Jake says he is a guinea pig, then barks. He is reaching back to the kittens and puppies game they have been playing. Stella laughs, "This is a guinea pig that barks! A guinea puppy! A guinea pup!' I ask Jake if he's a guinea pup. He nods his head and barks, smiling. Eliot and Truman crawl into the room, signaling to Stella that they are animals to be cared for (see Figure 60).

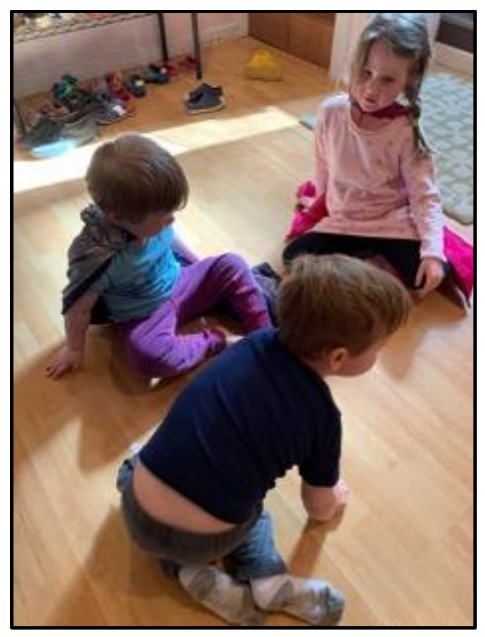

Figure 60. Guinea pup.

May $9_{\text {th, }} 2019$

\section{0:05 a.m.}

The children have been examining gems, stones, and crystals on a big tray. As they work, Ana tells a story. I missed it, coming over just as she finished. Ana: (to me) "This is the stone that the goddess La Luna took." Archer: "And it traps her in the moon" (see Figure 61). 


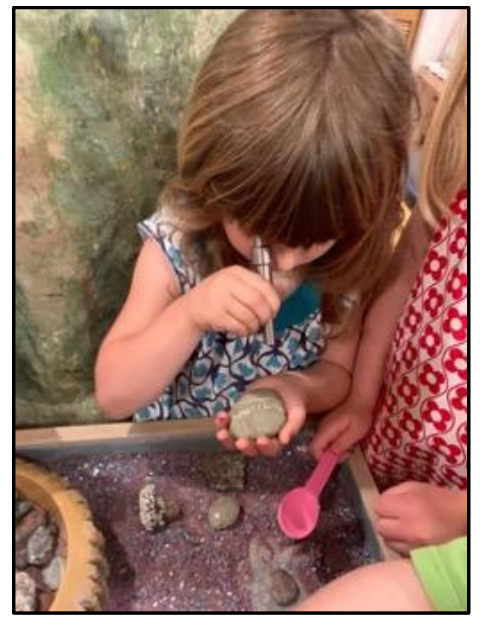

Figure 61. La Luna stone.

\section{$10: 25$}

Kyle is building a village in the studio with reuse materials I have borrowed from the creative reuse center I work for on my college campus. He observes me watching with interest.

Kyle: "This is the story. . . Ana's story . . I am making it." Me: "I haven't heard it yet."

Kyle: "Oh. A girl was walking to school, and she found some money, and she found it in a cave, and she tried it to take it, and then she leaved it there, and then she got trapped in the moon ..." (his voice trailing off)

Me: "And she got trapped in the moon ..."

Kyle: ". . for a hundred years."

Me: "And who was this person that was walking that found it?"

Kyle: "I don't know the name. And the stone is still living in our village. And if you found it, do not touch it or it will trap you in the moon for a hundred years.

Truman: "I saw it outside."

\section{1:00 a.m.}

I ask Ana about the story she told earlier. She begins: "So. Once upon a time, there was a princess named Luna. She would wear a white gown every day. And one day, she was walking to school like every other day, and where the schoolhouse should be, there was a cave . . a miner section I mean. And inside of that miner section there was a LA LUNA JEWEL. 'Cause inside the La Luna jewel, there was powers. She took it! And as soon as she took it she was TRANSFERRED into the skyyyy. And she was TRAPPED in the moon."

There are a few moments of silence. 
Me: "Trapped in the moon?"

Ana: ". . for a HUNDRED YEARS."

Me: "Kyle said that stone is somewhere in the 'Portland Village,' (reading from my notes) and that if anyone touches it ..."

Ana: "I forget about it."

Archer: ". . you would get trapped in the moon."

Ana: "Yes! (Jumping to her feet). We have to save La Luna!"

Me: "Is she in the moon right now?"

Ana: "Yeah. We have to get trapped in the moon but then use our powers to get La Luna and get out of the moon."

Fiona: "'Cause I, 'cause I have my faerie powers, and my faerie powers can make the moon vanish for long enough that we can get out with La Luna and then it comes back after we get out with La Luna.

Ana: "Yeah."

Fiona: "And then we fly down."

Ana: (To Fiona) "Did you know that I was a water spirit?"

Me: "Tell me more about that. I'm recording still."

Ana: "I was a water spirit from when I was born until now."

Fiona: "I'm still a faerie. Even when I was born I was a faerie. My name means faerie." Jake: "Even I was born a faerie. My mom said I was as small as a faerie."

\section{May 13th, 2019}

The gem, stone, and crystal table (known by the children as "the miners' table"), is a place of many stories. The children talk about the stones giving them powers or making them rich. They often refer to the gem and stone book to identify items or gather details for narrative purposes (see Figures 62 and 63).

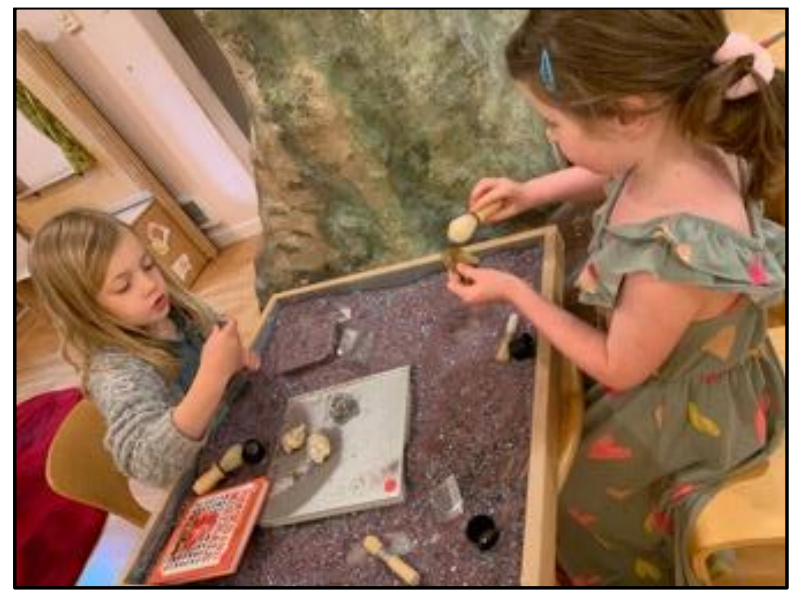

Figure 62. Stories at the Miners' table. 


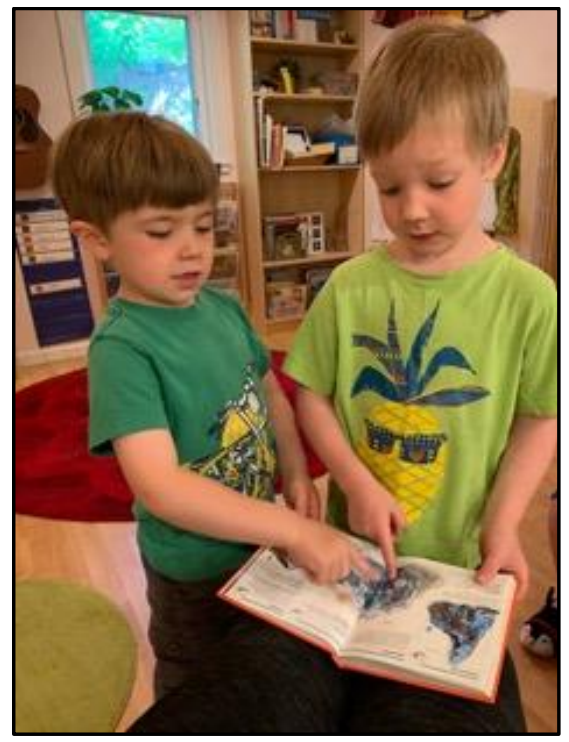

Figure 63. Gem and stone.

\section{0:05 a.m.}

Archer, a stated disbeliever of magic, is at the miners' table examining the stone that Ana has been referring to as the "La Luna stone." After some time, he offers a verdict: "This is not an ordinary stone" (see Figure 64).

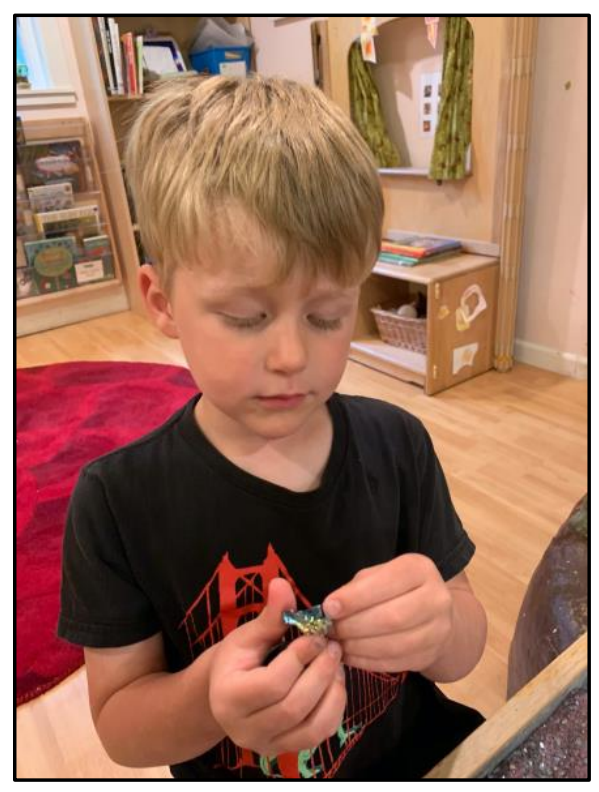

Figure 64. "This is not an ordinary stone." 


\section{0:45 a.m.}

The La Luna story has followed Ana into dramatic play. I enter the room just in time to hear her proclaim, "Touched the wrong stone! Now I must sleep for one hundred years" (see Figure 65).

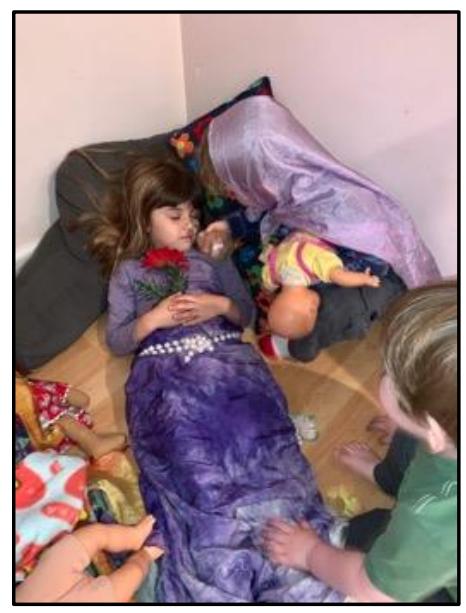

Figure 65. Sleep for one hundred years.

\section{May 15th, 2019}

Our Chicken Chart says today is hatching day. This morning we read The Talking Eggs (San Souci, 1989) at morning meeting and ventured out to the coop to check for activity. To our delight we saw a hatching egg. We only got a little peek so as not to disturb the mother hen (see Figure 66).

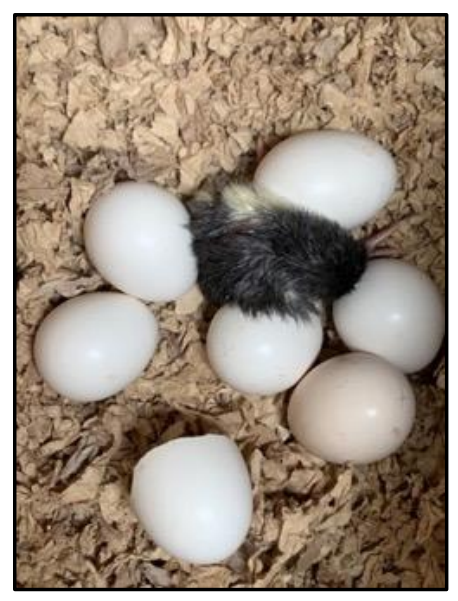

Figure 66. Hatching. 
Porcelain clay is available on canvas on the floor of the studio today. Children arrange themselves on the canvas and use the clay to make nests and eggs, creating stories as they work (see Figure 67).

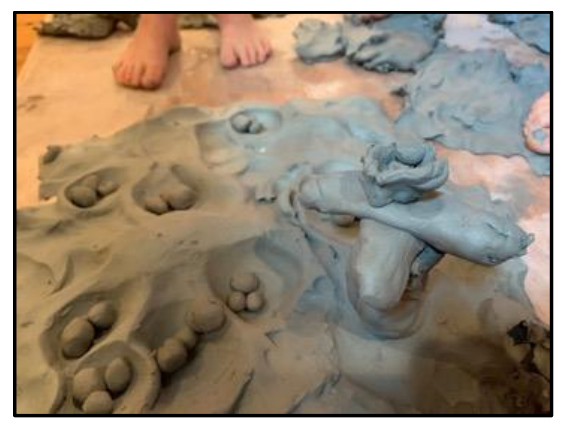

Figure 67. Clay nests.

\section{0:35 a.m.}

Ana has worn purple dress to school in an attempt to recreate a moment that I shared with her on video yesterday. We had been talking about a game she and her old friend Aidan used to play in the studio, where she pretends to fall of the clay "island" and into the water, and Aidan drags her back to dry land. She stands on the clay and pretends to lose her balance, dramatically toppling over as she did in the video. The children are first annoyed, and then angry. She is smashing the nests and eggs they are making. She starts shouting, "You're supposed to save me! You're supposed to save me!" (See Figure 68). She begins crying; frustrated that she is not able to reproduce the episode she saw in the video. I console her. She explains to me that she thought by wearing the same dress she did "that day" (in the video), the same things would happen.

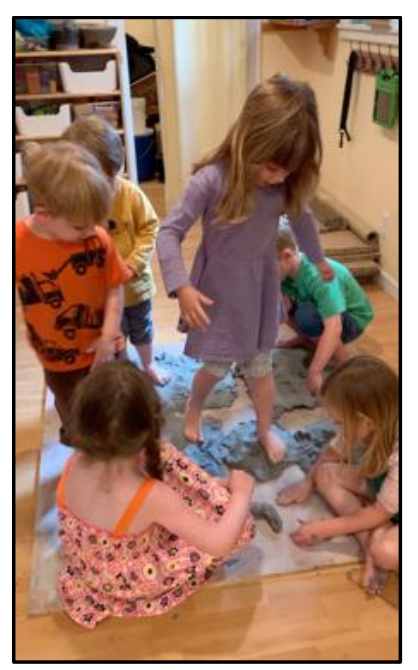

Figure 68. "You're supposed to save me!" 
May 16th, 2019

\section{9:05 a.m.}

This morning at class meeting I had the unfortunate job of telling the children that the chick that hatched yesterday had died. I told the story of checking on the chick, and leaving food and water really close for them, and then finding them in the morning, curled around an eggshell, quiet and still. Truman interrupts my story by shouting until he gets my attention. "Well, I'm a robot. . . Miss Angela! I'm a robot who saves chickens!" The children suggest we bury the chick in the backyard, and I tell them that I do not want to do that because my dogs or wild animals might dig the chick up. Ana says, "How 'bout we can make a place where we can lay the dead baby chick. Maybe we can make, a little, like ofrenda like we did for Maggie for the baby chick." We agree to this plan. A few of the children want to see the body. I remind them of the dead bird we found on the way to the arboretum, how the body was flat. I tell them that the dead chick doesn't look like that; it just looks like it's asleep. Fiona relays an anecdotal, or small story, to the group.

Fiona: "One time Violet saw a crow fall from the sky."

Me: "What did she do?"

Fiona: "I don't know."

Me: "Was the crow alive or dead?"

Fiona: "Dead. "Cause, it fell from the sky."

I read Margaret Wise Brown's The Dead Bird (Brown, M.W., 1965) to the class (see Figure 69). Mr. Danny sings the song at the end that the children in the book sing after they bury the bird.

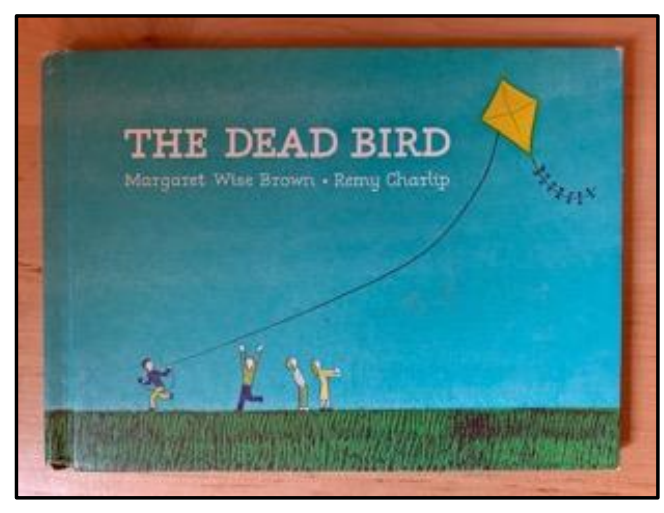

Figure 69. The Dead Bird.

Me: "Danny, That's so beautiful! It kind of reminds me of the beautiful song Truman sung yesterday about a baby chick hatching."

Kyle: "Miss Angela. Did you know dead bodies can turn into spirits?" 
Me: "Can you say more about that?"

Kyle: "They can when they get buried."

Me: "And then, is the dead body a spirit? Or is the spirit something else?"

Fiona: "The spirit is in the bones."

Archer: "What about the bird?

Fiona: "Um. The bird's spirit is . . I don't know."

Me: "I don't know either."

Jake: "Me either."

Kyle: "Me either."

Archer: "Me neither."

Fiona: "But the spirit of the bird, and the spirit of people, they go to their friends, and it reminds them about the person that died."

We revisit the idea of making an ofrenda for the baby chick. I ask Ana to remind us what an ofrenda is. She says, "An ofrenda is a place where you can put things that people, like the baby chick, loved. And I noticed that the baby chick was curled up against another egg. So maybe we should put, like, a plain egg on there. Because I think the baby chick was trying to help the egg. THAT egg."

I tell the children about the offerings for morning explore. I have brought in several new stones for what we now refer to as "the mining table." Ana points to one excitedly:

"That's the La Luna stone!" The children gather 'round for a closer look. Me: "Ah! We found it!"

Ana: "But you have to do it outside in order to get trapped in the moon."

\section{9:30 a.m.}

Several children stay behind after morning meeting to see the chick's body. They decide to put a feather and the eggshell in the box with the bird. "Things she loves," says Jake (see Figure 70). Then they set off to make offerings for the ofrenda. Several children work together to make clay nests with marble and stone eggs in them. "Flowers," Fiona says, "we need flowers" (see Figure 71). They arrange the chick's body in the middle of the ofrenda, surrounded by flowers and nests.

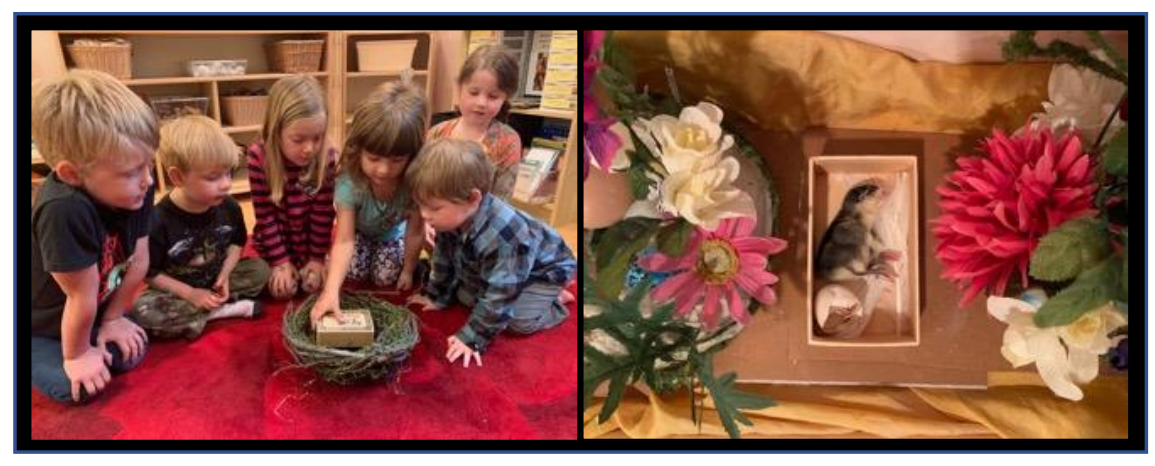

Figure 70. Offerings for the chick. 


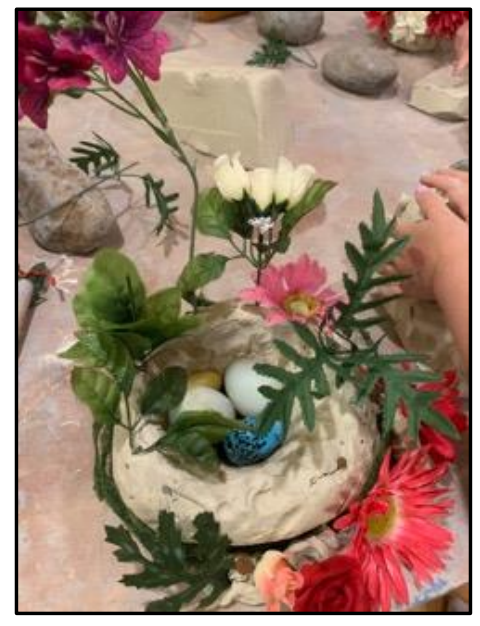

Figure 71. Nest.

\section{0:15 a.m.}

The ofrenda (which means offering in Spanish) reminded Fiona of a favorite book from this winter, Milo and the Magical Stones (Pfister, 1997). (see Figure 72).

Fiona: "Remember the mice made an offering to the island?"

Ana: "Yeah, to thank the island for giving them light."

Stella: "We should do that."

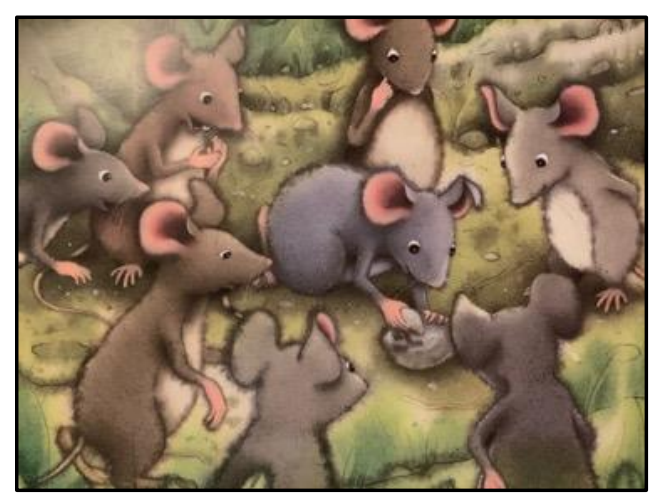

Figure 72. Milo and the magical stones.

The three children return to the table with the stones and clay and begin making an offering like the mice make in the book. They carve a sun symbol on it as Milo does when he is making his gift to the island. They rub the glitter off of sparkly ribbon to make the stone "glow." Ana says, "It's for the goddess" (see Figure 73). 


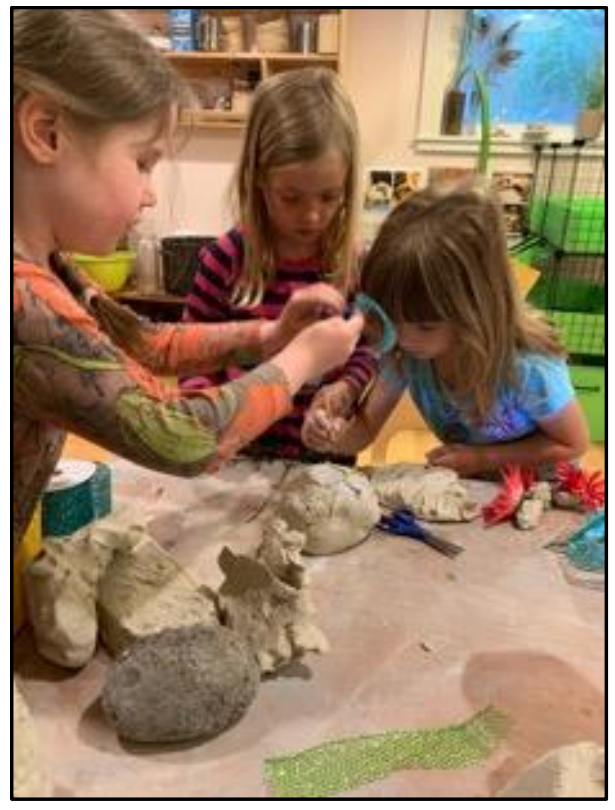

Figure 73. "It's for the goddess."

They turn down the classroom lights and begin singing as they place the stone in the hollow of the cob tree. They arrange electric votives around it, pointing out that it looks like the cave in the book. It feels very ceremonial; reminiscent of what the mice do in the book when giving thanks to the island. Jake takes the book off the shelf and brings it over to the cave, covering the opening and allowing a bit of light to peek through (see Figure 74).

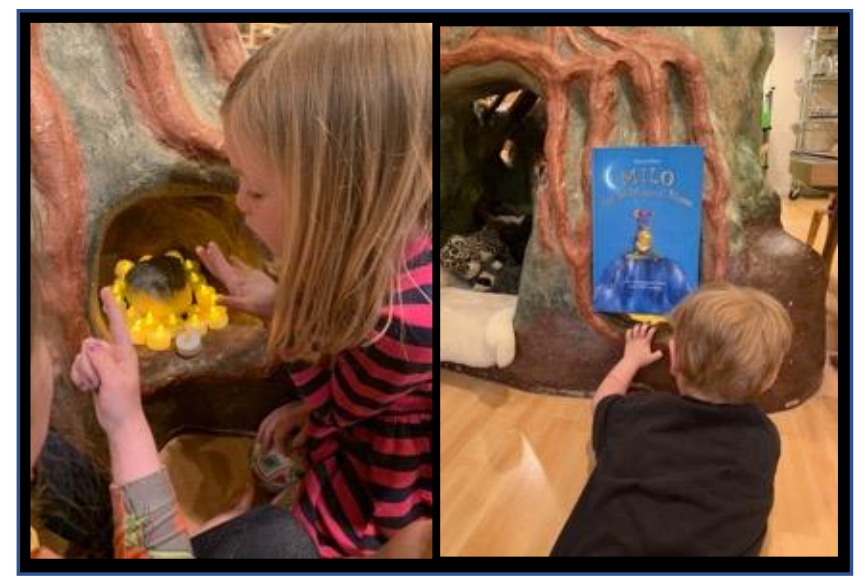

Figure 74. A gift for the island. 


\section{Gatherings}

I was struck by Ana's proposal today regarding the baby chick, which could be regarded as speculative thinking (Stengers, 2011) — a dreaming up of what is with what could be or should be. She said, "I noticed that the baby chick was curled up against another egg. So maybe we should put, like, a plain egg on there [the ofrenda]. Because I think the baby chick was trying to help the egg. THAT egg." More of a story fragment than a full story, Ana's suggestion that the baby chick was trying to help the egg was a fabulation of sorts; an extraordinary narrative proposal that was likely "more interesting than true" (Whitehead, 1978). As with Stella's speculative fabulations regarding faeries, Ana's proposal was, among other things, an invitation for us to join her in a world where such a thing is possible. Her proposal was premised on the notion that the chick loved the egg, and thus it should be included in the ofrenda. To think with this episode and my research question of how nonhumans and materials matter in children's storytelling, I surmise that the egg mattered in Ana's story because it was found with the chick's body, and thus held material significance.

In the following section, I continue my analysis of the data by drawing lines “through space and time" (Bozalek \& Zembylas, 2017, p. 120) between interconnected elements from weeks 7-9 and the previous weeks of the study, weeks 1-8. After 9 weeks of gathering stories, the entangled lines of relation between narrative episodes and elements is increasing in complexity. It sometimes feels difficult to offer these stories the justice they require due to the sheer impossibility of acknowledging all of the implicated lines of connection. 


\section{Weeks 7-9_Drawing Lines}

The surprise package from Iceland containing a book and postcards about elves generated the production of countless elf narratives during this period as children sought to make meaning of the concept of elves for themselves. In doing so, they produced narratives about elves that were specific to their ongoing storylines, such as elves having access to magic objects that have the power to rescue one from poverty. This is exemplified in the story Fiona told during week 7: "And the elf was on top of the rainbow, and the elf grabbed the diamond and the star at the top. The diamond and the star were magic. And the elf used them to make his dinner when he didn't have any groceries."

There is another line to be drawn between Fiona's story and a favorite classroom book during this period, The Elves and the Shoemaker, in which elves intervene to save a shoemaker and his wife from poverty by making exquisite shoes in the middle of the night for them to sell. I cannot determine if this connection was a conscious one for Fiona in the production of her story, but there are strong "implicated relationalities" (Nxumalo, 2016a, p. 50) between the two stories.

Reaching back to the Magic Word storyline from week 4, Archer, Ana, and Jake illustrated the potential of magic to be used for either good or bad. Ana's character uses Magic Word, given to her by a magician, to provide homes for people who need them, and Archer's character steals Magic Word with the intention of taking the homes away. Ana made another reference to the dual potential of magic in a statement she made during week 5, "Witches can make good or bad magic, we don't care." The capability of magic 
to do bad re-emerged during week 8 in the form of the La Luna jewel that trapped La Luna in the sky for one hundred years.

Death also continued as a more-than-human presence in our classroom community during this period. After encountering a dead bird on our way to the arboretum in week 7 , the children shared narrative fragments involving death while at the arboretum, (“I see a dead elf”, and, "People are buried here. It's a graveyard!”). The death of the baby chick generated further dialogue among the children about spirits, such as Kyle's proposition that "dead bodies can turn into spirits" and Fiona's comment that "The spirit [of the bird] is in the bones." Drawing a line back to week one where Truman was resurrected from the dead by necklaces, and week 7 where Truman drew a picture of "lightning that died a faerie into an egg," we see that death has been a presence throughout the study. In weeks 10-12, however, death will emerge more clearly as a more-than-human narrative force.

As mentioned in Chapter 3, I planned to attend to narrative silences in this study (Gubrium \& Holstein, 1998), where children refuse to share their story or discuss their thinking, or to tell any story at all. This "off the map" data does indicate something, even while seeming to tell us nothing. In weeks 7-9, narrative silences presented themselves two times during outside play; once in week 7 when Kyle and Mason did not want to share the details of their narrative play in the treehouse, and again in week 8 when a group of children stopped their discussion about elves when they saw me approaching. Our outside play typically is an in-between time when children can talk and play without a high level of observation by adults. I presume that the narrative silences were prompted 
by discussions and experiences that for whatever reason children did not want to offer up for closer examination. These narrative silences can serve as a reminder that sometimes children willingly dwell in the margins of the school day because it is important for them to be able to have discussions that are beyond adult scrutiny.

The following section introduces weeks 10-12, the final weeks of the study. By this time, two recurring stories in the study have become vital more-than-human presences for this classroom community.

Weeks 10-12. In weeks 10-12, we are all carrying a growing awareness that the end of the school year is approaching, and many children will be going off to kindergarten. This especially lively time produced both a culmination and a breaking open of the stories that have emerged throughout the study. In week twelve, we encounter our third and final dead bird of the study. A lifelong devotee of fairy tales, where important things often come in threes, the final dead bird encounter served as a material sign for me that the year and the study were coming to a close.

\section{May 20th, 2019}

\section{9:05 a.m.}

This morning at class meeting I tell the children that another chick hatched and survived, and it is likely to be the only one. I let them know that I read about raising an only chick and discovered that they will frequently peep to call out for other chicks. I learned that it is helpful to put a mirror in the coop, so they do not feel alone. The children have connections about what it means to be the only child in the family. A few children say they have a beta fish, or a dog or cat, so they are not the only child, just the only human child in their family. I bring in the chick for the children to meet. Kyle says, "Miss Angela, I was reading a book about chicks, and if you hold them, they might think you are their brother or sister." We exchange a smile.

The children have decided that since this is the only chick out of 10 eggs that survived, (even after I dropped the egg!) it must be a magic chick. As I am holding the chick and 
talking to the children, the chick climbs up my sleeve. For a moment I cannot find her. Kyle dramatically says, "The magical disappearing chick!" Other children laugh and repeat the phrase. This is a story the children would tell and retell well into the next school year.

\section{9:40 a.m.}

Today is our chance to finish making what the children are calling spells. They have been working for weeks to create custom concoctions for themselves to wear in a pouch around their neck.

Jake is at the light table choosing stones for his spell. He holds one up to his ear and says, "This one is saying, Take me! Take me!"

Me: "Oh! Like the talking eggs."

Jake: "Yeah. And this one is saying, Don't take me! Don't take me!"

Ana: "One of these is definitely calling to me it's like 'Take me! Take me!'” (see Figure 75).

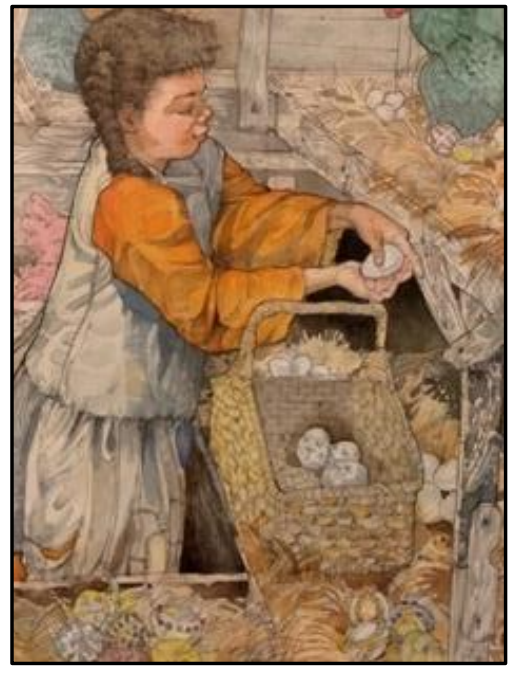

Figure 75. The talking eggs.

Ana is choosing meteorite fragments for her spell. She picks one up and is about to put it in her vial and then says, "Nope. This one said, 'Don't take me." She holds her hand over my hand and filled with tiny gems. When her hand jumps a little bit from the energy of the stone she knows she has found the stone that's meant for her. Archer is watching and uses the same technique when choosing his stones (see Figure 76). 


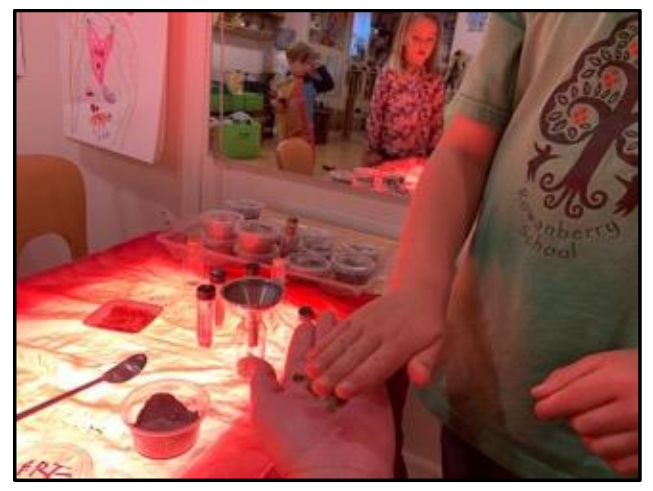

Figure 76. Choosing stones.

Kyle is holding the stones up to his ear one by one, and either choosing them or putting them back based on if it says 'Take me' or not. I ask him, "How do you know it's saying, 'Take me'?"

Kyle: "It says it! It has a voice" (see Figure 77). I say, "It sounds like the stone is choosing you!" and he laughs, "I guess we choose each other."

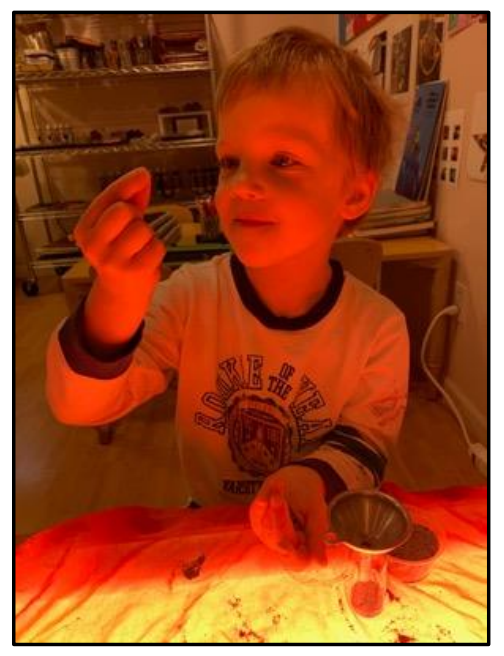

Figure 77. "I guess we choose each other."

\section{1:05 a.m.}

Mason has been drawing in his journal and wants me to help "write his words." He dictates, "Once upon a time there was a big tornado and it spinned every bit about over and over and over and over and over . . and OVER." He spins in circles as he tells me the words.

Kyle has written an almost identical story to Mason's tornado story. He starts to tell the story: "A big tornado spun everything around over and over . . " Ana notices Rosie 
hopping in circles. She says, "Rose is reading the story! Rosie can read" We all laugh (see Figure 78). Later, when updating our Thinking Wall, Ana classifies this photo as "Animal Magic."

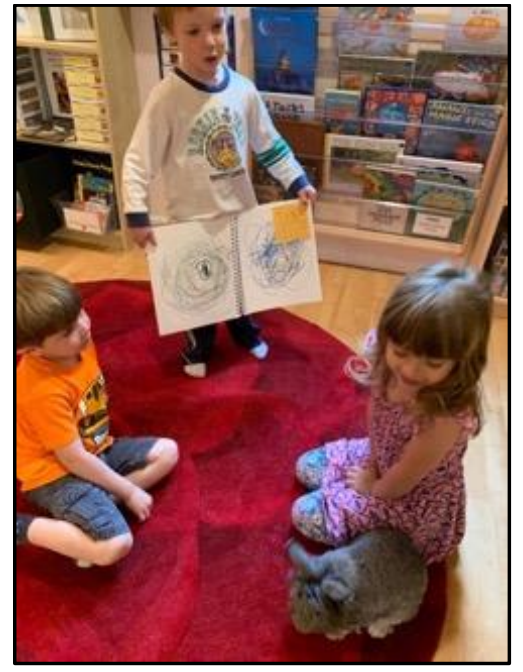

Figure 78. Rosie reads.

\section{May 21st, 2019}

\section{9:10 a.m.}

This morning we pass around the baby chick again. We are calling her Tina. Kyle: "I can feel her spirit."

Me: "How did you feel her spirit?"

Kyle: "From her legs."

Mason: "It was warm to me. Warm" (see Figure 79).

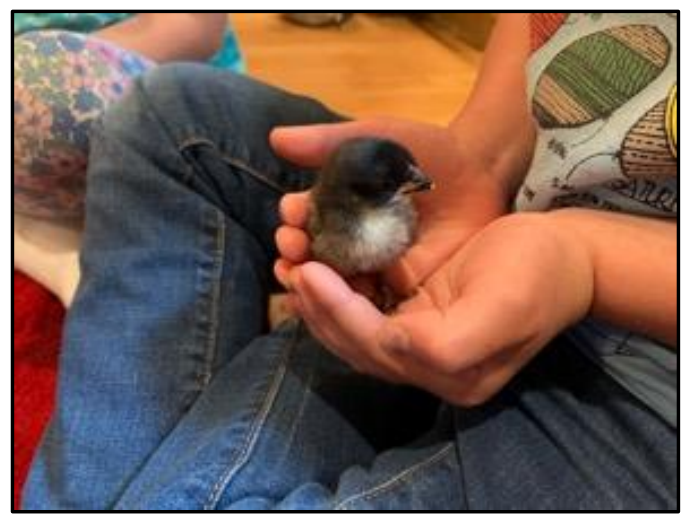

Figure 79. "I can feel her spirit." 
Truman looks in the mirror that we put in the middle of the rose rug for the chick. "I'm a chick! I am a baby chick" (see Figure 80). I find this interesting because Truman is an only child, and we had just discussed the concept of only children and the theory that looking in the mirror can make chicks feel less lonely.

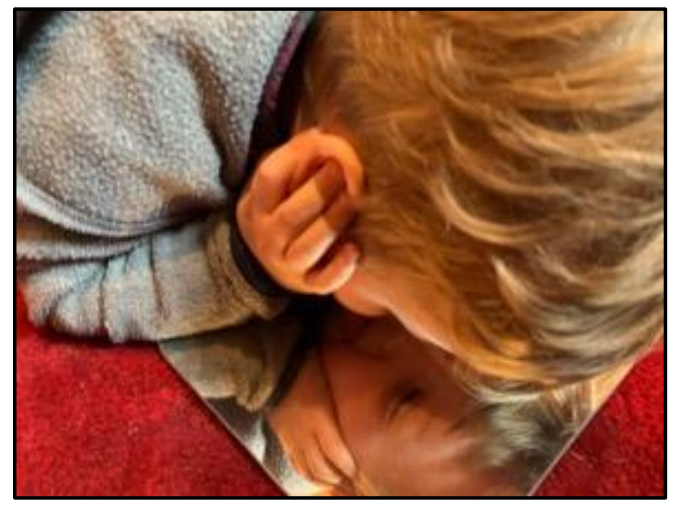

Figure 80. "I am a baby chick."

\section{0:10 a.m.}

Archer and Ana are playing together at the light table, where I have offered a provocation inspired by the book Child of Faerie, Child of Earth (Yolen, 1997). In the book, the Child of Earth works on a farm caring for animals, and the Child of Faerie lives in the spirit world and they become friends and visit each other in their respective realms. The Child of Earth gives an egg as a gift to the Faerie child, and the Faerie child pulls a feather from the egg to give to her as a gift in return.

Archer, (laughing): "You're on that side like her, and I'm on this side like him." Ana: "We are friends just like them, you know. Friends in both worlds" (see Figure 81).

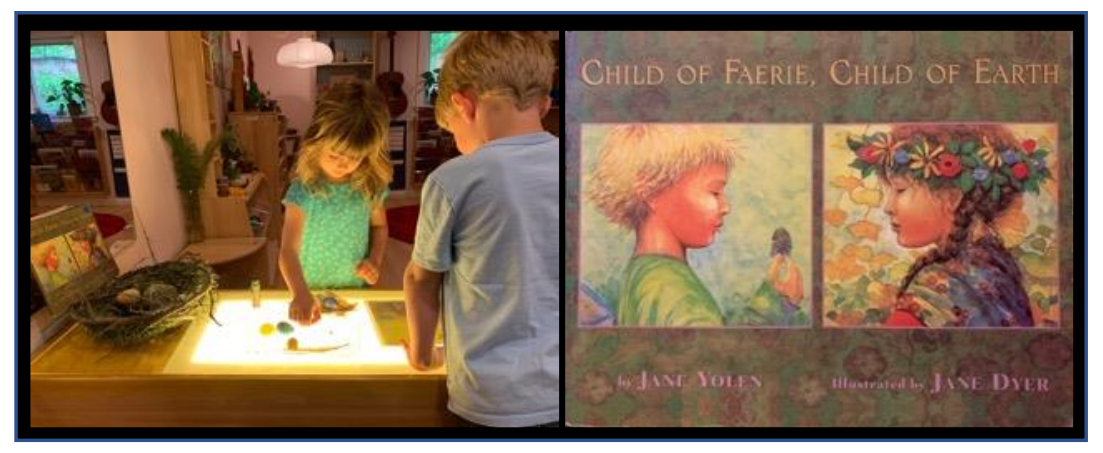

Figure 81. Child of Faerie, Child of Earth. 
Ana is arranging eggs and the feathers on the light table. She puts on the egg wreath as a crown to resemble the child of earth from the cover of the book (see Figure 82), saying, "Guess who I am?"

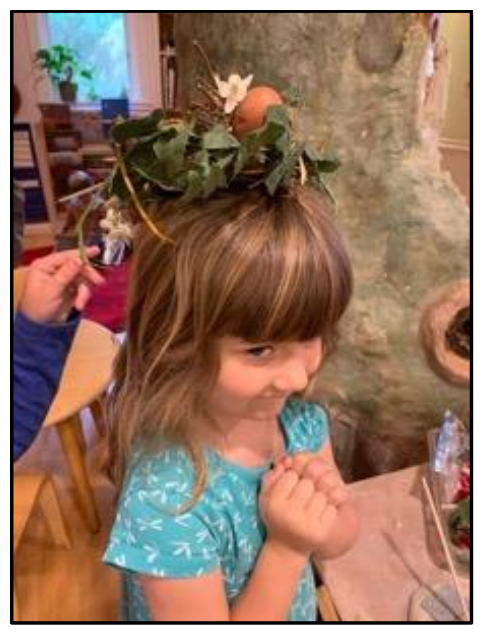

Figure 82. Child of earth.

\section{0:20 a.m.}

Ana is seated next to me at the writing table and says this of her spell: "My spell has secret gems in it that are always hiding in my spell. But whenever I turn it, I can always catch a little glimpse of them. But my magic powers are unlocked by only me, it's a secret spell. My spell does power to make me turn into a mermaid and to make my fly. One of my jewels is green. But my spell isn't just for me. If I have secret friends, I can show them my power."

Me: "Share with them or show them?"

Ana: "Show them. Because my powers are only for me and that is my power." Me (to Archer): "Will you tell me about your spell?" (Silence. Long pause.) Archer: "Well if I do tell you, it's only you."

Me: "You mean I shouldn't share it at class meeting?"

Archer nods. I say, "Okay," and Archer proceeds to quietly tell me about his powers. Ana finishes her drawing and says, "My power made me have silver hair. Since I'm holding it, it went up into my arm and into my hair."

\section{0:40 a.m.}

Archer, Fiona, and Ana made faerie villages today with clay, natural materials, and ceramic eggs. I invited the class over to hear about their work. Fiona and Ana had many stories to share about the village that highlighted the idea offaeries taking care of the eggs. I heard Archer participating in the story of the faerie village as they were creating 
it, but he chose to exercise narrative silence, a refusal to share a story, when asked to share it with the group (see Figure 83).

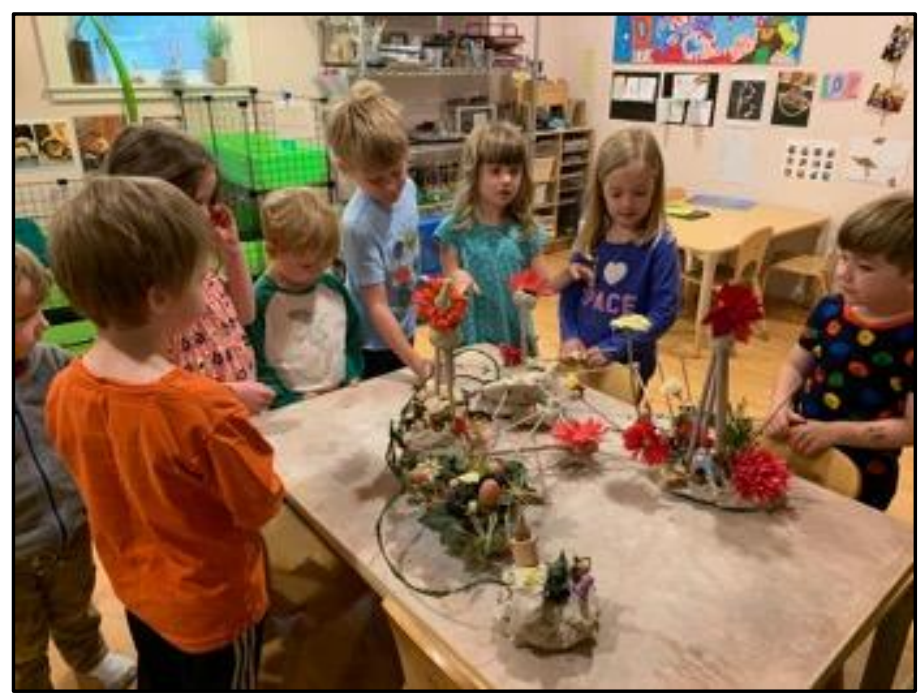

Figure 83. Stories and silences.

\section{1:50 a.m.}

During outside time Ana asks me where she can find a basket. "I need a basket to be the child of earth." Fiona chimes in, "I'll be the faerie." Ana finds an empty basket in the shed and fills it with chicken feed, saying, "I am toiling away" (see Figure 84). This is taken from a line in the book describing the child of earth: "She was a child of humankind, of earth and toil and care."

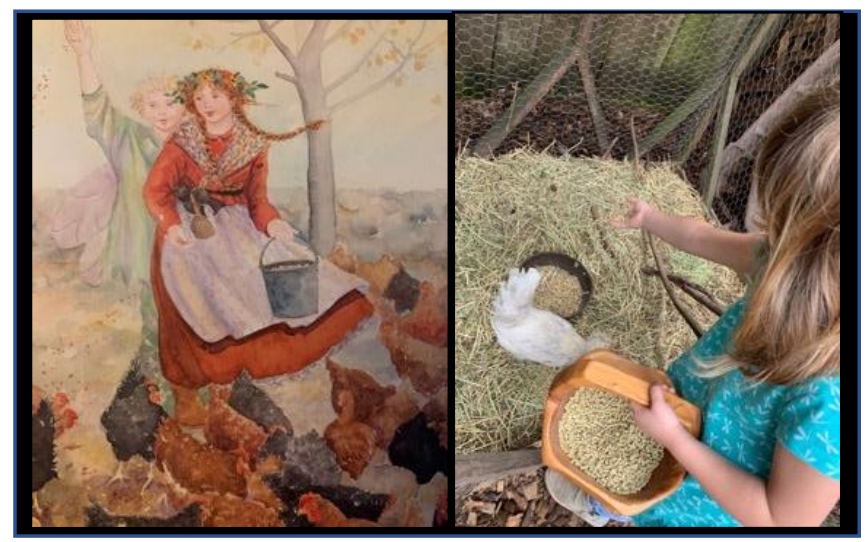

Figure 84. Toiling away. 
Fiona climbs a tree in the garden and poses like the illustration of the faerie child in the book. She asks me to take a picture of her (see Figure 85).

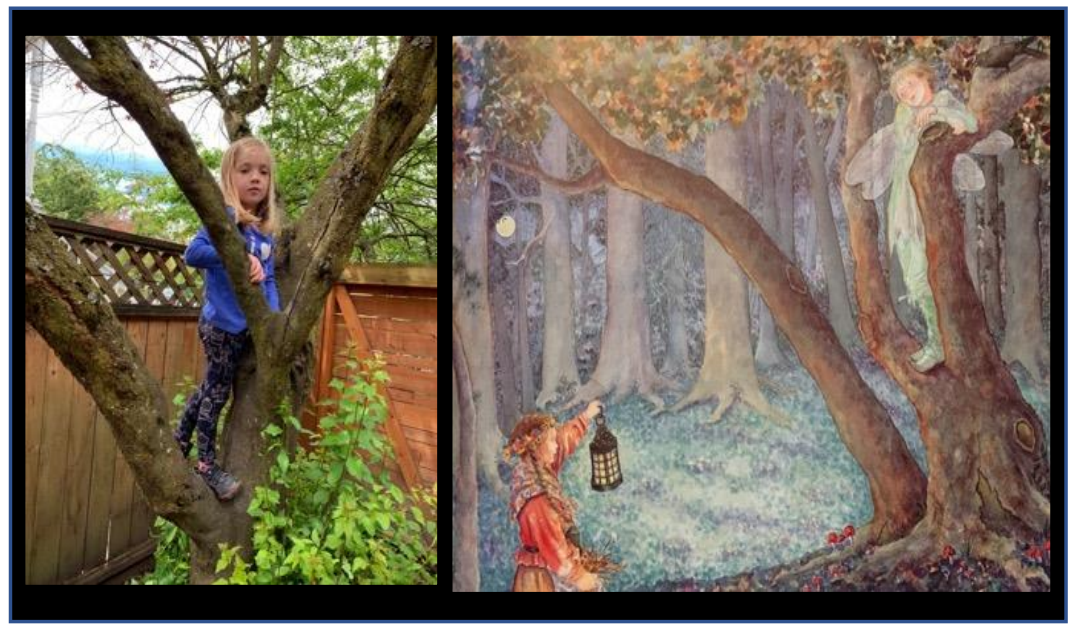

Figure 85. Child of faerie.

\section{May 22nd, 2019}

This morning Ana built an egg terrarium and tells me the following story:

"So, I made this . . it's kind of like a terrarium for, like, eggs; the flower faerie can help them grow. And if they're not hatching when they should be she'll say, 'peep peep!' and they'll think that another chick hatched so they'll come out of their egg. So, um, she takes good care of them if they don't have a mother. And these eggs don't have a mother so that's why she's taking care of them. I built this out of moss and fake flowers. I put a flower faerie sitting on a flower, and I have a leaf covering up the egg so they can stay warm, "cause the flower faerie does not want to sit on them so she uses that leaf."

\section{9:05 a.m.}

It is class meeting. The pouches have arrived in the mail, and today the children can wear their "spells" for the first time. I read documentation to them from a previous class meeting where we talked about where magic comes from.

Me: "I was thinking about our conversation the other day, where I asked you all, 'is magic in Mason's spell? Inside this actual thing? (Holding up the "spell.") Or is it in Mason?' And you said it's in both. That there's power in Mason and there's power in the spell."

Ana: "And I said that when they come together, they make SUPERPOWER." 
Me: "Yes! And Fiona said the power in Mason is in his heart, and all the other powers are in the materials, and when his heart connects with his spell, then that's where the power comes from. Do I have that right, Fiona?"

Truman: "MISS ANGELA."

Fiona: "Yes. That's why he has to wear his spell around his neck to touch his heart." Truman: "MISS ANGELA. If the magic lives in his heart, then he might die, and the doctor might sick him."

Ana: "When the spell touches your heart you can get really, really, really, POWERFUL!"

Me: "What I'm hoping you guys can do today is put these on (the spells) and spend some time with them and see what happens, and then we can talk about it."

Ana: "Unless it's a secret."

Eliot: (solemnly) "If Stella turns into a frog I would be so sad."

Me: "Stella, are you going to turn into a frog?"

Stella (Eliot's sister) shakes her head no.

Me: "It seems like your brother might be worried about that."

Eliot nods his head.

\section{9:40 a.m.}

Michelle, a classroom teacher, is sitting with Fiona, Stella, Jake, and Eliot looking at a book. They are discussing the illustrations.

Fiona: "Maybe the author did that (made the animals in color) because they are trying to tell us that the animals are magic. Everything is getting whiter and brighter and magic is white."

Jake: "Maybe the girl is doing it."

Fiona: "Maybe the girl is seeing it" (see Figure 86).

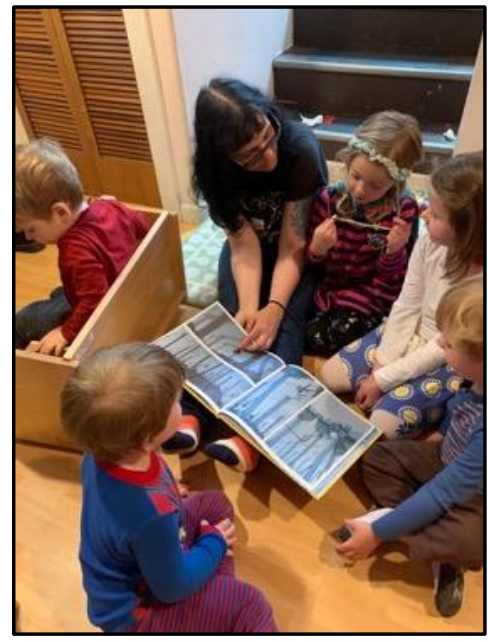

Figure 86. "Animals are Magic." 
Ana: (Sitting with the guinea pig) "Can you put my pouch away? Jeremy is biting on it. Maybe guinea pigs like magic too!"

During our class discussion we revisited our earlier conversation about the children's spells. I inquired, "Did anyone discover some magic happening when you wore your spells this morning?"

Ana: "I discovered Animal Magic. I could talk to Jeremy (the guinea pig). I told Jeremy to wait while I went to go get Leroy (the other guinea pig) and he understood me!" Stella: "I have Animal Magic too. I can talk to guinea pigs and bunnies" (see Figure 87).

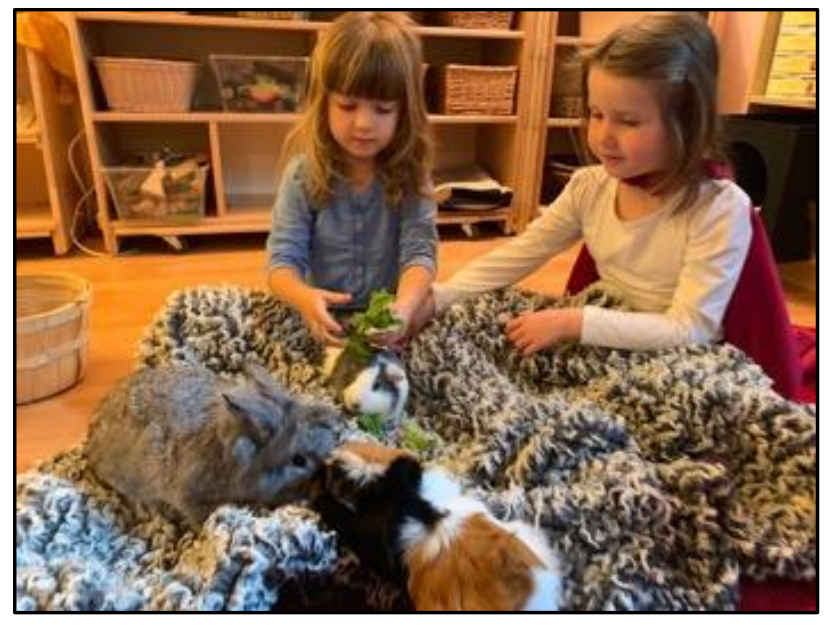

Figure 87. "I have animal magic."

Me: "Ah! I saw you talking to them earlier."

Stella: "Yeah, they understood me. Also, when I am close to Jake, the puppy, he can talk. When I get farther away he can only bark." Jake: "Like, RUFF!"

\section{9:55 a.m.}

Truman: "There's magic in here! MAGIC MAGIC MAGIC MAGIC making it (his rocket shooter) fly!" (see Figure 88). 


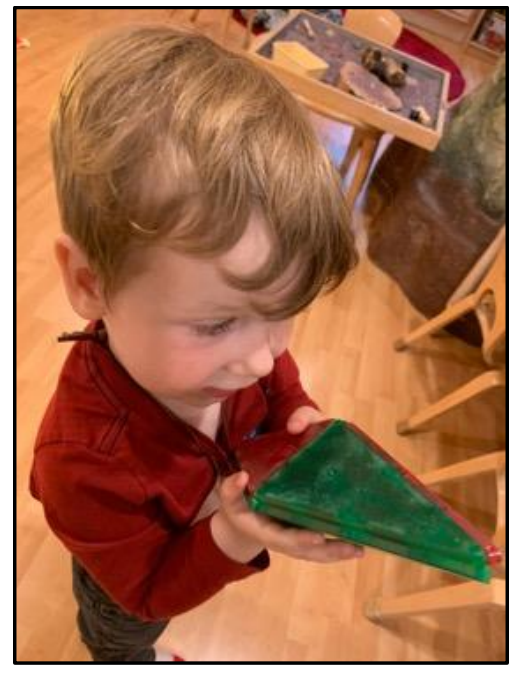

Figure 88. Rocket shooter.

\section{9:55 a.m.}

Stella calls me over to the watercolor table where she has made a painting. She wants me to write her words for her.

Stella: (showing me her illustration) "It's, like, a (barely audible) bowl..."

Me: "Did you say ball or bowl?"

Stella: "A ball ... that turns into a bowl ..."

Me: "Ha!"

Stella: ". . . that turns into a ball again, over and over, until a flower gets magical, and it starts getting windy."

Me: "Ah! And what is this?"

Stella: "It's a star that also makes the flower magical. And it gets even more windy" (see Figure 89).

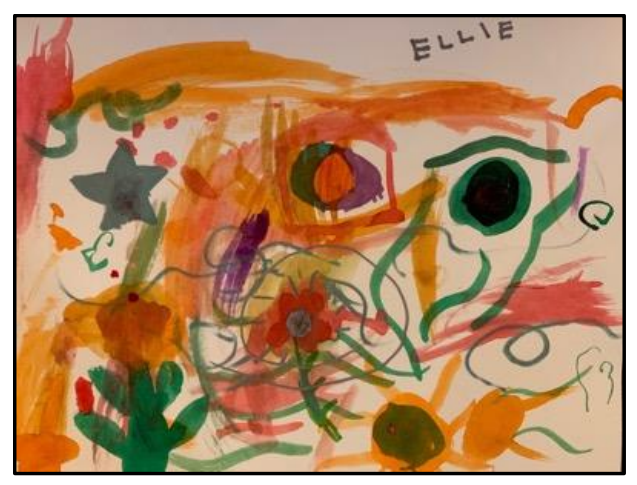

Figure 89. "It starts getting windy."

\section{0:00 a.m.}


Fiona has also illustrated a picture that she wants to tell me about. "This one is a magical faerie, and this is a bird that . . um . . . it laid eggs and now it's going into a magical nest, and this is a magical tree with special, pretty, little gold and silver, and sparkly colored, like pink and stuff, um, leaves, and the trunk was orange and rainbow colored. It was rainbow and sparkly."

Me: "I was wondering, were you thinking about that story as you were painting it, or did you make it up just now as you were telling me?"

Fiona: "I made it up as I was telling it" (see Figure 90).

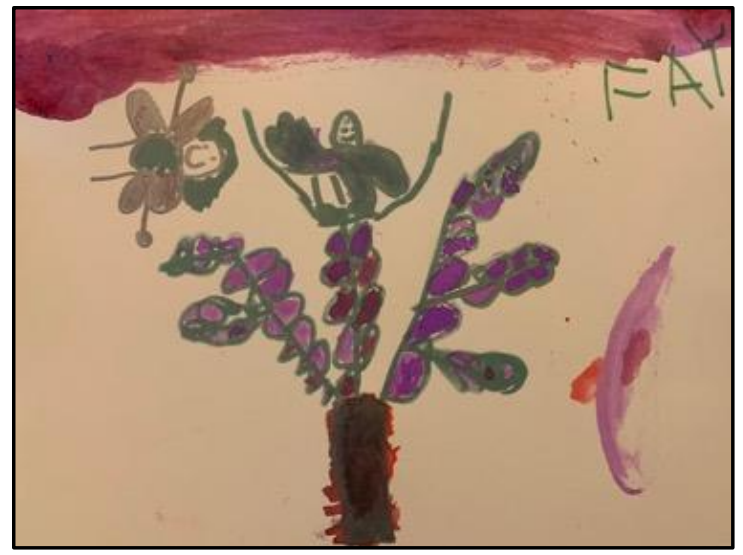

Figure 90. Fiona's illustration.

\section{1:05 a.m.}

We finally have the opportunity to share Mason's tornado story with the class today.

"Once upon a time there was a big tornado... As with the story he told at the beginning of last year, "A Circle Turn," the children jump up and begin laughing and spinning in circles to embody his story (see Figure 91) as he recites the words, ". . . and it spinned every bit about over and over and over and over and over . . and OVER." Some of the children were present at the original story event, while others are participating without that context. This time, Mason seemed to have confidence in the power of his wild circle drawing and the repeated words to incite spinning and enthusiastic laughter. His story was an incantation. 


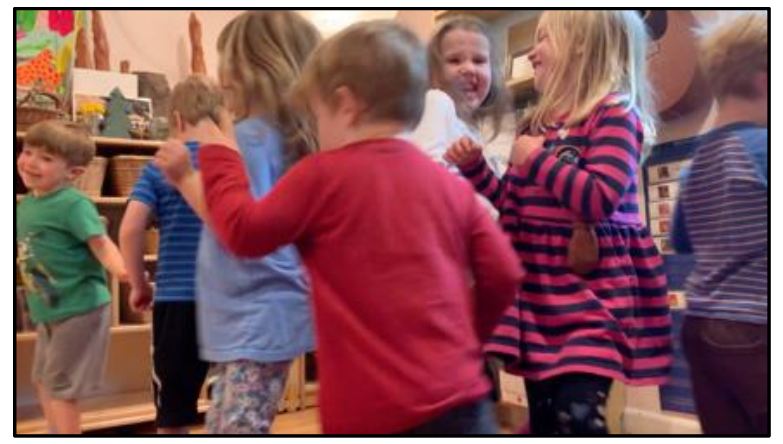

Figure 91. "Once upon a time, there was a big tornado..."

\section{May 28th, 2019}

The children are putting the last of the gems and jewels in their vials for their "spells" this morning. Ana is talking about how she chose her final items.

"Gold is for Golden starshine, and blue is for blue ocean. Hold on, there is one more calling me ... this one is shining for me. It's Purple-wind power."

Me: "Shining for you. I haven't heard that before."

Ana: "It's how something calls when it doesn't have a voice. Like this!" (see Figure 92).

She shows me how her hand can feel which objects "have a shine" for her.

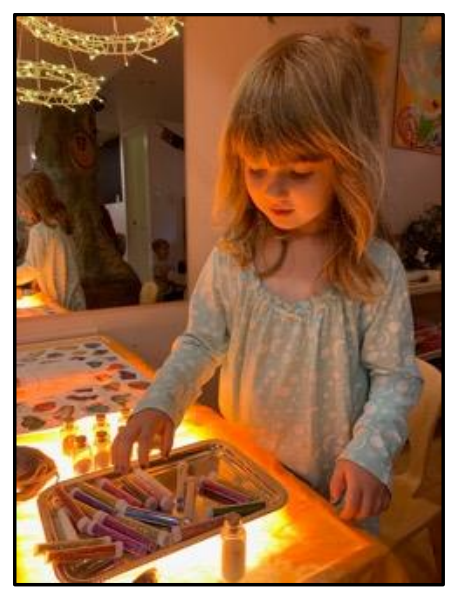

Figure 92. "This one is shining for me."

May 29th, 2019

\section{0:25 a.m.}

Stella: "This is my kitten Golden Light Feather." 
Jake: "Meow."

Jamir leads Stella around the room (see Figure 93).

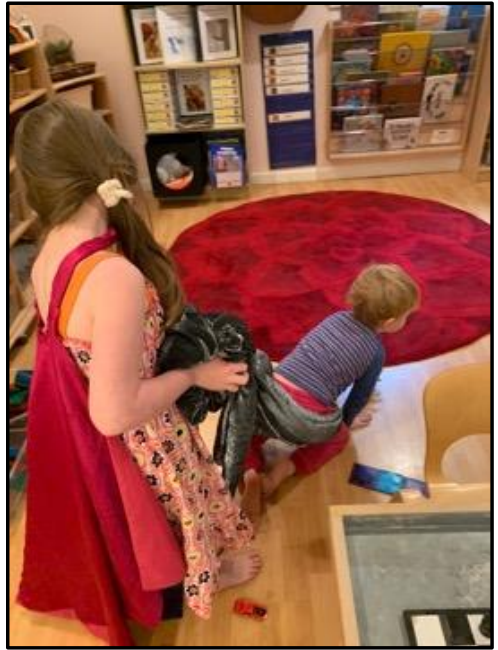

Figure 93. Golden Light Feather.

Stella: "I am a faerie ... (holding out her cloak) . . a faerie Queen." Me: "Is that why you were wearing the long cloak?"

Stella nods.

Archer: "And I am the Faerie King."

Stella (to Archer): "Can you tell I'm a faerie?"

Archer: "Well you ARE wearing that hat..."

Stella: "And I have flowers all over me" (see Figure 94).

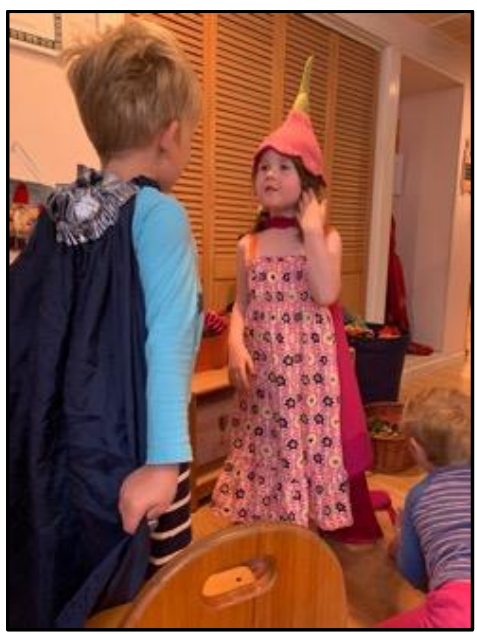

Figure 94. "Can you tell I'm a faerie?" 
Eliot: "I am a magic puppy named Nubby."

Truman: "Who's going to eat my soup?

Archer: "Can you tell I'm a Rock faerie? Because of this cape?" (see Figure 95).

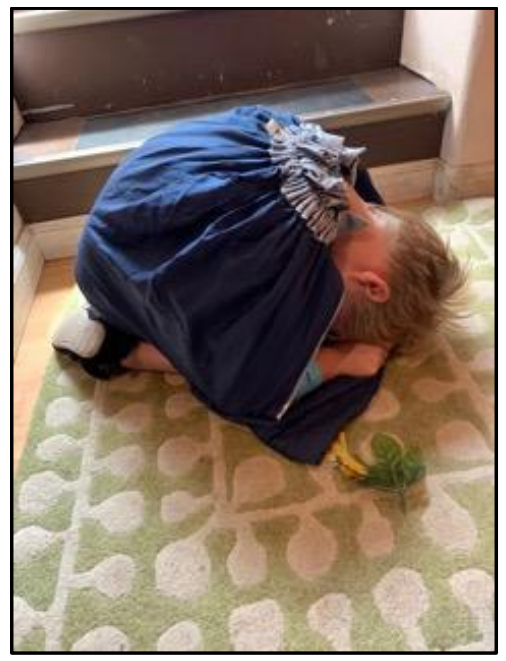

Figure 95. Rock faerie.

Ana (to all): "I am an autumn faerie."

Truman: "I am La Luna. Can you tie on my gown?"

\section{May 30th, 2019}

\section{9:45 a.m.}

Archer and Ana have volunteered to collaborate with me to update our thinking wall. This practice is a teacher-child collaboration and typically involves selecting images that I have taken on my phone and children have taken on the iPad and putting them together in groups. We have been working on grouping the photos for weeks in our class discussions. Archer and Ana, as part of an ongoing discussion, have invented a new category: Thing Magic. Today they are deciding on several photos of moments where they agree that Thing Magic occurred. This delights me, reminding me of Bennett's (2010) concept of Thing-Power. There is great interest in the material aspects of this endeavor ... writing words for the wall, watching the photos come out of the printer, and arranging and rearranging the photos in various groupings on the floor in front of the wall (see Figures 96 and 97). 


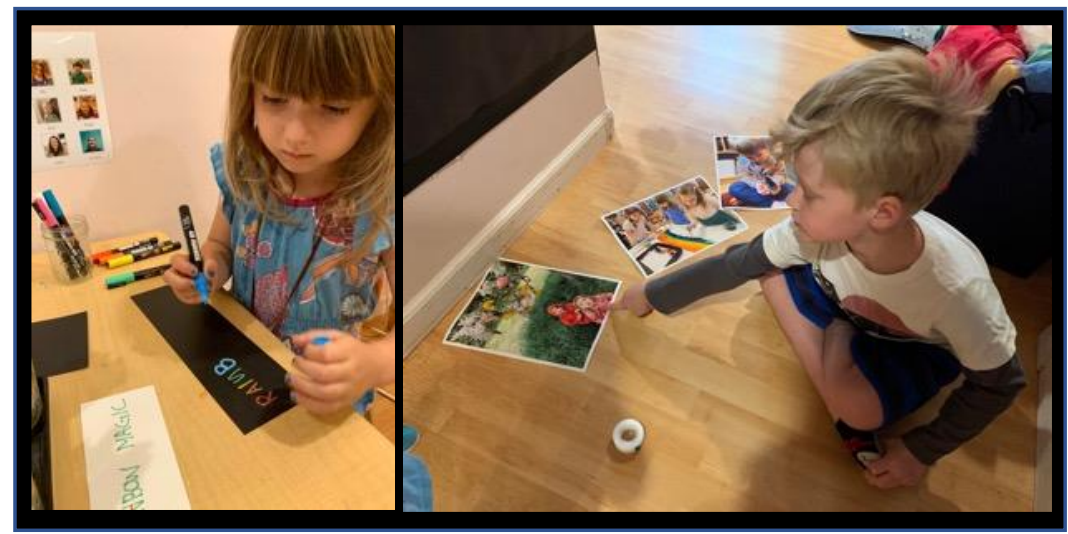

Figure 96. Composing the thinking wall.

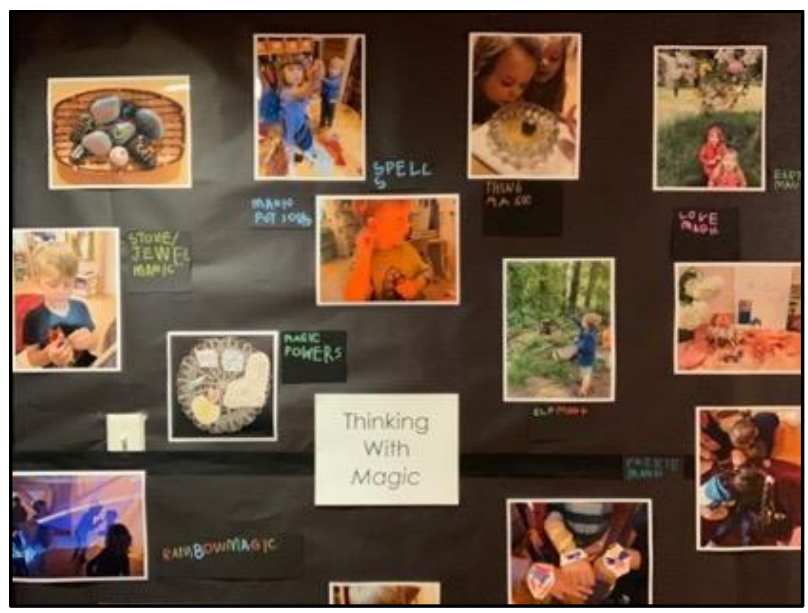

Figure 97. Thinking wall.

\section{0:20 a.m.}

In the studio, Mason and Kyle have been telling our student teacher about visiting Santa's Workshop. It is our collective understanding that Kyle has been there. She calls me over so I can also hear about it. They are constructing Santa's sleigh with magnetic building blocks and taking photos of their constructions on the iPad.

Me: "What do you guys know about going to Santa's Workshop?"

Mason: "All you have to do is write a million kazillion notes, that say 'Can I have elves, Yes or no?' to Santa, and then you get a ladder, walk on the tippy top of the ladder and stuff it up the chimney. Then you go back to sleep and when you wake up you go up there 
on the ladder to open up the presents, and inside there are elves. Kyle knows this because he's already done it! At Santa's Workshop."

Mason asks Kyle, "How do you get to Santa's Workshop?"

Kyle: "You take a plane at night."

Mason: "Take a bobsled, when you see a large, large building that's bigger than this school, that's Santa's Workshop."

Kyle: "You take a plane because it's in a different city in Iceland. Actually Greenland;

that's the north pole. You go For 60 days and 60 nights."

Me: "Wow. Did you go alone or ...?"

Mason: "Probably alone."

Kyle: "I was not with my parents. How do you find out you can go to Santa's Workshop?

You stuff notes up the chimney, and VOILA! Santa! He says, 'Ho, ho, ho come with me up the chimney!' Then you Fly with him all the way to the workshop, on his sled. (To Mason) It's a sled, not a bobsled. Santa does not have a bobsled."

Mason: "If he checks 'yes' you then you get to come to the workshop. With Santa's elves."

Kyle: "Santa's elves are a different type of elf. You only get a few of Santa's elves." Me: "A different type?"

Kyle: "Some elves are skinny... Santa's elves are not. And you only get a few. The rest have to work."

Mason and Kyle refer to this conversation as "Santa's Workshop," and later, "The story of Santa and His Elves." When Mason asks me to share the story with the group, he is referring to my notes on this particular discussion (see Figure 98).

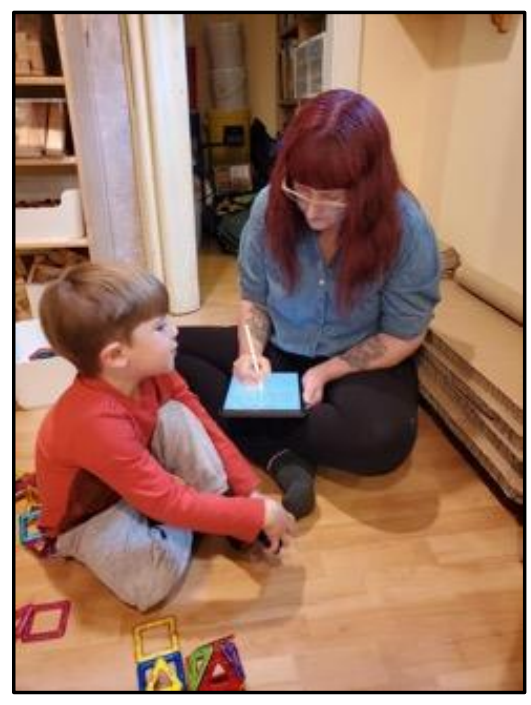

Figure 98. "Santa's workshop." 
June 4th, 2019

This morning we finish reading Thumbelina (Long, 2010) before heading out to the arboretum. Stella announces to the class that she can see faeries, gnomes, and elves. Ana says we may see a mermaid in the creek today, or a blue eel. On the bus I notice Mason is wearing a knitted Christmas hat that lights up and plays music. It is exceptionally warm outside; I ask Mason why he is wearing the hat. He whispers something to Kyle, who looks at me and smiles. "To see elves," he says (see Figure 99).

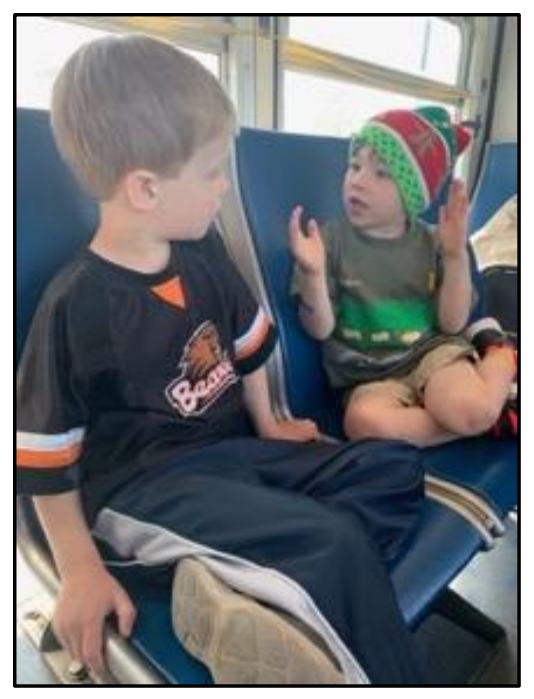

Figure 99. Mason's holiday hat.

\section{9:10 a.m.}

Ana (to Mason): "Mason! I found a crystal!"

Stella: "I saw a real faerie."

Fiona: "I saw traces of a mermaid, shimmering circles on the water going like this" (motions with hand). "Mermaids are water spirits."

\section{0:20 a.m.}

Mason and I are trailing behind everyone else on the way to the stone circle. I am taking pictures as I walk. In one of the images I notice an eye-shaped rainbow and I show it to Mason, astounded. He wants me to take a picture of him under it, but we do not have time. We have fallen behind the group and I cannot see or hear the rest of the children. We run off to show everyone the image (see Figure 100). 


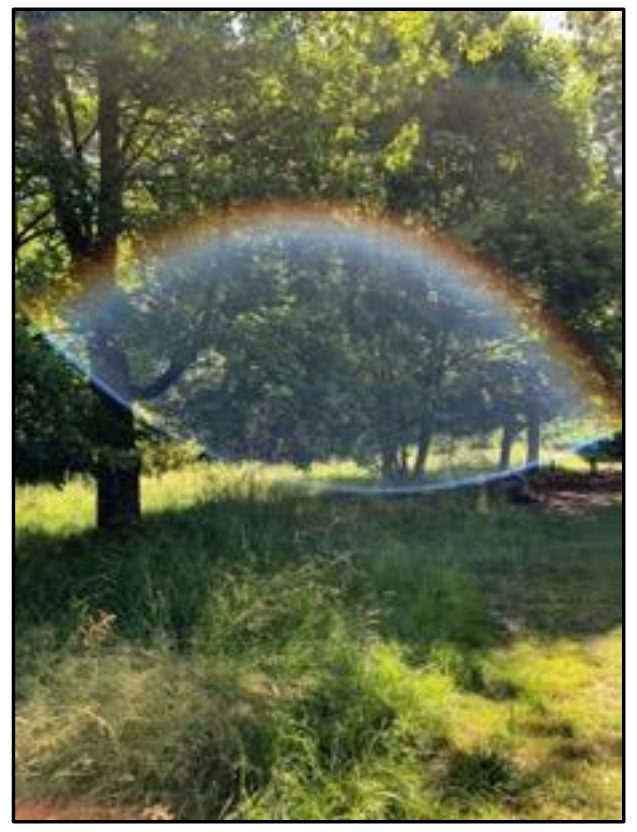

Figure 100. Found rainbow.

\section{0:50 a.m.}

We come upon a dead bird under a tree. It is larger than the dead chick, and the flattened bird from earlier in the spring (see Figure 101). The children circle around the bird and share small stories.

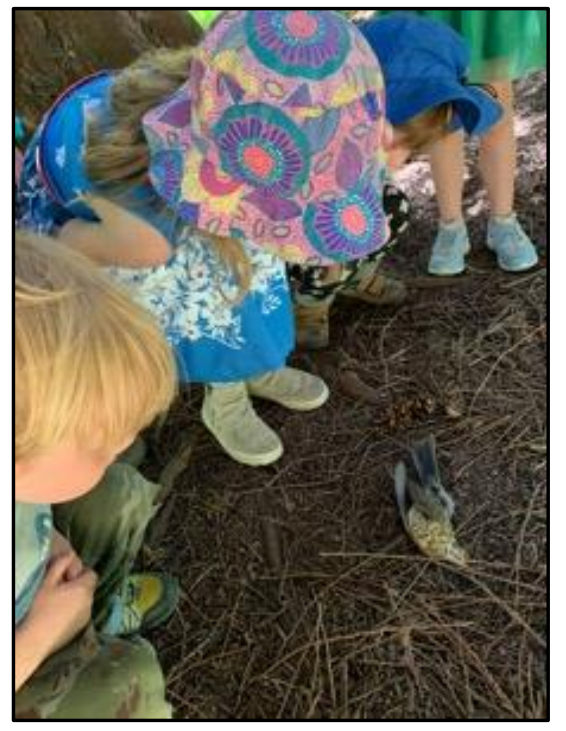

Figure 101. Dead bird discovery. 
Kyle: "Maybe he fallen from the tippy top of the tree."

Eliot: "It's a daddy bird."

A: "It makes me think of our baby chick that died at school."

Truman: "It's OK Miss Angela."

Ana: "It's OK, I know it's sad. I remember when Pono (her dog) died. He died of a heart attack."

Truman: "Maybe a car drove by and scratched him."

A: "Like the bird we saw last time by the road?"

Truman: "Yeah ... because..."

Stella: "It's too small under here for a car."

Truman: "It was a baby bird."

Jake: "This is like The Dead Bird" (Brown, M.W., 1965). Inspired by an illustration from the book, we surround the bird's body with leaves, flowers and ferns.

\section{1:25 a.m.}

We continue through the arboretum. The children stop occasionally noting things they find to be "interesting, remarkable, or important" along the way (see Figures 102 and 103).

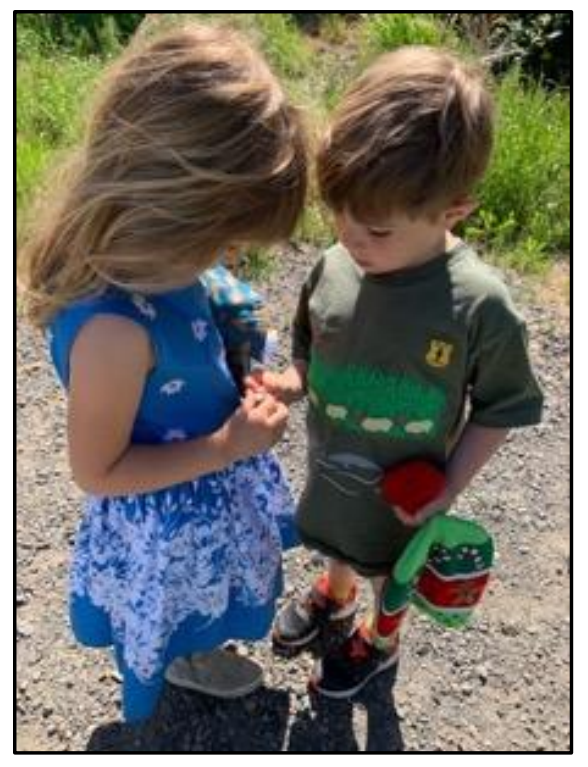

Figure 102. Found crystal.

Jake finds a crack in the earth and feels this is a sign of an elf. 


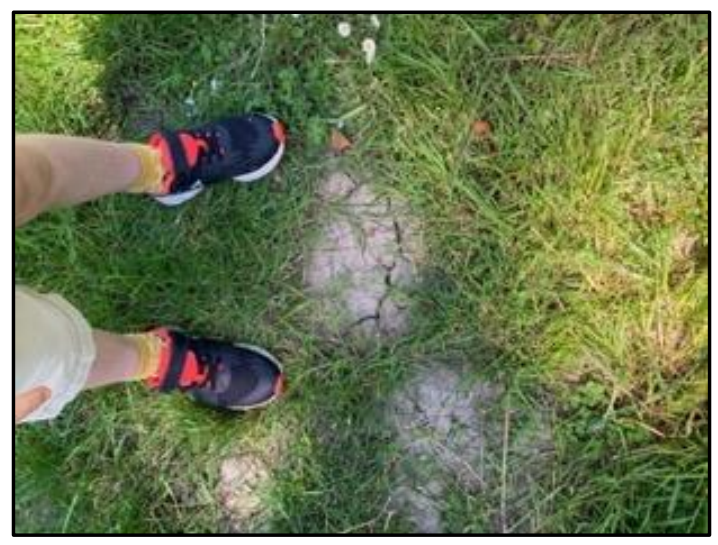

Figure 103. Found crack in the earth.

\section{1:45 a.m.}

The children come upon a field of tall grass and search through the grass looking for elves and faeries. Fiona gives the verbal cue that the children have been using to signal the presence of magic:

Fiona: "Look! The grass is moving but there is no wind."

Archer: "Sign of a faerie!"

Stella: "Faeries are so small that we can hardly see them in the grass. There is one hiding over there" (see Figure 104).

We lose a pair of binoculars and cannot find them despite retracing our steps. We look for so long that our time is cut short and we have to run to catch the bus back to school.

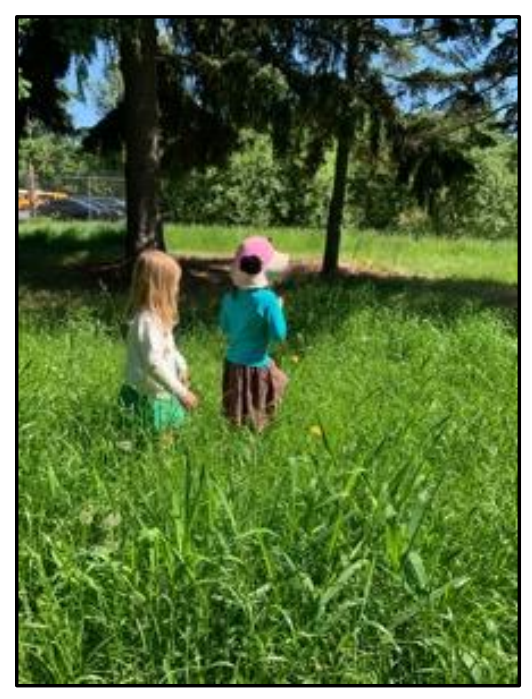

Figure 104. The grass is moving but there is no wind. 


\section{2:05 p.m.}

On the bus home, the children discuss the morning with us and with one another. Stella: "A faerie is this big" (see Figure 105).

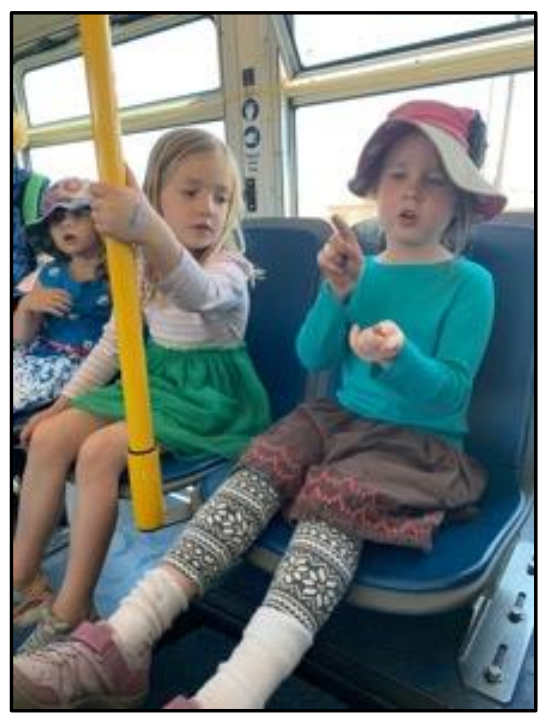

Figure 105. "A faerie is this big."

Me: "Like, as big as a squirrel"

Stella: "Yes, as big as a squirrel. And a kid faerie is this big. And a baby faerie is this big."

Fiona: "I was that big when I was a faerie. And I drank nectar from this kind of flower" (showing us a flower from the arboretum.)

Jake: "Like Thumbelina!"

Fiona: "Yeah like Thumbelina. And I drank water from a leaf."

I wrote the following free-writing gatherings segment directly after this outing; it pertains to my thoughts regarding the events of the day.

\section{Gatherings}

The children continue to make connections between the elements (earth, air, fire, water, air), seasons, and magic. The elements are vital more-than-human participants in the children's daily lives, and certainly in their narrations. They have repeatedly speculated on connections between elements and corresponding powers and presences. 
Examples from today alone include Fiona recognizing a shimmer in the creek as a sign of a mermaid ("mermaids are water spirits," she reminded me), and Archer indicating that when the grass is moving but there is no wind, a faerie is near. Many of the children I have encountered over the last several years share a strong belief in elemental magic. I have often reflected on the role of the media in this way of thinking. Some might argue that movies such as Frozen (Frozen, 2013) popularized the idea of a connection between magic and the elements, but I think that movies like Frozen are so wildly popular because they tap into powerful notions that are already established in children's imaginations. It is notable, however, that Eurocentric/Euro-Western ideations about magical lands and beings undoubtably influenced the shape that children gave to their imaginings and the presences they encountered, and thus, can be regarded as a colonizing force. Though decolonization is the process that "brings about the repatriation of Indigenous land and life" (Tuck \& Yang, 2012, p. 1) and is not interchangeable with social justice, anti-bias education, or projects of school reform, I do feel that decolonizing the imagination is critical, as it is "where all other forms of decolonization are born" (Imarisha et al., 2015, p. 4).

Tuck \& Yang (2012) state that "in order for the settlers to make a place their home, they must destroy and disappear the Indigenous peoples that live there" (p.6). When we spend time in the children's arboretum, my sense is that the narratives that emerge are produced in an assemblage with humans (both present and not), more-thanhuman presences in the arboretum (both living and dead), the histories of the arboretum itself (legacies of stolen land), our own histories and influences, and countless other 
untraceable connections that walk alongside us as we move through this place. With this in mind, my intention for our time at the arboretum is to disrupt our customary, colonized/colonizing ways of thinking.

Because of this, when we are in the arboretum I ask the children to practice, along with me, attuning to that which is unknown and unseen by "shifting, engaging, and noticing" (Iorio et al., 2017, p. 126) what is around us. Generally speaking, attunement seems to come easily to young children because of their open disposition. For example, Fiona's recognition of water spirit due to a perceived shimmer on the water brings Deborah Bird Rose's (2017) concept of "shimmer" to mind, which is ancestral power as experienced in the world. Rose proposed that "an encounter with shimmer may help us better to notice and care for those around us who are in peril” (p. G52). This proposal causes to consider how our attunement to, and storying with the arboretum can account for our "irreducible relations of responsibility" (Barad, 2010, p. 265) to the peril with/in the arboretum, such as ongoing damage to the lands, creatures, and waterways, and the "literal and figurative ghosting" (Nxumalo, 2018, p.5) of Indigenous peoples, land, and stories/histories. Further, since colonialism is an ongoing project that is accomplished through the severing of relational ties (Davis \& Todd, 2017), intentionally repairing lines of relations, between humans and storied land for example, can be a decolonizing act.

Next, we follow the thread along to June 5 th, where encounters in the digital atelier produce new matterings regarding our time spent with/in the arboretum.

\section{June 5th, 2019}

\section{9:05 a.m.}


This morning at class meeting we read the book When I Was Small (O'Leary, 2011). (see Figure 106). Jake tells us that he is the tiny boy from the book. Stella and Fiona say they are the tiny girls. Truman says, "I am the tiny mermaid," though there is no mermaid in the story. We discuss our plan for the morning. Archer has been asking to use the projector, so it is available in the digital atelier with images and video from yesterday at the arboretum.

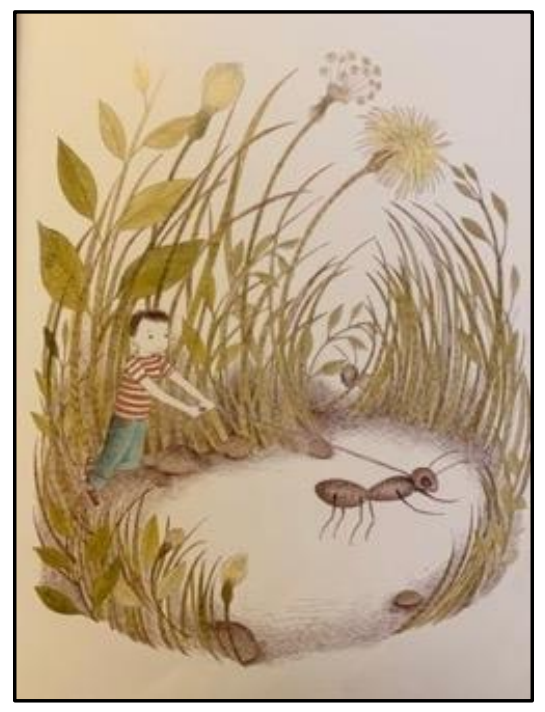

Figure 106. When I Was Small.

\section{9:25 a.m.}

The digital atelier is the heart of the action this morning. Children come and go from the space; the influence of our day at the arboretum feels tangible in the "thick now" of today's play. An image of the grass taken yesterday at the arboretum is digitally projected through hanging sheets of gauze and onto a curtain (see Figure 107). Children crawl around on the ground in front of the projection and move between the layers of fabric to interact in particular ways with the image. 


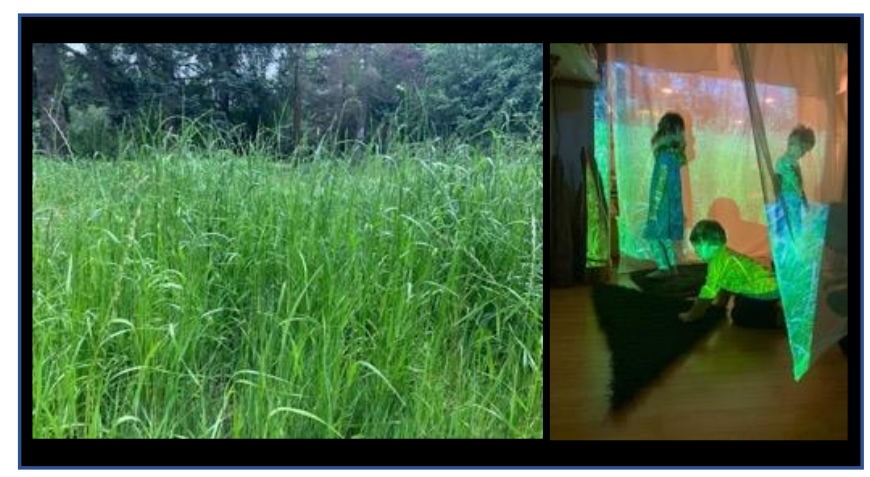

Figure 107. Re-visiting the tall grass.

Ana: "I can hardly see above the tall grass."

Archer: "The grass is moving but there is no wind..."

Understanding Archer's words as a signal to indicate the presence offaeries, a group of children become faeries playing in the tall grass. They tangle themselves in mesh curtains hanging from the ceiling, "caught" in the tall grass, calling for help (see Figure 108).

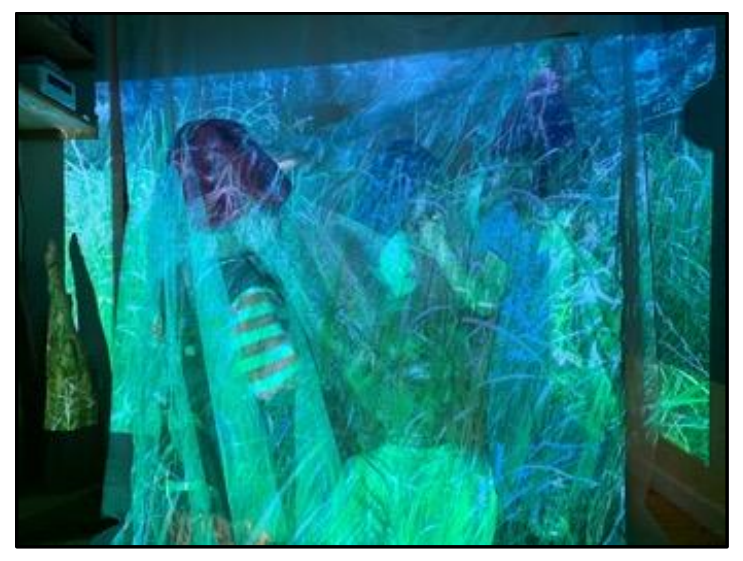

Figure 108. Caught in the tall grass.

\section{9:40 a.m.}

Fiona: "Ana gave this egg to me and told me a faerie would hatch from it. We have to plant it." She plants it between sections of plastic grass (see Figure 109). 


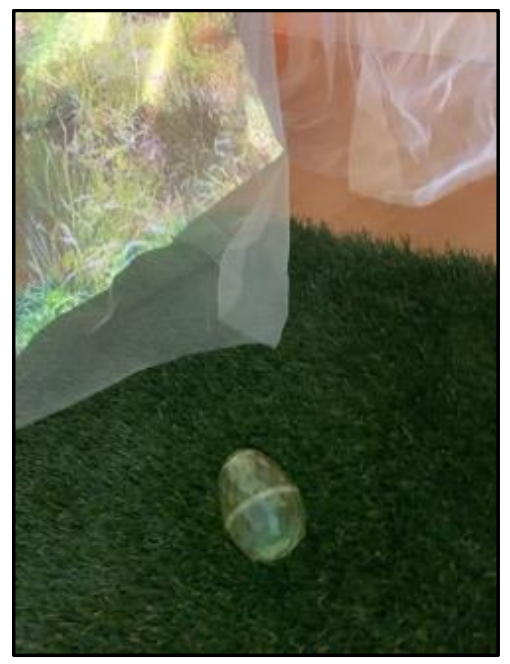

Figure 109. "We have to plant it."

Ana comes into the atelier and takes the little marble egg out of the clear plastic egg, saying, "There, now it will be easier for her to hatch."

Me: "Who is she?"

Ana: "My child" (see Figure 110).

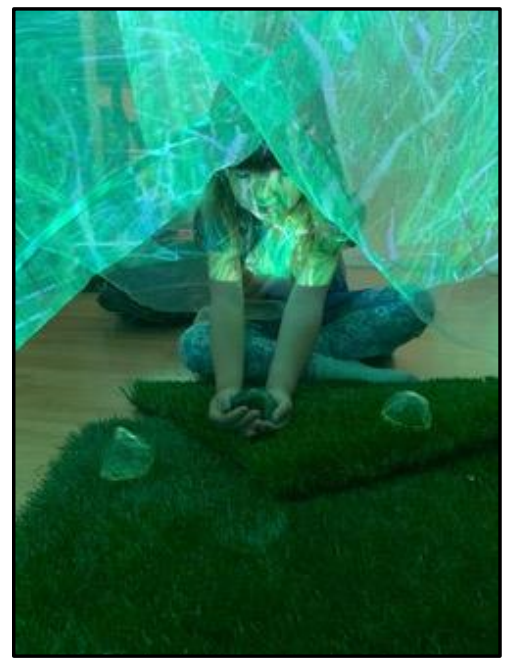

Figure 110. My child.

This small story brings me back to a conversation we had when the baby chicks were hatching. Some of them were never able to break free from the shell and died before they were able to fully hatch.

\section{9:55 a.m.}


Ana tiptoes up to me and says quietly, "I'm the elf that took your binoculars" (see Figure 111).

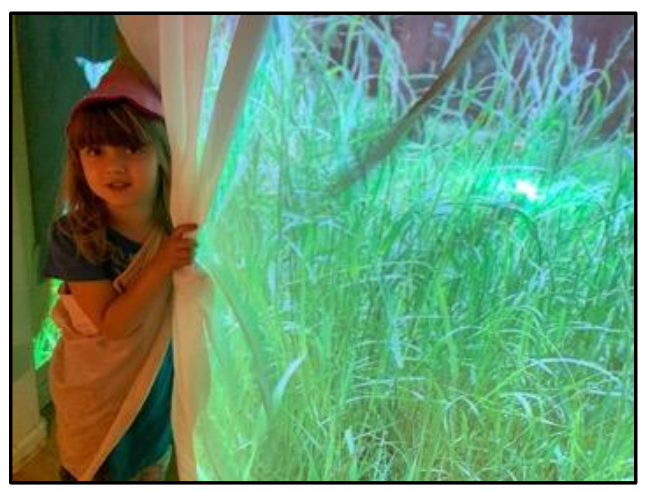

Figure 111. "I'm the elf that took your binoculars."

Me: "Well if you need them, you can have them."

Ana: "I need to see when humans are coming to the park." Me: "Then you can keep them."

\section{0:30 a.m.}

Most of the children have left the digital atelier. I take the opportunity to change the image, projecting the rainbow eye image from yesterday. Later, I notice Mason standing in the atelier alone, "under" the rainbow, as he had hoped to do yesterday (see Figure 112). I am struck by how there is more here than meets the eye . . more than simply a child and a projection. Mason and the digital projection have joined in an assemblage.

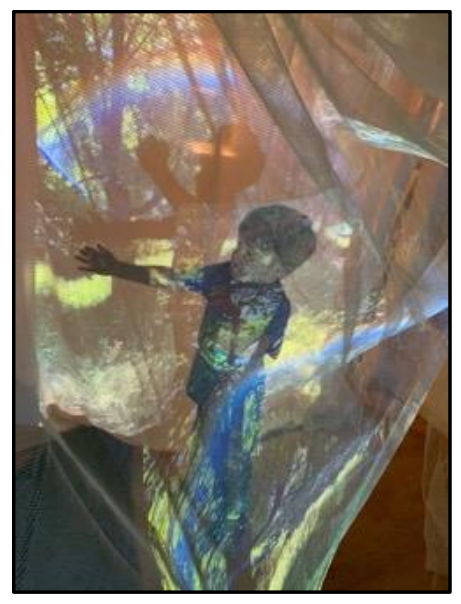

Figure 112. Mason and the rainbow. 


\section{2:30 p.m.}

When sharing stories at the end of the day to include on our thinking wall, Archer, Stella, Fiona, and Ana share a story about the time they played with faeries and elves at the arboretum and got tangled in the tall grass and almost missed the bus.

The following free-writing gatherings segment was written directly proceeding the events of June 5th and pertains to the ways in which a statement made by one child carried profound pedagogical implications for children's acknowledgement of the morethan-human world.

\section{Gatherings}

I find Ana's simple narrative fragment, "I am the elf who took your binoculars . . . I need to see when humans are coming to the park" to be significant. It indicates an awareness that we humans are not the only "lookers," but rather, others are we looking back on us. For a long while I have been concerned that we will unintentionally adopt colonizing practices in regard to arboretum rather than viewing ourselves as active participants in the arboretum's complex, more-than-human socialities (Tsing, 2013). I have been particularly wary of using binoculars; a one-sided tool of observation that can encourage a "colonial gaze," or "colonial ideals and imaginaries that work to overlay and attempt to make invisible the [Aboriginal] knowledges that are always, already there" (Hamm \& Boucher, 2017, p. 60). Thus, I was delighted with Ana's small story of an elf who stole our binoculars to see when humans are approaching. I found it to be a pedagogically rich acknowledgement that "we (humans) are not alone in our common worlds; and secondly that these worlds are not only about us" (Taylor \& Giugni, 2012, p. 112). 
June 6th, 2019

Although Kyle typically defers to his dear friend Mason in their daily activities, he takes the lead in their favorite storyline about Santa and His Elves. This is based on their shared understanding that he has been to the north pole and visited Santa's workshop. Today they are building Santa's workshop with magnetiles.

\section{9:25 a.m.}

Mason: "This is how big Santa's workshop this is. (To Kyle), "Is this how big Santa's workshop is?" Kyle nods.

Mason: "Do they sort the presents here?"

Kyle: "They do not sort the presents, but Santa looks at the labels. I am making a conveyor belt."

Mason: "Do they (the presents) come out into the sled?"

Kyle: "No, they come out into the bag."

Mason (to Stella): "We are building Santa's workshop."

Stella (looking around): "It does seem like Christmas night." (To Kyle), "Did you know what we were going to play? Because we were just about to play Christmas night."

Kyle: "Yes!"

Mason (to Kyle): "I want to be Santa. You can be an elf."

Kyle: "No, I want to be Santa."

Mason: "How about we just don't have a Santa."

Kyle: "Then who will deliver presents?" There is a pause. "How about we can both be Santa and the elves."

Mason: "Are there construction workers?"

Kyle: "I don't know about that part. I will have to ask Santa."

Mason (singing): "We are building another workshop, a second workshop, it's part of the first workshop."

Kyle: "Your bag is so heavy, you need deer. The deer have magic to make them fly. And the sled has a magic star on it that makes it go."

Mason (to Danny): "You are Santa. This is your workshop. He says, 'Go to sleep or I'll put you on the bad list.",

Mason (to Kyle): "We are the elves and we are good and it's only the start of a new year.

He is Santa and we are the elves so we can never go on the bad list. Only kids can go on the bad list."

Kyle: "I know that. I was talking about those kids in the dress-up area."

Archer approaches their structure and looks at it skeptically, saying, "That doesn't look like Santa's workshop."

Mason: "Have you been to Santa's workshop?" Archer shakes his head no.

Mason: "Kyle HAS been to Santa's workshop. If you haven't been to Santa's workshop how would you know what it looks like?" Archer walks away. 


\section{9:40 a.m.}

Kyle and Mason are elves working at the beading table. They are making gifts. Mason: "We are doing work getting ready for Christmas. Next Christmas" (see Figure 113).

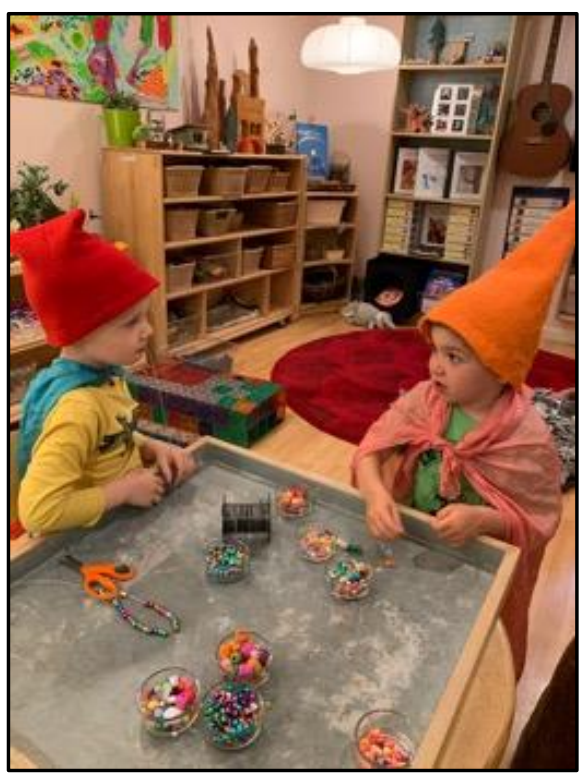

Figure 113. Getting ready for Christmas.

Kyle (to Mason): "Do you know what comes after Christmas? Halloween!" Mason: "No that one comes first."

Kyle: "Yes, Christmas is first. The elves can only go to Christmas."

Mason: "The elves can go to all the holidays. I don't know why you said that."

Kyle: "Because it's true."

There is a long pause.

Mason: "Santa is not the boss of them you know."

Kyle: "You know who is the boss of them?"

Mason: "Yes. Themselves. They are the boss of their own selves. I am the boss of my own self."

Stella: "We just went trick-or-treating. This is my candy."

Eliot: "This is my chocolate."

Jake: "It's Easter. I'm the Easter bunny."

Me: "I thought it was Halloween?"

Jake: "It is. The Easter bunny comes on Halloween" (see Figure 114). 


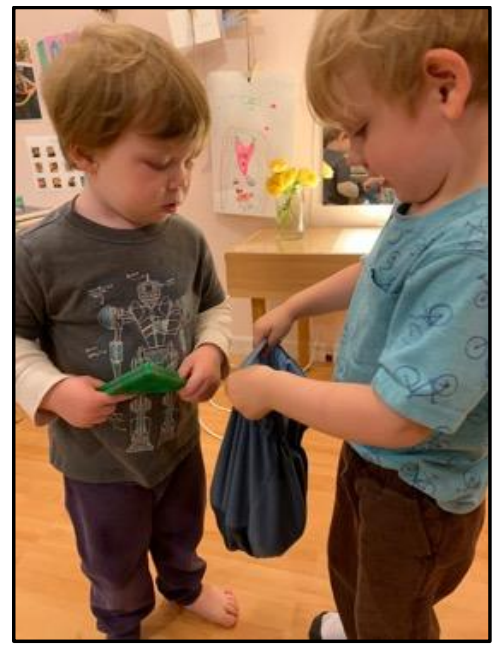

Figure 114. The Easter Bunny comes on Halloween.

Truman is running around the room flying a green spaceship and loudly chanting

"Ghost-es." He pauses to say, "I'm playing Star Wars. This is the noise the ghost makes when the man shoots the ghost." Mason and Kyle ignore him and continue their play. After realizing his ship is from Star Wars, they transform Santa's workshop into a Star Wars base. I notice the shifting storyline and say, "Wait, is this Santa's workshop or a Star Wars base?" They look up from their play and respond in unison, "Yes."

\section{1:00 a.m.}

Ana is working with green glass at the light table. When she stands under the hanging light, the glass reflects green light onto a piece a paper. She tells me she is making green light for La Luna. "It's part of the story, but I don't know how yet" (see Figure 115).

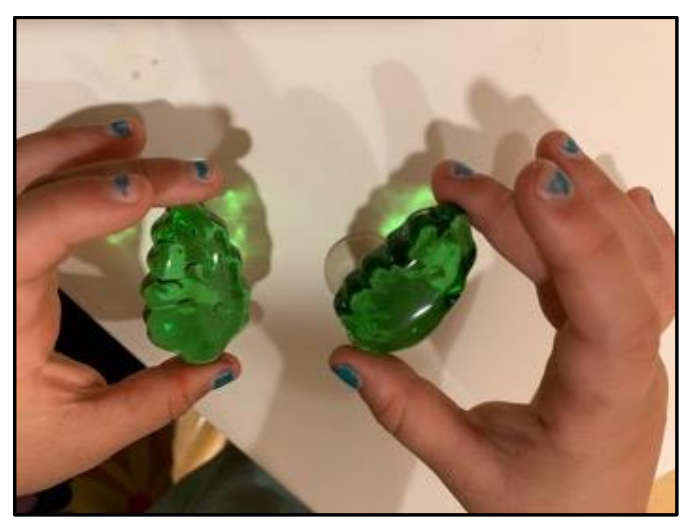

Figure 115. "It's part of the story, but I don't know how yet." 


\section{1:20 a.m.}

Truman told Danny a story about his Star Wars shooter that he wants me to read during story theater. He comes to story theater with his "space shooter" in his hand and begins talking. "It just shoots ghosts up in the air when it's Halloween. The shooter is green ... it has powers in it . . . and it goes up in the sky for MILES and MILES."

Me: "Do you want me to read what you told Danny? Or you can tell us about it yourself ..."

Truman: "Just read it."

Me (reading): "Once upon a time there was a Star Wars man and he had a big shooter to blast ghosts. And then he was trying to blast someone, and he took off in his rocket ship. And then he broke his rocket ship..."

Truman: ". . And then he built it again. The end!"

Mason and Kyle ask me to read their conversation about Santa's workshop at story theater. I had read it back to them earlier to make sure I understood them correctly. I begin reading it. When I get to the part that says, "then you can go to Santa's workshop" Fiona says, "Probably Christmas night." Stella adds, "So Santa doesn't see you." Mason: Quietly chants in a sing-song voice, "He does see you he does see you he does see you..."

Me: "I hear Mason saying he does see you."

Fiona (to Mason): "He does see YOU because you work in his workshop."

Archer: "Well they work at night so ..."

Kyle: (Solemnly) "Santa doesn't sleep at night."

There is an uncomfortable silence.

Ana: "Yes he delivers presents at night. So that means he sleeps all day and is up all night like an owl!" (Laughter.)

June 7 th, 2019

\section{9:10 a.m.}

It is class meeting on the last day of school. We review our plan to celebrate two big stories today, The Story of La Luna, and Santa and His Elves. These particular stories have become dynamic meeting spaces (Ahn \& Filipenko, 2007; Puroila et al., 2012) of encounter for our classroom community, as well as a meeting place for our collective research (Quintero, 2017). At the end of the day yesterday, I asked the stories' key players to think about how they wanted to do this. Ana has requested a digitally projected moon in a night sky, and a cave to help share her story in the digital atelier (see Figure 116). She also has an idea about using green shooting stars to get La Luna out from the moon, where she is trapped. Mason and Kyle are using our transcribed conversation from May 30th as the "story." They are excited about sharing it but are not clear about how it is going to happen, nor are they visibly concerned about this. We

decide to start with The Story of La Luna. 


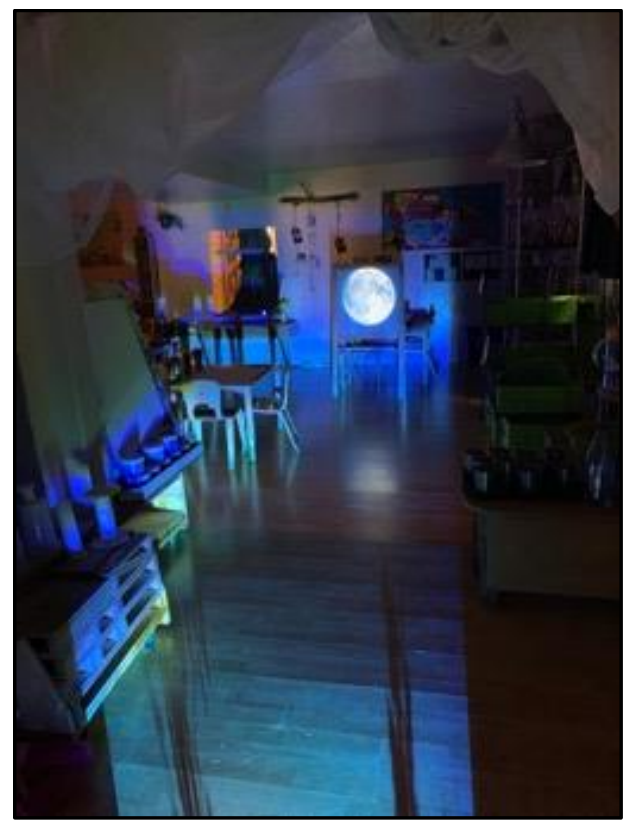

Figure 116. Digital moon.

\section{9:40 a.m.}

We migrate into the digital atelier for The Story of La Luna, where an image of the full moon is projecting onto the easel. We have never performed a story in the digital theater before. The children sit waiting with a sense of reverence. Ana has asked me to read the story. I begin reading the fourth written version of the story.

"Once upon a time there was a jewel, and then, once upon a time there was a girl. And the girl's name was La Luna. And one day La Luna was walking along the street to school in her white gown. And then one day, where the schoolhouse SHOULD be, it was gone! And in its place there was a cave. And in the cave, there was a jewel. And suddenly, she took the jewel! And as soon as she took the jewel, the cavern shooted her into the sky with the jewel. Then La Luna was trapped in the moon for one hundred years. Then the children came together, one by one, using all the green power they had to set her free..."

Ana calls the children by name one at a time to hold something green up to the light of the projector. This is an unscripted turn in the story. Some of the objects they have chosen are too dense and do not create green light. There is a scramble as children dart about the room searching for green things that will project green light. The children say, "Hurry! Before it's too late!" "Green power!" And, "More green things, get more green things!" (see Figure 117). Once the projector is shining green light onto the moon, Ana walks away from the digital projection, emerging from the moon as La Luna (see Figure 
118). She is welcomed by the cheering children. They join hands and turn in a ring, singing a favorite song from our lantern walk, "I see the moon and the moon sees me..."

The story was not being "acted out," but rather was produced anew in the moment; co narrated by an assemblage of children, a change in light provided by the digital projection, handfuls of green items from around the classroom, and more.

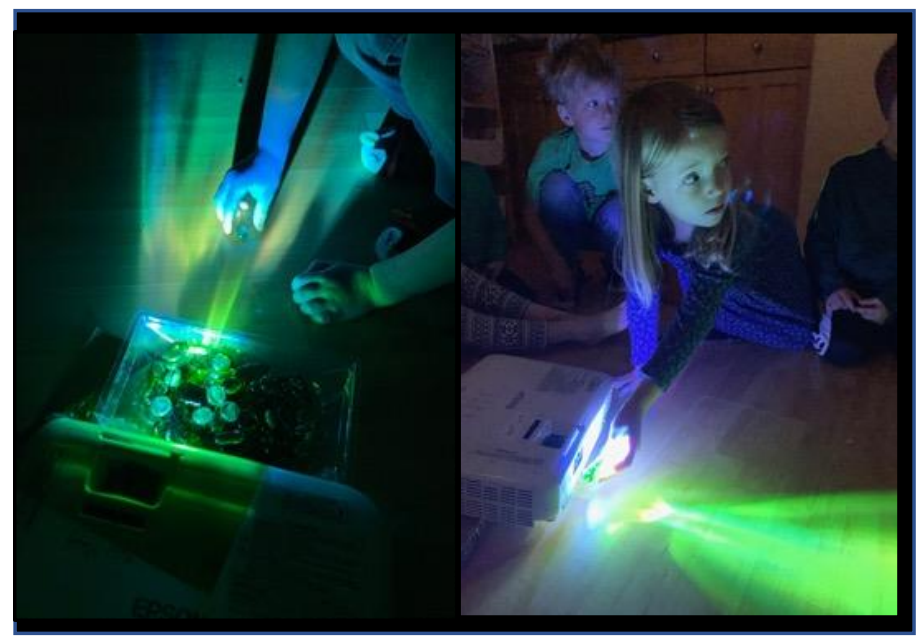

Figure 117. Green power.

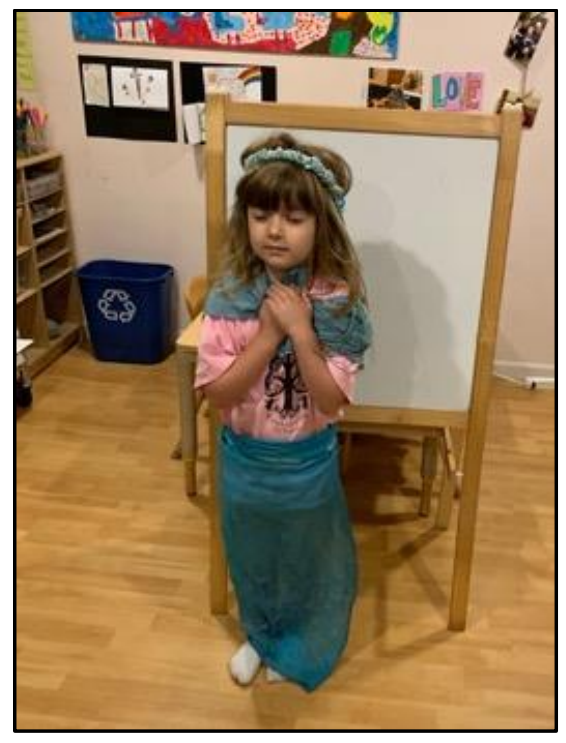

Figure 118. La Luna. 


\section{0:05 a.m.}

It is now time for Santa and His Elves. Mason, Kyle, and Archer have been inspired by the preceding story event to also employ the use of a digital projection for their story. Kyle chooses an image from online to serve as a digital backdrop. He chooses a scene with a candlelit tree and a fireplace, and a soundtrack of holiday music set to piano (see Figure 119). Even though it is June, to me, it suddenly feels like December.

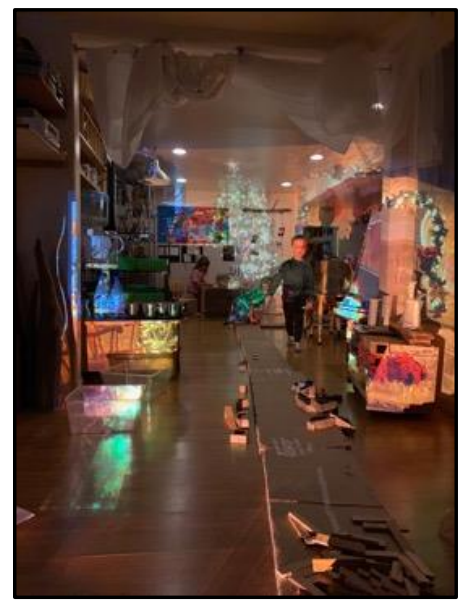

Figure 119. Setting the scene.

The affect of the moment is almost tangible. Mason rounds the corner from the other side of the room. Encountering the scene that Kyle had prepared, he exclaims, "It really IS Christmas!" The story unfolds. Archer and Mason are elves and Kyle is Santa. They take a long time making a big conveyor belt and pushing "toys" down the belt to Santa's sack. They try to make a big sack out of silk scarves, and it doesn't work, so I get them a black garbage bag which they are thrilled with (see Figures 120 and 121).

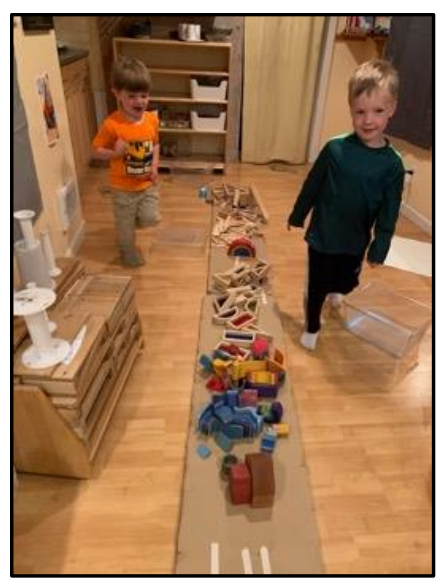

Figure 120. Conveyer belt. 


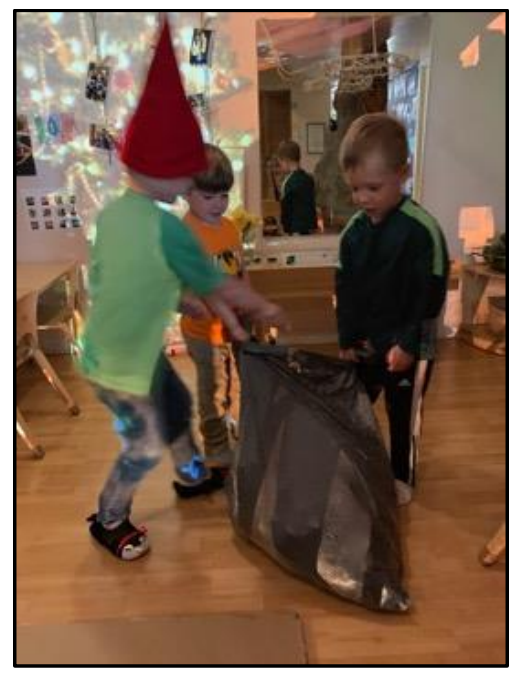

Figure 121. Santa's sack.

They push all the toys down the conveyor belt and into the garbage bag and say, "Santa! Your sack is almost ready!" They are delighted by how heavy the bag is.

Kyle: "It's Christmas! Now we get to unwrap our own presents!"

Stella: "I've already slept for 13 days."

Mason: "Santa brought me a street sweeper that lights up at night!"

Jake: "It's my birthday today Santa!"

Ana: "Merry Christmas Santa! (To me) "Santa brought you flowers mother!"

Me: "Thank you Santa!"

Kyle: (Presents Ana in a garbage bag to Archer.) "Archer, you got a final present this year!" Ana pops out of the bag and we all laugh.

Mason: "We can play Christmas morning outside."

The following free-writing gatherings segment was written immediately following the story celebrations of June 7 th to consider the context and implications of these powerful narrative events.

\section{Gatherings}

Ana's La Luna story sharing was similar to our typical story theater in the sense that the children were all gathered with the sole purpose of supporting her in sharing the story. However, we did not stick to a "script," and the story was not only supported by, 
but actively co-narrated with human and more-than-human participants (the children, the green glass, the digital projection of the moon). Mason and Kyle's story celebration of Santa and His Elves was not unlike any other day they would play out their storyline. However, the music, digital projection, the excited chatter among the children, and the black garbage bag contributed to the affective, material, and discursive domains of the story assemblage. Not subscribing to conventions regarding a performance, Mason and Kyle did not require or even request the full attention of their classmates. Rather, the other children were called to participation by the momentum of the narrative itself. The announcement made by Mason: “It's Christmas! Now we get to unwrap our own presents!" for example, brought the children running to gather toys from "under" the cob tree in our classroom.

Both The Story of La Luna and Santa and His Elves were of vital importance to the children and to our collective research, and I was concerned that the story sharing experiences would not honor the stories in a way that they deserve. But in each case, it seemed that the children valued the energy of the narrative event more than the integrity of the original storyline. Or perhaps better worded, the energy of the narrative event is what upheld the story's integrity.

The following pedagogical narration is the final one of the study and makes connections between implicated relationalities occurring throughout the study.

\section{Weeks 10-12—Drawing Lines}

The concept of power being activated by physical contact with a magic object or being emerged several times in weeks 10-12. In week 10, Fiona, Ana, and others argued 
that children's spells, the magic vials they created, transmit their power to a human or an animal through physical contact. Fiona said of Mason and his spell, "He has to wear his spell around his neck to touch his heart," and Ana asked if I could put her spell pouch away, saying, “Jeremy is biting on it. Maybe guinea pigs like magic too!” Also, in week ten, Kyle told me that he could feel the chick's spirit "from her legs" as she was standing on his lap, ostensibly because her legs made contact with him. Later that same day, Ana said of her invisible power, "My power made me have silver hair. Since I'm holding it, it went up into my arm and into my hair." I draw a rhizomatic line between these discussions about magic being transferred by touch and The Story of La Luna, where touching the stone "shooted her into the sky with the jewel." This idea can also be found as far back as week one, when Truman was brought back from the dead by being covered in magic necklaces, and week six, when Ana/Alice was shrunk by being sprayed with the contents of the "Drink Me" bottle. It is, in fact, one of the most recurrent ideas throughout the course of the study, emerging in many forms and culminating in our discussion about touching the spells in week ten.

\section{Looking back, looking forward}

As discussed in the Methods section of Chapter 3, my intention in this study was to seek out hot spots, where the data sparks or glows, "resonating in the body as well as the brain" (MacLure, 2013, p. 661). June 7th, culminating in the enactment of The Story of La Luna and Santa and His Elves, was spent in the affective glow of the data, where "things hanging in the air [were] worth describing" (Stewart, 2011, p. 447). The story 
events were a happening of sorts - an inexpressible, intangible experience closer to ritual than play or story alone.

Tsing (2015) asked, 'How do gatherings sometimes become 'happenings,' that is, greater than the sum of their parts?" (p. 23). This is not to say that a gathering can be reduced to fragments and measured accordingly, but rather to suggest that a gathering is specific, contextual, and irreducible to its individual components. In this instance, the story assemblages, or gatherings, created a feeling of being suspended in liminal space and time; "lodged in the queer temporality of the event" (MacLure, 2019); on the threshold between the world that existed before, and the world that would exist afterwards. The experience brought to mind a common invocation from Wiccan and magical activism rituals: We are between the worlds, and what happens between the worlds changes all the worlds (Calley Jones \& Mair, 2014).

Thinking with critical posthumanism/feminist new materialisms, I recognize that along with children, materials such as the green glass, elf hats, and the plastic garbage bag were crucial other-than-human participants in today's narrative events. However, as Ingold (2011) reminded us, materiality is not limited to the surface of the landscape or objects alone. Materiality also includes weathering, air, atmosphere, and more elements seen and unseen than I could possibly account for. Ingold's proposal allows me to consider the material affects of the digital projections, holiday music, and other nonphysical elements in a story assemblage, such as in this tentative mapping of Santa and His Elves (see Figure 122). 


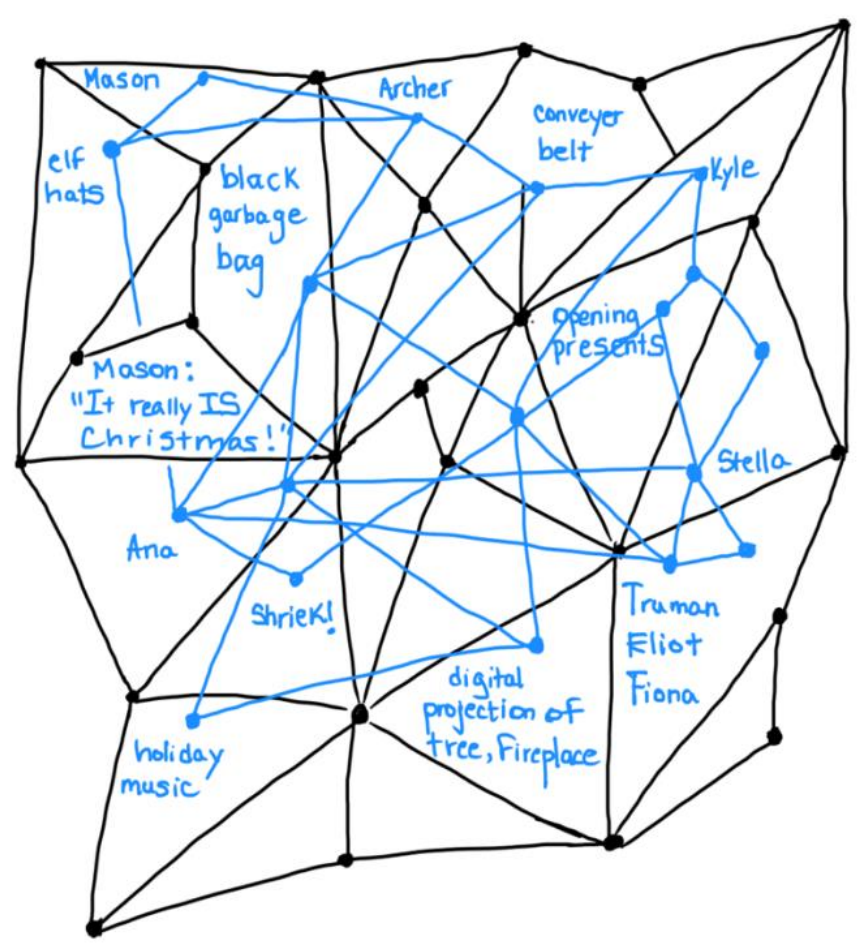

Figure 122. Santa and His Elves Story Assemblage.

At many times during the course of this study I was tempted to pull one thread from a story assemblage in an attempt to measure its individual contribution. To take an example from the final day of the study, I could have posed the question: How did the digital projection of the holiday scene in the classroom affect the Santa and His Elves story event? I came to realize that to address a question such as this would be a fruitless endeavor, for when you pull on one thread (or line), the entire network shifts in response. Haraway (2016b) likened this phenomenon to a string figure, which can be used to show the complex and dynamic lines of relations and "connections that matter" (p. 10) in assemblages (see Figure 123). 


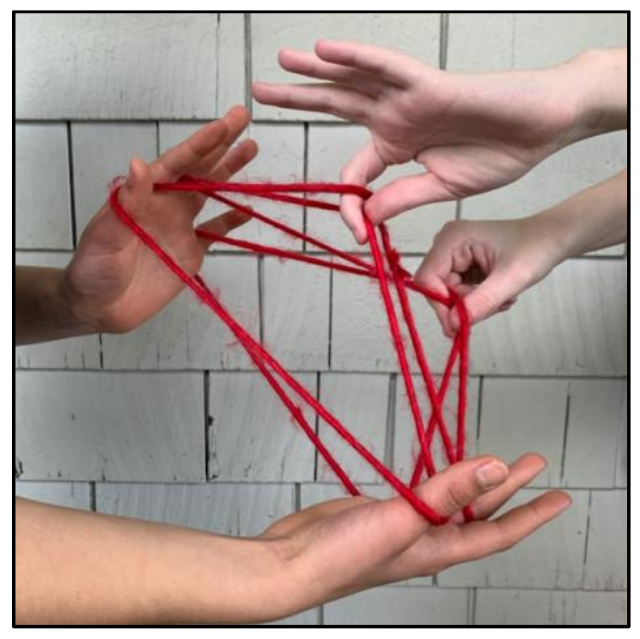

\section{Figure 123. String figures.}

Further, this practice of atomizing data is a colonizing practice to be resisted. Thus, rather than attempting to isolate particular narrative elements, I leaned on critical posthumanism/feminist new materialisms to map implicated relationships between narrative elements, events, and participants in the story assemblages (see Appendix G). In doing so, the children's impressionistic photography approach came to mind, where a sense of an assemblage is shown through movement, flow, and arrangement in favor of the depiction of a single, defined subject. Thinking with children's photography supports me in surrendering to the entangled complexity of the data and resisting conventional research practices that habitually sever relational ties (Davis \& Todd, 2017).

Chapter 4 presented the data in two ways: first, through a chronological catalogue of narrative events that included photographic data, children's words, illustrations, and free-writing gatherings authored by myself. Next, I offered pedagogical narrations to diffractively draw lines between narrative elements and events with relationalities as an approach to understanding the findings and identifying points of connection. 
In the upcoming and final chapter, I recast the findings into three areas that address the research question: How does the more-than-human matter in children's storytelling? I go on to offer a discussion of the findings and consider the implications for practice and policy. Lastly, I draw lines towards possible avenues for future research. 


\section{CHAPTER 5: DISCUSSION OF THE DATA}

In chapter 5, I offer a synthesis of the study's findings to address the research question: How does the more-than-human matter in children's storytelling? First, I provide a brief review of the purpose of the study and the research question. Then, thinking with critical posthumanism/feminist new materialisms, I build upon the presentation of data from Chapter 4 with a discussion on the implications of the findings for early childhood education and research. Next, I consider how choices made in my research design affected the results of the study. Before concluding, I put forward suggestions for future research on children's narrativity.

\section{Purpose of Study and Research Question}

The purpose of this post qualitative study was to position children's storytelling as a disruptive force to the privileging of western, positivist, and humanist knowledges in early childhood education and research, making space for ideas and knowledges that might otherwise be pushed into the margins. My research question was: How does the more-than-human matter in children's storytelling? Children's storytelling was centered at the heart of this study, with special attention given to unconventional stories that may not be recognized as such by normative standards of early childhood education. I use the phrase "normative standards" to mean those which are founded on white, Eurocentric/Euro-Western, anthropocentric perspectives of teaching and learning (Grosfóguel, 2009; Parnell, \& Iorio, 2015; Quintero, 2015; van Dooren \& Rose, 2016). To frame this study, I centered children's unconventional storytelling to illuminate the complex world of children's narrativity and to better understand children's knowledge 
making processes that occur outside the bounds of commonly legitimized ways of knowing and sanctioned classroom activities.

This research began in the middle of an inquiry, as Deleuze (1988) noted is often the case with post-qualitative inquirers. I had been observing the rich and complex world of early childhood education, where I have lived for much of my life, erode by increments. I felt that the rapidly expanding vision of early education as a platform to ensure core bodies of knowledge, though intended to ensure equity, posed a threat to nonconventional knowledges and methods of knowledge production. It was clear to me from my daily life with children that knowledge is not always intellectual, but can be embodied, affective, or otherwise. The encounter with Mason's story described in Chapter 1 served as a provocation for me and led me to recognize children's unconventional storytelling as a potential a mode of inquiry into unorthodox ways of being, knowing, and making in early childhood classrooms.

Now that I have reviewed the purpose of the study and the research question, I will go on to present a discussion on the findings touched on in Chapter 4. Though the study's findings emerged across the data, I will primarily be evidencing the findings through two of our enduring storylines, The Story of La Luna and Santa and His Elves. In the course of the study, these stories in particular have acted as dynamic meeting spaces (Ahn \& Filipenko, 2007; Puroila et al., 2012) of encounter for our classroom community, as well as a meeting place for our collective research (Quintero, 2017). I discuss the data in this way to offer synthesis by illuminating the findings through two significant, yet very different narratives. 


\section{Discussion of Findings}

In this study I gathered data produced over a 12-week period with 10 children aged 2.5-5.5. The data consists of observations, photographs taken by the children and myself, audio recordings of narrations and discussions about narrations, freewriting gatherings, and critical pedagogical narrative segments, which I used as both a data source and a data analysis approach. Attending to the new materialist concept of direct material engagement, I adopted an active membership role (Henward, 2015) as a teacher, co-researcher, and observant participator (Mein, 2011; Rautio, 2014; Tedlock, 1991) alongside children during this 12 -week, immersive study. Though I did not actively coauthor the children's stories, my participation as a classroom teacher who co-shapes the school culture, engages in documentation, and offers provocations for classroom discussions cannot be dismissed.

As noted in Chapter 4, there are three main findings that emerged from the data to address the research question of how the more-than-human matters in children's storytelling. Below, I show how each of the three findings were exhibited in the storylines The Story of La Luna and Santa and His Elves.

\section{Storytelling is a more-than-human event.}

The primary finding that emerged from this study is that storytelling is a morethan-human event. There were a host of more-than-human elements that were vital participants and active co-narrators in the ongoing production of stories during this study. More-than-human presences_-faeries, La Luna, Santa, dead birds, the elf who stole our binoculars, and elemental forces such as wind, water, ice, weathering, air, color, and 
atmosphere, were among the narrative contributors. Creatures such as our school rabbit and guinea pigs, and the three dead birds, as well as materials like fabric, stones, and plastic eggs, and more intangible elements such as digital photographs and projections were all players in the more-than-human socialities (Tsing, 2013) and assemblages from which the study's stories emerged. By making stories in partnership with creatures, presences, land, forces, things, and one another, the children were forging meaningful relations; "making kin" (Haraway, 2016b) with more-than-human others in the common worlds they share.

Words and vocalizations can also be counted among the nonhuman coconstructors of storytelling during this study. Examples from the data include the children chanting the words "Magic, Magic, Magic", "More Magic", and the word "Ghost-es" to produce material affects in narrative activities. Ana's story about the blue jewel week 6, where she "forgot the words" to a spell and thus lost her power, and Mason's tornado story which provoked Rosie to jump in circles as she "read" it; both exemplify children's understanding about the ability of words to produce material affects.

Throughout the study, children emphasized particular words in their verbal narrations to increase their impact, such as in the La Luna story where La Luna was “TRANSFERRED into the skyyyy." The power of spoken and written words was illustrated in week 5 when Ana asked me to write certain words in blue to make a material distinction between things that applied to her and things that applied to Rosie. It is also significant that the children named the talisman from Peru "Magic Word;" an acknowledgement of the powerful potential of words to produce material affects. 
My research question about how the more-than-human matters in children's storytelling is premised on the understanding that the more-than-human world does indeed matter; the crux of the question rests on how, or in what ways the more-thanhuman is significant to children's narrative world. I found that the specific ways in which more-than-human elements came to matter in the study's storytelling events depended entirely on the context. In this section, I show the more-than-human nature of children's storytelling within the context of two stories that by now the reader is familiar with, The Story of La Luna and Santa and His Elves.

Both The Story of La Luna and Santa and His Elves were generated not only within the human social realm, but also in assemblage with more-than-human presences and material participants. In the final written version of The Story of La Luna, for example, the story begins not with a human, but with a jewel. "Once upon a time there was a jewel, and then, once upon a time there was a girl." This jewel, an actual stone in the classroom, was acknowledged by Archer as "no ordinary stone" and was one of the main elements of the narrative. When La Luna touched the jewel, it transferred her into the sky, where she was trapped in the moon for one hundred years. An equally critical more-than-human element in this story is "green power," which ultimately releases La Luna from her bondage. Indeed, green power is so critical to The Story of La Luna, that when it was being performed in week 12, the children used a projector and various objects to project green light onto the moon so Ana, as La Luna, could be released, saying, "Green power! . . More green things, get more green things!" The story was not able to play out until the children had successfully generated enough green light, or green 
power, to release La Luna. Further, as noted in the pedagogical narrative segment from weeks 7-9, the story itself emerged as a more-than-human presence in the social life of the classroom as an intangible force that was as significant and vibrant as the human presences.

With Santa and His Elves, materials were central to both the story's ongoing production and its eventual performance. Each time I observed Mason and Kyle to be working with this story, they were simultaneously playing with materials to construct various aspects of the narrative; such as Santa's workshop, the conveyer belt, and toys that were to be delivered by Santa on Christmas night (see May 30th, June 6th, and June 7th). In fact, their material constructions were at least as important to them as the words to the story, which consisted of a dictated conversation and was rarely read aloud. For example, Kyle and Mason often took photos of their constructions and shared them at class meeting to demonstrate to the class that they had been working on their story. When they built Santa's workshop out of Magnetiles on June 6th, they invited the class over to see it without a narrative to accompany it as if they expected their friends to intuit the evolving story by simply witnessing the structure they had created. At the story celebration on June 7 th, material affects such as holiday music and sound of crackling fire in the digitally projected fireplace, elf hats, the garbage bag, and the conveyer belt amassed with toys, were key components to in the story event. In fact, the dictated conversation we had been loosely referring to as the "story" was not voiced at the story celebration. I waited for the right moment to read it, and eventually realized that it was 
not important. The story was being produced anew with this more-than-human event; the original text was unnecessary.

There were multiple occasions in the course of the study, however, where children leveraged the use of text, grammar, and verbal sounds or utterances for material affect in their storytelling. Engaging with a materialist theory of language (Deleuze et al., 1987), one might argue that language always has material implications. For the purposes of this inquiry however, the relevant issue is how language might participate as a more-thanhuman element in children's storytelling. Deleuze (2007) argued for the place of language in assemblages by saying, "In assemblages, you find states of things, bodies, various combinations of bodies, hodgepodges; but you also find utterances, modes of expression, and whole regimes of signs" (pp. 166-167). However, language is not privileged in an assemblage; it is merely one aspect whose degree of influence varies depending on multiple other factors.

One example of language as an active participant in an assemblage can be found in week five, when Mason requested that I read his story "Tornado Story" at a class discussion. Much like his story "A Circle Turn," that served as the impetuous for this study during the previous school year, he had wildly scribbled circles of every color in his journal along with the words: "Once upon a time there was a big tornado and it spinned every bit about over and over and over and over and over . . and OVER.” Mason had confidence in the power of the repeated phrase "over and over" combined with his drawing to generate a powerful affect among the children, which it did. Upon hearing "over and over," the children jumped up and began spinning around, continuing 
this activity until the story ended minutes later with the final, emphasized word, “. . and OVER." Upon this last word, the children collapsed as if a spell had been broken. These actions make me think to MacLure's (2016) notions of children's use of language. She said:

The child "knows" what adults have by and large forgotten. That nonsense is not the opposite, but the confederate of sense. That there are more ways to connect than through the exchanging of messages or the deciphering of meaning. That words and sounds are bodies too, capable of being detached from their syntagmatic and paradigmatic bonds and set in motion to draw a different line. (p. 179)

In "Tornado Story," Mason employed the use of language as a more-than-human force to produce material affects in his peers. His use of the phrase "over and over," repeated over and over was an incantation to compel and incite action. He was, as MacLure (2019) aptly described, "forcefully wielding words for transformation, rather than explanation" (p.5). This use of language by Mason is reminiscent of the chanting of the word "MAGIC, MAGIC, MAGIC ..." in week 10; the word "Ghost-es" in week twelve; or the phrase "more magic!" in week one. In each case the context was unique, and the intention cannot be assumed. However, in all of these instances, words were invoked for their material and affective potential.

An expanded concept of narrativity is required. The second finding that emerged from the data is that an expanded concept of narrativity is required to fully attune and attend to the multiplicitous storytelling that occurs in early childhood settings. Although deeply valued within early childhood education, children's storytelling has traditionally been framed by western, positivist, and humanist ideals, and modeled after the classic episodic Aristotelian narrative. Through this narrow lens, children's stories 
are framed by human and language centered traditions (see Kuby, 2017b), focused on oral or written narratives (Franzén, 2015; Puroila et al., 2012), with a clear beginning, middle, and end, and a discernable plot and character(s). In this study, very few stories met all of these qualifications, and some of them met so few that they would not have been recognized as such according to established storytelling conventions. Rather, the children's narrativity, which can refer to a story, but also includes the context and the material-discursive process of producing the story (Puroila et al., 2012), was characterized by multimodality, and the rhizomatic qualities of emergence, fragmentariness, non-linearity, and movement. It is important to note, that given the critical posthumanist/feminist new materialist orientation of this research, I view multimodality as a method of narrative production rather than of narrative representation. This means that when a story is being produced multimodally, it is being generated by a new assemblage rather than being simply represented in a different form.

The children in this study co-narrated multimodally in cooperation with morethan-human networks. This was sometimes done orally, either told aloud or dictated to a teacher, but was also accomplished through play, vocalizations, embodied gestures, actions, and more. In this 12-week study, narrations were sung, illustrated, physically displayed (the magical stone in the tree) or otherwise constructed (space-shooter), danced, "played out," embodied in movement, or the material itself (such as the paint markings on the stone circle at the arboretum). Narrations were also generated by events or "happenings" with a network of actors who participated in a story's ongoing production, such as in the story celebrations in week 12. 
During the study, multimodal forms of story production, such as illustration, song, and photography were central to the children's narrative culture (Kinnunen \& Puroila, 2016) and were acknowledged as valid methods of storytelling. This was evidenced throughout the study, but in particular by Truman's illustration of "lightning that died a faerie into an egg," As a 2.5-year-old, he was better able to create his story through a drawing than by verbalizing it. Immediately after drawing the picture, he ran off to "build" the story, looking for string to support his multimodal re-production. With a broader definition of narrativity, stories like Truman's can be validated as such rather than seen as a developmental step that will lead to "real" (meaning written or spoken) storytelling later. At 5 years old, Mason and Kyle, who are perfectly capable of articulating their stories yet prefer to physically construct them, are evidence that language-based stories ought not be the golden measure of narrative development.

To think with multimodality and the question of how the more-than-human matters in children's storytelling, I turn to our story companions, The Story of La Luna and Santa and His Elves. While Ana did actively subscribe to dominant conventions regarding narrativity by articulating The Story of La Luna, from beginning to end, Kyle and Mason never actually verbally relayed their story at all. It was only by overhearing their conversation about Kyle's visit to the North Pole and observing their narrative play that I was able to identify their emerging story. In our classroom, the children's journals are available daily. The children are frequently invited to illustrate their story and have an adult "write their words." It is at this point that we typically become aware of a child's investment in a story and invite them to explore their story using other modalities. 
Though Santa and His Elves was very important to Mason and Kyle, they chose to create and share their narrative primarily with materials, such as with their construction of Santa's sleigh, Santa's workshop, and the conveyer belt, and their photographs of these constructions. Rather than constructing elements in order to represent a fully formed story, they composed the story as they built it.

Additionally, the story celebration of Santa and His Elves on June 7th was an active, embodied production of the story in assemblage with both human and nonhuman actors rather than an "acting out" of a pre-existing story. According to conventional understandings regarding children's narrative practices, Mason and Kyle's material constructions, such as the Santa's workshop built with Magnetiles, and narrative productions, such as the story celebration with his classmates, might be regarded as supplementary to the "actual," or written story. I am proposing that we ought to expand our concept of narrativity to consider these material productions and events as not merely multimodal representations of the story, but the embodied story itself.

Similarly, the story celebration of The Story of La Luna on June 7th, which I had been unintentionally framing as a "playing out" of a somewhat static narrative, was actually a generative re-creation of the story. For the performance we moved from the rose rug where we typically hold story theater to the digital atelier where the moon was projected, by Ava's request. In doing so, we left behind the defined areas we customarily use for a stage and audience. Thus, I attempted to impose our customary performance conventions with questions such as, "Who are the actors?" and "Where should the audience sit?" Ana, in thinking with the story rather than about it, seemed to ignore these 
queries and dove immediately into the event. I read her latest version of the story aloud. The spoken words, the children, the digital projection of the moon, the green glass, and jewels, acted as a network in radical relationality (Nxumalo et al., 2018) in a more-thanhuman, material-discursive narrative production. During this story event, my understanding of narrativity was expanded and the expectations I previously held regarding story theater fell away. The children, however, were immersed in their affective experience of the story, unbounded by restrictive expectations.

In this study, some narrative ideas seemed to come from nowhere, perhaps because their origin is unknown to us. Other narrative concepts went underground, perhaps shooting off rhizomatically in unexpected directions, while still others emerged and re-emerged in various forms, moving erratically in-between relations; effectively disrupting "constraints of authority, regularity, and commonsense" (Lather, 1993, p. 680). Each of the stories, even the most conventional ones, were nomadic; displaying unpredictable movement and change.

One such example of the emergent, non-linear, and nomadic nature (indicating movement) of children's narrativity in this study is the concept of ghosts, which was first introduced in week 1 in two different stories told a day apart and seemed to disappear; reemerging in week 12 as a significant part of Thurman's Star Wars story. Due to the nomadic activity of this narrative element, I cannot be definitively determine whether or not Thurman's use of the concept was inspired by the earlier encounters with ghosts. If it was, it is unlikely that he would be conscious of, or explicitly verbalize the connection. Nomadic thinking has a capacity for moving in-between things, "creating connections 
where things were previously disconnected or seemed unrelated" (Braidotti, 2002, p. 173). Rather than diminishing the value of children's storytelling, the acknowledgement of its rhizomatic nature can be seen as an indication of the complex, irreducible, and sophisticated nature of children's knowledge production.

Storytelling as speculative fabulation. The third and final finding from this study concerns children's storytelling as speculative fabulation (Haraway, 2013, 2016a, 2016b); a proposal about what the world could be, should be, or might be. Speculative fabulation is a hybrid child of fiction and scholarship born of Whitehead's (1978) speculative pragmatism, Stengers' (2011) speculative thinking, and the feminist speculative fiction writings of Ursula K. Le Guin (1976) and Maureen Barr (1993). In this study, children occasionally presented their stories as speculative fabulations (Haraway, 2013, 2016a, 2016b); thought experiments for envisioning alternative worlds. and invocations to bring those worlds into being.

As Salazar (2017) noted, speculative fabulation can provide "an opening into a lively world of relationships between humans and the non-human or the more than human" (p. 166). The speculative fabulations that emerged during this 12-week study were a figurative process of world-making with children and more-than-human assemblages of human, nonhuman, material elements, and forces. These proposals for living, thinking, and doing otherwise, were situated in more-than-human matters of care and concern (See Puig de la Bellacasa, 2017) held by the children. Thus, the more-thanhuman world was significant both to the material-discursive narrative process by which these stories were produced, and to the stories themselves. 
For instance, Ana's speculative fabulation, The Story of La Luna carried a common theme from her narratives wherein humans collaborate with things to bring about helpful results. In The Story of La Luna, thing magic enables a jewel to trap La Luna in the moon for one hundred years. However, in the final telling of the story on

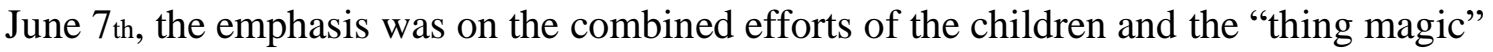
generated by green objects in the classroom to help La Luna: "Then the children came together, one by one, using all the green power they had to set her free ..." This theme of the powerful potential of thing magic in Ana's speculative play can be found in week 1 with the discovery of a never-ending food tree that has an egg inside it that can be eaten every morning for breakfast. We see it again in with Archer in week 4, where her character used a talisman referred to as Magic Word to "help people that were nice people that were trying to find homes." Thing magic re-emerged in Ana's speculative fabulation from week 9, where she said, "I noticed that the baby chick was curled up against another egg. So maybe we should put, like, a plain egg on there [the ofrenda]. Because I think the baby chick was trying to help the egg. THAT egg."

Italian children's author Gianni Rodari (1996) urged us to consider that "everyday things hide secrets for those who know how to see and hear them" (Turner \& Wilson, 2009, p 6). In Ana's speculative fabulations, she invoked what Bennett (2010) called thing power and the children in the study named thing magic (see May 30th) to generate a helpful outcome: To save the child/goddess La Luna; to find homes for the homeless; to keep people from going hungry; to communicate with a friend from another realm. To think with my research question of how the more-than-human matters in 
children's storytelling, I offer the proposal that thing magic, a more-than-human force, mattered in Ana's speculative fabulations because it provided a bridge between the world as it appears, and the world as it could be, should be, or might be.

Stella's speculative fabulations, on the other hand, tended to be small stories told anecdotally to friends that include more-than-human creatures such as faeries, elves, and talking animals. In Stella's favorite recurring storyline she proposed that she is a faerie who cares for lost or hurt animals. In week 8 , she became a superhero who used her powers to care for animals, such as baby lions and our class guinea pig. Stella's speculative fabulations ask us to envision alongside her a world that is alive with animals that can talk, faeries that are real, and beings who can enlist magic to "make an actual ice castle that you could go into." Stella's stories are both proposals of possible worlds and affective "lures for feeling" (Whitehead, 1978, p. 25) that inspired and excited her peers. This was exemplified in week 7 when her proposal that "real fairies live in my garden and I'm the only one in her family who can see them," inspired a jealous outrage in her friend Fiona.

Ana and Stella's extraordinary narrative proposals are, among other things, an invitation for us to join them in a world where matters of concern can be met with the remarkable power of care (Puig de la Bellacasa, 2017)—where a talisman gifted by a magician can find people homes, where a dead chick can be comforted by the presence of an egg, and where faeries care for lost or hurt animals. Neither truth nor untruth, these stories lie somewhere in-between and resist conventional literary categorizations. 
Speculative fabulations are powerful in that they can be a way of imagining alternatives when we have been told there are none (Moss, 2015a). A generative worlding rather than a reflection of things "as they are," these stories have the potential to disrupt western, positivist, and humanist knowledges in early childhood education and research. As Rodari (1996) said, "It takes a great dose of imagination to see beyond the school as it is now, and to imagine the crumbling of its 'reformatory as curriculum' walls. But it also requires that one believe the world can continue and become more humane" (p.117). Thus, children's speculative fabulations, a methodology commonly occurring in early childhood settings, can be enlisted for the collective and care-ful (re)imagining of the classrooms, schools, and worlds "as they are."

Having shown how these three main findings emerged from the data, I now proceed to discussing the implications of the findings for early childhood practice, policy, and research.

\section{Implications for Practice}

This investigation revealed the powerful potential of children's stories that are likely to "fly under the radar" in early childhood classrooms due to their unconventional nature. These stories, which may not be recognized as such, thrive in the between zones (Braidotti, 2002; Hohti 2016a) of the school day-between sanctioned classroom activities and noteworthy moments, where there is "almost nothing to see" (Braidotti, 2002, p. 173). By taking these unconventional stories seriously, we take seriously children's "non-standard” ways of doing, knowing, being, and making, and acknowledge that children are not the only significant actors in the early childhood classroom. 
The first, most critical implication of this research is that storytelling is a morethan-human event generated in partnership with more-than-human narrators. It would greatly serve our understanding as early childhood educators and scholars to recognize that children's stories are produced in partnership with the "non-natal kin" (Haraway, 2016b, p. 130) that comprise the more-than-human socialities (Tsing, 2013) of their daily classroom life. Recognizing more-than-human elements as vital participants rather than mere "screens upon which humans project their intentions, meanings, signs, and discourses" (Bryant, 2011, p. 247) allows us to attend to 'what is already happening' in the complex, entangled, more-than-human world that children inhabit.

Further, this study evidenced a need for an expanded concept of narrativity in order to fully attune and attend to children's storytelling. If we expand our understanding of narrativity to include wordless stories - stories that are danced or sung, stories found and made, or otherwise embodied — these formerly marginalized stories and their creators would be recognized and legitimized in educational spaces. Consequently, expanding the concept of narrativity is more than an ideological exercise, it is a decolonizing move that holds the potential to "keep the way open" in early childhood education for ways of being, knowing, and making beyond the familiar and the comfortable.

Further, this research serves as a call to take children's storytelling seriously. Paley (1998) often discussed storytelling as children's way of “inventing new worlds" (p. 50). More than just "inventive," however, storytelling can serve as speculative fabulations, a process by which children envision alternative worlds and generatively “compose those worlds with others" (Haraway, 2016b, p. 219). As well, children's 
speculative storytelling can offer a platform to "challenge taken-for-granted knowledges" (Åsberg, Thiele, van der Tuin, 2015, p. 153) and for "visioning, imagining, and critiquing the social space around us, and ultimately challenging the colonial norms fraught in our daily lives" (Simpson, 2011, p. 34). For example, What if we used all of our resources, maybe even those we are not yet aware of, to provide homes and food for people who need them? What if we used stories to cultivate a culture of care and concern for every being, from lost or injured animals, to nature spirits, to silenced presences who need attending to?

Perhaps most significantly, speculative fabulations challenge us to ask a critical question of our social imaginaries: What aren't we seeing? Relegating children's extraordinary proposals to fiction or fantasy is a way of escaping the responsibility that these stories entail and shuts down one of children's best strategies for imagining things otherwise. What if instead, we were to join with children in envisioning and bringing about worlds where justice and care for all worldly creatures are central to our endeavors?

\section{Implications for Policy}

The troubling trends towards universality in early childhood education can be viewed as a story of its own regarding "whose voices and knowledge count" (Bloch, 2014, p. 24) in early childhood curriculum and pedagogy, and therefore what comes to matter (Barad, 2007; Latour, 2004a), in early childhood education. Oftentimes, this story is told by economic experts, policymakers, child development specialists, and curriculum developers, and draws upon dominant knowledge paradigms and so called "scientifically 
inescapable truths" (Mozère, 2012, p. 60). These typically white, Eurocentric/EuroWestern, and anthropocentric, or human centered perspectives of teaching, learning, and researching are largely disconnected from the lives and experiences of children in early childhood settings.

To disrupt this dangerous single story (Adichie, 2009) regarding whose knowledges are legitimate and whose are not, I turned to children for their stories to learn what they find to be interesting, remarkable, and important, and how they make meaning and produce knowledge every day. I found that ideas about teaching and learning, rather than being reduced to a common outcome or measure, need to be greatly expanded in order to understand and support children's complex ways of knowing and being. Further, I found that children's storytelling provides an excellent platform for a collaborative (re)imagining of education that engenders care, concern, and justice for the human world and beyond.

My message to policymakers is this: Whether they are developed through crossnational learning standards (OECD, 2019) or initiatives such as preschool-third grade alignment (Early Learning Division, 2017), standardized educational programming is a neocolonial project that is consistently problematic for the multiplicitous cultures and contexts of young children. This research shows that the compulsory assimilation of children into a universal standard (a) privileges the experience and values of the dominant culture, thereby marginalizing ways of thinking, knowing, and being that cannot assimilate into that culture, (b) acts as a technology for reproducing whiteness and racism as a norm, (c) ensures the repetition of the same harmful histories, lesson 
plans and practices that are already in place, (d) fails to offer children opportunities to encounter unpredictability and surprise by curtailing engagement with the different, the interesting and the remarkable, (e) enculturates young children into a disposition of compliance and narrow-mindedness, and (f) shuts down multiplicity, complexity, and possibilities for thinking "otherwise" in a time when these qualities have never been more necessary. Thus, standardized educational programming perpetuates inequity in terms of both ideas and practices and, by necessity, undermines the inclusion and social justice it aims to achieve. This research offers an alternative by engaging with children's stories to offer possibilities for thinking "otherwise" — by keeping us open to complexity; by looking beyond the exclusively human realm; and by thinking with children's proposals about how the world could be, should be, or might be.

\section{Lines of Flight: Implications for Future Research}

This research touched on the potential for children to think with the more-thanhuman relational presences of the land in which they care for and attune to. The childparticipants in this study spend time with land now referred to as the Children's Arboretum. The histories, knowledges, and stories of the Multnomah and Clackamas peoples, the original stewards of the land, are lively presences that are always already there (Simpson, 2011), participating in relational encounters in ways that demand a closer look. Often times, as in the context of the Children's Arboretum, these presences are subject to ongoing settler colonialism and systemic erasure and can thus are what Nxumalo (2016b) called "absent presences" (p. 641) requiring recognition and care. To decolonize our storied places, we must attend to the "Indigenous relational presences, 
Indigenous onto-epistemologies, and past-present land histories" (Nxumalo \& Cedillo, 2017, p. 100) of these places.

Though these considerations were prominent in my thinking, I was not able to give them the attention that they deserve within the scope of this study. Nxumalo's (2015, 2016b, 2018) refiguring presences provides an appropriate launching point from which to address this question for future research: How can we develop storied relations with/in colonized land in a way that does not contribute to ongoing settler colonialism and systemic Indigenous erasure?

Another avenue for future inquiry is thinking with storytelling from a more-thanhuman perspective. As this critical posthumanist/feminist new materialist research has shown, children's story assemblages are comprised of both human and nonhuman elements - separation of those worlds is a false distinction. Just as the majority of stories shared here held a focus on the human participants, I could have instead focused on the more-than-human participants, "flipping the script" on conventional storytelling and research matterings. As an early childhood educator and researcher, however, children are a primary focus of my work. Thus, despite the more-than-human scope of this research study, children's voices, ideas, and actions were often centered. I did occasionally shift my perspective to the other-than-human in this study; a practice I have begun to experiment with in the context of environmental education research (Molloy Murphy, 2020). It is powerful work that I look forward to continuing. With this, my second question for future research is: How can thinking with storytelling from a morethan-human perspective expand our notion of justice beyond the human? 


\section{Additional Considerations}

The intentional small-scale design of this study was one of its greatest strengths. The stories were so numerous and entangled among 10 children that it is difficult to imagine how I could have done justice to the nuances of the storytelling of a larger group. In fact, even with a 12-week study I was not able to attend to every story-a testament to the incredibly rich world of children's narrativity. I feel that a close study of week 12 on its own, for example, would be a wonderful framing to address how the more-thanhuman matters in children's storytelling.

I am hopeful that readers of this work will find a multiplicity of threads to follow that connect to their own contexts, as in Haraway's (2016b) string figures where we make "connections that matter" (p. 10) which are sometimes lost or broken, and other times lead us to "something consequential and maybe even beautiful, that wasn't there before" (p. 10). As string figures are practices for thinking as well as making (Haraway, 2016b), I hope that readers will take this work from the many hands that crafted it, change it, and pass it on.

\section{(In)Conclusion}

While a great deal of research has addressed the exclusively human social aspects of young children's storytelling practices, few researchers have looked beyond the human realm to understand the broader influences. Thinking with a critical posthumanist/feminist new materialist framework, this study examined the human and more-than human assemblages that constitute children's daily lives and thus, are coparticipants in their storytelling. 
This research study established that stories can act as proposals to envision other worlds; to help us imagine alternatives where we have been told there are none. I argue that by (a) acknowledging storytelling as a more-than-human event, (b) expanding our concept of narrativity, and (c) thinking with children's proposals for how the world could be, should be, or might be, we can begin to imagine education otherwise. In doing so, we can move away from the oppressive standards, practices, and pedagogies that promote orthodoxy in educational systems for young children and create openings for new possibilities.

This study broke from conventional education research by considering not what worlds are being reflected in children's storytelling, but rather what worlds are being produced. This is an important distinction at this particular moment in history, when we must consider what knowledges are legitimized and what are outcast by our systems of education, and what worlds are produced and re-produced in the process. Ulmer (2017) reminded us that "justice is a more-than-human endeavor" (p. 833). Thus, in the pursuit of social and planetary justice, it might serve us well to consider speculative, hopeful, and care-ful practices of storytelling and worldmaking with children and the more-thanhuman. 


\section{REFERENCES}

Adichie, C. (2009). The danger of a single story. TED Global 2009. Retrieved from https://www.ted.com/talks/chimamanda_adichie_the_danger_of_a_single_story

Ahn, J., \& Filipenko, M. (2007). Narrative, play, art, and self: Intersecting worlds. Early Childhood Education Journal, 34(4), 279-289.

Alaimo, S., Hekman, S., \& Hekman, S. J. (Eds.). (2008). Material feminisms. Bloomington, IN: Indiana University Press.

Algava, A. (2016). Beyond child-centered constructivism: A call for culturally sustaining progressive pedagogy. Occasional Paper Series, 2016(35), 46-60.

Anderson, D. (Producer), \& Unkrich, L. (Director). (2017). Coco [film]. United States: Pixar Animation Studios.

Anderson, I. M. (2014). Early childhood educators' perception of Oregon's professional development system: A hermeneutic phenomenological study (Order No. 3669067). Available from Dissertations \& Theses @ Portland State University; ProQuest Dissertations \& Theses Global. (1648435120).

Aoki, T. T. (1993). Legitimating lived curriculum: Towards a curricular landscape of multiplicity. Journal of Curriculum and Supervision, 8(3), 255-268.

Ariès, P. (1962). Centuries of Childhood. London, UK: Jonathan Cape.

Arndt, S., \& Tesar, M. (2016). A more-than-social movement: The post-human condition of quality in the early years. Contemporary Issues in Early Childhood, 17(1), $16-25$.

Åsberg, C., Thiele, K., \& Van Der Tuin, I. (2015). Speculative before the turn: Reintroducing feminist materialist performativity. Cultural Studies Review, 21(2), 145 .

Bamberg, M., \& Georgakopoulou, A. (2008). Small stories as a new perspective in narrative and identity analysis. Text \& Talk: An Interdisciplinary Journal of Language, Discourse Communication Studies, 28(3), 377-396.

Barad, K. (2003). Posthumanist performativity: Toward an understanding of how matter comes to matter. Signs: Journal of Women in Culture and Society, 28(3), 801-831.

Barad, K. (2007). Meeting the universe halfway: Quantum physics and the entanglement of matter and meaning. Durham, NC: Duke University Press. 
Barad, K. (2010). Quantum entanglements and hauntological relations of inheritance: Dis/continuities, spacetime enfoldings, and justice-to-come. Derrida Today, 3(2), 240-268.

Barad, K. (2014). Diffracting diffraction: Cutting together-apart. Parallax, 20(3), $168-187$.

Barr, M. (1993). Lost in space : Probing feminist science fiction and beyond. Chapel Hill, N.C.: University of North Carolina Press.

Beckett, C. J. À. (2007). Playing in the in-between: Implications for early childhood education of new views of social relations. Kensington, NSW, Australia: University of New South Wales.

Bell, A., \& Russell, C. (2000). Beyond human, beyond words: Anthropocentrism, critical pedagogy, and the poststructuralist turn. Canadian Journal of Education, 25(3), $188-203$.

Bennett, J. (2004). The force of things: Steps toward an ecology of matter. Political Theory, 32(3), 347-372.

Bennett, J. (2010). Vibrant matter: A political ecology of things. Durham, NC: Duke University Press.

Bentley, D. F., \& Pinedo-Burns, H. J. (2017). I have a voice. I have a story: The artistic practice of practitioner research. In J. M. Iorio \& W. Parnell (Eds.), Meaning making in early childhood research: Pedagogies and the personal (pp. 53-77). New York, NY: Routledge.

Berger, I. (2010). Extending the notion of pedagogical narration through Hannah Arendt's political thought. In V. Pacini-Ketchabaw (Ed.), Flows, rhythms, and intensities of early childhood education curriculum (Vol. 45; pp. 57-76). New York, NY: Peter Lang.

Bhabha, H. (1996). The other question: Difference, discrimination, and the discourse of colonialism. In H. Baker, M. Diawara, \& R. H. Lindeborg (Eds.), Black British cultural studies: A reader (pp. 87-106). Chicago, IL: University of Chicago Press.

Biesta, G. (2006). Beyond learning: Democratic education for a human future. Boulder, CO: Paradigm.

Binder, M. (2013). Remembering why: The role of story in educational research. In Education, 17(2), 42-60. 
Binder, M. (2014). The storied lives children play: Multimodal approaches using storytelling. Canadian Children, 39(2), 11-20.

Blaise, M. (2012). Playing it straight: Uncovering gender discourse in the early childhood classroom. London, UK: Routledge.

Blaise, M., Hamm, C., \& Iorio, J. M. (2016). Modest witness (ing) and lively stories: Paying attention to matters of concern in early childhood. Pedagogy, Culture \& Society. 31-42.

Blazek, M. (2018). Children and young people's emotional geographies. In T. Skelton \& S. Aitken, (Eds.), Establishing geographies of children and young people. (pp. 121). Singapore: Springer.

Bloch, M. N. (2014). Interrogating reconceptualizing early care and education (RECE) 20 years along. In M. N. Bloch, B. B. Swadener, \& G. S. Cannella (Eds.), Reconceptualizing early childhood care and education: A reader (pp. 19-31). New York, NY: Peter Lang.

Bloch, M. N., Swadener, B. B., \& Cannella, G. S. (Eds.). (2014). Reconceptualizing early childhood care and education: A reader. New York, NY: Peter Lang.

Bloch, M. N., Swadener, B. B., \& Cannella, G. S. (2018). Reconceptualizing early childhood education and care, a reader: Critical questions, new imaginaries and social activism. New York, NY: Peter Lang.

Bogard, K., \& Takanishi, R. (2005). PK-3: An aligned and coordinated approach to education for children 3 to 8 years old. Society for Research in Child Development Social Policy Reports, 19(3), 1-23.

Bozalek, V., \& Zembylas, M. (2017). Diffraction or reflection? Sketching the contours of two methodologies in educational research. International Journal of Qualitative Studies in Education, 30(2), 111-127.

Braidotti, R. (2002). Metamorphoses: Towards a materialist theory of becoming. Malden, MA: Polity.

Braidotti, R. (2013). The posthuman. Cambridge, UK: Polity.

Braidotti, R., \& HlAnajova, M. (Eds.). (2018). Posthuman glossary. London, UK: Bloomsbury Academic.

Bredekamp, S., \& Rosegrant, T. (1995). Reaching potentials: Transforming early childhood curriculum and assessment (Vol. 2). Washington, DC: National Association for the Education of Young Children. 
Brown, M.W., (1965). The dead bird. (R. Charlip, illus.). New York: Harper \& Row.

Bruner, J. (1986). Actual minds, possible worlds. Cambridge, MA: Harvard University Press.

Bruner, J. (1991). The narrative construction of reality. Critical Inquiry, 18(1), 1-21.

Bryant, L. (2011). The democracy of objects. Ann Arbor, MI: Open Humanities Press.

Burman, E. (2008). Deconstructing developmental psychology (2nd ed.). London, UK: Routledge.

Cagliari, P., Castegnetti, M., Giudici, C., Rinaldi, C., Vecchi, V., \& Moss, P. (Eds). (2016). Loris Malaguzzi and the schools of Reggio Emilia: A selection of his writings and speeches 1945-1993. New York, NY: Routledge.

Calley Jones, C., \& Mair, H. (2014). Magical activism: What happens between the worlds changes the worlds. Annals of Leisure Research, 17(3), 296-313. https://doi.org/10.1080/11745398.2014.943255

Cannella, G. S., Swadener, B. B., \& Che, Y. (2007). Entry: Reconceptualizing early childhood education. International Encyclopedia of Early Childhood Education. Westport, CT: Praeger.

Cannella, G. S., \& Viruru, R. (2003). Childhood and postcolonization: Power, education, and contemporary practice. New York, NY: RoutledgeFalmer. Carr, M., Mitchell, L., \& Rameka, L. (2016). Some thoughts about the value of an OECD international assessment framework for early childhood services in Aotearoa New Zealand. Contemporary Issues in Early Childhood, 17(4), 450-454.

Chaillé, C. (2008). Constructivism across the curriculum in early childhood classrooms: Big ideas as inspiration. Boston, MA: Allyn \& Bacon.

Chaillé, C., \& Britain, L. (1991). The young child as scientist: A constructivist approach to early childhood science education. New York, NY: Harper Collins.

Cliffe, J., \& Solvason, C. (2016). Using rhizomatic thinking in early childhood pedagogy to avoid making other into same. TACTYC Reflections, 1-6.

Common Worlds Research Collective. (2020). Homepage. Retrieved January 6, 2020, from http://commonworlds.net

Coole, D., \& Frost, S. (2010a). Introducing the new materialisms. In. D. Coole \& S. Frost (Eds.), New materialisms: Ontology, agency, and politics (pp. 1-43). Durham, NC: Duke University Press. 
Coole, D., \& Frost, S. (Eds). (2010b). New materialisms: Ontology, agency, and politics. Durham, NC: Duke University Press.

Cooper, P. (2005). Literacy learning and pedagogical purpose in Vivian Paley's storytelling curriculum. Journal of Childhood Literacy, 5(3), 229-251.

Cooper, P. (2009). The classrooms all young children need: Lessons in teaching from Vivian Paley. Chicago, IL: University of Chicago Press.

Cremin, T., \& Flewitt, R. (2017). Laying the foundations: Narrative in early learning. In T. Cremin, R. Flewitt, B. Mardell, \& J. Swann (Eds.), Storytelling in early childhood: Enriching language, literacy and classroom culture (pp. 13-28). London; New York, NY: Routledge, Taylor \& Francis Group.

Cremin, T., Flewitt, R., Mardell, B., \& Swann, J. (Eds.). (2016). Storytelling in early childhood: Enriching language, literacy and classroom culture. New York, NY: Routledge, Taylor \& Francis Group.

Cremin, T., Flewitt, R., Swann, J., Faulkner, D., \& Kucirkova, N. (2018). Storytelling and story-acting: Co-construction in action. Journal of Early Childhood Research, 16(1), 3-17.

Dahlberg, G., \& Moss, P. (2005). Ethics and politics in early childhood education. London, UK: RoutledgeFalmer.

Davies, B. (2010). The implications for qualitative research methodology of the struggle between the individualised subject of phenomenology and the emergent multiplicities of the poststructuralist subject: The problem of agency. Reconceptualizing Educational Research Methodology, 1(1), 54-68.

Davies, B. (2014a). Listening to children: Being and becoming. New York, NY: Routledge.

Davies, B. (2014b). Reading anger in early childhood intra-actions: A diffractive analysis. Qualitative Inquiry, 20(6), 734-741.

Davies, B. (2016). Emergent listening. In N. K. Denzin \& M. D. Giardina Eds.), Qualitative inquiry through a critical lens (pp. 73-84). New York, NY: Routledge.

Davis, H., \& Todd, Z. (2017). On the Importance of a Date, or Decolonizing the Anthropocene. ACME: An International E-Journal for Critical Geographies, 16(4).

Deacon, R. (2005, Spring). Moral orthopedics: A Foucauldian account of schooling as discipline. Telos, 2005(130), 84-102. 
Deleuze, G. (1987). Dialogues (with Claire Parnet). Trans. Hugh Tomlinson and Barbara Habberjam. New York, NY: Columbia University Press.

Deleuze, G. (1988). Spinoza: Practical philosophy (R. Hurley, Trans.). San Francisco, CA: City Lights Books.

Deleuze, G. (1992, Winter). Postscript on the societies of control. October, 59, 3-7.

Deleuze, G. (1994). Difference and repetition (P. Patton, Trans.). New York, NY: Columbia University Press.

Deleuze, G. (2007). Eight years later: 1980 interview. In G. Deleuze (Ed.), Two regimes of madness: Texts and interviews 1975-1995 (pp. 175-180). New York, NY: Semiotext(e).

Deleuze, G., \& Guattari, F. (1983). Anti-Oedipus: Capitalism and schizophrenia. (R. Hurley, M. Seem, \& H. R. Lane, Trans.). London, UK: The Athlone Press.

Deleuze, G., \& Guattari, F. (1994). What is philosophy? (G. Burchell \& H. Tomlinson, Trans.). London, UK: Verso.

Deleuze, G., Guattari, F., \& Massumi, B. (1987). A thousand plateaus: Capitalism and schizophrenia. London, UK: Continuum.

Del Vecho, P. (Producer), \& Buck, C. \& Lee. J. (Directors). (2013). Frozen [film]. United States: Walt Disney Pictures.

Derrida, J. (1974). Of grammatology (G. C. Spivak, Trans.). Baltimore, MD: The Johns Hopkins University Press.

Dunn, J. (1980). The little rabbit. (P. Dunn, illus.). Random House Children's Books.

Early Learning Division. (2017). Resources and tools, Oregon Early Learning Division. Retrieved from https://oregonearlylearning.com/early-learning-kindergartenguidelines

Edwards, C., Gandini, L., \& Forman, G. (Eds.). (1993). The hundred languages of children: The Reggio Emilia approach to early childhood education. Norwood, NJ: Ablex.

Edwards, R. (2010). The end of lifelong learning. A post-human condition. Studies in the Education of Adults 42 (1). 5-17.

Engel, S. (2003). My harmless inside heart turned green: Children's narratives and their inner lives. In B. van Oers (Ed.), Narratives of childhood: Theoretical and 
practical explorations for the innovation of early childhood education (pp. 3950). Amsterdam, The Netherlands: VU University Press.

Engel, S. (2006). Narrative analysis of children's experience. In S. Greene \& D. Hogan (Eds.), Researching children's experience: Approaches and methods (pp. 199216). London, UK: Sage.

Fee, M. (2019). Indigenous Cosmopolitics and English Literacy in the Pacific Northwest. Journal of Intercultural Studies: Worlds at Home: On Cosmopolitan Futures, 40(5), 580-594.

Fenwick, T. (2010). Re-thinking the "thing": Sociomaterial approaches to understanding and researching learning in work. Journal of Workplace Learning, 22(1/2), 104116.

Fenwick, T., \& Edwards, R. (2011). Considering materiality in educational policy: Messy objects and multiple reals. Educational Theory, 61(6), 709-726.

Fenwick, T., \& Landri, P. (2012). Materialities, textures and pedagogies: Socio-material assemblages in education. Pedagogy, Culture \& Society, 20(1), 1-7.

Floyd, C., \& Cooper, P. (2008). A storytelling curriculum: 400 classrooms and us-22 years later. Exchange, 181, 45-48.

Foucault, M. (1977). Discipline and punish: The birth of prison. New York, NY: Pantheon.

Foucault, M. (1982). The subject and power. Critical inquiry, 8(4), 777-795.

Franzén, K. (2015). Being a tour guide or travel companion on the children's knowledge journey. Early Child Development and Care, 185(11-12), 1928-1943.

Freire, P. (1997). Pedagogy of hope. Granby, MA: Bergin \& Garvey.

Freire, P. (2018). Pedagogy of the oppressed. New York, NY: Bloomsbury Academic.

Fróði. (2018). What does it take to see an elf? ( R. Jónsdóttir, Trans.). Reykjavik, Iceland: The Elf Garden.

Gallacher, L. A., \& Gallagher, M. (2008). Methodological immaturity in childhood research? Thinking through participatory methods. Childhood, 15(4), 499-516.

Gathering the stories of place. (2015). Volcanoes in Cascadian myth. Retrieved from https://www.gatheringthestories.org/2015/01/06/volcanoes-in-cascadian-myth/ 
Giroux, H. A. (1983). Theories of reproduction and resistance in the new sociology of education: A critical analysis. Harvard Educational Review, 53, 257-293.

Giroux, H. A. (1992a). Border crossings: Cultural workers and the politics of education. New York, NY: Routledge.

Giroux, H. A. (1992b). Paulo Freire and the politics of postcolonialism. JAC: A Journal of Composition Theory, 12(1), 15-26.

Goodman, N. (1976) Languages of art: An approach to a theory of symbols (2nd ed.). Indianapolis, IN: Hackett.

Gorski, P. C. (2008). Good intentions are not enough: A decolonizing intercultural education. Intercultural Education 19(6), 515-525.

Gorski, P. C. (2011). Unlearning deficit ideology and the scornful gaze: Thoughts on authenticating the class discourse in education. In R. Ahlquist, P. Gorski, \& T. Montano (Eds.), Assault on kids: How hyper-accountability, corporatization, deficit ideologies, and Ruby Payne are destroying our schools (pp. 152-176). New York, NY: Peter Lang.

Graue, M. E. (1993). Ready for what?: Constructing meanings of readiness for kindergarten. SUNY press.

Graves, B. (2006). PK-3: What is it and how do we know it works? New York, NY: Foundation for Child Development.

Greene, S., \& Hill, M. (2006). Researching children's experience: Methods and methodological issues. In S. Greene \& D. Hogan (Eds.), Researching children's experience: Approaches and methods (pp. 1-21). London, UK: Sage.

Grosfóguel, R. (2009, Fall). A decolonial approach to political-economy: Transmodernity, border thinking and global coloniality. KULT 6: Special Issue. Epistemologies of Transformation: The Latin American Decolonial Option and its Ramifications, 10-38.

Grosz, E. (2002). Notes on the thing. Perspecta, 33, 78-79.

Gubrium J., \& Holstein, J. (1998). Narrative practice and the coherence of personal stories. The Sociological Quarterly, 39, 163-187.

Gubrium, J., \& Holstein, J. (2008). Narrative ethnography. In S. N. Hesse-Biber \& P. Leavy (Eds.), Handbook of emergent methods (pp. 241-264). New York, NY: Guilford Press. 
Hamm, C., \& Boucher, K. (2017). Engaging with place: Foregrounding aboriginal perspectives in early childhood education. In N. Yelland \& D. F. Bentley (Eds), Found in translation: Connecting reconceptualist thinking with early childhood education practices (pp. 58-75). New York, NY: Routledge.

Haraway, D. (2003). The companion species manifesto. Chicago, IL: Prickly Paradigm Press.

Haraway, D. (2004). The Haraway reader (pp. 125-150). New York, NY: Routledge.

Haraway, D. (2008a). Otherworldly conversations; terran topics; local terms. In S. Alaimo \& S. Heckman (Eds.), Material feminisms (pp. 157-187). Bloomington, IN: Indiana University Press.

Haraway, D. (2008b). When species meet. Minneapolis, MN: University of Minnesota Press.

Haraway, D. (2016a). Speculative fabulation. YouTube Video. Retrieved from https://www.youtube.com/watch?v=zFGXTQnJETg.

Haraway, D. (2016b.) Staying with the trouble: Making kin in the Chthulucene. London, UK: Duke University Press.

Haraway, D. (2013). SF: Science fiction, speculative fabulation, string figures, so far. Ada: A Journal of Gender, New Media, and Technology, (3).

Haraway, D. (2017, October 23). Making oddkin: Storytelling for earthly survival. Public lecture. New Haven, Connecticut: Yale University. Retrieved from: https://www.youtube.com/watch?v=z-iEnSztKu8\&t=17s

Harris, A. M. (2018). A Story Is Not a Thing (but It Does Have a Life). Departures in Critical Qualitative Research, 7(4), 25-29.

Heckman, J. J. (2006). Skill formation and the economics of investing in disadvantaged children. Science, 312(5782), 1900-1902.

Heidegger, M. (1962). Being and time. New York, NY: Harper \& Row.

Helm, J., \& Katz, L. G. (2016). Young investigators: The project approach in the early years (Early Childhood Education Series). New York, NY: Teachers College Press.

Henward, A. S. (2015). (Re) imagining participant observation with preschool children. In W. Parnell \& J. M. Iorio (Eds.), Disrupting early childhood education research: Imagining new possibilities (pp. 73-85). New York, NY: Routledge. 
Hodgins, B., Thompson, D., \& Kummen, K. (2017). Weavings walks and wonderings: Stories of the liveliness of pedagogical narrations. In A. Fleet, C. Patterson, \& J. Robertson (Eds.), Pedagogical documentation in early years practice: Seeing through multiple perspectives (pp. 193-206). Thousand Oaks, CA: Sage.

Hohti, R. (2016a). Children writing ethnography: Children's perspectives and nomadic thinking in researching school classrooms. Ethnography and Education, 11(1), 74-90.

Hohti, R. (2016b). Classroom matters: Research with children as entanglement. Helsinki, Finland: University of Helsinki.

Hohti, R. (2016c). Now - and now - and now: Time, space and the material entanglements of the classroom. Children \& Society, 30(3), 1-25.

Hohti, R. (2018). Siiri and the "bag lady": Analysing the material entanglements of special needs. Reconceptualizing Educational Research Methodology, 9(1) 6-16.

Højgaard, L., \& Søndergaard, D. M. (2011). Theorizing the complexities of discursive and material subjectivity: Agential realism and poststructural analyses. Theory \& Psychology, 21(3), 338-354.

Honan, E. (2004). (Im)plausibilities: A rhizo-textual analysis of policy texts and teacher's work. Educational Philosophy and Theory, 36(3), 267-281.

Honan, E. (2007). Writing a rhizome: An (im)plausible methodology. International Journal of Qualitative Studies in Education, 20(5), 531-546.

Horton, J. (2018). For the love of cuddly toys. Children's Geographies, 16(4), 446-454.

Hultman, K., \& Lenz Taguchi, H. (2010). Challenging anthropocentric analysis of visual data: A relational materialist methodological approach to educational research. International Journal of Qualitative Studies in Education, 23, 525-542.

Hursh, D. (2001). Neoliberalism and the control of teachers, students, and learning: The rise of standards, standardization, and accountability. Cultural Logic, 4(1), 4-1.

Hursh, D., \& Martina, C. A. (2003). Neoliberalism and schooling in the U.S.: How state and federal government education policies perpetuate inequality. Journal for Critical Education Policy Studies, 1(2), 1-13.

Hyvärinen, M. (2008). Narrative form and narrative content. In I. Järventie \& M. Lähde (Eds.), Methodological challenges in childhood and family research (pp. 43-63). Tampere, Finland: Tampere University Press. 
Hyvärinen, M., Hydén, L.-C., Saarenheimo, M., \& Tamboukou, M. (2010). Beyond narrative coherence: An introduction. In M. Hyvärinen, L.-C. Hydén, M. Saarenheimo, \& M. Tamboukou (Eds.), Beyond narrative coherence (pp. 1-15). Amsterdam, The Netherlands: John Benjamins.

Imarisha, W., Brown, Adrienne M., Thomas, Sheree R., \& Institute for Anarchist Studies, issuing body. (2015). Octavia's brood: Science fiction stories from social justice movements. Oakland, CA: AK Press.

Ingold, T. (2011). Being alive: Essays on movement, knowledge and description. New York, NY: Routledge.

Iorio, J. M., Hamm, C., Parnell, W., \& Quintero, E. (2017). Place, matters of concern, and pedagogy: Making impactful connections with our planet. Journal of Early Childhood Teacher Education, 38(2), 121-135.

Iorio, J. M., \& Parnell, W. (2015a). Reaching toward the possible. In W. Parnell \& J. M. Iorio (Eds.), Disrupting early childhood education research: Imagining new possibilities (pp. 1-6). New York, NY: Routledge.

Iorio, J. M., \& Parnell, W. (Eds.). (2015b). Rethinking readiness in early childhood education: Implications for policy and practice. New York, NY: Palgrave Macmillan.

Iorio, J. M., \& Parnell, W. (2017). Crisis, empowerment, and learning in early childhood: Deepening meaning through arts-based research and action research. In J. M. Iorio \& W. Parnell (Eds.), Meaning making in early childhood research: Pedagogies and the personal (pp. 30-52). New York, NY: Routledge.

Iorio, J. M., \& Parnell, W. (Eds.). (2018). Meaning making in early childhood research: Pedagogies and the personal. New York, NY: Routledge.

Iorio, J. M., Parnell, W., Quintero, E., \& Hamm, C. (2018). Early childhood teacher educator as public intellectual. In M. Bloch, B. Swadener, \& G. Canella (Eds.), Reconceptualizing early education and care: Critical questions, new imaginaries and social activism (pp. 299-312). New York, NY: Peter Lang.

Iovino, S., \& Oppermann, S. (2012, Spring). Material ecocriticism: Materiality, agency, and models of narrativity. Ecozon@, 3(1), 17.

Iovino, S., \& Oppermann, S. (Eds.). (2014). Material ecocriticism. Bloomington, IN: Indiana University Press.

Jackson, A., \& Mazzei, L. (2012). Thinking with theory in qualitative research: Viewing data across multiple perspectives. Hoboken, NJ: Taylor \& Francis. 
James, A., \& Prout, A. (Eds.). (2015). Constructing and reconstructing childhood: Contemporary issues in the sociological study of childhood. New York, NY: Routledge.

Jay, M. (2003). Critical race theory, multicultural education, and the hidden curriculum of hegemony. Multicultural Perspectives, 5(4), 3-9.

Jones, B. (2018). Mattering. In R. Braidotti \& M. Hlavajova, M. (Eds.), Posthuman glossary (pp. 244-246). New York, NY: Bloomsbury.

Jones, E. (1970). Introduction. In L. Dittmann (Ed.), Curriculum is what happens: Planning is the key (pp. 3-10). Washington, DC: National Association for the Education of Young Children.

Jones, E., \& Nimmo, J. (1994). Emergent curriculum. Washington, DC: NAEYC.

Karlsson, L. (2013). Storycrafting method-To share, participate, tell and listen in practice and research. The European Journal of Social \& Behavioural Sciences, 6(3), 1109-1117. doi:10.15405/ejsbs.88.

Katz, L., \& Chard, S. (1994). The project approach. ERIC Digest. Champaign, IL: ERIC Clearinghouse on Elementary and Early Childhood Education.

Kauerz, K. (2007). Making the case for P-3. (Document No. EC-07-01). Denver, CO: Education Commission of the States.

Kessler, S., \& Swadener, B.B. (1992) Reconceptualizing the early childhood curriculum: Beginning the dialogue. New York, NY: Teachers College Press.

Kind, S. (2013). Lively entanglements: The doings, movements and enactments of photography. Global Studies of Childhood, 3(4), 427-441.

Kinnunen, S., \& Puroila, A. M. (2016). "If my sister was here"-The narrative in-between space in young children's photography process. Childhood, 23(2), 236-254.

Koro-Ljungberg, M. (2012). Methodology is movement is methodology. Critical qualitative research reader, 82-90. New York, NY: Peter Lang.

Koro-Ljungberg, M. (2015). Reconceptualizing qualitative research: Methodologies without methodology. Thousand Oaks, CA: Sage.

Koro-Ljungberg, M., MacLure, M., \& Ulmer, J. (2015). D...a...t...a..., data++, data and some problematics. In N. K. Denzin \& Y. S. Lincoln (Eds.), The SAGE handbook of qualitative research (pp. 462-484). Thousand Oaks, CA: Sage. 
Kozol, J. (2000) Ordinary resurrections: Children in the years of hope. New York, NY: Crown.

Kraftl, P. (2019). Children's geographies: Encounters and experiences. In T. Schwanen \& R. van Kempen (Eds.), Handbook of urban geography (pp. 354-368). Northampton, MA: Edward Elgar.

Kuby, C. (2017a). Rhizomes and intra-activity with materials: Ways of disrupting and reimagining early literacy research, teaching and learning. In J. M. Iorio \& W. Parnell (Eds.), Meaning making in early childhood research: Pedagogies and the personal (pp. 146-165). New York, NY: Routledge.

Kuby, C. (2017b). Why a paradigm shift of "more than human ontologies" is needed: putting to work poststructural and posthuman theories in writers' studio. International Journal of Qualitative Studies in Education, 30(9), 877-896.

Kuby, C., \& Crawford, S. (2018). Intra-activity of humans and nonhumans in writers' studio: (Re) imagining and (re) defining "social." Literacy, 52(1), 20-30.

Kuby, C., Rucker, T. G., \& Kirchhofer, J. M. (2015). “Go be a writer”: Intra-activity with materials, time and space in literacy learning. Journal of Early Childhood Literacy, 15(3), 394-419.

Kuhn, T. S. (1962). The structure of scientific revolutions. Chicago, IL: University of Chicago Press.

Kumashiro, K. K. (2000). Toward a theory of anti-oppressive education. Review of Educational research, 70(1), 25-53.

Lather, P. (1993). Fertile obsession: Validity after poststructuralism. The Sociological Quarterly, 34(4), 673-693.

Lather, P. (1998). Critical pedagogy and its complicities: A praxis of stuck places. Educational Theory, 48(4), 487-497.

Lather, P. (2013). Methodology-21: What do we do in the afterward? International Journal of Qualitative Studies in Education, 26(6), 634-645.

Lather, P. (2016). Top ten+ list: (Re) thinking ontology in (post) qualitative research. Cultural Studies? Critical Methodologies, 16(2), 125-131.

Lather, P., \& St., Pierre, E. A., \& (2013). Post-qualitative research. International Journal of Qualitative Studies in Education, 26(6), 629-633.

Latour, B. (2004a). Why has critique run out of steam? From matters of fact to matters of concern. Critical Inquiry, 30(2), 225-248. 
Latour, B. (2004b). The politics of nature: How to bring science into democracy. Cambridge, MA: Harvard University Press.

Lee, J. (2002). Racial and ethnic achievement gap trends: Reversing the progress toward equity? Educational Researcher, 31(1), 3-12.

Lenz Taguchi, H. (2005). Getting personal: How early childhood teacher education troubles students' and teacher educators' identities regarding subjectivity and feminism. Contemporary Issues in Early Childhood, 6(3), 244-255.

Lenz Taguchi, H. (2010a). Going beyond the theory/practice divide in early childhood education: Introducing an intra-active pedagogy. New York, NY: Routledge.

Lenz Taguchi, H. (2010b). Rethinking pedagogical practices in early childhood education: A multidimensional approach to learning and inclusion. In N. Yelland (Ed.), Contemporary perspectives on early childhood education (pp. 14-32). Maidenhead, UK: Open University Press.

Lenz Taguchi, H. (2011). Investigating learning, participation and becoming in early childhood practices with a relational materialist approach. Global Studies of Childhood 1(1), 36-49.

Lenz Taguchi, H. (2012). A diffractive and Deleuzian approach to analyzing interview data. Feminist Theory, 13, 265-281.

Lenz Taguchi, H. (2016). "The concept as method" tracing-and-mapping the problem of the neuro (n) in the field of education. Cultural Studies? Critical Methodologies, $16(2), 213-223$.

Lenz Taguchi, H., \& Palmer, A. (2014). Reading a Deleuzio-Guattarian cartography of young girls" “schoolrelated” ill-/wellbeing. Qualitative Inquiry, 20, 764-771.

Lenz Taguchi, H., \& St. Pierre, E. (2017). Using concept as method in educational and social science inquiry. Qualitative Inquiry, 23(9), 643-648.

Leonardo, Z. (2004). The color of supremacy: Beyond the discourse of "white privilege." Educational Philosophy and Theory, 36(2), 137-152.

Le Guin, U. (1976). The left hand of darkness (Ace science fiction). New York: Ace Books.

Lindgren, A. (1960). The Tomten. (H. Wiberg, illus.). Floris Books.

Lloro-Bidart, T. (2018). A feminist posthumanist multispecies ethnography for educational studies. Educational Studies, 54(3), 253-270. 
Long, S. (2010). Thumbelina. (S. Long, illus.). Chronicle Books.

Lupinacci, J., \& Happel-Parkins, A. (2016). (Un)learning anthropocentrism: An ecojustice framework for teaching to resist human-supremacy in schools. In S. Rice \& A. G. Rud (Eds.), The educational significance of human and non-human animal interactions (pp. 13-30). New York, NY: Palgrave Macmillan.

Macedo, D. (1999). Our common culture: A poisonous pedagogy. In M. Castells, R. Flecha, P. Freire, H. A. Giroux, D. Macedo, \& P. Willis (Eds.), Critical education in the new information age (pp. 117-132). Lanham, MD: Rowman \& Littlefield.

MacLure, M. (2013). Researching without representation? Language and materiality in post-qualitative methodology. International Journal of Qualitative Studies in Education, 26(6), 658-667.

MacLure, M. (2015). The "new materialisms": A thorn in the flesh of critical qualitative inquiry? In G. Cannella, M. S. Perez, \& P. Pasque (Eds.), Critical qualitative inquiry: Foundations and futures (pp. 93-112). New York, NY: Routledge.

MacLure, M. (2016). The refrain of the a-grammatical child: Finding another language in/for qualitative research. Cultural Studies? Critical Methodologies, 16(2), 173182.

MacLure, M. (2019). Witches and Wild Women: Bad Girls of the Anthropocene. In Lecture given at the American Educational Research Association Annual Meeting in Toronto, Canada.

MacNaughton, G. (2003). Shaping early childhood: Learners, curriculum and contexts. Berkshire, UK: McGraw-Hill Education.

Malone, K. (2016a). Posthumanist approaches to theorizing children's human-nature relations. In K. Nairn \& P. Kraftl (Eds.), Space, place, and environment (pp. 185206). Singapore: Springer Singapore.

Malone, K. (2016b). Theorizing a child-dog encounter in the slums of La Paz using posthumanistic approaches in order to disrupt universalisms in current "child in nature" debates. Children's Geographies, 14(4), 390-407.

Mardell, B., \& Swann, J. (2017). Conclusion: Storytelling and story acting: Rays of hope for the early years classroom. In T. Cremin, R. Flewitt, B. Mardell, \& J. Swann (Eds.), Storytelling in early childhood: Enriching language, literacy and classroom culture (pp. 186-198). New York, NY: Routledge, Taylor \& Francis Group. 
Martin, A. D., \& Kamberelis, G. (2013). Mapping not tracing: Qualitative educational research with political teeth. International Journal of Qualitative Studies in Education, 26, 668-679.

Maxwell, J. A. (2013). Qualitative research design: An interactive approach (3rd ed). Thousand Oaks, CA: Sage.

May, T. (2005). Gilles Deleuze: An introduction. [e-book]. New York, NY: Cambridge University Press. Retrieved from https://www.cambridge.org/core/books/gillesdeleuze/F8C52DB2028E005FF6A2D3A8C490B789 https://ndpr.nd.edu/news/ gilles-deleuze-an-introduction/

Mazzei, L. A. (2007). Toward a problematic of silence in action research. Educational Action Research 15(4), 631-642.

Mazzei, L. A., \& Jackson, A. (2016). Voice in the agentic assemblage. Educational Philosophy and Theory, 29(11), 1090-1098.

McNeil, M. 2010. "Post-millennial feminist theory: Encounters with humanism, materialism, critique, nature, biology and Darwin." Journal for Cultural Research 14(4), 427-436.

Mein, E. (2011). Multimodal literacies, pedagogy, and the construction of identity-based social movements: The case of Espina y Jugo in Mexico. Equity \& Excellence in Education, 44(3), 296-310.

Miller, M. (2016). Whiteness scholarship in early childhood education. New Zealand Research in Early Childhood Education, 19, 49-61.

Miller, P. J., Potts, R., Fung, H., Hoogstra, L., \& Mintz, J. (1990). Narrative practices and the social construction of self in childhood. American Ethnologist, 17(2), 292311.

Mitchell, C. (2011) Doing visual research. Thousand Oaks, CA: Sage.

Mitchell, L. (2019). Democratic policies and practices in early childhood education: An Aotearoa New Zealand Case Study; Vol. 24). Singapore: Springer.

Miyazaki, H., Van., B. J., Paquin, A., Leachman, C., Walt Disney Home Entertainment (Firm), Sutajio Jiburi, Kabushiki Kaisha., Tokuma Shoten., ... Buena Vista Home Entertainment (Firm). (2012). Castle in the sky. United States: Disney.

Molloy Murphy, A. (2018). (Re) considering squirrel--From object of rescue to multispecies kin. Journal of Childhood Studies, 43(1), 60-67. 
Molloy Murphy, A. (2020, January). (Re)Conceptualizing plastic as multispecies kin. Paper presented at Responding to Ecological Challenges with/in Contemporary Childhoods: An Interdisciplinary Colloquium on Climate Pedagogies, Ontario, CA.

Moss, P. (2006). Early childhood institutions as loci of ethical and political practice. International Journal of Educational Policy, Research, and Practice: Reconceptualizing Childhood Studies, 7(1), 127-136.

Moss, P. (2008). There are alternatives! Markets and democratic experimentalism in early childhood education and care (Working Papers in Early Childhood Development, No. 53). Available from Bernard van Leer Foundation, PO Box 82334, 2508 EH, The Hague, The Netherlands.

Moss, P. (2015a). Forward. In W. Parnell \& J. M. Iorio (Eds.), Disrupting early childhood education research: Imagining new possibilities (pp. xiii-xvi). New York, NY: Routledge.

Moss, P. (2015b). There are alternatives! Contestation and hope in early childhood education. Global Studies of Childhood, 5(3), 226-238.

Moss, P. (2017). Power and resistance in early childhood education: From dominant discourse to democratic experimentalism. Journal of Pedagogy, 8(1), 11-32.

Moss, P. (2018). Alternative narratives in early childhood: An introduction for students and practitioners. New York, NY: Routledge.

Moss, P., Dahlberg, G., Grieshaber, S., Mantovani, S., May, H., Pence, A., Vandenbroeck, M. (2016). The Organisation for Economic Co-operation and Development's international early learning study: Opening for debate and contestation. Contemporary Issues in Early Childhood, 17(3), 343-351.

Moss, P., \& Urban, M. (2010). Democracy and experimentation: Two fundamental values for education. Guetersloh, Germany: Bertelsmann Stiftung.

Moss, P., \& Urban, M. (2017). The Organisation for Economic Co-operation and Development's International Early Learning Study: What happened next. Contemporary Issues in Early Childhood, 18(2), 250-258

Mozère, L. (2012). Is experimenting on an immanent level possible in RECE? (Reconceptualizing Early Childhood Education). Indo-Pacific Journal of Phenomenology, 12(1), 55-63.

Murris, K. (2016). The posthuman child: Educational transformation through philosophy with picturebooks. New York, NY: Routledge. 
Murris, K., Reynolds, R.-A., \& Peers, J. (2018). Reggio Emilia inspired philosophical teacher education in the Anthropocene: Posthuman child and the family (tree). Journal of Childhood Studies, 43(1), 15-29.

Myers, C. (2014). A "terribly inefficient" production: Unsettling methodologies with children through Deleuzian notions of time. Reconceptualizing Educational Research Methodology, 5(2), 34-45.

Myers, C. (2015). Children, among other things: Entangled cartographies of the morethan-human kindergarten classroom. Doctoral Thesis, Kent State University. Retrieved from https://etd.ohiolink.edu/

Nicolopoulou, A. (2004). "When your powers combine, I am Captain Planet": The developmental significance of individual- and group-authored stories by preschoolers. Discourse Studies, 6(3), 347-371.

Nimmo, J., Marcilio, A., Fowler, A., \& Goyal, V. (2018). Voices of children: Intercultural collaborations in understanding and documenting the meaning of children's rights through dialogue and video. In S. M. Akpovo, M. J. Moran, \& R. Brookshire (Eds.), Collaborative cross-cultural research methodologies in early care and education contexts (pp. 151-168). New York, NY: Routledge.

Novinger, S., \& O'Brien, L. (2003). Beyond "boring, meaningless shit" in the academy: Early childhood teacher educators under the regulatory gaze. Contemporary Issues in Early Childhood, 4(1), 3-31. doi:10.2304/ciec.2003.4.1.4

Nxumalo, F. (2015). Forest stories: Restorying encounters with 'natural' places in early childhood education. In V. Pacini-Ketchabaw \& A. Taylor (Eds.), Unsettling the colonial places and spaces of early childhood education (pp. 21-42). New York: Routledge.

Nxumalo, F. (2018). Situating Indigenous and Black Childhoods in the Anthropocene. In R. Latiner Raby \& E. J. Valeau (Eds.), Handbook of Comparative Studies on Community Colleges and Global Counterparts (pp. 1-22). Springer International Publishing. https://doi.org/10.1007/978-3-319-51949-4_37-2

Nxumalo, F. (2019). Decolonizing place in early childhood education. (Indigenous and decolonizing studies in education). New York, NY: Routledge.

Nxumalo, F. (2014). Unsettling encounters with "natural” places in early childhood education (Doctoral dissertation). Retrieved from https://dspace.library.uvic.ca/bitstream/handle/1828/5772/Nxumalo_Fikile_PhD_ 2014.pdf;sequence $=1$

Nxumalo, F. (2016a). Storying practices of witnessing: Refiguring quality in everyday pedagogical encounters. Contemporary Issues in Early Childhood, 17(1), 39-53. 
Nxumalo, F. (2016b). Towards "refiguring presences" as an anti-colonial orientation to research in early childhood studies. International Journal of Qualitative Studies in Education, 29(5), 640-654.

Nxumalo, F., \& Cedillo, S. (2017). Decolonizing place in early childhood studies: Thinking with Indigenous onto-epistemologies and Black feminist geographies. Global Studies of Childhood, 7(2), 99-112. Retrieved from https://doi.org/10.1177/2043610617703831

Nxumalo, F., \& Pacini-Ketchabaw, V. (2017). "Staying with the trouble" in child-insecteducator common worlds. Environmental Education Research, 23(10), 14141426.

Nxumalo, F., Vintimilla, C., \& Nelson, N. (2018). Pedagogical gatherings in early childhood education: Mapping interferences in emergent curriculum. Curriculum Inquiry, 433-453.

Ochs, E., \& Capps, L. (2001). Living narrative: Creating lives in everyday storytelling. Cambridge, MA: Harvard University Press.

Ogbu, J. (1988). Class stratification, racial stratification and schooling. In L. Weis (Ed.), Class, race, and gender in American education, (pp. 163-189). New York, NY: State University of New York Press.

Olson, S. (2012). Celebrating an Aorkian experience: A curriculum scholar review for EDU 6120. Curriculum Theory Projects.

Olsson, L. M. (2009). Movement and experimentation in young children's learning: Deleuze and Guattari in early childhood education. New York, NY: Routledge.

Oppermann, S. (2018). Storied matter. In R. Braidotti \& M. Hlavajova, M. (Eds.), Posthuman glossary. Retrieved from https://www.academia.edu/23028796/STORIED_MATTER_Entry_for_Posthuma n_Glossary._Edited_by_Rosi_Braidotti_and_Maria_Hlavajova_London_Bloomsb ury_forthcoming_

Organisation for Economic Co-operation and Development. (2019) International early learning study. Retrieved from http://www.oecd.org/edu/school/internationalearly-learning-and- child-well-being-study.htm

Osberg, D. (2008). The logic of emergence: An alternative conceptual space for theorizing critical education. Journal of the Canadian Association for Curriculum Studies, 6(1), 133-161. 
Osberg, D., \& Biesta, G. (2008). The emergent curriculum: Navigating a complex course between unguided learning and planned enculturation. Journal of Curriculum Studies, 40(3), 313-328.

Osberg, D., \& Biesta, G. (2009). The end/s of education: Complexity and the conundrum of the inclusive educational curriculum. International Journal of Inclusive Education, 14(6), 593-607.

Paananen, M., Kumpulainen, K., \& Lipponen, L. (2015). Quality drift within a narrative of investment in early childhood education. European Early Childhood Education Research Journal, 23(5), 690-705.

Pacini-Ketchabaw, V. (Ed.). (2010). Flows, rhythms, and intensities of early childhood education curriculum. New York, NY: Peter Lang.

Pacini-Ketchabaw, V. (2012). Postcolonial entanglements: Unruling stories. Child \& Youth Services, 33(3-4), 303-316.

Pacini-Ketchabaw, V., \& Nxumalo, F. (2015). Unruly raccoons and troubled educators: Nature/culture divides in a childcare centre. Environmental Humanities, 7(1), $151-168$.

Pacini-Ketchabaw, V., Nxumalo, F., Kocher, L., Elliot, E., \& Sanchez, A. (2015). Journeys: Reconceptualizing early childhood practices through pedagogical narration. Toronto, Ontario, Canada: University of Toronto Press.

Pacini-Ketchabaw, V., \& Taylor, A. (Eds.). (2015). Unsettling the colonial places and spaces of early childhood education. New York, NY: Routledge.

Pacini-Ketchabaw, V., Taylor, A., \& Blaise, M. (2016). Decentering the human in multispecies ethnographies. In C. A. Taylor \& C Hughes (Eds.), Posthuman research practices in education (pp. 149-167). Basingstoke, UK: Palgrave Macmillan.

Paley, V. G. (1986). Mollie is three: Growing up in school. Chicago, IL: University of Chicago Press.

Paley, V. G. (1988). Bad guys don't have birthdays. Chicago, IL: University of Chicago Press.

Paley, V. G. (1990). The boy who would be a helicopter: The uses of storytelling in the classroom. Cambridge, MA: Harvard University Press.

Paley, V.G. (1998). The girl with the brown crayon. Cambridge, MA: Harvard University Press. 
Paley, V. G. (2000). White Teacher. Cambridge, MA: Harvard University Press.

Paley, V. G. (2009). A child's work: The importance of fantasy play. University of Chicago Press.

Parnell, W. (2011). Teacher collaboration experiences: Finding the extraordinary in the everyday moments. Early Childhood Research and Practice, 13(2), 1-15.

Parnell, W. (2012, May). Reconstruction: Meltdown in the midst of beauty. Indo-Pacific Journal of Phenomenology, 12 (Specia0112021 Edition), 8 pp.

Parnell, W., Anderson, I., \& Molloy Murphy, A. (2019, November). (Re)Turning the Kaleidoscope: Diffracting research questions to offer openings. Paper presented at the 27th International conference for Reconceptualizing Early Childhood Education, Las Cruces, NM.

Parnell, W., Downs, C., \& Cullen, J. (2017). Fostering intelligent moderation in the next generation: Insights from REMIDA-inspired reuse materials education. The New Educator, 13(3), 234-250.

Parnell, W., \& Iorio, J. M. (Eds.). (2015). Disrupting early childhood education research: Imagining new possibilities. New York, NY: Routledge.

Parnell, W., \& Iorio, J. M. (2017). Vivid life and learning: Rendering thorough illustrations rather than chopping human stories to bits. In J. M. Iorio \& W. Parnell (Eds.), Meaning making in early childhood research: Pedagogies and the personal (pp. 1-7). New York, NY: Routledge.

Parr, A. (Ed.). (2010). The Deleuze dictionary (Rev. ed.). Edinburgh, UK: Edinburgh University Press.

Pedersen, H. (2010). Animals in schools: Processes and strategies in human-animal education. Purdue University Press.

Pederson, H. (2015). Education policy making for social change; A posthumanist intervention. In N. Snaza \& J. A. Weaver (Eds.), Posthumanism and educational research. (pp. 56-75). New York, NY: Routledge.

Pérez, M. S., \& Saavedra, C. M. (2017). A call for onto-epistemological diversity in early childhood education and care: Centering global south conceptualizations of childhood/s. Review of Research in Education, 41(1), 1-29.

Peters, L., Ortiz, K., \& Swadener, B. B. (2015). Something isn't right: Deconstructing readiness with parents, teachers, and children. In J. M. Iorio \& W. Parnell (Eds.), Rethinking readiness in early childhood education: Implications for policy and practice (pp. 33-47). New York, NY: Palgrave Macmillan. 
Petitfils, B. (2015). Researching the posthuman paradigm: The "subject" as curricular lens. In N. Snaza \& J. A. Weaver (Eds.), Posthumanism and educational research (pp. 30-42). New York, NY: Routledge.

Pfister, M. (1997). Milo and the magical stones. (M. Pfister, illus.). North-South Books.

Pink, S. (2008). An urban tour: The sensory sociality of ethnographic place-making. Ethnography, 9, 175-196.

Prout, A. (2005). The future of childhood. New York, NY: Routledge.

Prout, A. (2011). Taking a step away from modernity: Reconsidering the new sociology of childhood. Global Studies of Childhood, 1(1), 4-14.

Puig de la Bellacasa, M. (2017). Matters of care: Speculative ethics in more than human worlds (Posthumanities Book No. 41). Minneapolis, MN: University of Minnesota Press.

Puroila, A.-M., Estola, E., \& Syrjälä, L. (2012). Does Santa exist? Children’s everyday narratives as dynamic meeting places in a day care centre context. Early Child Development and Care, 182(2), 191-206.

Quintero, E. P. (2015). Storying learning in early childhood: When children lead participatory curriculum design, implementation, and assessment. New York, NY: Peter Lang.

Quintero, E. P. (2017). Carrying our roots/llevar a nuestras raíces. Global Studies of Childhood, 7(2), 179-195.

Quintero, E. P., \& Rummel, M. K. (2014). Storying: A path to our future: Artful thinking, learning, teaching, and research. New York, NY: Peter Lang.

Rahman, K. (2013). Belonging and learning to belong in school: The implications of the hidden curriculum for indigenous students. Discourse: Studies in the Cultural Politics of Education, 34(5), 660-672.

Rautio, P. (2013). Children who carry stones in their pockets: On autotelic material practices in everyday life. Children's Geographies, 11(4), 394-408.

Rautio, P. (2014). Mingling and imitating in producing spaces for knowing and being: Insights from a Finnish study of child-matter intra-action. Childhood, 21(4), 461474.

Rautio, P. (2017). "A super wild story": Shared human-pigeon lives and the questions they beg. Qualitative Inquiry, 23(9), 722-731. 
Reconceptualizing Early Childhood Education. (2014). Reconceptualizing early childhood education: A brief introduction. Retrieved from http://www.receinternational.org/about.html\#sthash.kOB8b85E.dpbs

Rice, S. (2016). The educational significance of human and non-human animal interactions: Blurring the species line. New York, NY: Basingstoke, UK: Palgrave Macmillan.

Riessman, C. K. (1993). Narrative analysis. Thousand Oaks, CA: Sage.

Rinaldi, C. (1995). The emergent curriculum and social constructivism: An interview with Lella Gandini. In C. Edwards, L. Gandini, \& G. Forman (Eds.), The hundred languages of children: The Reggio Emilia approach to early childhood education (pp. 101-111). Exeter, UK: Ablex.

Rinaldi, C. (1998). Projected curriculum constructed through documentationProgettazione. In C. P. Edwards, L. Gandini, \& G. E. Forman (Eds.), The hundred languages of children: The Reggio Emilia approach-Advanced reflections (2nd ed., pp. 113-125). Greenwich, CN: Ablex.

Rinaldi, C. (2006). In dialogue with Reggio Emilia: Listening, researching and learning. New York, NY: Routledge.

Rodari, G. (1996). The grammar of fantasy (J. Zipes Trans.). New York, NY: Teachers and Writers Collaborative.

Rose, D. B. (2014). Arts of living on a damaged planet. In Deborah Bird Rose. Retrieved from http://deborah-birdrose.com/tag/symbiotic-mutualism/

Rose, D. B. (2015). Becoming-witness. In D. Peterson \& M. Bekoff (Eds.), The Jane effect: Celebrating Jane Goodall (pp. 231-232). San Antonio, TX: Trinity University Press.

Rose, D. B. (2017). Shimmer: When all you love is being trashed. In A. Tsing, H. Swanson, E. Gan, \& N. Budandt (Eds.), Arts of living on damaged planet: Ghosts and monsters of the Anthropocene (pp. G51-G63). Minneapolis, MN: University of Minnesota Press.

Rose, D. B., \& van Dooren, T. (2017). Encountering a more-than-human world: Ethos and the arts of witness. In U. K. Heise, J. Christensen, \& M. Niemann (Eds.), The Routledge companion to the environmental humanities (pp. 120-128). New York, NY: Routledge.

Rotas, N. (2015). Ecologies of praxis: Teaching and learning against the obvious. In N. Snaza \& J. A. Weaver (Eds.), Posthumanism and educational research. (pp. 91103). New York, NY: Routledge. 
Simpson, L. (2011). Dancing on our turtle's back: Stories of Nishnaabeg re-creation, resurgence, and a new emergence. Winnipeg: Arbeiter Ring Publishers.

St. Pierre, E. A. (1997). Methodology in the fold and the irruption of transgressive data. International Journal of Qualitative Studies in Education, 10(2), 175-189.

St. Pierre, E. A. (2011). Post qualitative research: The critique and the coming after. In N. K. Denzin \& Y. S. Lincoln (Eds.), The Sage handbook of qualitative research (4th ed.; pp. 611-626). Thousand Oaks, CA: Sage.

St. Pierre, E. A. (2013). The posts continue: Becoming. International Journal of Qualitative Studies in Education, 26(6), 646-657.

St. Pierre, E. A. (2014). A brief and personal history of post qualitative research: Toward "post inquiry." Journal of Curriculum Theorizing, 30(2), 2-19.

St. Pierre, E. A. (2018). Writing post qualitative inquiry. Qualitative Inquiry, 24(9), 603-608.

St. Pierre, E. A. (2019). Post qualitative inquiry in an ontology of immanence. Qualitative Inquiry, 25(1), 3-16.

Salazar, J. (2017). Speculative fabulation: Researching worlds to come in Antarctica. In Salazar, J. F., Pink, S., Irving, A., \& Sjöberg, J. (Eds.), Anthropologies and futures: Researching emerging and uncertain worlds (pp. 151-170). New York, NY: Bloomsbury Academic.

San Souci, R. (1989). The Talking Eggs: A Folktale from the American South. (J. Pinkney, illus). Dial Books.

Schlossberg, N. K. (1989). Marginality and mattering: Key issues in building community. New directions for student services, 1989(48), 5-15.

Sellers, M. (2013). Young children becoming curriculum: Deleuze, Te Whāriki and curricular understandings. New York, NY: Routledge.

Sellers, M. (2015). "Working with (a) rhizoanalysis" and working (with) a rhizoanalysis. Complicity, 12(1), 6.

Smith, L. T., Tuck, E., \& Yang, K. W. (2019). Indigenous and decolonizing studies in education mapping the long view. New York, NY: Routledge.

Snaza, N. (2015). Toward a genealogy of educational humanism. In N. Snaza \& J. A. Weaver (Eds.), Posthumanism and educational research. (pp. 17-29). New York, NY: Routledge. 
Snaza, N., Appelbaum, P., Bayne, S., Morris, M., Rotas, N., Sandlin, J., . . Weaver, J. (2014). Toward a posthumanist education. Journal of Curriculum Theorizing, 30(2), 39-55.

Snaza, N., \& Weaver, J. (Eds.). (2015). Posthumanism and educational research. New York, NY: Routledge.

Soler, J., \& Miller, L. (2003). The struggle for early childhood curricula: A comparison of the English Foundation stage curriculum, Te Whāriki and Reggio Emilia. International Journal of Early Years Education, 11(1), 57-68.

Soto, L. D. (2005). Children make the best theorists. In L. D. Soto \& B. B. Swadener (Eds.), Power and voice in research with children (pp. 9-19). New York, NY: Peter Lang.

Soto, L. D., \& Swadener, B. B. (2002). Toward liberatory early childhood theory, research and praxis: Decolonizing a field. Contemporary Issues in Early Childhood, 3(1), 38-66.

Spaggiari, S. (1997). The invisibility of the essential. In V. Vecchi (Ed.), Shoe and meter: Children and measurement (pp. 10-13). Reggio Emilia, Italy: Reggio Children.

Staggs, L. (2000). Curriculum guidance for the early years. Early Years Educator, 2(6), 21-23.

Steffen, W., Broadgate, W., Deutsch, L., Gaffney, O., \& Ludwig, C. (2015). The trajectory of the Anthropocene: The great acceleration. The Anthropocene Review 2(1), 81-98.

Stengers, I. (2011). Thinking with whitehead: A free and wild creation of concepts. Cambridge, MA: Harvard University Press.

Stengers, I. (2018). Another science is possible: A manifesto for slow science. Cambridge, UK: John Wiley \& Sons.

Stewart, K. (2011). Atmospheric attunements. Environment and Planning D: Society and Space, 29(3), 445-453.

Strozzi, P. (2001). Daily life at school: Seeing the extraordinary in the ordinary. In Project Zero \& Reggio Children (Eds.), Making learning visible: Children as individual and group learners (pp. 58-77). Reggio Emilia, Italy: Reggio Children.

Sturken, M., \& Cartwright, L. (2009) Practices of looking. New York, NY: Oxford University Press. 
Sundberg, J. (2014). Decolonizing posthumanist geographies. Cultural Geographies, 21(1), 1-15.

Swadener, B. B., \& Lubeck, S. (1995). Children and families "at promise”: Deconstructing the discourse of risk. Albany, NY: State University of New York Press.

Takanishi, R. (2016). First things first!: Creating the new American primary school. New York, NY: Teachers College Press.

Taylor, A. (2011). Reconceptualising the nature of childhood. Childhood, 18(4), 420433.

Taylor, A. (2017). Beyond stewardship: Common world pedagogies for the Anthropocene. Environmental Education Research, 23(10), 1448-1461.

Taylor, A., Blaise, M., \& Giugni, M. (2013). Haraway’s “bag lady story-telling”: Relocating childhood and learning within a "post-human landscape." Discourse: Studies in the Cultural Politics of Education, 34(1), 48-62.

Taylor, A., \& Giugni, M. (2012). Common worlds: Reconceptualising inclusion in early childhood communities. Contemporary Issues in Early Childhood, 13(2), 108119.

Taylor, A., \& Pacini-Ketchabaw, V. (2015). Learning with children, ants, and worms in the Anthropocene: Towards a common world pedagogy of multispecies vulnerability. Pedagogy, Culture \& Society, 23(4), 507-529.

Taylor, A., \& Pacini-Ketchabaw, V. (2017). Kids, raccoons, and roos: Awkward encounters and mixed affects. Children's Geographies, 15(2), 131-145.

Taylor, A., \& Pacini-Ketchabaw, V. (2018). The common worlds of children and animals: Relational ethics for entangled lives. Routledge.

Taylor, A., Pacini-Ketchabaw, V., \& Blaise, M. (2012). Children's relations with the more-than-human world. Contemporary Issues in Early Childhood, 13(2), 81-85.

Tedlock, B. (1991). From participant observation to the observation of participation: The emergence of narrative ethnography. Journal of Anthropological Research, 47(1), 69-94.

Tesar, M., \& Arndt, S. (2016). Vibrancy of childhood things: Power, philosophy, and political ecology of matter. Cultural Studies $\leftrightarrow$ Critical Methodologies, 16(2), 193-200. 
Thorne, B. (1993). Gender play: Girls and boys in school. New Brunswick, NJ: Rutgers University Press.

Todd, Z. (2016). An indigenous feminist's take on the ontological turn: "Ontology" is just another word for colonialism: An indigenous feminist's take on the ontological turn. Journal of Historical Sociology, 29(1), 4-22.

Truman, S. E. (2019). Feminist New materialisms. In: Atkinson, P.A., Delamont, S., Hardy, M.A. and Williams, M. (eds.) The SAGE Encyclopedia of Research Methods. London, UK: Sage.

Tsing, A. (2011). Arts of inclusion, or, how to love a mushroom. Australian Humanities Review, 50, 5-21.

Tsing, A. (2013). More than human sociality: A call for critical description. In K. Hastrup (Ed.), Anthropology and nature (pp. 27-42). New York, NY: Routledge.

Tsing, A. (2015). The mushroom at the end of the world: On the possibility of life in capitalist ruins. Princeton University Press.

Tuck, E., \& McKenzie, M. (2015). Place in research: Theory, methodology, and methods. New York, NY: Routledge.

Tuck, E., \& Yang, K. W. (2012). Decolonization is not a metaphor. Decolonization: Indigeneity, education \& society, 1(1).

Turner, T., \& Wilson, D. (2009). Reflections on documentation: A discussion with thought leaders from Reggio Emilia. Theory into Practice, 49(1), 5-13.

Ulmer, J. B. (2017). Posthumanism as research methodology: Inquiry in the Anthropocene. International Journal of Qualitative Studies in Education, 30(9), 832-848.

Unger, R. (2005). What should the Left propose? New York, NY: Verso.

Urban, M. (2014). Learning from the margins. In M. N. Bloch, B. B. Swadener, \& G. S. Cannella (Eds.), Reconceptualizing early childhood care and education: A reader (pp. 273-287). New York, NY: Peter Lang.

Urban, M. (2018). Learning from the margins: Early childhood imaginaries, "normal science," and the case for a radical reconceptualisation of research and practice. In G. Cannella (Ed.), Reconceptualizing early childhood education and care-a reader: Critical questions, new imaginaries and social activism (pp. 273-288). New York, NY: Peter Lang. 
Urban, M. (2019). The shape of things to come and what to do about Tom and Mia: Interrogating the OECD's International Early Learning and Child Well-Being Study from an anti-colonialist perspective. Policy Futures in Education, 17(1), 87-101.

Vagle, M. (2009). Validity as intended: "Bursting forth toward" bridling in phenomenological research. International Journal of Qualitative Studies in Education, 22(5), 585-605.

van Dooren, T. (2014). Flight ways. New York, NY: Columbia University Press.

van Dooren, T., \& Rose, D. B. (2016). Lively ethnography: Storying animist worlds. Environmental Humanities, 8(1), 77-94.

Viruru, R. (2005). The impact of postcolonial theory on early childhood education. Journal of Education 35(1), 7-29.

Viruru, R. (2006). Postcolonial technologies of power: Standardized testing and representing diverse young children. International Journal of Educational Policy, Research, and Practice: Reconceptualizing Childhood Studies, 7(1), 49-70.

Vygotsky, L. S. (1978). Mind in society: The development of higher psychological processes. Cambridge, MA: Harvard University Press.

Wall Kimmerer, R. (2013a). Braiding sweetgrass: Indigenous wisdom, scientific knowledge and the teachings of plants. Minneapolis, MN: Milkweed Editions.

Wall Kimmerer, R. (2013b). The fortress, the river and the garden: A new metaphor for cultivating mutualistic relationship between scientific and traditional ecological knowledge. In A. Kulnieks, D. R. Longboat, \& K. Young (Eds.), Contemporary studies in environmental and Indigenous pedagogies: A curricula of stories and place (pp. 49-76). Rotterdam, The Netherlands: Brill Sense.

Waters, P. (2014). Tracking trolls and chasing pixies. Departures in Critical Qualitative Research, 3(3), 239-263.

Watts, V. (2013) Indigenous place-thought and agency amongst humans and non humans (First Woman and Sky Woman go on a European world tour!). Decolonization: Indigeneity, Education \& Society, 2(1), 20-34.

Whitehead, A. (1978). Process and reality (corrected ed.). New York, NY: Free Press.

Wien, C. A. (2012). The power of emergent curriculum: Stories from early childhood settings. Washington, DC: National Association for the Education of Young Children. 
Wolfe, C. (2010). What is posthumanism? Minneapolis, MN: University of Minnesota Press.

Yolen, J. (1997). Child of Faerie, Child of Earth. (J. Dyer, illus.). Little, Brown Books for Young Readers.

Young, M. F. D. (2006). Education, knowledge and the role of the state: The "nationalization" of educational knowledge? In A. Moore (Ed.), Schooling, society and curriculum (pp. 19-30). London, UK: Routledge.

Zipes, J. (2006). Fairy tales and the art of subversion: The classical genre for children and the process of civilization ( 2 nd ed.). New York, NY: Routledge. 


\section{Appendix A: Letter to Parents}

Dear Rowanberry Parent,

As you are all aware, I am working on my dissertation research and I am hopeful that you will allow your child to participate in my study. If you agree to allow your child to participate in this research, I will also ask them for their assent. Participation in the study consists of engaging in our everyday classroom practices such as story creation, story sharing, and discussions about stories, except that I will collect up things they say and do as data.

My hope is to find out what it is at school that inspires the children to tell stories. My research question is: How does the more-than-human matter in children's storytelling? Please let me know if you want to talk about this research project some more. Also, understand that your child is in no way required to participate in this dissertation research. I will be giving you a form to sign that explains more of the details about this study.

Thank you for considering,

Angela Molloy Murphy

--

Angela Molloy Murphy, MEd

EdD Student, Portland State University

Email: molloym2@pdx.edu 
Appendix B: Child Assent Script

Child Assent Script Project Title: Storytelling in the Margins: How Children's Small Stories Come to
Matter

Researcher: $\quad$ Angela Molloy Murphy, C\&I

Portland State University

Researcher Contact: molloym2@pdx.edu

I will be describing the study to the children (who are familiar with the concept of research) and recording their agreement for assent. The assent statement will read as follows:

"Your parents have said that you may take part in a research project about our classroom stories. If you choose to do it, you will be asked to continue participating in our everyday classroom practices. At times, we will take photos in the classroom about things that inspire the stories we tell. Then we will talk about these stories and photos in our morning meetings. This is all typical stuff we do now and I'll be writing down what we say and do and bringing that back to you to discuss it. If you don't want your stories and photos to be part of my study, just let me know. You will still participate in all of the ways we do now with cameras and story-telling and morning meeting discussions, but I won't use your stories and ideas in my project. Also, if you have any questions about what you will be doing, just ask me to explain. Please say yes or no as to whether you would like to participate in the study or not. Remember, it is your choice." 
Appendix C: Research Questions, Methods, and Action Required

\begin{tabular}{|l|l|l|}
\hline $\begin{array}{l}\text { Research } \\
\text { Question }\end{array}$ & Method & Action Required \\
\hline $\begin{array}{l}\text { How does } \\
\text { the more- } \\
\text { than-human } \\
\text { matter in } \\
\text { children's } \\
\text { storytelling? }\end{array}$ & Observation & $\begin{array}{l}\text { Daily observations made as observant participator. Anecdotal } \\
\text { notes taken. }\end{array}$ \\
\hline & Free-writing & $\begin{array}{l}\text { Daily, 10-15 minutes, immediately following classroom } \\
\text { discussions. }\end{array}$ \\
\hline & $\begin{array}{l}\text { Pedagogical } \\
\text { narrations }\end{array}$ & $\begin{array}{l}\text { The anecdotal observations and free-writing "gatherings", will be } \\
\text { churned into pedagogical narrative segments throughout the 12- } \\
\text { week study. }\end{array}$ \\
\hline Photography & $\begin{array}{l}\text { Photographs will be taken over the 12-week data collection period } \\
\text { in the following ways: }\end{array}$ \\
\hline $\begin{array}{l}\text { 1.Photographs taken by me of the children engaged in and around } \\
\text { the classroom spaces and on outings. } \\
\text { 2.Photographs taken by me or the children of material artifacts of } \\
\text { children's } \\
\text { narrative processes, such as loose parts arrangements, clay work, } \\
\text { graphic productions. } \\
\text { 3.Photographs taken by the children of people/things/places that } \\
\text { inform their narrative processes. }\end{array}$ \\
\hline Audio Recordings \\
discussions & $\begin{array}{l}\text { Story sharing and discussions using photographs, journal } \\
\text { illustrations, and material artifacts of storytelling.(Daily,15-30 } \\
\text { minutes) }\end{array}$ \\
$\begin{array}{l}\text { Narrations and discussions about narrations that occur throughout } \\
\text { the school day and class discussions will be audio recorded for } \\
\text { transcription. }\end{array}$ \\
\hline
\end{tabular}




\title{
Appendix E: Class Discussion Protocol
}

\section{Class Discussion Protocol}

\author{
Project Title: Storytelling in the Margins: How Children's Small Stories Come to Matter \\ Researcher: Angela Molloy Murphy, C\&l \\ Portland State University \\ Researcher Contact: molloym2@pdx.edu
}

For this study, we will utilize class discussions to invite children's active contribution by engaging in dialogue with them about their stories and their narrative processes. The design for these class discussions was inspired by the "Listening Sessions" created by Nimmo et al., (2018) for the project, Voices of children: Intercultural collaborations in understanding and documenting the meaning of children's rights through dialogue and video. The intention of listening sessions is to (re) position children as active rather than passive contributors in research regarding them.

During the class discussions, any stories told that morning will be shared with the storyteller/(s)' permission. Children may elect to share these stories any way they wish; such as telling the story themselves, having an adult read the story aloud, inviting friends to perform the story, sharing a journal illustration or photograph of material work that was part of their storytelling process, or any combination of these sharing methods.

At these class meetings, we will view the photographs taken by children that morning (with their permission.) Children will be invited to discuss their photographs with open-ended prompts such as: Tell me about this photo.

What would you like to tell us about this photo?

What is interesting or important to you in this photo?

These discussions will be audio recorded digitally on an iPad and transcribed as data. 
Appendix F: Visual Representation of Gatherings

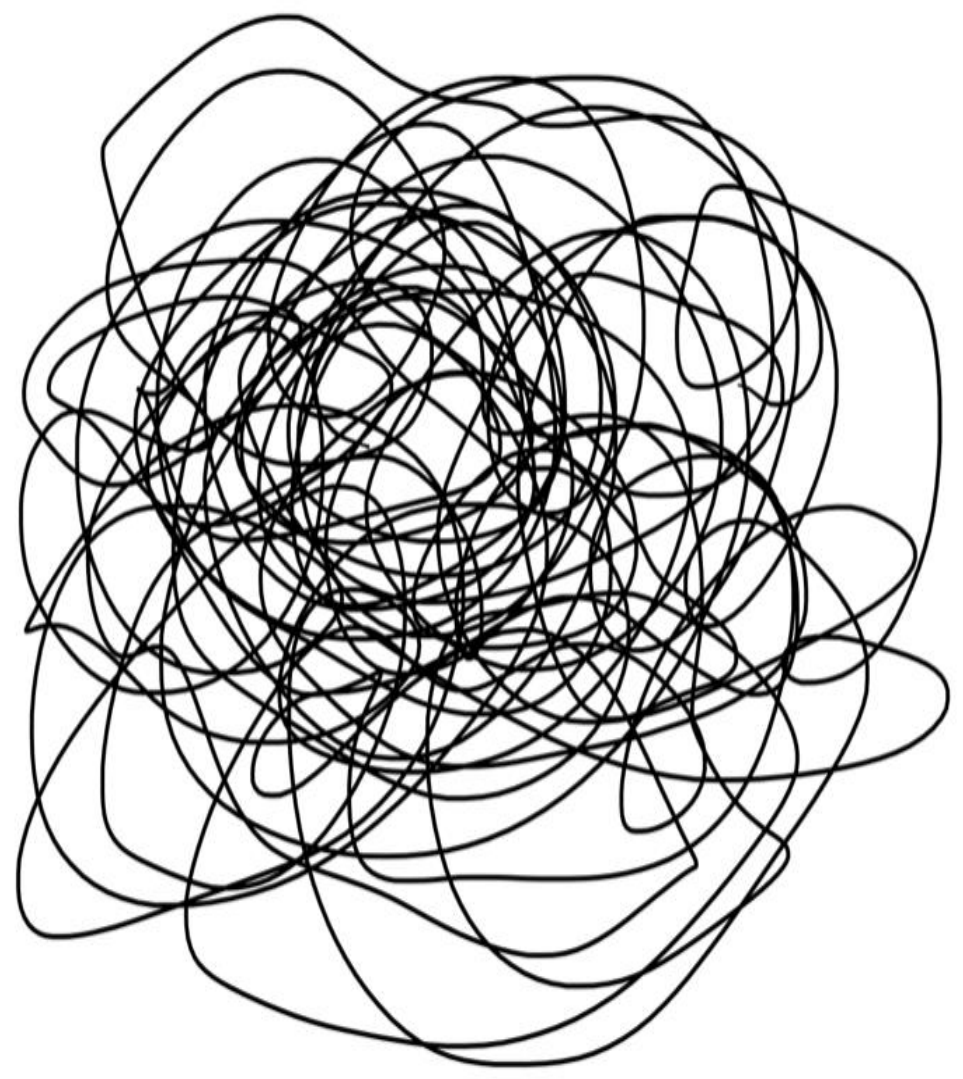


Appendix G: Visual Representation of Assemblage

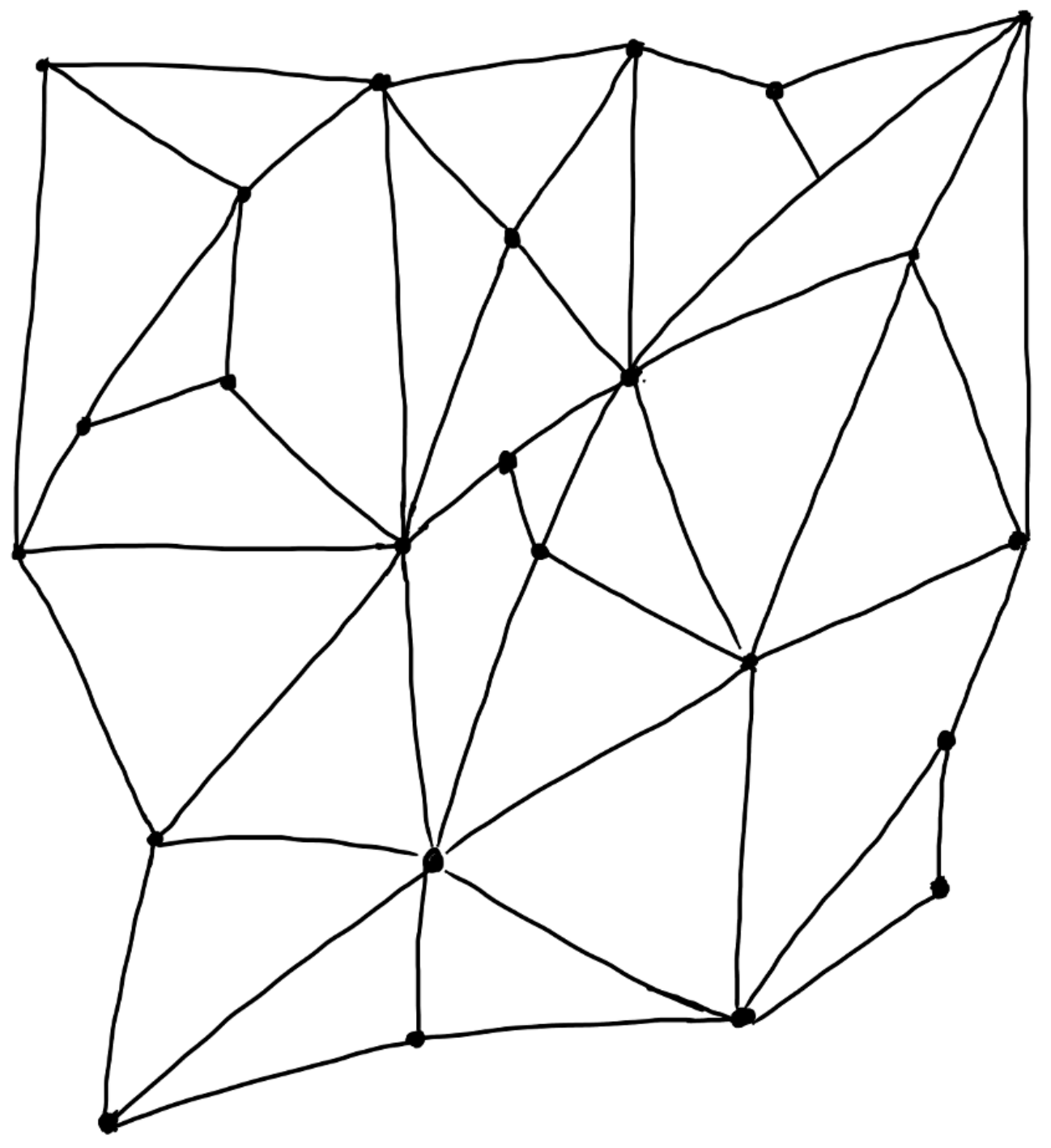

